\title{
Quality of Source Water from Public-Supply Wells in the United States, 1993-2007
}

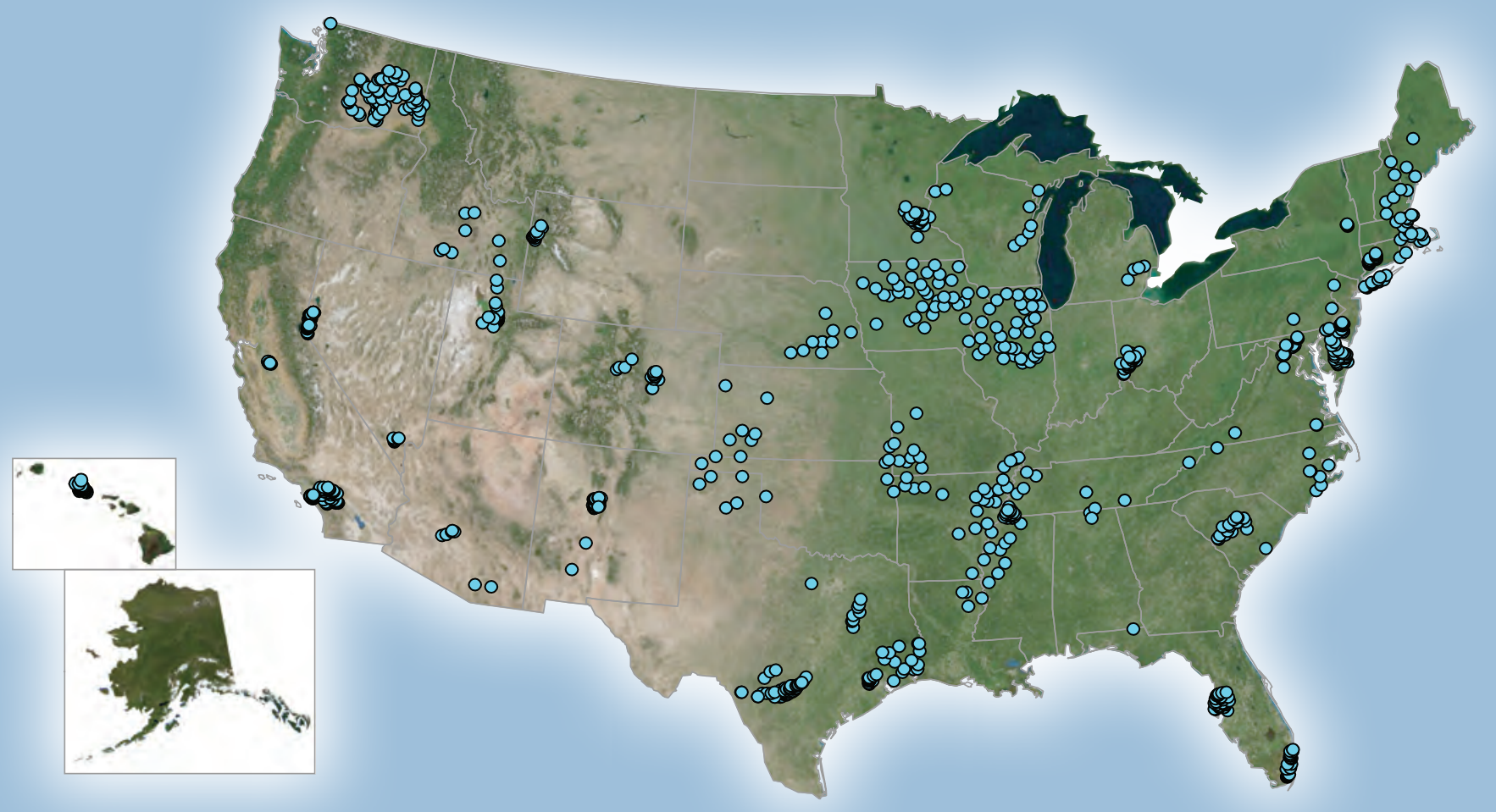

Scientific Investigations Report 2010-5024 
Cover illustration: Map showing the 932 public-supply wells included in this study. World-imagery base map from ESRI (৫) 2009), based on source data from ESRI, i-cubed, USDA FSA, USGS, AEX, GeoEye, and Getmapping (http://server.arcgisonline.com/ArcGIS/rest/services/World_Imagery/MapServer). 


\section{Quality of Source Water from Public- Supply Wells in the United States, 1993-2007}

By Patricia L. Toccalino, Julia E. Norman, and Kerie J. Hitt

National Water-Quality Assessment Program

Scientific Investigations Report 2010-5024 


\title{
U.S. Department of the Interior \\ KEN SALAZAR, Secretary
}

\section{U.S. Geological Survey \\ Marcia K. McNutt, Director}

\section{U.S. Geological Survey, Reston, Virginia: 2010}

\author{
For more information on the USGS — the Federal source for science about the Earth, its natural and living resources, \\ natural hazards, and the environment, visit http://www.usgs.gov or call 1-888-ASK-USGS \\ For an overview of USGS information products, including maps, imagery, and publications, \\ visit http://www.usgs.gov/pubprod \\ To order this and other USGS information products, visit http://store.usgs.gov
}

Any use of trade, product, or firm names is for descriptive purposes only and does not imply endorsement by the U.S. Government.

Although this report is in the public domain, permission must be secured from the individual copyright owners to reproduce any copyrighted materials contained within this report.

Suggested citation:

Toccalino, P.L., Norman, J.E., and Hitt, K.J., 2010, Quality of source water from public-supply wells in the United States, 1993-2007: U.S. Geological Survey Scientific Investigations Report 2010-5024, 209 p.

Additional information about this study is available at http://water.usgs.gov/nawqa/studies/public wells/. 


\section{Foreword}

The U.S. Geological Survey (USGS) is committed to providing the Nation with reliable scientific information that helps to enhance and protect the overall quality of life and that facilitates effective management of water, biological, energy, and mineral resources (http://www.usgs.gov). Information on the Nation's water resources is critical to ensuring long-term availability of water that is safe for drinking and recreation and is suitable for industry, irrigation, and fish and wildlife. Population growth and increasing demands for water make the availability of that water, now measured in terms of quantity and quality, even more essential to the long-term sustainability of our communities and ecosystems.

The USGS implemented the National Water-Quality Assessment (NAWQA) Program in 1991 to support national, regional, state, and local information needs and decisions related to water-quality management and policy (http://water.usgs.gov/nawqa). The NAWQA Program is designed to answer: What is the quality of our Nation's streams and groundwater? How are conditions changing over time? How do natural features and human activities affect the quality of streams and groundwater, and where are those effects most pronounced? By combining information on water chemistry, physical characteristics, stream habitat, and aquatic life, the NAWQA Program aims to provide science-based insights for current and emerging water issues and priorities. From 1991-2001, the NAWQA Program completed interdisciplinary assessments and established a baseline understanding of water-quality conditions in 51 of the Nation's river basins and aquifers, referred to as Study Units (http://water. usgs.gov/nawqa/studyu.html).

National and regional assessments are ongoing in the second decade (2001-2012) of the NAWQA Program as 42 of the 51 Study Units are selectively reassessed. These assessments extend the findings in the Study Units by determining status and trends at sites that have been consistently monitored for more than a decade, and filling critical gaps in characterizing the quality of surface water and groundwater. For example, increased emphasis has been placed on assessing the quality of source water and finished water associated with the Nation's largest community water systems. During the second decade, NAWOA is addressing five national priority topics that build an understanding of how natural features and human activities affect water quality, and establish links between sources of contaminants, the transport of those contaminants through the hydrologic system, and the potential effects of contaminants on humans and aquatic ecosystems. Included are studies of the fate of agricultural chemicals, effects of urbanization on stream ecosystems, bioaccumulation of mercury in stream ecosystems, effects of nutrient enrichment on aquatic ecosystems, and transport of contaminants to public-supply wells. In addition, national syntheses of information on pesticides, volatile organic compounds (VOCs), nutrients, trace elements, and aquatic ecology are continuing.

The USGS aims to disseminate credible, timely, and relevant science information to address practical and effective water-resource management and strategies that protect and restore water quality. We hope this NAWOA publication will provide you with insights and information to meet your needs, and will foster increased citizen awareness and involvement in the protection and restoration of our Nation's waters.

The USGS recognizes that a national assessment by a single program cannot address all water-resource issues of interest. External coordination at all levels is critical for cost-effective management, regulation, and conservation of our Nation's water resources. The NAWQA Program, therefore, depends on advice and information from other agencies — federal, state, regional, interstate, tribal, and local—as well as nongovernmental organizations, industry, academia, and other stakeholder groups. Your assistance and suggestions are greatly appreciated.

Matthew C. Larsen

Associate Director for Water 
This page intentionally left blank. 


\section{Contents}

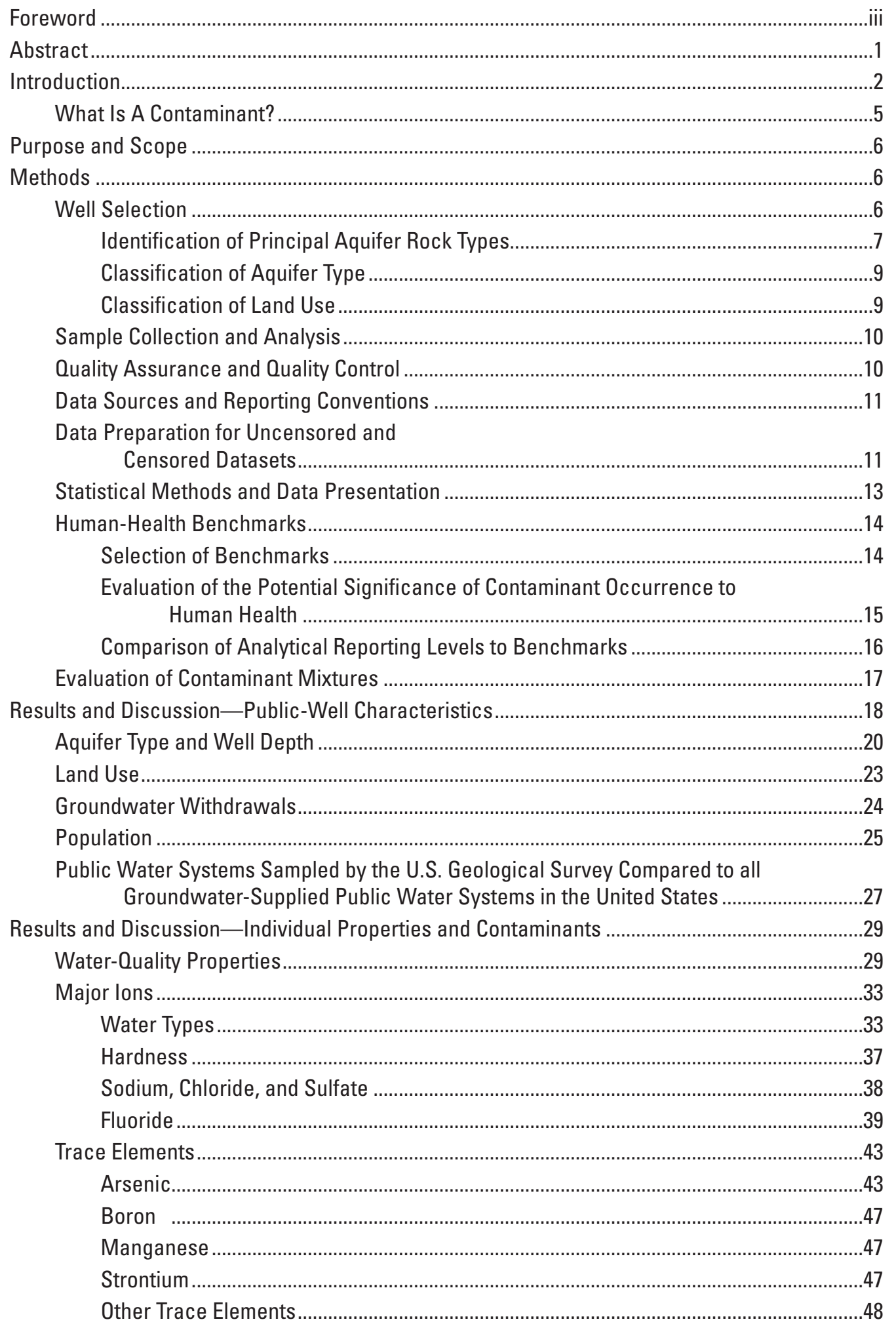




\section{Contents-Continued}

Results and Discussion_-Individual Properties and Contaminants_Continued

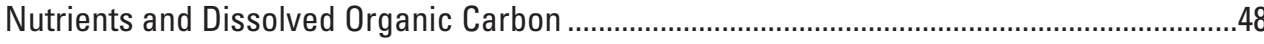

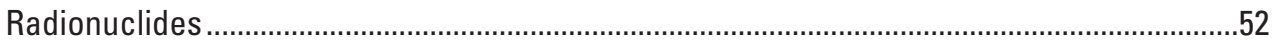

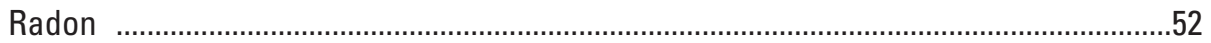

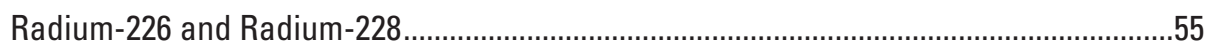

Gross Alpha- and Gross Beta-Particle Radioactivities ................................................56

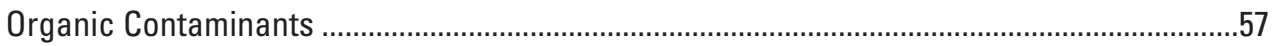

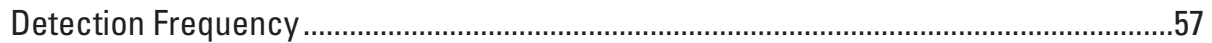

Comparison to Human-Health Benchmarks.....................................................................62

Fecal-Indicator Microorganisms ...........................................................................................74

Summary of Comparison of Contaminant Concentrations to Human-Health Benchmarks ...76

Results and Discussion-Occurrence and Characteristics of Contaminant Mixtures ...................85

Occurrence, Complexity, and Distribution of Mixtures .........................................................86

Composition of Mixtures.....................................................................................................90

Assessing the Potential Significance of Mixtures to Human Health ......................................100

Comparisons with Previous National-Scale Public-Well Studies .................................................101

Selected National-Scale Studies .................................................................................... 102

USEPA Studies of Regulated Contaminants ................................................................102

USEPA Studies of Unregulated Contaminants ..........................................................102

Comparison of Detection Frequencies...................................................................................103

Comparison of Concentrations Greater Than Benchmarks ...................................................104

USEPA Data on Health-Based Violations.........................................................................105

Comparisons with Previous National-Scale USGS Domestic-Well Study ...................................105

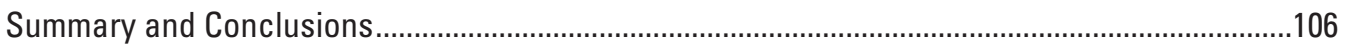

Contaminant Occurrence and Comparison of Concentrations to Human-Health

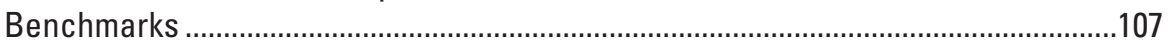

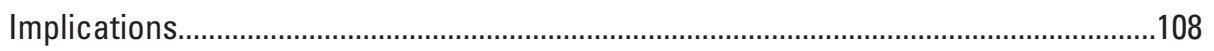

National and Regional Distributions of Water Quality........................................................108

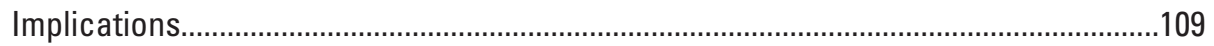

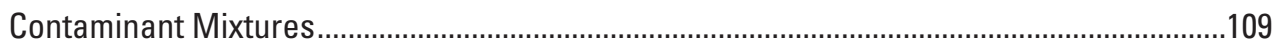

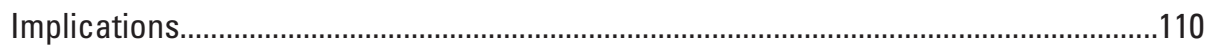

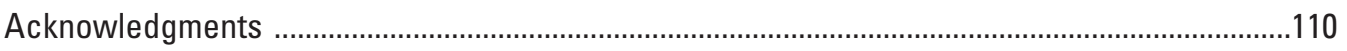

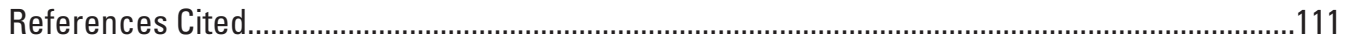




\section{Contents-Continued}

Appendix 1. Summary of Selected National-Scale Studies on Contaminant Occurrence in Public Wells in the United States.

Appendix 2. Description of the Sampling Networks (Groundwater Assessment Studies) Associated with 932 Public Wells Sampled During 1993-2007..........................................131

Appendix 3. Descriptions of Principal Aquifer Rock Types

Appendix 4. List of Six Water-Quality Properties and 215 Contaminants Analyzed in Public-Well Samples Collected During 1993-2007, Including Reporting Levels for Non-Detections and Human-Health Benchmarks for Drinking Water....

Appendix 5. Primary Use Groups Associated with Pesticide Compounds and Volatile Organic Compounds Analyzed in Public-Well Samples Collected During 1993-2007 ......143

Appendix 6. Alkalinity Calculations ........................................................................................148

Appendix 7. Water Hardness Calculations ...........................................................................149

Appendix 8. Concentration Statistics for Water-Quality Properties, Major lons, Nutrients, Radionuclides, and Fecal-Indicator Microorganisms Analyzed in Public-Well Samples Collected During 1993-2007

Appendix 9. Concentration Statistics for Trace Elements Analyzed in Public-Well Samples Collected During 1993-2007.

Appendix 10. Detection Frequencies for Trace Elements at Various Common Assessment Levels in Public-Well Samples Collected During 1993-2007.

Appendix 11. Detection Frequencies for Pesticide Compounds at Various Common Assessment Levels in Public-Well Samples Collected During 1993-2007.

Appendix 12. Detection Frequencies for Volatile Organic Compounds at Various Common Assessment Levels in Public-Well Samples Collected During 1993-2007.

Appendix 13. Concentration Statistics for Pesticide Compounds and Volatile Organic Compounds Detected in at Least 1 Percent of Public-Well Samples Collected During 1993-2007.

Appendix 14. Organic Contaminants Not Detected in any Public-Well Sample Collected During 1993-2007.

Appendix 15. Contaminants That Were Detected, but Do Not Have Human-Health Benchmarks, in Public-Well Samples Collected During 1993-2007

Appendix 16. Comparison Among Detection Frequencies for Regulated Contaminants Analyzed in Selected National-Scale Public-Well Studies

Appendix 17. Comparison Among Percentages of Public Wells or Public Water Systems with Concentrations Greater Than Human-Health Benchmarks for Regulated Contaminants Analyzed in Selected National-Scale Public-Well Studies

Appendix 18. Comparison Among Detection Frequencies for Unregulated Contaminants Analyzed in Selected National-Scale Public-Well Studies.

Appendix 19. Comparison Among Percentages of Public Wells or Public Water Systems with Concentrations Greater Than Human-Health Benchmarks for Unregulated Contaminants Analyzed in Selected National-Scale Public-Well Studies

Appendix 20. Comparison Among Contaminants on the Third Contaminant Candidate List, Those Analyzed in Public-Well Samples Collected by the NAWQA Program, 1993-2007, and Those Analyzed for the Unregulated Contaminant Monitoring Program.

Appendix 21. Comparison of Findings from This National-Scale Public-Well Study to

Findings from a National-Scale Domestic-Well Study 


\section{Figures}

Figure 1. Map showing the location of the NAWQA Study Units and the 932 public wells that were sampled during 1993-2007....

Figure 2. Map showing geographic distribution of areal extent, by rock type, of all principal aquifers in the United States and location of the 932 public wells sampled during 1993-2007 and the principal aquifer rock type associated with each well

Figure 3. Bar graph showing public water system sizes and types for the 932 public wells sampled during 1993-2007

Figure 4. Boxplots showing distributions of well depths and depths to top of open interval for public wells sampled during 1993-2007, by principal aquifer rock type

Figure 5. Boxplots showing distributions of well depths in relation to aquifer type for public wells sampled during 1993-2007....

Figure 6. Map showing geographic distribution of aquifer types for 932 public wells sampled during 1993-2007.

Figure 7. Bar graph showing percentage of samples among unconfined and confined aquifers in relation to principal aquifer rock type for public wells sampled during 1993-2007

Figure 8. Bar graph showing comparisons among land-use characteristics associated with 932 public wells sampled during 1993-2007; about 122,000 public wells across the United States; and all land area in the United States

Figure 9. Bar graph showing land-use classifications in relation to system sizes for public wells sampled during 1993-2007.

Figure 10. Bar graph showing comparisons among the distributions of groundwater withdrawals for public supply, by rock type, for all principal aquifers in the United States and for those principal aquifers represented by the public wells sampled during 1993-2007....

Figure 11. Maps showing population (1995) that uses groundwater from public wells for drinking water in percentage of total county population, and people per square mile of land area, by county

Figure 12. Bar graphs showing comparisons among the percentage of groundwater-supplied systems and population served by groundwater-supplied systems, for public water systems sampled by the National Water-Quality Assessment (NAWQA) Program (1993-2007) and for all public water systems in the United States in 2008, by size and type of system

Figure 13. Boxplots showing distributions of $\mathrm{pH}$, alkalinity, dissolved oxygen, and total dissolved-solids concentrations, by principal aquifer rock type, in public-well samples collected during 1993-2007....

Figure 14. Maps showing geographic distributions of $\mathrm{pH}$, alkalinity, dissolved oxygen, and total dissolved-solids concentrations in public-well samples collected during 1993-2007

Figure 15. Boxplots showing distributions of dissolved-oxygen concentrations in relation to aquifer type in public-well samples collected during 1993-2007

Figure 16. Trilinear diagram showing water-type classification categories in terms of major-ion percentages

Figure 17. Trilinear diagrams showing the ionic composition of source water from public-well samples collected during 1993-2007, by principal aquifer rock type ... 35

Figure 18. Map showing geographic distribution of water hardness concentrations in 809 public-well samples collected during 1993-2007 


\section{Figures-Continued}

Figure 19. Boxplots showing distributions of water hardness, by principal aquifer rock type, in public-well samples collected during 1993-2007

Figure 20. Map showing geographic distribution of fluoride concentrations in 808 public-well samples collected during 1993-2007

Figure 21. Boxplots showing distributions of arsenic, boron, manganese, and strontium concentrations, by principal aquifer rock type, in public-well samples collected during 1993-2007

Figure 22. Map showing geographic distribution of arsenic concentrations and Benchmark Quotients (BO) in 638 public-well samples collected during 1993-2007

Figure 23. Map showing geographic distribution of nitrate concentrations and Benchmark Quotients (BO) in 806 public-well samples collected during 1993-2007

Figure 24. Boxplots showing distributions of nitrate concentrations by principal aquifer rock type, aquifer type, and land use in public-well samples collected during 1993-2007

Figure 25. Boxplots showing distributions of nitrate concentrations in relation to increasing ammonia concentrations in public-well samples collected during 1993-2007

Figure 26. Map showing geographic distribution of radon activities, and activities in relation to proposed Maximum Contaminant Levels, in 506 public-well samples collected during 1993-2007

Figure 27. Boxplots showing distributions of radon activities, by principal aquifer rock type, in public-well samples collected during 1993-2007

Figure 28. Boxplots showing distributions of radon activities, by system size, in public-well samples collected during 1993-2007

Figure 29. Bar graph showing detection frequencies of pesticide compounds and volatile organic compounds (VOCs) at different common assessment levels in public-well samples collected during 1993-2007

Figure 30. Map showing geographic distribution of the number of pesticide compounds and volatile organic compounds detected in 915 public-well samples collected during 1993-2007

Figure 31. Bar graphs showing detection frequencies of pesticide compounds and volatile organic compounds (VOCs) by principal aquifer rock type, aquifer type, and system size, for public-well samples collected during 1993-2007 .....

Figure 32. Bar graph showing detection frequencies of pesticide compounds and volatile organic compounds (VOCs), by primary use group or source, for public-well samples collected during 1993-2007

Figure 33. Bar graph showing detection frequencies of individual pesticide compounds and volatile organic compounds (VOCs) in relation to common assessment levels of 0.02 and 0.2 micrograms per liter in public-well samples collected during 1993-2007

Figure 34. Map showing geographic distribution of Benchmark Quotients (B0) for pesticide compounds and volatile organic compounds (VOCs) for 915 public-well samples collected during 1993-2007

Figure 35. Graph showing distributions of Benchmark Quotients (BO) for all pesticide compounds and volatile organic compounds (VOCs) with concentrations greater than one-tenth of human-health benchmarks in one or more public-well samples collected during 1993-2007 


\section{Figures-Continued}

Figure 36. Map showing geographic distribution of dieldrin concentrations and Benchmark Quotients (BO) for 896 public-well samples collected during 1993-2007

Figure 37. Maps showing geographic distributions of perchloroethene (PCE) and trichloroethene (TCE) concentrations and Benchmark Quotients (BO) in public-well samples collected during 1993-2007

Figure 38. Map showing geographic distribution of chloroform concentrations and Benchmark Quotients (B0) for 831 public-well samples collected during 1993-2007

Figure 39. Maps showing geographic distributions of atrazine and deethylatrazine concentrations and Benchmark Quotients (BO) for 853 public-well samples collected during 1993-2007

Figure 40. Map showing geographic distribution of methyl tert-butyl ether (MTBE) detections in 832 public-well samples collected during 1993-2007

Figure 41. Map showing geographic distribution of detections of fecal-indicator microorganisms in 353 public-well samples collected during 1993-2007

Figure 42. Bar graph showing the percentage of source-water samples with concentrations greater than human-health benchmarks and concentrations greater than one-tenth of benchmarks

Figure 43. Bar graph showing summary of percentage of source-water samples with one or more contaminants with concentrations greater than human-health benchmarks and concentrations greater than one-tenth of benchmarks, by contaminant group, for public-well samples collected during 1993-2007

Figure 44. Maps showing geographic distribution of contaminant concentrations relative to human-health benchmarks for 932 public-well samples collected during 1993-2007

Figure 45. Bar graph showing percentage of source-water samples with one or more contaminants with concentrations greater than human-health benchmarks, by aquifer type and contaminant group, for public-well samples collected during 1993-2007

Figure 46. Map showing geographic distribution of contaminant mixtures, relative to individual human-health benchmarks, for public-well samples collected during 1993-2007

Figure 47. Graph showing frequency of contaminant occurrence in mixtures, for each of three mixtures categories, for public-well samples collected during 1993-2007 .. 88

Figure 48. Map showing geographic distribution of the numbers of contaminants in mixtures with concentrations greater than individual human-health benchmarks and concentrations greater than one-tenth of individual benchmarks, for public-well samples collected during 1993-2007

Figure 49. Bar graph showing the proportion of contaminant mixtures with concentrations greater than one-tenth of individual human-health benchmarks $(\mathrm{B} 0>0.1)$ in unconfined and confined aquifers, in relation to the complexity of the mixtures. ....

Figure 50. Bar graph showing the proportion of mixtures of pesticide compounds and volatile organic compounds (VOCs) in unconfined and confined aquifers, in relation to the complexity of the mixtures 


\section{Tables}

Table 1. Classifications for sizes of public water systems $\ldots \ldots \ldots \ldots \ldots \ldots \ldots \ldots \ldots \ldots \ldots 2$

Table 2. Descriptions for types of public water systems......................... 3

Table 3. Land-use categories for public wells sampled during 1993-2007 ............... 9

Table 4. Interpretation of Benchmark Quotient values for potential human-health significance and implications for water-quality monitoring $\ldots \ldots \ldots \ldots \ldots \ldots \ldots \ldots \ldots$

Table 5. Contaminants analyzed in public-well samples collected during 1993-2007 for which maximum reporting levels are greater than human-health benchmarks $\ldots 16$

Table 6. Principal aquifers and well depths for 932 public wells sampled during 1993-2007, by principal aquifer rock type

Table 7. Distribution of sizes and types for the 629 public water systems sampled during 1993-2007, by numbers of sampled wells per system

Table 8. Comparison of water-quality properties and contaminant concentrations to non-health guidelines in public-well samples collected during 1993-2007

Table 9. Water hardness classification scheme

Table 10. Number of detections and comparison of concentrations to human-health benchmarks for water-quality properties, major ions, nutrients, radionuclides, and fecal-indicator microorganisms in public-well samples collected during 1993-2007

Table 11. Number of detections and comparison of concentrations to human-health benchmarks for trace elements in public-well samples collected during 1993-2007

Table 12. Number of detections and comparison of concentrations to human-health benchmarks for pesticide compounds in public-well samples collected during 1993-2007

Table 13. Number of detections and comparison of concentrations to human-health benchmarks for volatile organic compounds in public-well samples collected during 1993-2007

Table 14. Summary of contaminant occurrence and comparisons of concentrations to human-health benchmarks, by contaminant group, for public wells sampled during 1993-2007

Table 15. Overall summary of comparison of contaminant concentrations to human-health benchmarks for 932 public-well samples collected during 1993-2007

Table 16. Potential health effects, contaminant sources, and principal aquifer rock types associated with the 10 contaminants with concentrations greater than human-health benchmarks in at least 1 percent of public-well samples collected during 1993-2007

Table 17. Contaminant mixture categories, criteria for examination of unique mixtures, and number of unique mixtures examined in public-well samples collected during 1993-2007

Table 18. Summary of composition of the most common unique mixtures, by contaminant mixture category, for 383 public-well samples collected during 1993-2007 ....... 91

Table 19. Composition and detection frequency of 21 unique mixtures with concentrations greater than individual human-health benchmarks in 383 public-well samples collected during 1993-2007 


\section{Tables-Continued}

Table 20. Composition and detection frequency of 68 unique mixtures with concentrations greater than one-tenth of individual human-health benchmarks in 383 public-well samples collected during 1993-2007

Table 21. Composition and detection frequency of 125 unique mixtures with concentrations greater than one-tenth of individual human-health benchmarks plus any organic contaminant detection in 383 public-well samples collected during 1993-2007 ... 95

Table 22. Composition and detection frequency of 23 unique mixtures of organic contaminants in 814 public-well samples collected during 1993-2007

Table 23. Chemical contaminants evaluated by the U.S. Environmental Protection Agency for possible regulation in drinking water

\section{Conversion Factors, Abbreviations, and Acronyms}

\begin{tabular}{|c|c|c|}
\hline Multiply & By & To obtain \\
\hline \multicolumn{3}{|c|}{ Length } \\
\hline meter $(\mathrm{m})$ & 3.281 & foot (ft) \\
\hline kilometer (km) & 0.6214 & mile (mi) \\
\hline meter $(\mathrm{m})$ & 1.094 & yard (yd) \\
\hline \multicolumn{3}{|c|}{ Area } \\
\hline square kilometer $\left(\mathrm{km}^{2}\right)$ & 0.3861 & square mile $\left(\mathrm{mi}^{2}\right)$ \\
\hline \multicolumn{3}{|c|}{ Volume } \\
\hline liter (L) & 33.82 & ounce, fluid (fl. oz) \\
\hline liter (L) & 0.2642 & gallon (gal) \\
\hline milliliter $(\mathrm{mL})$ & 0.0002642 & gallon (gal) \\
\hline \multicolumn{3}{|c|}{ Mass } \\
\hline gram $(\mathrm{g})$ & 0.03527 & ounce, avoirdupois (oz) \\
\hline kilogram $(\mathrm{kg})$ & 2.205 & pound avoirdupois (lb) \\
\hline \multicolumn{3}{|c|}{ Radioactivity } \\
\hline picocurie per liter $(\mathrm{pCi} / \mathrm{L})$ & 0.037 & becquerel per liter $(\mathrm{Bq} / \mathrm{L})$ \\
\hline
\end{tabular}

Temperature in degrees Celsius $\left({ }^{\circ} \mathrm{C}\right)$ may be converted to degrees Fahrenheit $\left({ }^{\circ} \mathrm{F}\right)$ as follows:

$$
{ }^{\circ} \mathrm{F}=\left(1.8 x^{\circ} \mathrm{C}\right)+32
$$

Specific conductance is given in microsiemens per centimeter at 25 degrees Celsius $(\mu \mathrm{S} / \mathrm{cm}$ at $\left.25^{\circ} \mathrm{C}\right)$.

Concentrations of chemical contaminants in water are given in milligrams per liter $(\mathrm{mg} / \mathrm{L})$ or micrograms per liter $(\mu \mathrm{g} / \mathrm{L})$.

Concentrations of total coliforms and Escherichia coli in water are given in colonies per 100 milliliters (col/100 mL).

Activities of radionuclides in water are given in picocuries per liter (pCi/L). 
Abbreviations and Acronyms Used in this Report

\begin{tabular}{|c|c|}
\hline $\begin{array}{c}\text { Abbreviation or } \\
\text { Acronym }\end{array}$ & Definition \\
\hline$\alpha$ & acceptable statistical significance level \\
\hline AMCL & Alternative Maximum Contaminant Level \\
\hline ATSDR & Agency for Toxic Substances and Disease Registry (CDC) \\
\hline AWWA & American Water Works Association \\
\hline $\mathrm{BO}$ & Benchmark Quotient \\
\hline BTEX & benzene, toluene, ethylbenzene, and xylenes \\
\hline $\mathrm{CaCO}_{3}$ & calcium carbonate \\
\hline CCL & Contaminant Candidate List \\
\hline CDC & U.S. Centers for Disease Control and Prevention \\
\hline CWS & community water system \\
\hline DBCP & dibromochloropropane \\
\hline DBP & disinfection by-product \\
\hline DNOC & 2-methyl-4,6-dinitrophenol \\
\hline DOC & dissolved organic carbon \\
\hline DWLOC & Drinking Water Level of Comparison \\
\hline E. coli & Escherichia coli \\
\hline FIFRA & Federal Insecticide, Fungicide, and Rodenticide Act \\
\hline GCMS & gas chromatography/mass spectrometry \\
\hline alpha-HCH & alpha-hexachlorocyclohexane \\
\hline HBSL & Health-Based Screening Level \\
\hline HPLC & high-performance liquid chromatography \\
\hline LRL & laboratory reporting level \\
\hline LT-MDL & long-term method detection level \\
\hline MCL & Maximum Contaminant Level \\
\hline MDL & method detection level \\
\hline $\mathrm{mrem} / \mathrm{yr}$ & millirems per year \\
\hline MRL & minimum reporting level \\
\hline MTBE & methyl tert-butyl ether \\
\hline NAWQA & National Water-Quality Assessment Program (USGS) \\
\hline NLCD & National Land Cover Database \\
\hline NWOL & National Water Quality Laboratory \\
\hline $\mathrm{p}$ & attained statistical significance level \\
\hline PCE & perchloroethene \\
\hline QC & quality control \\
\hline rho & Spearman correlation coefficient \\
\hline SDWA & Safe Drinking Water Act \\
\hline SDWIS & Safe Drinking Water Information System (USEPA) \\
\hline SMCL & Secondary Maximum Contaminant Level \\
\hline SWOA & Source Water-Quality Assessment (USGS NAWOA) \\
\hline TCE & trichloroethene \\
\hline TCT & total chlorotriazines \\
\hline TDS & total dissolved solids \\
\hline THM & trihalomethane \\
\hline TTHM & total trihalomethanes \\
\hline 1,2,4-TMB & 1,2,4-trimethylbenzene \\
\hline UCM & Unregulated Contaminant Monitoring program \\
\hline UCMR & Unregulated Contaminant Monitoring Rule \\
\hline USEPA & U.S. Environmental Protection Agency \\
\hline USGS & U.S. Geological Survey \\
\hline VOC & volatile organic compound \\
\hline
\end{tabular}


This page intentionally left blank. 


\title{
Quality of Source Water from Public-Supply Wells in the United States, 1993-2007
}

\author{
By Patricia L. Toccalino, Julia E. Norman, and Kerie J. Hitt
}

\section{Abstract}

More than one-third of the Nation's population receives their drinking water from public water systems that use groundwater as their source. The U.S. Geological Survey (USGS) sampled untreated source water from 932 public-supply wells, hereafter referred to as public wells, as part of multiple groundwater assessments conducted across the Nation during 1993-2007. The objectives of this study were to evaluate (1) contaminant occurrence in source water from public wells and the potential significance of contaminant concentrations to human health, (2) national and regional distributions of groundwater quality, and (3) the occurrence and characteristics of contaminant mixtures. Treated finished water was not sampled.

The 932 public wells are widely distributed nationally and include wells in selected parts of 41 states and withdraw water from parts of 30 regionally extensive aquifers used for public water supply. These wells are distributed among 629 unique public water systems - less than 1 percent of all groundwater-supplied public water systems in the United States - but the wells were randomly selected within the sampled hydrogeologic settings to represent typical aquifer conditions. Samples from the 629 systems represent source water used by one-quarter of the U.S. population served by groundwater-supplied public water systems, or about 9 percent of the entire U.S. population in 2008.

One groundwater sample was collected prior to treatment or blending from each of the 932 public wells and analyzed for as many as six water-quality properties and 215 contaminants. Consistent with the terminology used in the Safe Drinking Water Act (SDWA), all constituents analyzed in water samples in this study are referred to as "contaminants". More contaminant groups were assessed in this study than in any previous national study of public wells and included major ions, nutrients, radionuclides, trace elements, pesticide compounds, volatile organic compounds (VOCs), and fecal-indicator microorganisms. Contaminant mixtures were assessed in subsets of samples in which most contaminants were analyzed.

Contaminant concentrations were compared to humanhealth benchmarks - regulatory U.S. Environmental Protection Agency (USEPA) Maximum Contaminant Levels (MCLs) for contaminants regulated in drinking water under the SDWA or non-regulatory USGS Health-Based Screening Levels (HBSLs) for unregulated contaminants, when available. Nearly three-quarters of the contaminants assessed in this study are unregulated in drinking water, and the USEPA uses USGS data on the occurrence of unregulated contaminants in water resources to fulfill part of the SDWA requirements for determining whether specific contaminants should be regulated in drinking water in the future.

More than one in five (22 percent) source-water samples from public wells contained one or more naturally occurring or man-made contaminants at concentrations greater than human-health benchmarks, and 80 percent of samples contained one or more contaminants at concentrations greater than one-tenth of benchmarks. Most individual contaminant detections, however, were less than one-tenth of human-health benchmarks. Public wells yielding water with contaminant concentrations greater than benchmarks, as well as those with concentrations greater than one-tenth of benchmarks, were distributed throughout the United States and included wells that withdraw water from all principal aquifer rock types included in this study.

Ten contaminants individually were detected at concentrations greater than human-health benchmarks in at least 1 percent of source-water samples and collectively accounted for most concentrations greater than benchmarks. Seven of these 10 contaminants occur naturally, including three radionuclides (radon, radium, and gross alpha-particle radioactivity) and four trace elements (arsenic, manganese, strontium, and boron); three of these 10 contaminants (dieldrin, nitrate, and perchloroethene, or PCE) primarily have man-made sources. Radon activities were greater than the proposed MCL of 300 picocuries per liter $(\mathrm{pCi} / \mathrm{L})$ in 55 percent of samples and were greater than the proposed Alternative MCL of 4,000 pCi/L in 0.6 percent of samples. The remaining six contaminants from natural sources were detected at concentrations greater than benchmarks in 3 to 19 percent of samples. Dieldrin, PCE, and nitrate each were detected at concentrations greater than benchmarks in 1 to 3 percent of samples. Contaminants from natural sources accounted for three-quarters of contaminant concentrations greater than human-health benchmarks in source-water samples; contaminants from man-made sources accounted for one-quarter of such concentrations. 
Trace elements and radionuclides were detected at concentrations greater than benchmarks in samples from both confined and unconfined aquifers, consistent with the fact that these contaminants originate primarily from aquifer materials. By contrast, man-made contaminants were detected at concentrations greater than benchmarks mainly in samples from unconfined aquifers, consistent with the fact that these contaminants originate from man-made sources at the land surface. For example, more than two-thirds of the samples with concentrations of pesticide compounds or VOCs greater than benchmarks were from public wells in the highly populated areas of states bordering the East Coast, primarily in semi-consolidated sand and gravel aquifers (mostly unconfined aquifers) that underlie the Coastal Plains.

Collectively, pesticide compounds or VOCs were detected in 64 percent of source-water samples, and concentrations of one or more of these contaminants were greater than benchmarks in 4.5 percent of samples. The most frequently detected organic contaminants were disinfection by-products, such as chloroform and bromodichloromethane, the herbicide atrazine and one of its degradates, deethylatrazine, the gasoline oxygenate methyl-tert-butyl ether (MTBE), and solvents, such as PCE, trichloroethene (TCE), and 1,1,1-trichloroethane. MCLs or HBSLs were not available for some frequently detected contaminants, such as MTBE and deethylatrazine, so detections of these contaminants could not be evaluated in the context of human health. One or more properties or contaminants were detected at concentrations outside of USEPA's recommended ranges for the aesthetic quality of water in about one-half of the samples. Fecal-indicator microorganisms were detected in about 12 percent of source-water samples.

Contaminants detected in source-water samples usually co-occurred with other contaminants as mixtures. Few human-health benchmarks have been established for contaminant mixtures, but about 4 percent of samples contained mixtures of two or more contaminants at concentrations greater than individual benchmarks, and most samples (84 percent) contained mixtures of two or more contaminants at concentrations greater than one-tenth of individual benchmarks. Mixtures of two or more contaminants at concentrations greater than one-tenth of individual benchmarks were dominated by inorganic contaminants, and all of the most common unique mixtures (detected in 5 to 33 percent of samples) were composed of a trace element (arsenic, strontium, or uranium were most common), nitrate, and (or) radon (activities greater than $300 \mathrm{pCi} / \mathrm{L}$ ). When mixtures of organic contaminants were assessed, regardless of the availability of human-health benchmarks, about three-quarters of the organic mixtures contained atrazine, simazine, or deethylatrazine, about two-thirds contained chloroform, and 43 percent contained PCE or TCE. The most complex mixtures in source water-those with the greatest number of contaminants - were most often detected in samples from unconfined aquifers, mostly from unconsolidated sand and gravel aquifers in the western United States.
Findings from this study indicate the ubiquitous nature of natural and man-made contaminant sources and that all principal aquifer rock types included in this study are vulnerable to contamination. Early attention to potential groundwater contamination is vital because groundwater contamination is difficult and costly to reverse once it occurs.

\section{Introduction}

Safe drinking water is essential to public health, and the quality of the Nation's drinking-water supply is an issue of growing national importance (U.S. General Accounting Office, 1997). In 2008, about 105 million people in the United States - about 34 percent of the Nation's population — obtained their drinking water from about 140,000 public water systems that derive all or part of their source-water supply from groundwater (U.S. Environmental Protection Agency, 2008c; U.S. Census Bureau, 2009).

In this report, groundwater quality in samples collected from public-supply wells, hereafter referred to as public wells, refers to the quality of untreated source water captured by wells that supply drinking water to public water systems. The Safe Drinking Water Act (SDWA) defines a public water system as one that serves piped drinking water to at least 25 people or 15 service connections for at least 60 days a year (U.S. Environmental Protection Agency, 2003g). The U.S. Environmental Protection Agency (USEPA) classifies public water systems according to the size of the system and the number of people they serve (table 1), the type of system, the source of the water (groundwater versus surface water), and whether the same customers are served year-round (table 2) (U.S. Environmental Protection Agency, 2010d). Public water systems range from very small, privately owned systems, such as for mobile-home parks, to large, publicly owned systems that serve millions of people (U.S. Environmental Protection Agency, 2002a). The USEPA does not regulate drinkingwater wells that serve fewer than 25 people, although some state and local governments set rules to protect users of such wells (The National Academies, 2008). The quality of finished

Table 1. Classifications for sizes of public water systems.

[System size classifications are from U.S. Environmental Protection Agency (2010d)]

\begin{tabular}{lc}
\hline \multicolumn{1}{c}{ System size } & Number of people served \\
\hline Very small & 25 to 500 \\
Small & 501 to 3,300 \\
Medium & 3,301 to 10,000 \\
Large & 10,001 to 100,000 \\
Very large & More than 100,000 \\
\hline
\end{tabular}


Table 2. Descriptions for types of public water systems.

[Descriptions of system types are from U.S. Environmental Protection Agency (2003g)]

\begin{tabular}{ll}
\hline \multicolumn{1}{c}{ System type } & \multicolumn{1}{c}{ System type description } \\
\hline Community Water System (CWS) & $\begin{array}{l}\text { A public water system that serves the same people year-round. } \\
\text { Most residences are served by CWSs. }\end{array}$ \\
$\begin{array}{l}\text { Non-Transient Non-Community } \\
\text { Water System }\end{array}$ & $\begin{array}{l}\text { A public water system that serves the same people at least } \\
6 \text { months per year, but not year-round. Examples include schools, } \\
\text { factories, and hospitals that have their own water systems. }\end{array}$ \\
$\begin{array}{l}\text { Transient Non-Community Water } \\
\text { System }\end{array}$ & $\begin{array}{l}\text { A public water system that serves the public but not the same } \\
\text { individuals for more than 6 months. Examples include rest } \\
\text { areas, gas stations, and campgrounds. }\end{array}$ \\
\hline
\end{tabular}

drinking water (after treatment and before distribution) from the Nation's public water systems is regulated by the USEPA under the SDWA (U.S. Environmental Protection Agency, 2004c).

The SDWA, originally passed by Congress in 1974 and amended in 1986 and 1996, requires many actions to protect drinking water and its sources - rivers, lakes, reservoirs, springs, and groundwater wells. The SDWA authorizes the USEPA to set national health-based standards for drinking water to protect against naturally-occurring and anthropogenic (man-made) contaminants that may be detected in drinking water (U.S. Environmental Protection Agency, 2004c). The SDWA broadly defines a contaminant as "any physical, chemical, biological, or radiological substance or matter in water" (U.S. Code, 1996) (see sidebar on page 5). USEPA oversees the states, localities, and water suppliers who implement the drinking-water standards.

As part of determining whether drinking-water regulations are needed, the SDWA requires USEPA to publish a list of unregulated contaminants called the Contaminant Candidate List (CCL) every 5 years (U.S. Code, 1996). The CCL includes contaminants that currently are not subject to any proposed or promulgated national primary drinking water regulations, which are known or anticipated to occur in public water systems, and which may require regulation under the SDWA in the future. Following the publication of each CCL, USEPA decides whether to regulate at least five contaminants from the CCL in drinking water (called regulatory determinations) on the basis of the contaminant's potential for adverse human-health effects and occurrence in public water systems, and a meaningful opportunity to protect public health (National Research Council, 1999a; U.S. Environmental Protection Agency, 2010a). The first, second, and third CCLs were published in 1998, 2005, and 2009, respectively, and included chemical and microbial contaminants (U.S. Environmental Protection Agency, 2010a). The USEPA uses
U.S. Geological Survey (USGS) data on the occurrence of unregulated contaminants in water resources as part of both the CCL and regulatory determination processes.

Millions of people in the United States receive highquality drinking water from public water systems, but drinking-water safety cannot be taken for granted (U.S. Environmental Protection Agency, 2004c). Sources of drinking water are vulnerable to a wide range of contaminants from agricultural, industrial, urban, residential, and natural sources (U.S. General Accounting Office, 1997). Drinking water that is not properly treated or disinfected, or which travels through improperly maintained distribution systems, also may pose a health risk (U.S. Environmental Protection Agency, 2004c). Understanding contamination in public wells is not only a public-health issue, but also is an economic issue because remediating contaminated groundwater or replacing supply wells is expensive and difficult (Landon and others, 2006). Numerous studies have demonstrated the presence of naturally occurring and anthropogenic contaminants in finished groundwater (U.S. Environmental Protection Agency, 2001c, 2002b, 2003f) and in untreated source water from public wells (Gilliom and others, 2006; Zogorski and others, 2006; Ayotte and others, 2007).

In this study, source water-quality conditions in untreated groundwater were assessed for 932 public wells sampled across the Nation by the USGS National WaterQuality Assessment (NAWQA) Program during 1993-2007. NAWQA studies were designed as integrated water-resource assessments of important hydrologic systems of the Nation, but were not specifically designed to conduct a national-scale assessment of water quality in public wells. The public wells sampled in this study represent a small fraction of all public wells in the United States, but the wells are widely distributed nationally and were randomly selected within the sampled hydrogeologic settings to represent typical aquifer conditions. 
A greater number of contaminant groups-naturally occurring and anthropogenic - were assessed in this study than in any previous national study of public wells. The water-quality findings from this study, together with the accumulation of findings from previous studies, provide a foundation for improving our understanding and management of this critical source of drinking water.

Many statewide, regional, and national studies have provided important information about various aspects of public-well water quality. This study, however, differs from most previous national-scale studies (Appendix 1) in several ways:

- The quality of the source (untreated) water that supplies groundwater to public water systems is assessed, whereas many previous studies examined the quality of finished (treated) drinking water delivered to consumers (Westrick and others, 1984; Longtin, 1988; U.S. Environmental Protection Agency, 2001c, 2003f). An evaluation of contaminant occurrence in source water provides background information regarding the presence of a contaminant in the environment. Because water samples were collected prior to any treatment or blending that potentially could alter contaminant concentrations, the sampled groundwater represents the quality of the source water and not necessarily the quality of finished water ingested by the people served by these public wells. Some organic contaminants, however, such as gasoline-related contaminants, herbicides and herbicide degradates, and solvents recently have been detected at similar concentrations in source and finished water from public wells in a USGS study (Hopple and others, 2009).

- Specific sites or areas with known water-quality problems are not sampled, whereas some previous studies include, and in some instances, focus on areas of known contamination (Westrick and others, 1984; Focazio and others, 2001).

- More contaminants and (or) contaminant groups are assessed than in previous public-well studies (Longtin, 1988; Westrick, 1990; Grady and Casey, 2001), including many inorganic, organic, and microbial contaminants. A recent USGS study of 221 public wells (Hopple and others, 2009) assessed as many as 125 more anthropogenic organic contaminants than were assessed in this study -including personal-care and domestic-use products, manufacturing additives, and pavement- and combustion-derived contaminants - but did not include analyses of inorganic or microbial contaminants.

- Contaminants evaluated include some that are regulated in drinking water under the SDWA and many that are not, whereas studies of SDWA compliance data commonly focus only on contaminants that are regulated in drinking water (U.S. Environmental Protection Agency, 1999b, 2003f, 2008c). Many unregulated contaminants analyzed in this study are not included in other source-water and finished-water monitoring programs, such as the Unregulated Contaminant Monitoring (UCM) program (U.S. Environmental Protection Agency, 2010f).

- By focusing on source water-quality conditions and by analyzing many contaminants that are not regulated in drinking water by USEPA, this study complements the extensive sampling of finished water from public water systems that is routinely conducted for the purposes of regulatory compliance monitoring by federal, state, and local drinking-water programs.

- Analytical reporting levels used in this study typically are 2-fold to more than 1,000-fold lower than in many previous studies (U.S. Environmental Protection Agency, 2001c, 2002b, 2003f). USGS analytical methods were designed to detect concentrations as low as technically and economically feasible. The analytical methods used in this study have detection levels that are often 100-fold to 1,000-fold less than human-health benchmarks for water quality. Detections of contaminants, therefore, do not necessarily indicate a concern for human health, but rather identify the environmental presence of a wide variety of contaminants, many of which are not commonly monitored in water resources. Contaminant occurrence documented at these low reporting levels also can help to identify emerging issues and to track changes in concentrations over time (Gilliom and others, 2006).

- The reporting levels for the analytical methods used by the USEPA, water utilities, or commercial laboratories for the analysis of finished-water samples for compliance monitoring typically are higher than reporting levels for analytical methods used by USGS. As a result, detection frequencies of contaminants described in USGS reports may be greater than detection frequencies described in annual water-quality reports (consumer confidence reports) provided by water utilities.

- More human-health benchmarks are available for this study than for pre-2005 studies that included the occurrence of contaminants that are not regulated in drinking water. USGS, in collaboration with USEPA and others, has developed Health-Based Screening Levels (HBSLs) for many contaminants that are not regulated in drinking water under the SDWA. HBSLs supplement USEPA benchmarks and provide a basis for a more comprehensive evaluation of contaminant-occurrence data in the context of human health (Toccalino and others, 2005). 
- The co-occurrence of contaminants as mixtures and the potential significance of mixtures to human health are assessed. Data from this study enhance previous studies of contaminant mixtures by examining the co-occurrence of a larger number of contaminants in source water from public wells, and by assessing the occurrence of mixtures relative to individual human-health benchmarks.
- Contaminant occurrence is examined by regional aquifers, providing a framework for understanding water-quality conditions within similar hydrogeologic and geographic regions. The nationally consistent sampling and analysis design used by the NAWQA Program enables comparisons of water-quality conditions among geographic areas and across the United States.

- This study examines the occurrence of contaminants that can be a nuisance but generally not a health concern.

\section{What Is A Contaminant?}

A contaminant is defined in the Safe Drinking Water Act (SDWA) as "any physical, chemical, biological, or radiological substance or matter in water" (U.S. Code, 1996). This broad definition of contaminant includes every substance that may be dissolved or suspended in water-everything but the water molecule itself. The presence of a contaminant in water does not necessarily mean that there is a human-health concern.

Whether a particular contaminant in water is potentially harmful to human health depends on the contaminant's toxicity and concentration in drinking water. Other factors include the susceptibility of individuals, amount of water consumed, and duration of exposure (U.S. Environmental Protection Agency, 2008a). For example, some contaminants that typically occur naturally, such as selenium and chromium, are essential trace elements and are required in low doses for normal physiologic function, but high doses can cause adverse health effects (Eaton and Klaassen, 2001). By contrast, anthropogenic organic contaminants, such as pesticides, are not required by humans at any dose, and may or may not cause adverse effects in humans depending on factors such as exposure and toxicity. Contaminant concentrations were compared to regulatory and non-regulatory human-health benchmarks for drinking water to provide an initial perspective on the potential significance of detected contaminants to human health (see discussion in the Methods sub-section, "Human-Health Benchmarks" on page 14).

Contaminants originate from a wide range of natural and anthropogenic sources. Most inorganic and microbial contaminants analyzed in this study occur naturally, although their concentrations in groundwater may be altered by human activities. For example, nitrate from natural sources is present in most wells, but concentrations often are increased by contributions from anthropogenic sources in agricultural and urban areas. By contrast, most organic contaminants analyzed in this study are man-made, although some also may form in groundwater through various chemical and biological transformation processes.

A total of six water-quality properties and 215 contaminants were analyzed in this study, and are listed below. Other types of contaminants, such as pathogens, and other organic contaminants, such as pharmaceuticals, were not analyzed in this study.

- Water-quality properties (6), such as pH

- Inorganic contaminants (36)

- Major ions (9), such as chloride

- Trace elements (23), such as selenium

- Radionuclides (4), such as radon

- Nutrients (8), such as nitrate

- Organic contaminants (168)

- Pesticide compounds (83), such as atrazine

- Volatile organic compounds (85), such as chloroform

- Fecal-indicator microorganisms (3), such as total coliforms 


\section{Purpose and Scope}

The purpose of this study is to summarize the quality of source water from 932 public wells sampled by the NAWQA Program during 1993-2007 and to evaluate the implications of findings for potential human-health concerns and for future assessment and monitoring. The public wells were distributed within parts of 41 states, withdraw water from parts of one-half (30) of the principal aquifers in the United States, and were sampled as part of interdisciplinary assessments of surface-water and groundwater quality in study areas throughout the United States (Gilliom and others, 1995; Lapham and others, 2005; U.S. Geological Survey, 2010a).

Groundwater samples were collected from public wells prior to treatment or blending and analyzed for as many as six water-quality properties and 215 contaminants (see sidebar on page 5). The three primary objectives of this source-water study were:

1. Evaluate contaminant occurrence in public wells and the potential significance of contaminant concentrations to human health. Contaminant concentrations were compared to human-health benchmarks - regulatory Maximum Contaminant Levels (MCLs) for contaminants regulated by USEPA in drinking water under the SDWA or nonregulatory HBSLs for unregulated contaminantswhen available, to provide an initial perspective on the potential significance of detected contaminants to human health. Individual contaminants that were most commonly detected at concentrations greater than human-health benchmarks, and greater than one-tenth of benchmarks, were identified for more detailed evaluations of geographic distribution patterns and factors that govern occurrence.

2. Evaluate national and regional distributions of groundwater quality and selected contaminants in public wells. Water-quality conditions in samples from public wells were assessed in relation to potential factors that may affect water quality, including aquifer type (confined versus unconfined), principal aquifer rock type, the size and type of public water systems, and land use.

3. Assess the co-occurrence and characteristics of contaminant mixtures. The large number of contaminants analyzed in the source-water samples allows for the investigation of contaminant mixtures within and among contaminant groups. The long-term cumulative human-health effects of exposure to low concentrations of multiple contaminants are unknown for most contaminant mixtures (Yang, 1994; Carpenter and others, 2002), but assessing the potential effects of chemical mixtures is an area of active research (Hertzberg and MacDonell, 2002; Agency for Toxic Substances and Disease Registry, 2004a; U.S. Environmental Protection Agency, 2007a). This study can contribute to this research by identifying those contaminant mixtures that are most commonly detected in the Nation's public wells and which mixtures are detected at concentrations greater than or approaching human-health benchmarks.

\section{Methods}

This section describes the methods used in this report for well selection, sample collection and analysis, quality assurance and quality control, and sources of data. All methods are consistent with those used by the NAWQA Program, which uses nationally consistent study designs and methods of sampling and analysis. More information about the overall design of the NAWQA Program is available elsewhere (Gilliom and others, 1995; Gilliom and others, 2001; Lapham and others, 2005). This section also describes methods used for data treatment and analysis, which are consistent with those methods used in other USGS national-scale reports (U.S. Geological Survey, 1999; Gilliom and others, 2006; Zogorski and others, 2006). Lastly, this section describes how contaminant concentrations were evaluated in the context of human health, and the approach used to evaluate contaminant mixtures.

\section{Well Selection}

This study included 932 public wells located in parts of 40 NAWQA Study Units in 41 states (fig. 1). Each public well was sampled once during 1993-2007, and each well was part of a groundwater assessment study (sampling network), which usually also included other types of wells (Appendix 2). Assessment studies typically were designed to describe the water quality of major aquifers used for drinking water within Study Units throughout the United States. Most public wells sampled (83 percent) were part of Major Aquifer Studies or Source Water-Quality Assessment (SWQA) studies. For the purposes of this study, public wells that were part of multiple assessment studies were assigned to one network and prioritized in the order shown in Appendix 2.

Specific criteria for well selection and documentation for the NAWQA Program are described elsewhere (Lapham and others, 1995, 1997; Koterba, 1998; Carter and others, 2007; Delzer and Hamilton, 2007). Criteria included the proximity of the public well to a randomly selected location within each study area, the availability of well-construction and aquifer information, and the availability of a suitable public-well sampling location. A wide variety of ancillary data for each well were collected around the time of sample collection (U.S. Geological Survey, 2010b). Examples of ancillary data include latitude and longitude, well depth, lithology and principal aquifer(s) or rock types contributing water to the well, land use near the well, and aquifer type (that is, confined versus unconfined aquifers). 


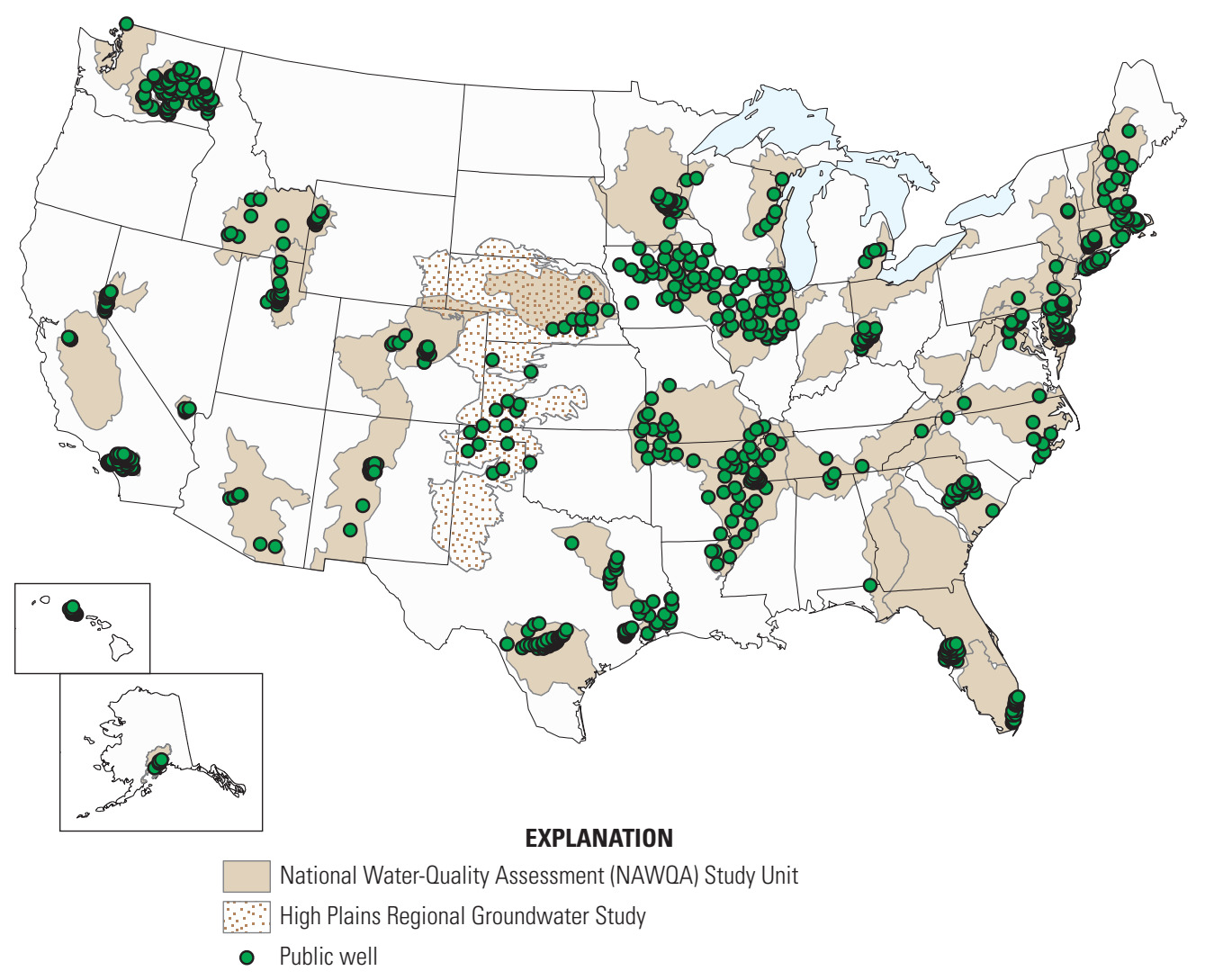

Figure 1. Location of the NAWQA Study Units and the 932 public wells that were sampled during 1993-2007.

Public wells were excluded from this study if (1) the well was only associated with a limited special study (for example, a pilot study, or a study that targeted high contaminant concentrations), (2) finished (treated) drinking-water samples were collected (because only source-water quality data are considered in this study), or (3) wells were less than 1,000 m apart from each other in order to eliminate wells that may hydraulically influence each other. Excluding wells closer than $1,000 \mathrm{~m}$ apart is consistent with the approach used in (1) USGS SWQA studies to ensure that the contributing areas for wells did not overlap (Carter and others, 2007; Hopple and others, 2009), and (2) national predictions of groundwater vulnerability to nitrate by reducing spatial clustering and avoiding double counting of estimated nitrogen loads (Nolan and Hitt, 2006).

\section{Identification of Principal Aquifer Rock Types}

The public wells in this study were categorized in terms of the principal aquifers and rock types from which they withdraw water. The 932 public wells withdraw water from parts of 30 regionally extensive aquifers used for water supply; these aquifers constitute about one-half of the principal aquifers in the United States (U.S. Geological Survey, 2009). A principal aquifer is defined as a regionally extensive aquifer or aquifer system that has the potential to be used as a source of potable water (Miller, 2000; U.S. Geological Survey, 2010c). Using principal-aquifer data, the public wells were grouped according to lithology into eight rock-type categories following the classifications used in the National Atlas (Miller, 2000; U.S. Geological Survey, 2003, 2009) with a few modifications. The eight rock-type categories are listed below, are shown geographically in figure 2 , and are further described in Appendix 3.

1. Unconsolidated sand and gravel aquifers (non-glacial origin)

2. Glacial sand and gravel aquifers

3. Semi-consolidated sand and gravel aquifers

4. Sandstone aquifers

5. Sandstone and carbonate-rock aquifers

6. Carbonate-rock aquifers

7. Basaltic and other volcanic-rock aquifers

8. Crystalline-rock aquifers 

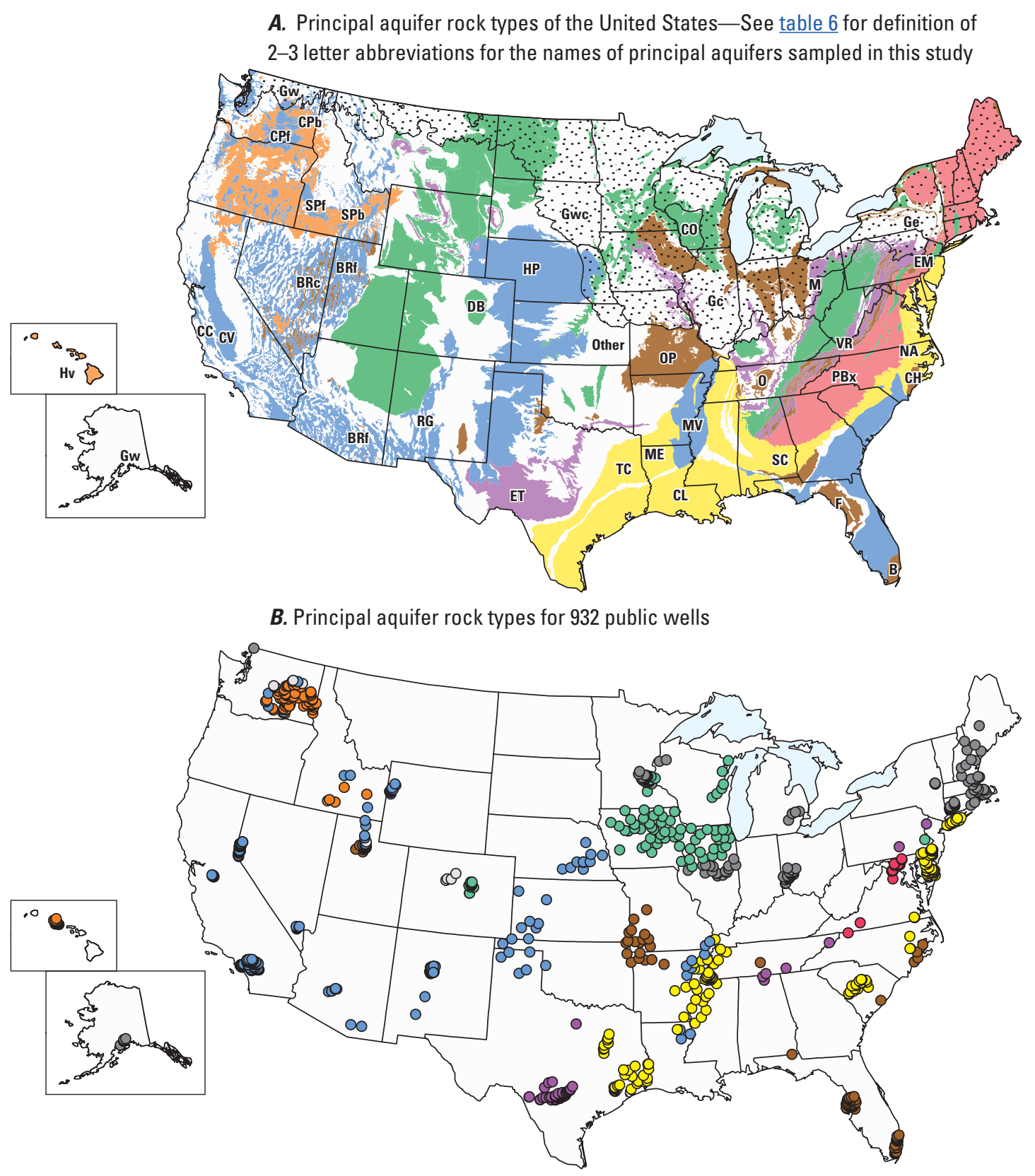

EXPLANATION

Principal aquifer rock type (Figure $2 A$ )

Unconsolidated sand and gravel aquifers (non-glacial origin)

Glacial sand and gravel aquifers

Dots are combined with color of underlying aquifer.

Aquifers are discontinuous within area shown.

Semi-consolidated sand and gravel aquifers

Sandstone aquifers

Sandstone and carbonate-rock aquifers

Carbonate-rock aquifers

Basaltic and other volcanic-rock aquifers

Crystalline-rock aquifers

Other aquifers
Number of public wells (Figure 2B)

- 284

- 118

○ 172

○ 94

- 66

- 81

- 89

- 17

○ 11

Figure 2. Geographic distribution of $(A)$ areal extent, by rock type, of all principal aquifers in the United States and $(B)$ location of the 932 public wells sampled during 1993-2007 and the principal aquifer rock type associated with each well. 
Modifications from rock-type classifications used in the National Atlas included dividing unconsolidated sand and gravel aquifers into two categories: unconsolidated sand and gravel aquifers of non-glacial origin, and glacial sand and gravel aquifers. For consistency with previous studies (Warner and Arnold, 2006; DeSimone, 2009), the glacial sand and gravel aquifers were further split into eastern, central, west central, and western glacial aquifers, based on geography and differing source materials (Warner and Arnold, 2006). Additionally, the areal extent of glacial sand and gravel aquifers used in this study extended farther westward than shown in the National Atlas, and included deposits of both Laurentide and Cordilleran continental glaciations (Warner and Arnold, 2006). The igneous and metamorphic crystalline-rock aquifers also were divided into two categories - crystalline-rock aquifers and basaltic and volcanic-rock aquifers-consistent with previous studies (Zogorski and others, 2006; DeSimone, 2009).

\section{Classification of Aquifer Type}

When the public wells were sampled, information about aquifer type was obtained from various sources including well owners, well-construction logs, and other records from state or local jurisdictions (U.S. Geological Survey, 2006). The aquifer type for each public well was coded as (1) unconfined single aquifer, (2) unconfined multiple aquifers, (3) confined single aquifer, (4) confined multiple aquifers, or (5) mixed (confined and unconfined multiple aquifers) in the Ground-Water SiteInventory System, which is part of the USGS National Water Information System (U.S. Geological Survey, 2004). For this study, unconfined single and multiple aquifers were combined into one category (unconfined aquifers), confined single and multiple aquifers were combined into another category (confined aquifers), and the mixed aquifers category was retained without any change.

\section{Classification of Land Use}

The land use associated with each public well was classified according to the dominant land uses in a circular buffer area of 500-m radius around each well (table 3) using the land-use categories described in Gilliom and others (2006). The land-use dataset used for these classifications was the second-generation National Land Cover Database (NLCD 2001) (Homer and others, 2004; K.J. Hitt, U.S. Geological Survey, written commun., 2008). NLCD 2001 updates the original (Vogelmann and others, 2001) and enhanced (Nakagaki and Wolock, 2005) versions of NLCD 1992. In NLCD 2001, land use is classified for each $30 \times 30-\mathrm{m}$ area of land in the conterminous United States (K.J. Hitt, U.S. Geological Survey, written commun., 2008).

A 500-m-radius buffer was created around each public well (1-km-diameter circle), then the fraction of the total buffer represented by each land-use category within the buffer was calculated (K.J. Hitt, U.S. Geological Survey, written commun., 2008). Several previous USGS studies classified land use by using a 500-m-radius circle centered on various types of wells (Moran and others, 2006; Nolan and Hitt, 2006; DeSimone, 2009). The 500-m-radius buffer is not expected to represent the actual contributing area for the public wells because public wells generally are deeper, have longer screened intervals, and pump larger volumes of water relative to other well types, such as domestic or monitoring wells. As a result, the contributing areas for public wells can extend up-gradient from wells, be large (more than $500 \mathrm{~m}$ from the wells), irregularly shaped, and not necessarily contiguous with the area around the well (Franke and others, 1998; Kauffman and others, 2001; Johnson and Belitz, 2009). Empirical studies, however, indicate that the use of a 500-m-radius circular buffer can be a useful indicator of the characteristics of the landscape of interest to water-quality investigations near public wells (Koterba, 1998). A recent study supports this finding, and concluded that a 500-m-radius circular buffer is adequate for assigning land use to public wells (Johnson and Belitz, 2009).

Table 3. Land-use categories for public wells sampled during 1993-2007.

[Land-use classifications are from Gilliom and others (2006). Each public well was classified according to the dominant land uses in a circular buffer area of 500-meter radius around the well; >, greater than; $\leq$, less than or equal to]

\begin{tabular}{lr}
\hline \multicolumn{1}{c}{ Land-use category } & Land-use classification criteria \\
\hline Agricultural & $>50$ percent agricultural land and $\leq 5$ percent urban land \\
Urban & $>25$ percent urban land and $\leq 25$ percent agricultural land \\
Undeveloped & $\leq 5$ percent urban land and $\leq 25$ percent agricultural land \\
Mixed & All other combinations of urban, agricultural, and undeveloped land \\
\hline
\end{tabular}




\section{Sample Collection and Analysis}

Groundwater samples were collected from 932 public wells during 1993-2007 and analyzed for as many as six water-quality properties and 215 contaminants; one sample per well was used in this analysis. As a result, percentages of samples presented in this study are the same as percentages of wells. Trends within the 15 -year study period were not assessed, but changes in contaminant occurrence over time were not expected to be large compared to geographic variability because of the relatively slow movement of groundwater. But, the occurrence of some contaminantsparticularly in unconfined aquifers - may have changed over time in some wells because of variability in contaminant sources and aquifer characteristics and because pumping and other human activities can enhance the mobility of contaminants.

Water samples were collected and processed using methods designed to yield samples that were representative of environmental conditions, minimally affected by contamination, and consistent among NAWQA Study Units nationwide. All samples were collected at the wellhead (the point at which the groundwater exits the well, near the land surface) before any treatment or blending that potentially could alter contaminant concentrations. All samples were collected by USGS personnel using prescribed field protocols described elsewhere (Koterba and others, 1995; Embrey and Runkle, 2006; Gilliom and others, 2006; Moran and others, 2006; U.S. Geological Survey, variously dated). DeSimone (2009) provides a detailed description of USGS sampling and analytical methods used for groundwater samples. Samples collected for analysis of alkalinity, major ions, nutrients, trace elements, radionuclides other than radon, and pesticide compounds were filtered in the field or before analysis; concentrations of these contaminants, therefore, represent dissolved concentrations. Samples collected for analysis of volatile organic compounds (VOCs), radon, and fecalindicator microorganisms were not filtered (DeSimone, 2009).

The six water-quality properties and 215 contaminants analyzed in this study are listed by contaminant group in Appendix 4; pesticide compounds and VOCs were further categorized into primary-use or source groups (Carter and others, 2007) in Appendix 5. Water-quality properties - such as $\mathrm{pH}$ and dissolved oxygen - generally were measured in the field during sampling using approved USGS methods. The chemical contaminants (major ions, trace elements, nutrients, radionuclides, pesticide compounds, VOCs) were analyzed using approved USGS methods at the USGS National Water Quality Laboratory (NWQL) in Denver, Colorado. Water samples for analyses of fecal-indicator bacteria were processed within 6 hours of collection and analyzed using membrane-filtration methods by the sampling teams (Embrey and Runkle, 2006; Myers and others, 2007). Samples for the analyses of coliphage were shipped to the USGS Ohio Water
Microbiological Laboratory within 24 hours of collection or on the same day of collection, and were analyzed using USEPA's method 1601, a two-step enrichment procedure (U.S. Environmental Protection Agency, 2001a). For about 8 percent of samples in this study, alkalinity [reported as milligrams per liter $(\mathrm{mg} / \mathrm{L})$ as calcium carbonate $\left.\left(\mathrm{CaCO}_{3}\right)\right]$ was calculated from reported bicarbonate concentrations, $\mathrm{pH}$, and temperature (Appendix 6). Water hardness (also reported as $\mathrm{mg} / \mathrm{L}$ as $\mathrm{CaCO}_{3}$ ) was calculated from calcium and magnesium concentrations for 809 samples (Appendix 7).

\section{Quality Assurance and Quality Control}

The quality of contaminant-occurrence data collected by the USGS is ensured by several measures, including: written protocols for well selection, sample collection, and chemical analysis; field and laboratory quality-control (QC) samples; and field-measurement and laboratory evaluation programs, such as blind-sample programs (Moran and others, 2006).

To ensure that sample collection and handling procedures do not introduce contamination to water-quality samples, QC samples were collected for each groundwater study, including field-blank water samples to assess potential contamination, replicate water samples to assess variability, and field matrix spikes to assess potential contaminant degradation or matrix effects (Gilliom and others, 2006). Environmental data determined to be affected by contamination were excluded from this study; these data were identified in the NAWQA Data Warehouse (U.S. Geological Survey, 2010b) as "V-coded" data. DeSimone (2009) summarized the results of national-scale investigations of field QC data for the contaminants in this study. These investigations indicated that the analytical data for groundwater samples collected by the NAWQA Program were reproducible and representative of environmental conditions (DeSimone, 2009).

A national review of field QC samples from public and domestic wells revealed that water-quality data for two VOCs, toluene and 1,2,4-trimethylbenzene (1,2,4-TMB), have potential random contamination associated with field protocols (J.S. Zogorski and D.A. Bender, U.S. Geological Survey, written commun., 2008). As a result, all data for toluene and 1,2,4-TMB in this study were evaluated at common assessment levels of 0.03 and $0.05 \mu \mathrm{g} / \mathrm{L}$, respectively, consistent with a recent national assessment of water quality from domestic wells (DeSimone, 2009). All detections of toluene less than $0.03 \mu \mathrm{g} / \mathrm{L}$ were treated as non-detections, and concentrations were treated as less than $(<) 0.03 \mu \mathrm{g} / \mathrm{L}$. Likewise, all detections of 1,2,4-TMB less than $0.05 \mu \mathrm{g} / \mathrm{L}$ were treated as $<0.05 \mu \mathrm{g} / \mathrm{L}$. At these concentrations, the maximum probability of environmental sample contamination resulting from field protocols is about 1 percent for each VOC (J.S. Zogorski and D.A. Bender, U.S. Geological Survey, written commun., 2008). 
Four pesticide compounds (carbaryl, carbofuran, linuron, and terbacil) were analyzed using two different analytical methods-high-performance liquid chromatography (HPLC) and gas chromatography/mass spectrometry (GCMS). For these four pesticide compounds, only results from the GCMS method were used in this study because there were more results associated with the GCMS method and because the reporting levels for the GCMS method tend to be lower than for the HPLC method (J.D. Martin, U.S. Geological Survey, oral commun., 2007). Results for pesticide compounds analyzed using HPLC between March 1999 and March 2000 were excluded from this study because sample holding times were exceeded (Furlong and others, 2003).

\section{Data Sources and Reporting Conventions}

Water-quality data and ancillary data associated with each well site were retrieved from the NAWQA Data Warehouse database (U.S. Geological Survey, 2010b) in May 2008. Water-quality data for one sample per public well was retrieved to preclude bias in summary statistics from wells that were sampled more than once; this one sample was the primary sample for the site. The primary sample for a site usually has the greatest number of analytical results in a given NAWQA Cycle. If a site was sampled in NAWQA Cycle 1 (the first 10 years of monitoring, 1991-2001) and Cycle 2 (monitoring beginning in 2001), the most recent water-quality data from Cycle 2 were used. In this study, 497 public wells were sampled in Cycle 1, 378 were sampled in Cycle 2, and 57 public wells were sampled in both cycles.

If key ancillary data associated with a site were not available from the Data Warehouse, then Study Unit personnel supplied those data. Data about the size and type of public water systems sampled in this study, and the number of people served by these systems, was from the USEPA Safe Drinking Water Information System (SDWIS) (M.A. Horn, U.S. Geological Survey, written commun., November 2007 and August 2008). Land-use data were obtained from geographic information system ancillary data, specifically the NLCD 2001 for 500-m radius buffers around each public well (K.J. Hitt, U.S. Geological Survey, written commun., 2008). The principal aquifer associated with some public wells was identified using data from USGS regional principal aquifer assessments (Lapham and others, 2005; T.L. Arnold, U.S. Geological Survey, written commun., 2007).

Water-quality data commonly include contaminant concentrations less than laboratory reporting levels (LRLs). These non-detections may be reported as "less than" one of several types of reporting levels (Helsel, 2005a). The USGS NWQL used different reporting conventions for water-quality data during the study period, indicating changes in reporting policy, primarily minimum reporting levels (MRLs) and LRLs. The MRL is an estimate of the smallest detected concentration of a constituent that may be reliably reported using a given analytical method (Timme, 1995), and is similar to a method detection level (MDL). The LRL generally is 2-fold greater than the long-term method detection level (LT-MDL). The LRL is based on minimizing the probability of false negative error. The chance of falsely reporting a non-detection for a sample that actually contained an analyte at a concentration equal to or greater than the LRL is no more than 1 percent (Childress and others, 1999). MRLs, LRLs, and LT-MDLs can change through time. DeSimone (2009) further discusses these reporting conventions.

Confirmed detections less than the MRL or LRL were reported as estimated values. Various conditions may create estimated values, including results that were extrapolated beyond the calibration range used in the analytical method and moderate matrix interferences in the sample. Estimated values are reliable detections but with greater than average uncertainty in quantitation (Childress and others, 1999). In this study, estimated values were used without qualification.

Concentrations of several pesticide compounds were reported as estimated because they have lower or more variable recovery relative to other pesticide compounds (Zaugg and others, 1995; Werner and others, 1996; Foreman and Gilliom, 1998; Gilliom and others, 2006). These pesticide compounds were azinphos-methyl, carbaryl, carbofuran, deethylatrazine, and terbacil — analyzed using GCMS — and aldicarb, aldicarb sulfone, aldicarb sulfoxide, chlorothalonil, dichlobenil, and 2-methyl-4,6-dinitrophenol (DNOC)analyzed using HPLC. These estimated concentrations also were used without qualification.

\section{Data Preparation for Uncensored and Censored Datasets}

The datasets used in this national public-well study are available online at http://water.usgs.gov/nawqa/studies/public wells/. The term "uncensored data" refers to data that were not evaluated relative to common assessment levels, and the term "censored data" refers to data that were evaluated relative to common assessment levels.

Three general steps were carried out to prepare the uncensored data for nationally consistent analyses across all contaminants. First, results associated with "non-standard" methods were removed from the dataset. For example, about 99 percent of the samples analyzed for the pesticide simazine were analyzed using GCMS and about 1 percent of the samples were analyzed using HPLC. In this case, the HPLC results for simazine were removed from the dataset to increase comparability between results for a given contaminant. In addition, MRL or LRL values commonly were elevated for results associated with "non-standard" methods relative to results associated with "standard" methods for the same contaminant analyzed during the same time period. 
For example, for simazine, the reporting level for samples analyzed using HPLC was 5-fold greater than the reporting level for samples analyzed using GCMS during the same time period. Removing results from "non-standard" methods affected 12 pesticide compounds - 1 to 5 percent of results were removed for 10 pesticide compounds; 11 to 13 percent of results were removed for two pesticide compounds (bromacil and propachlor, respectively). Two results were removed for one trace element. Results were not removed for any other contaminant group as a result of "non-standard" methods.

In the second step, non-detections that could be attributed to sample analytical difficulties, such as matrix interference, were identified. Analytical values reported as non-detections at concentrations greater than the MRL or LRL (a "raised" reporting level) were deleted from the dataset, consistent with the approach used by Gilliom and others (2006, Appendix 8B). For example, if the MRL was $0.02 \mu \mathrm{g} / \mathrm{L}$ and the result was $<0.03 \mu \mathrm{g} / \mathrm{L}$, that result was removed from the dataset. Few results were removed as a result of elevated non-detections, and elevated non-detections usually were isolated cases. Less than 1 percent of results for most pesticide compounds, major ions, nutrients, and radionuclides were removed, about 3 percent of all VOC results were removed, and less than 2 percent of most trace element results were removed.

In the third step, LRLs were reassigned to LT-MDLs for non-detections and MRLs were left as is and assumed to be conceptually equivalent to the LT-MDLs. The NWQL reported non-detections relative to MRLs and LRLs. Information on historical LT-MDLs was obtained from NWQL (National Water Quality Laboratory, 2009). Reassigning < LRL values to $<$ LT-MDL values does not alter the data for detections, but makes reporting conventions in the dataset more consistent (Helsel, 2005a; Bonn, 2008).

In addition to the uncensored datasets used in this study, concentration data for trace elements, pesticide compounds, and VOCs also were censored to common assessment levels for analyses in which detection frequencies were compared. Uncensored data for trace elements, pesticide compounds, and VOCs were used, however, when detection frequencies among contaminants were not compared and when concentrations were compared to human-health benchmarks. Using uncensored data in these cases allows the full distribution of results to be used, which is especially important when concentrations are compared to human-health benchmarks. Otherwise, the lowest concentrations would be censored (treated as non-detections), which could overestimate the percentage of contaminant detections at concentrations greater than human-health benchmarks or greater than one-tenth of benchmarks; concentrations greater than or approaching benchmarks tend to be greater than common assessment levels.
Common assessment levels were used when detection frequencies were compared because the numerical values of MRLs and LT-MDLs changed through time during the study period for many contaminants and varied among contaminants during the same time period. As a result, comparing detection frequencies among contaminants potentially is misleading when detection frequencies are calculated using uncensored data. Detection frequencies have been found to be inversely related to reporting levels (Kolpin and others, 2000), and regional patterns of contaminant occurrence may be distorted by greater detection frequencies in areas where analytical methods with lower reporting levels were used (DeSimone, 2009).

Common assessment levels were selected to match those used in previous studies (Gilliom and others, 2006; Zogorski and others, 2006; DeSimone, 2009) in order to facilitate comparisons among studies. For trace elements, a common assessment level of $1 \mu \mathrm{g} / \mathrm{L}$ was used, except for boron $(12 \mu \mathrm{g} / \mathrm{L})$ and iron $(10 \mu \mathrm{g} / \mathrm{L})$ because reporting levels were higher for boron and iron than for other trace elements; these common assessment levels are consistent with those used in previous trace-element studies (J.D. Ayotte, U.S. Geological Survey, written commun., July 2008). Common assessment levels of $0.02,0.1$, and $0.2 \mu \mathrm{g} / \mathrm{L}$ were applied to pesticide compounds and VOCs. All three of these common assessment levels were applied to pesticide compounds analyzed using GCMS, but the $0.02 \mu \mathrm{g} / \mathrm{L}$ assessment level was not applied to pesticide compounds analyzed using HPLC because the reporting levels for those compounds were greater than $0.02 \mu \mathrm{g} / \mathrm{L}$. The use of common assessment levels represents a compromise between the need to accommodate comparisons to contaminants with high reporting levels and the desire to minimize the loss of information about contaminants detected at low concentrations (Kolpin and others, 2000). When common assessment levels were used, detections less than the assessment level were treated as non-detections. For example, if the common assessment level was $0.02 \mu \mathrm{g} / \mathrm{L}$ and the result was a detection of $0.01 \mu \mathrm{g} / \mathrm{L}$, then that result was treated as $<0.02 \mu \mathrm{g} / \mathrm{L}$.

VOC data were prepared in two ways, consistent with prior assessments (Moran and others, 2006; Zogorski and others, 2006; Carter and others, 2008; DeSimone, 2009). First, the common assessment level of $0.2 \mu \mathrm{g} / \mathrm{L}$ was applied to all VOC results. The common assessment levels of 0.02 and $0.1 \mu \mathrm{g} / \mathrm{L}$ were not applied to the VOC data in this case because, prior to April 1996, the LRL for most VOCs was $0.2 \mu \mathrm{g} / \mathrm{L}$ (Rose and Schroeder, 1995; Moran and others, 2006). VOC analyses in samples collected after April 1996 were conducted using a new, low-level analytical method developed by the USGS for natural waters (Connor and others, 1998; Zogorski and others, 2006). Second, the common assessment levels of 0.02 and $0.1 \mu \mathrm{g} / \mathrm{L}$ were applied only to those samples collected after April 1996, resulting in the removal of about 7 percent of the VOC data. 
Common assessment levels were not applied to data for major ions, nutrients, or radionuclides. Raw (uncensored) water-quality data were used for these inorganic contaminants because detection frequencies were not compared among these contaminants. Additionally, many of these contaminants are naturally occurring and are commonly detected, so detection frequencies were not expected to vary greatly even if a common assessment level was used.

\section{Statistical Methods and Data Presentation}

Statistical methods included the calculation of detection frequencies, concentration statistics (median and percentile concentrations), and rank-based methods for comparisons among contaminant concentrations and (or) explanatory variables.

Detection frequencies were calculated for all detections (detections at any concentration), and for detections censored at each of the common assessment levels described above. For each common assessment level, as well as for detections at any concentration, the frequency of detection for each contaminant was calculated as $(n / N) \times 100$. Here, $n$ is the number of samples in which an individual contaminant was detected at a concentration greater than or equal to a given assessment level, and $\mathrm{N}$ is the total number of samples analyzed for an individual contaminant. When calculating detection frequencies by contaminant group (for example, percentage of samples with VOC detections), $\mathrm{n}$ is the number of samples in which at least one contaminant in a class was detected at a concentration greater than or equal to an assessment level, and $\mathrm{N}$ is the total number of samples analyzed for a given contaminant group (Moran and others, 2006).

Concentration statistics (median and percentile concentrations) were calculated using the Kaplan-Meier method on left-censored data described by Helsel (2005b, p. 63-68) and Bonn (2008). The procedures were implemented in the S-Plus software package (Insightful Corp., version $7.0,2005)$. This method involves no assumptions about the underlying distribution of a dataset and can handle complex datasets with multiple reporting levels and detected concentrations that are less than a reporting level. The $10^{\text {th }}, 25^{\text {th }}, 50^{\text {th }}, 75^{\text {th }}, 90^{\text {th }}, 95^{\text {th }}$, and $99^{\text {th }}$ percentiles were calculated and provide information about the magnitude of concentrations at selected points in the cumulative frequency distribution of the concentrations.

Nonparametric, rank-based methods were used for comparison of contaminant concentrations or property values to one another or to potential explanatory variables. The Wilcoxon signed-rank test was used for matched pairs of data, such as for one-to-one plots (Helsel and Hirsch, 2002, chap. 6). The Spearman's rho test was used for correlations between two continuous variables (Helsel and Hirsch, 2002, chap. 8), in conjunction with examination of scatterplots for each pair of variables. For each method, all observations less than the common reporting levels were treated as ties at the lowest rank (Helsel and Hirsch, 2002). The $\alpha$-value, a significance level or decision criteria, was set at 5 percent $(0.05)$ for all tests. The null hypothesis of no difference among groups was rejected when the p-value (attained significance level) of the test was less than the $\alpha$-value; when $p<0.05$, the alternate hypothesis that at least one group was different was accepted (Helsel and Hirsch, 2002).

The Kruskal-Wallis test for left-censored data was used for analyses of one continuous variable (such as concentration) and multiple categorical values (such as principal aquifer rock type), as for boxplots (Helsel and Hirsch, 2002, chap. 7). If the Kruskal-Wallis test resulted in a p-value $<0.05$ (that is, when the alternate hypothesis that at least one group was different was accepted), then a left-censored multi-comparison test (based on a Wilcoxon rank-sum test) was performed to determine significance values among all combinations of groups, based on differences in distributions. For the multicomparison test, the $\alpha$-value was adjusted for the total number of comparisons using Bonferroni's method (Keppel, 1991, p. 167), which simply divides the $\alpha$-value ( 0.05 ) by the total number of possible comparisons to correct for the family-wise error rate specified by the $\alpha$-value. The Kruskal-Wallis and multi-comparison tests were implemented in TIBCO Spotfire $\mathrm{S}+$ (version 8.1, 2008).

Multi-comparison test results are shown on boxplots as letters; distributions of groups showing the same letter are not significantly different at the 95 -percent confidence level (Helsel and Hirsch, 2002). For example, if four groups are on a boxplot showing the letters "A", "AB", "BC", and "C", then the distribution of group " $\mathrm{A}$ " is not significantly different than the distribution of group " $\mathrm{AB}$ ", but it is significantly different than the distributions of groups "BC" and " $\mathrm{C}$ " at the 95-percent confidence level. Figures with boxplots in this study are truncated at the $10^{\text {th }}$ and $90^{\text {th }}$ percentiles (values outside of the $10^{\text {th }}$ to $90^{\text {th }}$ percentile range are not shown), but the full distribution of data was used to determine the level of significance among groups (shown as letters on boxplots).

For maps showing the geographic distribution of contaminants, the large number and close proximity of wells resulted in overlapping symbols in many areas. Well symbols on maps are layered such that symbols on the top layer represent the highest concentrations, symbols on the bottom layer represent the lowest concentrations, and symbols showing detections are on top of symbols showing non-detections. 


\section{Human-Health Benchmarks}

In this study, contaminant concentrations in groundwater were compared to human-health benchmarks for drinking water to provide an initial perspective on the potential significance of detected contaminants to human health and to help prioritize further investigations (Toccalino and others, 2006). Such comparisons also provide preliminary information about where adverse effects are more likely to occur (based on where concentrations are greater than benchmarks) and which contaminants may be responsible for possible adverse effects (Gilliom and others, 2006). Comparisons of contaminant concentrations to human-health benchmarks are not designed to evaluate specific effects of contaminants on human health, and are not a substitute for comprehensive risk assessments, which generally include many additional factors, such as multiple avenues of exposure (Toccalino and others, 2006).

\section{Selection of Benchmarks}

Several types of human-health benchmarks are available to identify contaminant concentrations of potential human-health concern in drinking water. As used in this study, regulated contaminants are those contaminants for which the USEPA has established drinking-water standards (MCLs) under the SDWA, and unregulated contaminants are those that are not regulated in drinking water under the SDWA and therefore do not have MCLs. Contaminants that are not federally regulated in drinking water under the SDWA may be regulated in drinking water by some states, and also may be regulated in other contexts and under other statutes, such as the Federal Insecticide, Fungicide, and Rodenticide Act (FIFRA).

For the purposes of placing study findings in the context of human health, concentrations of contaminants that are regulated by USEPA in drinking water under the SDWA were compared to MCLs, and concentrations of unregulated contaminants were compared to USGS HBSLs, when available. Because regulatory MCLs and non-regulatory HBSLs are both used in this study to provide an initial perspective on the potential significance of detected contaminants to human health, they are henceforth collectively referred to as "human-health benchmarks".

MCL values for 58 regulated contaminants were obtained from USEPA (U.S. Environmental Protection Agency, 2006a, 2009b), and HBSL values for 96 unregulated contaminants were obtained from the HBSL website (Toccalino and others, 2008). MCL and HBSL values are listed in Appendix 4. All human-health benchmarks used in this study were the most currently available benchmarks as of September 2009. USEPA published a revised edition of drinking water standards and guidelines in late 2009 (U.S. Environmental Protection Agency, 2009a), but data from the revised USEPA report were not available in time for inclusion in this report. Neither MCLs nor HBSLs were available for 67 contaminants or water-quality properties analyzed in this study (Appendix 4).
MCLs are legally enforceable USEPA drinking-water standards that set the maximum permissible level of a contaminant in water that is delivered to any user of a public water system. MCLs are set as close as feasible to the maximum level of a contaminant at which no known or anticipated adverse effects on human health would occur over a lifetime, taking into account the best available analytical and treatment technologies, cost considerations, expert judgment, and public comments (U.S. Environmental Protection Agency, 2010e). As a result, not all MCLs are based on health-effects data alone. In this study of untreated source waters, contaminant concentrations that are greater than MCLs do not represent MCL violations because MCLs apply to finished water and all samples were collected from source waters. None of the source-water samples were collected for regulatory compliance purposes; further, compliance with most MCLs is based on running average concentrations, not on concentrations detected in single samples as collected in this study.

HBSLs are non-enforceable benchmark concentrations of contaminants in water that were developed by the USGS in collaboration with the USEPA and others using: (1) USEPA Office of Water methodologies for establishing drinking-water guidelines, and (2) the most recent, USEPA peer-reviewed, publicly available human-health toxicity information (Toccalino and others, 2003, 2006). As a result, HBSL values are consistent with existing USEPA drinking-water guideline values, such as Lifetime Health Advisory values and Cancer Risk Concentration values (when they exist), except for unregulated contaminants for which more recent toxicity information has become available (Toccalino, 2007).

Lifetime Health Advisories are concentrations in drinking water that are not expected to cause adverse noncarcinogenic effects from a lifetime of exposure; Cancer Risk Concentrations are concentrations in drinking water associated with specified lifetime cancer risks (U.S. Environmental Protection Agency, 2006a). In this report, concentrations of unregulated contaminants were compared to HBSLs because HBSLs incorporate the most current USEPA toxicity information, and because HBSLs are available for more unregulated contaminants than are Lifetime Health Advisories or Cancer Risk Concentrations. More information about HBSL development is presented elsewhere (Toccalino and others, 2003, 2006; Toccalino, 2007).

Neither an MCL nor an HBSL is available for radon, but USEPA has proposed both an MCL of 300 picocuries per liter (pCi/L) and an Alternative MCL (AMCL) of 4,000 pCi/L for radon in public water systems (U.S. Environmental Protection Agency, 2006a). The lower proposed MCL for radon applies to states and public water systems that do not develop programs to address health risks from radon in indoor air; the higher proposed AMCL applies to states and public water systems that have established such programs (U.S. Environmental Protection Agency, 1999a, 2009e). 
Non-health guidelines were available for 14 water-quality properties or contaminants analyzed in this study (U.S. Environmental Protection Agency, 2006a). Concentrations of these 14 properties or contaminants were compared to Secondary Maximum Contaminant Levels (SMCLs) or taste or odor thresholds. SMCLs are non-enforceable guidelines regarding cosmetic effects, such as tooth or skin discoloration or aesthetic effects, such as taste, odor, or color of drinking water (U.S. Environmental Protection Agency, 2006a). Some public water systems monitor and treat their supplies for secondary contaminants, although federal regulations do not require them to do so. Conventional water treatment technologies, such as coagulation, flocculation, corrosion control, and filtration will remove various secondary contaminants (U.S. Environmental Protection Agency, 1992c), but untreated source water was sampled in this study, and information about which treatment technologies were used at most of the sampled systems is not available.

\section{Evaluation of the Potential Significance of Contaminant Occurrence to Human Health}

For each sample, a Benchmark Quotient (BQ) value was calculated for each detected contaminant with a humanhealth benchmark to aid in evaluating water-quality data in the context of human health (table 4). BQ values are ratios of the contaminant concentrations to their respective MCLs (for regulated contaminants) or HBSLs (for unregulated contaminants). Information about the interpretation of BQ values is presented elsewhere (Toccalino, 2007) and is summarized below.

A BQ value greater than $1(B Q>1)$ indicates that a contaminant concentration is greater than a human-health benchmark; such a concentration is of potential human-health concern, but does not necessarily indicate that adverse effects will occur because the benchmarks are conservative (protective) (Toccalino and others, 2006; Toccalino, 2007) and source-water samples were collected prior to any treatment or blending that could alter contaminant concentrations in finished drinking water (table 4). The likelihood for adverse effects generally increases as contaminant concentrations increase to greater than benchmarks (and BQ values increase to greater than 1). Exposure to individual contaminants with concentrations less than or equal to benchmarks $(\mathrm{BQ} \leq 1)$ is unlikely to result in adverse human-health effects because the benchmarks, as defined above, typically are concentrations in drinking water that are not anticipated to cause adverse effects from a lifetime of exposure (U.S. Environmental Protection Agency, 2006a; Toccalino, 2007).

A BQ value greater than $0.1(\mathrm{BQ}>0.1)$ indicates that a contaminant concentration is greater than one-tenth of a human-health benchmark. For individual contaminants, concentrations greater than one-tenth of a human-health benchmark commonly are used to identify contaminants that may warrant additional monitoring, to analyze trends in contaminant occurrence, and to provide an early and conservative indication of contaminant concentrations that approach benchmarks (Toccalino and others, 2006; Toccalino, 2007). Early attention to potential groundwater contamination, in particular, is vital because such contamination is difficult and costly to remediate (Gilliom and others, 2006). As a result, the presence of contaminants at concentrations less than or equal to, but approaching benchmarks $(0.1<\mathrm{BQ} \leq 1)$ can inform water-resource managers about needs for preventive actions for sources of these contaminants.

Table 4. Interpretation of Benchmark Quotient values for potential human-health significance and implications for water-quality monitoring.

\begin{tabular}{|c|c|}
\hline $\begin{array}{l}\text { Benchmark Quotient for } \\
\text { a contaminant } \\
\text { in water }\end{array}$ & Interpretation of Benchmark Quotient value \\
\hline$\leq 1$ & $\begin{array}{l}\text { Adverse effects are unlikely to be caused by this contaminant alone, even if water } \\
\text { with such a concentration were to be ingested over a lifetime. }\end{array}$ \\
\hline$>1$ & $\begin{array}{l}\text { The contaminant concentration is of potential human-health concern if water with } \\
\text { such a concentration were to be ingested without treatment over a lifetime. Adverse } \\
\text { human-health effects will not necessarily be caused by this contaminant because } \\
\text { MCLs and HBSLs are conservative (protective); they incorporate safety factors to } \\
\text { account for uncertainty in toxicity information. Additionally, water may be treated or } \\
\text { blended, potentially altering contaminant concentrations. }\end{array}$ \\
\hline$>0.1$ & $\begin{array}{l}\text { Contaminant may warrant additional monitoring to analyze trends in its occurrence. } \\
\text { These concentrations also provide an early and conservative indication of contaminants } \\
\text { that may approach concentrations of potential human-health concern, either individually } \\
\text { or in mixtures. }\end{array}$ \\
\hline
\end{tabular}


The use of concentrations greater than one-tenth of human-health benchmarks to identify contaminants that may warrant additional monitoring was selected to be consistent with several state and federal practices. Federal and state agencies use the criteria of one-tenth (or sometimes one-half) of a human-health benchmark for various purposes including (1) reporting contaminant occurrence in groundwater (U.S. Environmental Protection Agency, 1999b; New Jersey Department of Environmental Protection, 2003); (2) reporting pesticide detections in water to USEPA under FIFRA (Nebraska Department of Agriculture, 1997; U.S. Environmental Protection Agency, 1998); (3) ranking the susceptibility of wells to contamination (New Jersey Department of Environmental Protection, 2003, 2004); and (4) identifying contaminants of potential human-health concern for risk assessment evaluations (U.S. Environmental Protection Agency, 1993, 1994).

\section{Comparison of Analytical Reporting Levels to Benchmarks}

When evaluating the potential significance of contaminant-occurrence data to human health, the analytical reporting level (MRL or LT-MDL) for each contaminant should be less than the MCL or HBSL. This ensures that the laboratory methodologies are adequate to detect concentrations relevant to human health. If the MRL or LT-MDL for a contaminant is greater than the MCL or HBSL, then (1) the contaminant may be present at a concentration greater than a benchmark but not be detected (U.S. Environmental Protection Agency, 1989), and (2) there is greater uncertainty in evaluating the contaminant concentration in the context of human health (Toccalino and others, 2004).

The reporting levels for most contaminants varied during the timeframe of this study (Appendix 4). The maximum MRL or LT-MDL, however, was less than the human-health benchmark value for all but five contaminants - four VOCs and one pesticide compound (table 5). These results indicate that the low reporting levels that can be achieved with USGS analytical methods were adequate for detecting concentrations of potential human-health concern for most contaminants. Maximum reporting levels were compared to benchmarks because the maximum reporting levels are the most conservative reporting levels. That is, if the maximum reporting level was less than the benchmark for a contaminant, then all reporting levels for that contaminant were low enough to detect concentrations of potential concern. The maximum MRL or LT-MDL was at least 10-fold less than the MCL or HBSL for 86 percent of contaminants with humanhealth benchmarks. Further, the maximum reporting level was at least 100-fold or 1,000-fold less than benchmarks for about two-thirds or about one-third of the contaminants with benchmarks, respectively (data not shown).

For three of the five contaminants with maximum MRL or LT-MDL values greater than benchmarks (dieldrin, acrylonitrile, and dibromochloropropane (DBCP)), reporting levels were greater than benchmarks for more than one-half of

Table 5. Contaminants analyzed in public-well samples collected during 1993-2007 for which maximum reporting levels are greater than human-health benchmarks.

$[\mu \mathrm{g} / \mathrm{L}$, micrograms per liter; >, greater than; BQ, Benchmark Quotient (ratio of concentration to human-health benchmark); HBSL, Health-Based Screening Level; MCL, Maximum Contaminant Level; ND, not detected]

\begin{tabular}{|c|c|c|c|c|c|c|c|c|}
\hline Contaminant & $\begin{array}{c}\text { Number of } \\
\text { samples }\end{array}$ & $\begin{array}{l}\text { Detection } \\
\text { frequency } \\
\text { (percent) }\end{array}$ & $\begin{array}{l}\text { Most common } \\
\text { reporting } \\
\text { level }{ }^{1} \text { for non- } \\
\text { detections } \\
(\mu \mathrm{g} / \mathrm{L})\end{array}$ & $\begin{array}{l}\text { Maximum } \\
\text { reporting } \\
\text { level }^{1} \text { for non- } \\
\text { detections } \\
(\mu \mathrm{g} / \mathrm{L})\end{array}$ & $\begin{array}{c}\text { Human-health } \\
\text { benchmark } \\
(\mu \mathrm{g} / \mathrm{L})^{2}\end{array}$ & $\begin{array}{c}\text { Human-health } \\
\text { benchmark } \\
\text { type }^{2}\end{array}$ & $\begin{array}{l}\text { Non-detections with } \\
\text { reporting level > } \\
\text { benchmark } \\
\text { (percent) }\end{array}$ & $\begin{array}{c}\text { Samples } \\
\text { with B0>1 } \\
\text { (percent) }\end{array}$ \\
\hline Acrylonitrile & 771 & 0.1 & 0.6 & 2 & 0.06 & HBSL low ${ }^{3}$ & 100 & 0.1 \\
\hline Dibromochloropropane & 832 & 0.2 & 0.5 & 1 & 0.2 & MCL & 52.7 & 0.2 \\
\hline Dieldrin & 896 & 3.1 & 0.001 & 0.004 & 0.002 & HBSL low $^{3}$ & 58.1 & 3.0 \\
\hline Ethylene dibromide & 832 & 0.5 & 0.018 & 0.2 & 0.05 & MCL & 12.8 & 0.2 \\
\hline Methyl acrylonitrile & 771 & 0 & 0.28 & 2 & 0.7 & HBSL & 5.8 & ND \\
\hline
\end{tabular}

\footnotetext{
${ }^{1}$ Reporting levels are Minimum Reporting Levels (MRL) and (or) Long-Term Method Detection Levels (LT-MDL).

${ }^{2}$ Human-health benchmark values were current as of September 2009. MCL values were obtained from U.S. Environmental Protection Agency (2006a) and HBSL values were obtained from the HBSL website (Toccalino and others, 2008).

${ }^{3}$ Low end of HBSL range corresponding to a $10^{-6}$ ( 1 in 1 million) cancer risk. The HBSL range corresponds to a $10^{-6}$ to $10^{-4}$ cancer risk range.
} 
the samples with non-detections (table 5), so the percentage of samples with concentrations greater than benchmarks for these contaminants may be underestimated. All reporting levels for dieldrin and acrylonitrile, however, were less than the high end of their respective HBSL ranges. For ethylene dibromide, reporting levels were greater than the MCL for about 13 percent of non-detections, so the percentage of samples with concentrations greater than benchmarks may not be greatly underestimated. The most common reporting level for ethylene dibromide also was less than the MCL. For methyl acrylonitrile, reporting levels were greater than the HBSL for about 6 percent of non-detections, but methyl acrylonitrile was not detected in any sample (table 5).

\section{Evaluation of Contaminant Mixtures}

The occurrence and composition of contaminant mixtures were assessed in two subsets of source-water samples from public wells. The first subset of samples included 383 samples in which major ions, trace elements, nutrients, radon, and organic contaminants were analyzed. Fecal-indicator microorganisms, gross alpha- and gross beta-particle radioactivity, radium, and pesticide compounds analyzed using HPLC were not included in the contaminant mixtures analyses because they were analyzed in a limited number of samples. Three categories of contaminant mixtures were examined in the 383 samples, each building on the previous category.

1. The first category included only those mixtures with contaminant concentrations greater than individual human-health benchmarks $(\mathrm{BQ}>1)$. Only contaminants with MCLs or HBSLs were considered in this category, and radon activities were compared to the higher proposed AMCL of 4,000 $\mathrm{pCi} / \mathrm{L}$.

2. The second category included all contaminant mixtures in the first category, but also included mixtures with contaminant concentrations greater than one-tenth of individual benchmarks (BQ $>0.1)$. Only contaminants with MCLs or HBSLs were considered in this category. Contaminant concentrations that approach their human-health benchmarks are important to evaluate because toxicologic interactions can occur among contaminants at these concentrations, and because some interactions can result in greater adverse effects than from exposure to the individual contaminants in the mixture (Yang, 1994; Carpenter and others, 2002). This approach is consistent with USEPA and Agency for Toxic Substances and Disease
Registry (ATSDR) risk assessments of contaminant mixtures, where contaminants in a mixture for which estimated exposures are more than one-tenth of a noncancer toxicity values are identified (U.S. Environmental Protection Agency, 1994; Agency for Toxic Substances and Disease Registry, 2004a). For example, if two or more contaminants in a mixture have exposures greater than one-tenth of a toxicity value, then ATSDR further assesses the joint toxic action to determine whether additivity or other interactions among contaminants may result in a significant health hazard (Agency for Toxic Substances and Disease Registry, 2004a). In this $\mathrm{BQ}>0.1$ category, radon activities were compared to the lower proposed MCL of $300 \mathrm{pCi} / \mathrm{L}$. Fluoride was not included in this category because fluoride at this concentration $(0.4 \mathrm{mg} / \mathrm{L}$, or one-tenth of the $\mathrm{MCL})$ is less than the range of concentrations in drinking water recommended for the prevention of tooth decay (U.S. Centers for Disease Control and Prevention, 2001).

3. The third category included all contaminant mixtures in the second category, but also included detections of any organic contaminant, regardless of the BQ value or whether the organic contaminant has a human-health benchmark. Several detected organic contaminants do not have human-health benchmarks, so the inclusion of all organic contaminants in this category helps to identify commonly occurring mixtures that may contain any of the anthropogenic organic contaminants analyzed in this study.

The second subset of samples included 814 samples in which pesticide compounds analyzed using GCMS and VOCs were analyzed. Mixtures of these organic contaminants were examined regardless of the availability of human-health benchmarks or the concentrations relative to individual benchmarks.

The number, composition, and frequency of occurrence of unique mixtures in each subset of samples were determined using the methods of Squillace and others (2002) and J.C. Scott (U.S. Geological Survey, written commun., November 2008). Unique mixtures are specific combinations of any two, three, or more contaminants in a given sample, regardless of the presence of additional contaminants in the same sample (Squillace and others, 2002). A single sample can contain many unique mixtures. For example, a water sample in which three contaminants are detected $(\mathrm{A}, \mathrm{B}$, and $\mathrm{C})$ contains four unique mixtures $(\mathrm{AB}, \mathrm{AC}, \mathrm{BC}$, and $\mathrm{ABC})$. 


\section{Results and Discussion-Public-Well Characteristics}

The 932 public wells sampled during 1993-2007 were widely distributed nationally and included wells in parts of 41 states and 30 regionally extensive aquifers (when all glacial aquifers were counted as one aquifer system) (table 6 and fig. 2), representing about one-half of the principal aquifers in the United States (U.S. Geological Survey, 2009). As described in the section, "Identification of Principal Aquifer Rock Types" on page 7, the principal aquifers sampled in this study were grouped according to lithology into eight rock-type categories following the classifications used in the National Atlas (Miller, 2000; U.S. Geological Survey, 2003, 2009) (table 6, fig. 2, and Appendix 3). Aquifers within these rock-type categories are likely to share characteristics of groundwater flow and, in some cases, overall geochemistry (Miller, 2000).

Most public wells included in this study were selected to characterize the quality of water within major hydrogeologic settings of more limited extent than the regionally extensive principal aquifers (Appendix 2). As a result, the public wells are geographically clustered within principal aquifers, leaving extensive areas of principal aquifers without representation (fig. 2). Because of these unrepresented geographic areas and variable sampling densities within each principal aquifer (table 6), the sampled public wells are not considered to be statistically representative of groundwater quality within entire principal aquifers. However, the targeted major hydrogeologic settings represent important hydrologic systems within principal aquifers, and most sampled public wells were randomly selected within those settings.

System size and type data are available from the USEPA SDWIS database for 875 of the 932 public wells sampled in this study (M.A. Horn, U.S. Geological Survey, written commun., November 2007 and August 2008). The public wells sampled in this study represent all sizes and types of public water systems, as defined by the USEPA (tables 1 and 2). About one-half of the public wells were associated with large or very large systems and nearly 90 percent of the wells are part of Community Water Systems (CWSs) that serve the same people year round (fig. 3). Public-well samples collected from each system size were geographically distributed throughout the United States (data not shown).

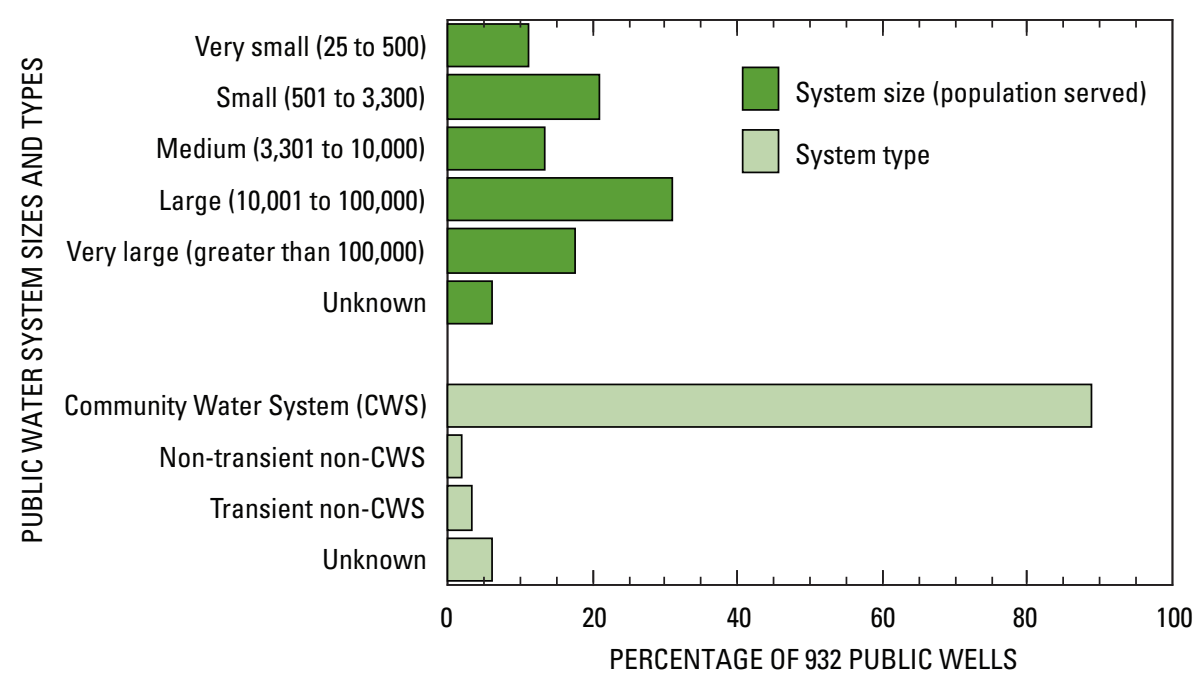

Figure 3. Public water system sizes and types for the 932 public wells sampled during 1993-2007. Public water system sizes and types are defined in tables 1 and 2 . System size and type data are from the USEPA Safe Drinking Water Information System (M.A. Horn, U.S. Geological Survey, written commun., November 2007 and August 2008). 
Table 6. Principal aquifers and well depths for 932 public wells sampled during 1993-2007, by principal aquifer rock type.

[Map identifier, 2-3 letter abbreviation showing principal aquifer location is shown in figure 2. Depths are given in feet below land surface.]

\begin{tabular}{|c|c|c|c|c|c|}
\hline $\begin{array}{c}\text { Map } \\
\text { identifier }\end{array}$ & Principal aquifer name & $\begin{array}{l}\text { Number of } \\
\text { wells, total }\end{array}$ & $\begin{array}{l}\text { Median well } \\
\text { depth (feet) }\end{array}$ & $\begin{array}{l}\text { Median depth } \\
\text { to top of open } \\
\text { interval (feet) }\end{array}$ & $\begin{array}{l}\text { Number of wells } \\
\text { for depth to top } \\
\text { of open interval }\end{array}$ \\
\hline \multicolumn{6}{|c|}{ Unconsolidated sand and gravel aquifers (non-glacial origin) } \\
\hline BRf & Basin and Range basin-fill aquifers & 86 & 510 & 253 & 84 \\
\hline $\mathrm{CC}$ & California Coastal Basin aquifers & 78 & 727 & 309 & 76 \\
\hline $\mathrm{CPf}$ & Columbia Plateau basin-fill aquifers & 12 & 154 & 130 & 9 \\
\hline $\mathrm{CV}$ & Central Valley aquifer system & 15 & 245 & 120 & 14 \\
\hline HP & High Plains aquifer & 27 & 302 & 203 & 27 \\
\hline MV & Mississippi River Valley alluvial aquifer & 11 & 115 & 87 & 9 \\
\hline RG & Rio Grande aquifer system & 40 & 1,000 & 475 & 40 \\
\hline SPf & Snake River Plain basin-fill aquifers & 15 & 101 & 65 & 5 \\
\hline- & All unconsolidated sand and gravel aquifers & 284 & 498 & 266 & 264 \\
\hline \multicolumn{6}{|c|}{ Glacial sand and gravel aquifers } \\
\hline Gc & Glacial aquifer system - central area & 47 & 125 & 96 & 43 \\
\hline $\mathrm{Ge}$ & Glacial aquifer system — east area & 49 & 62 & 48 & 43 \\
\hline Gw & Glacial aquifer system — west area & 10 & 121 & 104 & 10 \\
\hline Gwc & Glacial aquifer system - west central area & 12 & 209 & 203 & 2 \\
\hline- & All glacial sand and gravel aquifers & 118 & 85 & 62 & 98 \\
\hline \multicolumn{6}{|c|}{ Semi-consolidated sand and gravel aquifers } \\
\hline CL & Coastal Lowlands aquifer system & 29 & 1,012 & 590 & 28 \\
\hline ME & Mississippi Embayment aquifer system & 43 & 582 & 486 & 43 \\
\hline NA & Northern Atlantic Coastal Plain aquifer system & 74 & 133 & 100 & 62 \\
\hline $\mathrm{SC}$ & Southeastern Coastal Plain aquifer system & 18 & 285 & 253 & 18 \\
\hline $\mathrm{TC}$ & Texas coastal uplands aquifer system & 8 & 252 & 257 & 4 \\
\hline- & All semi-consolidated sand and gravel aquifers & 172 & 314 & 279 & 155 \\
\hline \multicolumn{6}{|c|}{ Sandstone aquifers } \\
\hline $\mathrm{CO}$ & Cambrian-Ordovician aquifer system & 79 & 1,360 & 629 & 52 \\
\hline DB & Denver basin aquifer system & 14 & 620 & 332 & 14 \\
\hline EM & Early Mesozoic basin aquifers & 1 & 500 & 40 & 1 \\
\hline- & All sandstone aquifers & 94 & 1,214 & 454 & 67 \\
\hline \multicolumn{6}{|c|}{ Sandstone and carbonate-rock aquifers } \\
\hline ET & Edwards-Trinity aquifer system & 59 & 787 & 475 & 57 \\
\hline M & Mississippian aquifers & 3 & 104 & 80 & 3 \\
\hline VR & Valley and Ridge aquifers & 4 & 211 & 221 & 3 \\
\hline- & All sandstone and carbonate-rock aquifers & 66 & 742 & 448 & 63 \\
\hline \multicolumn{6}{|c|}{ Carbonate-rock aquifers } \\
\hline $\mathrm{B}$ & Biscayne aquifer & 22 & 91 & 50 & 19 \\
\hline $\mathrm{BRc}$ & Basin and Range carbonate-rock aquifers & 3 & 980 & 510 & 3 \\
\hline $\mathrm{CH}$ & Castle Hayne aquifer & 4 & 221 & 180 & 4 \\
\hline $\mathrm{F}$ & Floridan aquifer system & 32 & 457 & 148 & 12 \\
\hline $\mathrm{O}$ & Ordovician aquifers & 1 & 203 & 50 & 1 \\
\hline OP & Ozark Plateaus aquifer system & 19 & 1,267 & 412 & 19 \\
\hline- & All carbonate-rock aquifers & 81 & 400 & 130 & 58 \\
\hline \multicolumn{6}{|c|}{ Basaltic and other volcanic-rock aquifers } \\
\hline $\mathrm{CPb}$ & Columbia Plateau basaltic-rock aquifers & 62 & 430 & 140 & 52 \\
\hline $\mathrm{Hv}$ & Hawaiian volcanic-rock aquifers & 22 & 452 & 285 & 22 \\
\hline $\mathrm{SPb}$ & Snake River Plain basaltic-rock aquifers & 5 & 400 & 185 & 5 \\
\hline- & All basaltic and other volcanic-rock aquifers & 89 & 430 & 189 & 79 \\
\hline \multicolumn{6}{|c|}{ Crystalline-rock aquifers } \\
\hline PBx & Piedmont and Blue Ridge crystalline-rock aquifers & 17 & 300 & 61 & 15 \\
\hline \multicolumn{6}{|c|}{ Other aquifers } \\
\hline Other & Other aquifers & 11 & 100 & 53 & 9 \\
\hline \multicolumn{6}{|c|}{ All Aquifers } \\
\hline- & All principal aquifers & 932 & 404 & 223 & 808 \\
\hline
\end{tabular}




\section{Aquifer Type and Well Depth}

An aquifer is a saturated permeable geologic unit that can transmit substantial amounts of water under ordinary hydraulic gradients. A confined aquifer is one that is located beneath a relatively impermeable (confining) layer, and an unconfined aquifer is one in which the water table forms the upper boundary (Freeze and Cherry, 1979; Heath, 1983; Domenico and Schwartz, 1990). Confined aquifers tend to be deeper than unconfined aquifers, which tend to occur near the land surface (Freeze and Cherry, 1979). The susceptibility of an aquifer to contamination from activities at the land surface can be directly related to the degree of aquifer confinement (Lindsey and others, 2009).

In general, an aquifer that is less susceptible to contamination tends to have a deep water table (for an unconfined aquifer), a thick low-permeability layer (such as clay-rich materials) between the aquifer and the land surface (for a confined aquifer), and a lack of highly permeable fractures that can act as conduits for fluid flow. By contrast, a highly susceptible aquifer tends to have a shallow water table, no clay-rich protecting layer, and may contain permeable fractures (Younger, 2007). For example, in karst terranes associated with carbonate-rock aquifers, water typically enters the aquifers rapidly through large openings (solutionally enlarged fractures), and contaminants in the water can be transported though pipe-like or channel-like conduits, rapidly spreading through the aquifers (Lindsey and others, 2009), making such karst areas highly susceptible to contamination. The vulnerability of an aquifer to contamination depends on intrinsic susceptibility (the physical aquifer properties that affect groundwater flow), along with the presence of contaminants and the factors that affect contaminant fate and transport (Focazio and others, 2002).

In general, deep public wells are presumed to be less vulnerable than shallow domestic wells to contaminants that originate on or near the land surface (Zogorski and others, 2006). Large withdrawal rates from public wells, however, combined with proximity to developed areas and the possible presence of short-circuiting flow paths, explain, in part, why public wells can be vulnerable to contamination, despite their depth. Deep public wells can intercept groundwater flowing along extensive flow paths with long residence times (Zogorski and others, 2006). Groundwater that is recharged over long distances from the sampled wells may capture water from various land-use settings and may contain degradation products from parent compounds and contaminants with substantial historical use (Gilliom and others, 2006).

Additionally, public wells in some hydrogeologic settings may intercept water with a wide range of ages, including relatively young water flowing along short flow paths that make such wells vulnerable to contaminants in recently recharged groundwater (McMahon and others, 2008). The vulnerability of groundwater from public wells that are screened in confined aquifers is strongly influenced by the movement of contamination-susceptible water-groundwater that was recharged in the modern or industrial era-along short-circuit pathways to the well screens (Landon and others, 2006).

Short-circuit pathways can be man-made (wellbores that span confining layers) or natural (breaches in confining layers) and can allow water and contaminants to bypass substantial portions of aquifers that would otherwise restrict their movement to deep public wells (Landon and others, 2009).

In this study, public-well characteristics varied by principal aquifer rock type. Well depths and depths to the top of the open intervals of wells were significantly greater $(p<0.05)$ in sandstone and sandstone and carbonate-rock aquifers than in other principal aquifer rock types. By contrast, well depths and depths to the top of open intervals were most shallow $(p<0.05)$ in glacial aquifers (table 6 and fig. 4 ). About 43 percent of the public wells sampled in this study are completed in confined aquifers, and about 54 percent of wells are completed in unconfined aquifers (fig. 5); the remaining 3 percent of wells are completed in mixed or unknown aquifer types. As expected, the public wells sampled in this study in confined aquifers tended to have significantly greater depths than wells in unconfined aquifers (fig. 5). Public wells sampled in confined aquifers were predominantly in the central United States (fig. 6) where there are groupings of sandstone, sandstone and carbonate-rock, carbonate-rock, and semiconsolidated sand and gravel aquifers (fig. 2). The greatest percentages of public wells sampled in confined aquifers were in sandstone, sandstone and carbonate-rock, and crystallinerock aquifers. Conversely, the greatest percentages of public wells sampled in unconfined aquifers were in sand and gravel aquifers (glacial and non-glacial), and in basaltic-rock aquifers (fig. 7). 


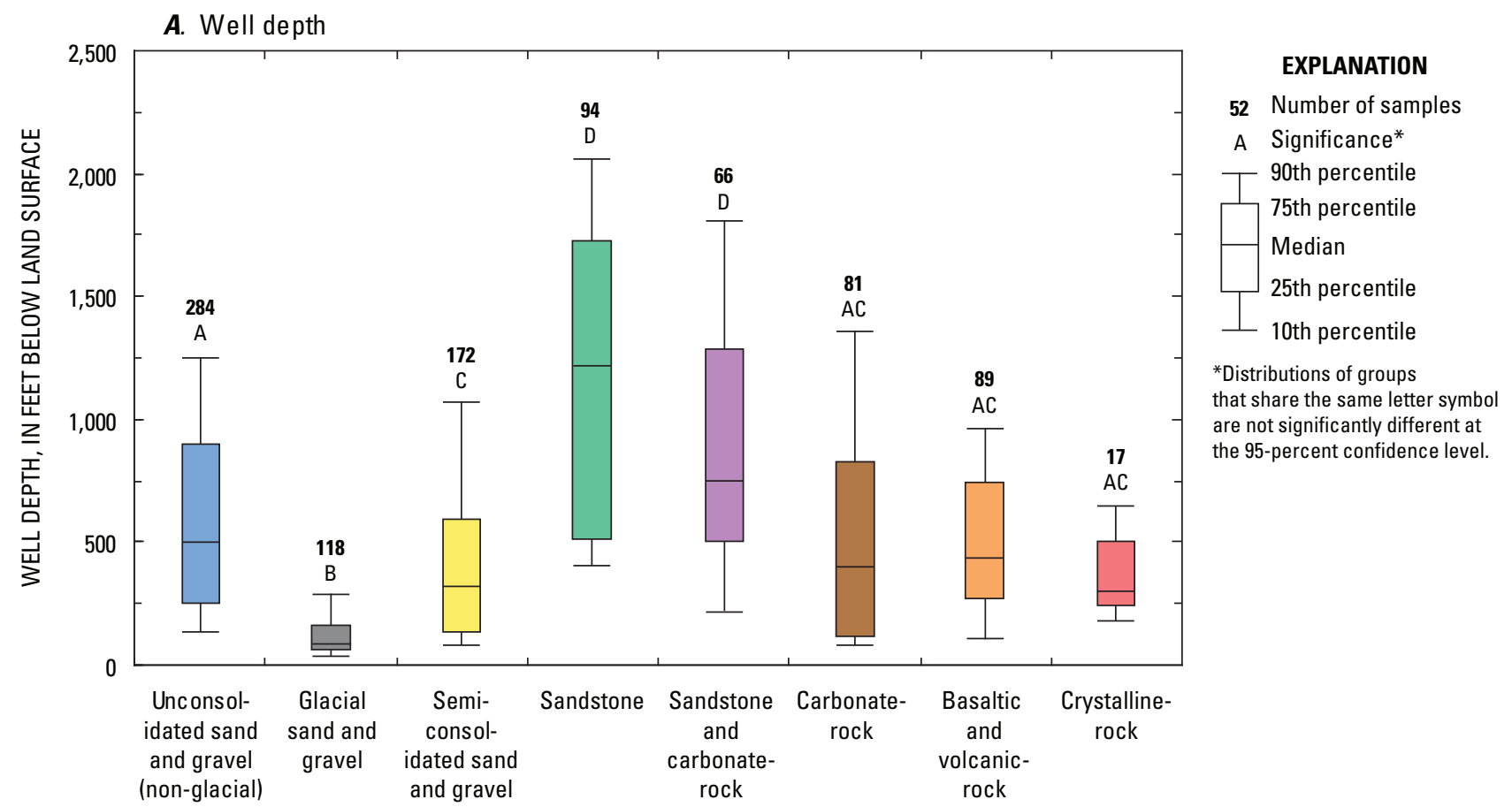

PRINCIPAL AQUIFER ROCK TYPE

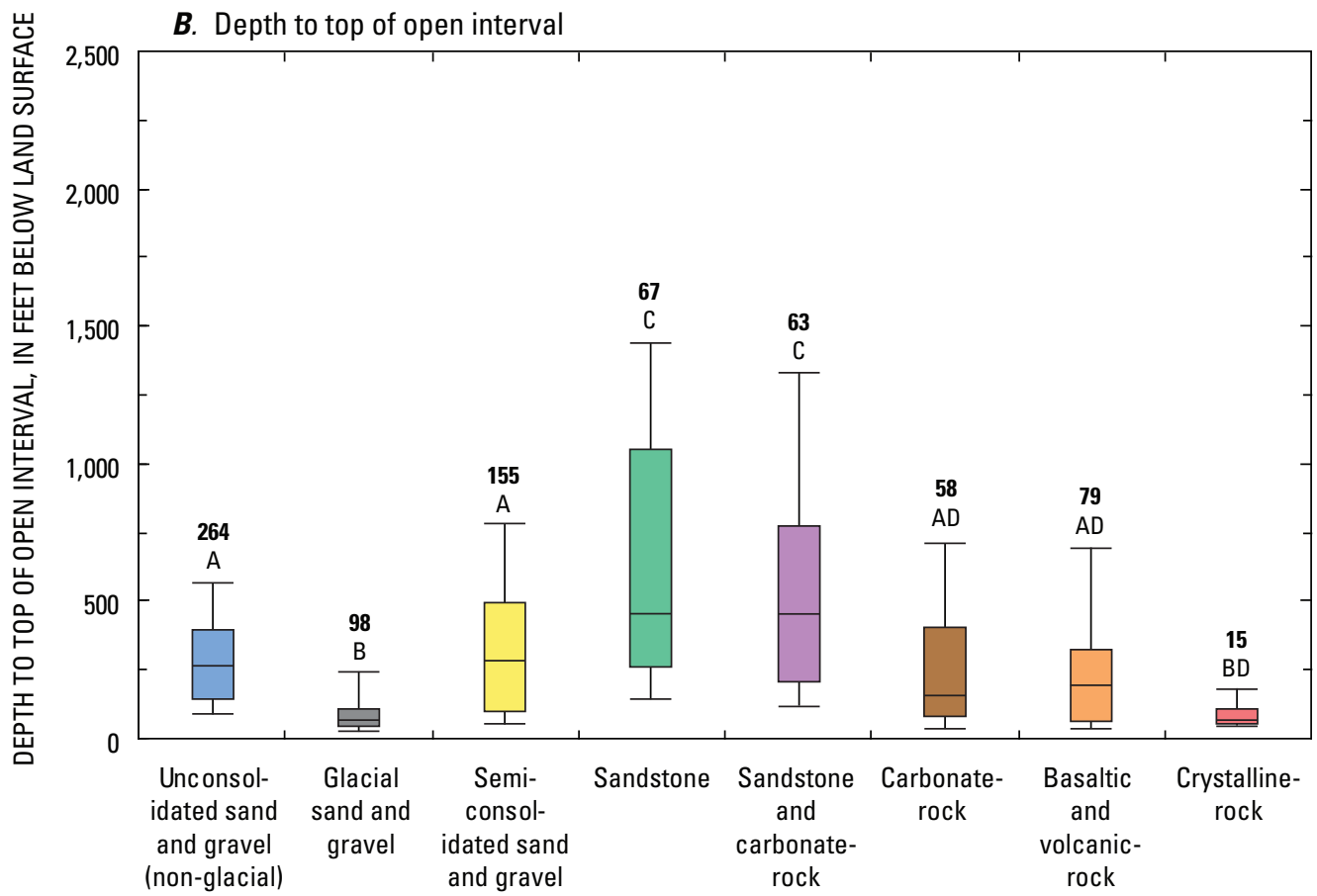

PRINCIPAL AQUIFER ROCK TYPE

Figure 4. Distributions of $(A)$ well depths and $(B)$ depths to top of open interval for public wells sampled during 1993-2007, by principal aquifer rock type. 


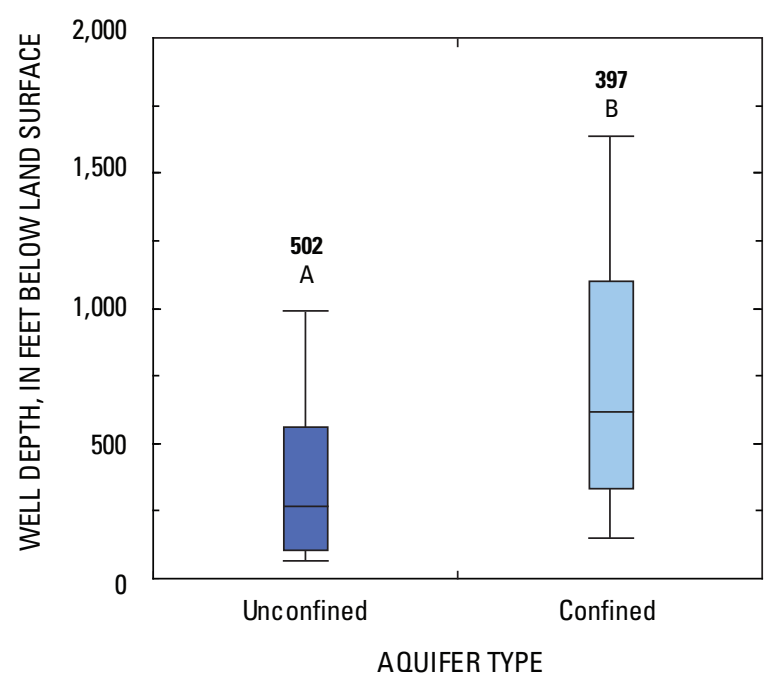

\section{EXPLANATION}

52 Number of samples

A Significance*

T 90th percentile

75th percentile

Median

25th percentile

10th percentile

Figure 5. Distributions of well depths in relation to aquifer type for public wells sampled during 1993-2007.

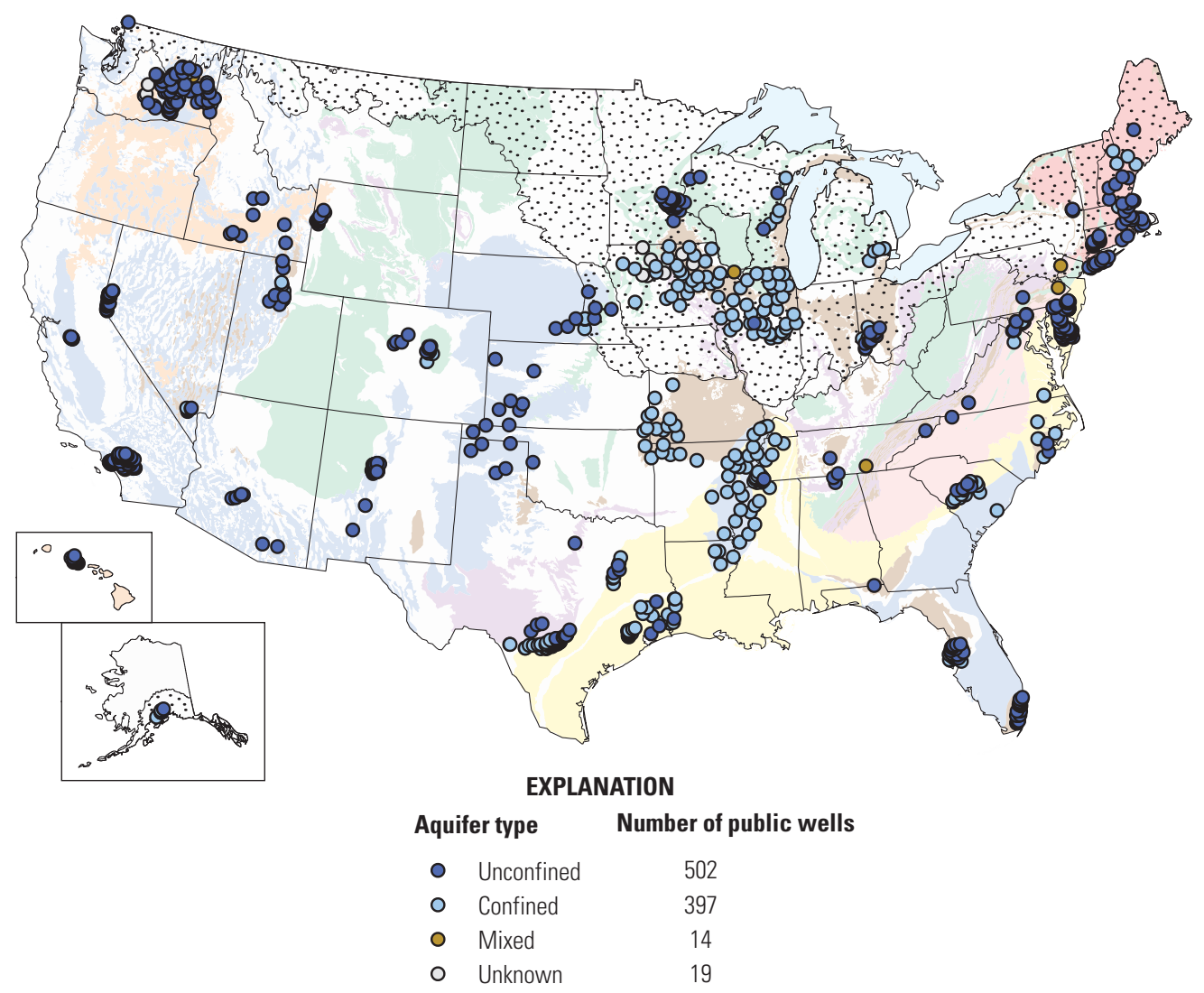

Figure 6. Geographic distribution of aquifer types for 932 public wells sampled during 1993-2007. (See fig. 2A for explanation of principal aquifer rock types.) 


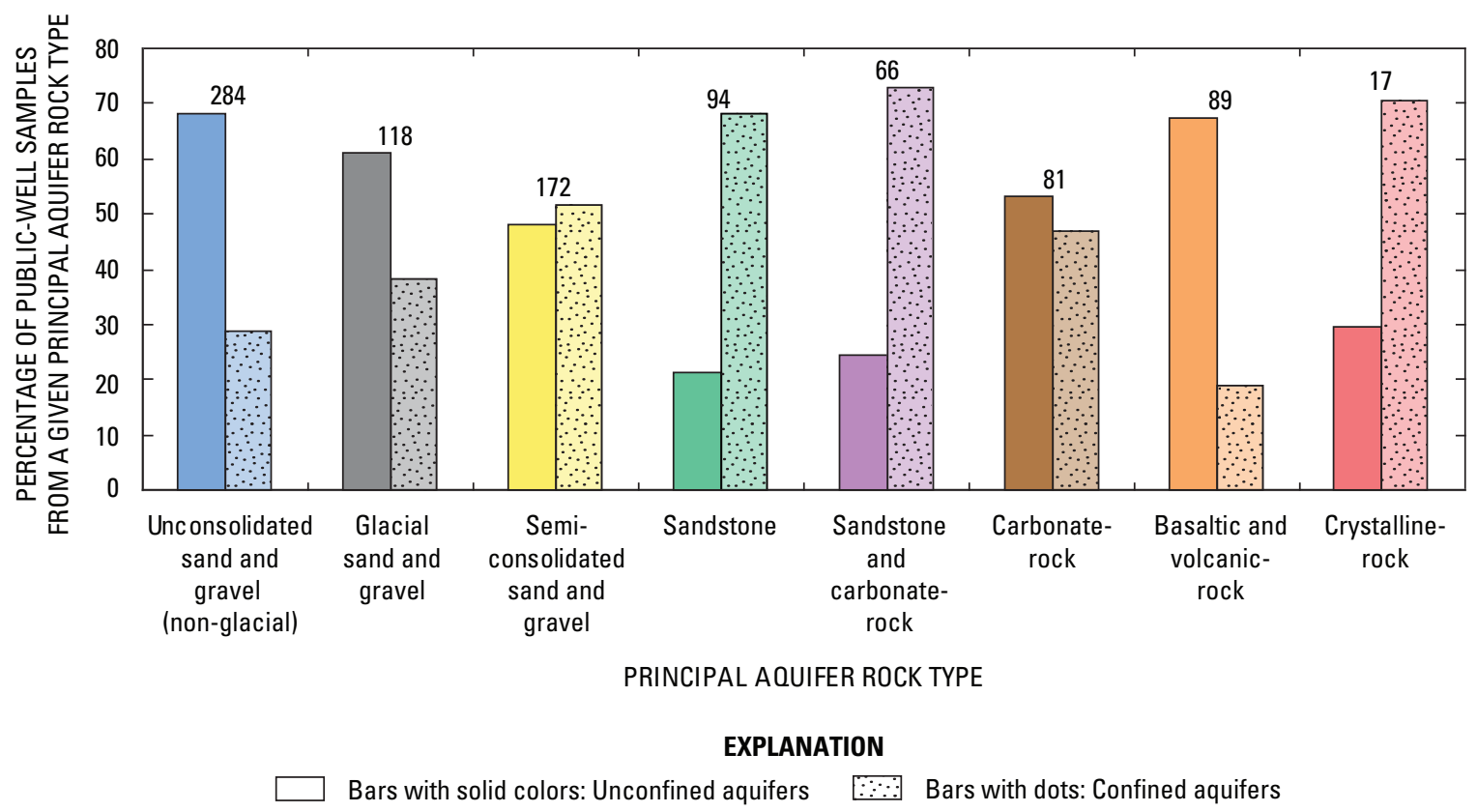

Figure 7. Percentage of samples among unconfined and confined aquifers in relation to principal aquifer rock type for public wells sampled during 1993-2007. Numbers above bars indicate the number of public wells sampled in each rock type. For each rock type, the total percentage of samples adds up to 100 percent. For example, of the 284 samples collected from unconsolidated sand and gravel aquifers, 68 percent of the samples were from unconfined aquifers, 29 percent were from confined aquifers, and 3 percent were from mixed or unknown aquifers (not shown).

\section{Land Use}

Most public wells were associated with urban or mixed land-use areas. This observation applied to the 932 public wells sampled in this study and to a much larger dataset of 121,837 public wells across the United States (ig. 8). Well location information for the 121,837 public wells was determined from the USEPA SDWIS database and the USGS National Water Information System (C.V. Price, U.S. Geological Survey, written commun., 2007). Most public wells sampled in this study in urban land-use areas were associated with large or very large systems. Conversely, the few public wells that were sampled in agricultural land-use areas typically were associated with very small or small systems (fig. 9).

Because public wells tend to be associated with urban or mixed land-use areas, the land uses associated with public wells tend to over-represent urban areas and to under-represent agricultural and undeveloped areas as compared to the entire national distribution of these land-use settings, by land area (fig. 8). These findings are not surprising because, in this study, most public-well samples were collected from aquifers or aquifer systems that are major current or future sources of water supply (Gilliom and others, 2006). As a result, public wells typically were sampled in areas of high population densities and (or) in areas underlain by major aquifers, without regard to land use (Appendix 2). The sampled groundwater, therefore, reflects the effects of a mixture of different land uses on water quality. Because the public wells were sampled without regard to land use, there was no apparent pattern in the geographic distribution of their land-use classifications across the United States (data not shown). 


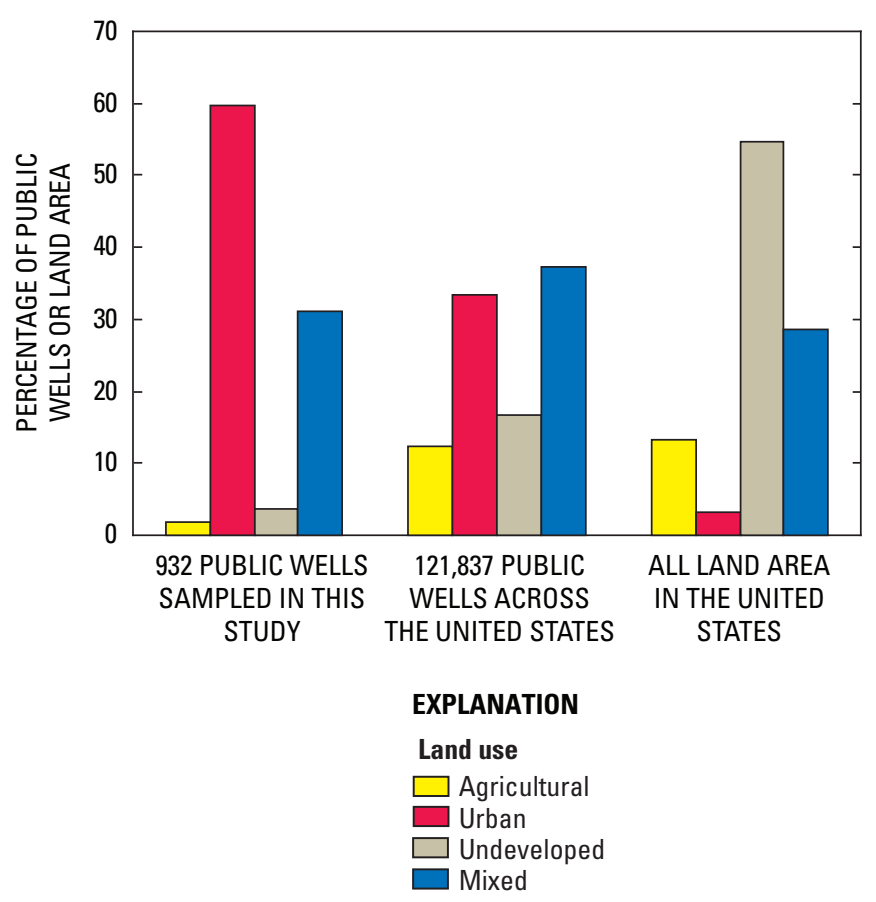

The proportion of 932 sampled public wells in each land-use category was classified according to the dominant land uses in a circular buffer area of 500 -meter radius around each well using the 2001 National Land Cover Database (NLCD 2001) (K.J. Hitt, U.S. Geological Survey, written commun., 2008).

Well location information for the 121,837 public wells across the United States was determined from the U.S. Environmental Protection Agency Safe Drinking Water Information System and the USGS National Water Information System. The proportion of public wells in each land-use category was interpolated from 1-kilometer-resolution percentage grids based on an enhanced version of NLCD 1992 (C.V. Price, U.S. Geological Survey, written commun., February 2007).

For all land area in the United States, the proportion of land area in each land-use category was determined using NLCD 2001 national grids for every square kilometer in the conterminous United States. (K.J. Hitt, U.S. Geological Survey, written commun., June 2008).

Figure 8. Comparisons among land-use characteristics associated with 932 public wells sampled during 1993-2007; about 122,000 public wells across the United States; and all land area in the United States. Land-use classifications are defined in table 3.

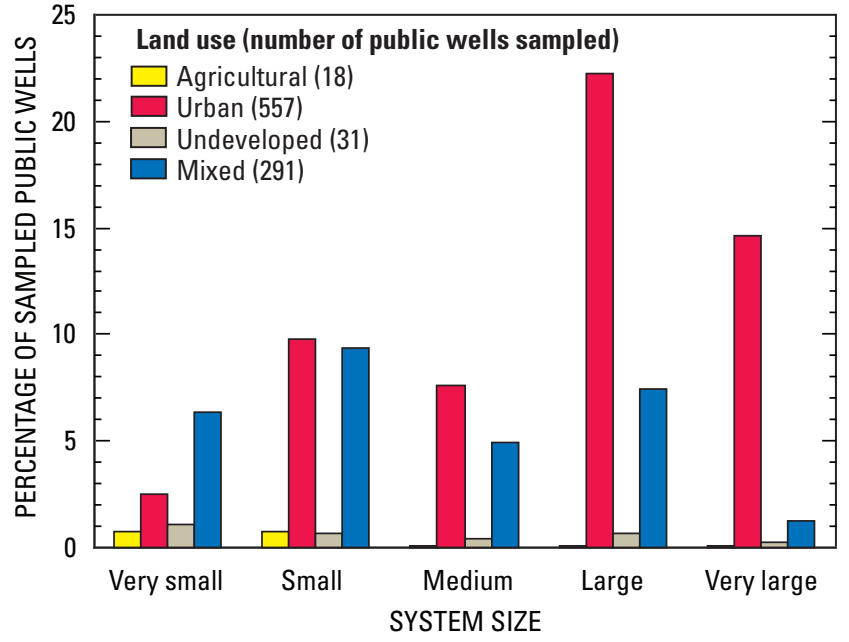

Figure 9. Land-use classifications in relation to system sizes for public wells sampled during 1993-2007. Land-use classifications are defined in table 3 . System-size data are unavailable for 35 public wells.

\section{Ground water Withdrawals}

In 2005, withdrawals from public wells for drinking water in the United States were 14.6 billion gallons of water per day (Kenny and others, 2009). Estimated withdrawals from public wells increased by a factor of four between 1950 and 2005 (Kenny and others, 2009) although the population of the entire United States increased by about a factor of two during this same time period (U.S. Census Bureau, 2009). The percentage of public water supplies from groundwater increased from 26 percent in 1950 to 33 percent in 2005 (Kenny and others, 2009).

Based on groundwater withdrawals in 2000 (Maupin and Barber, 2005), the distribution of groundwater withdrawals among the principal aquifers represented by the public wells sampled in this study closely matched the distribution of groundwater withdrawals from all principal aquifers in the United States (fig. 10). This similarity indicates that the public wells sampled by USGS were located in the principal aquifers that supplied the majority of public water withdrawals in the United States in 2000. 


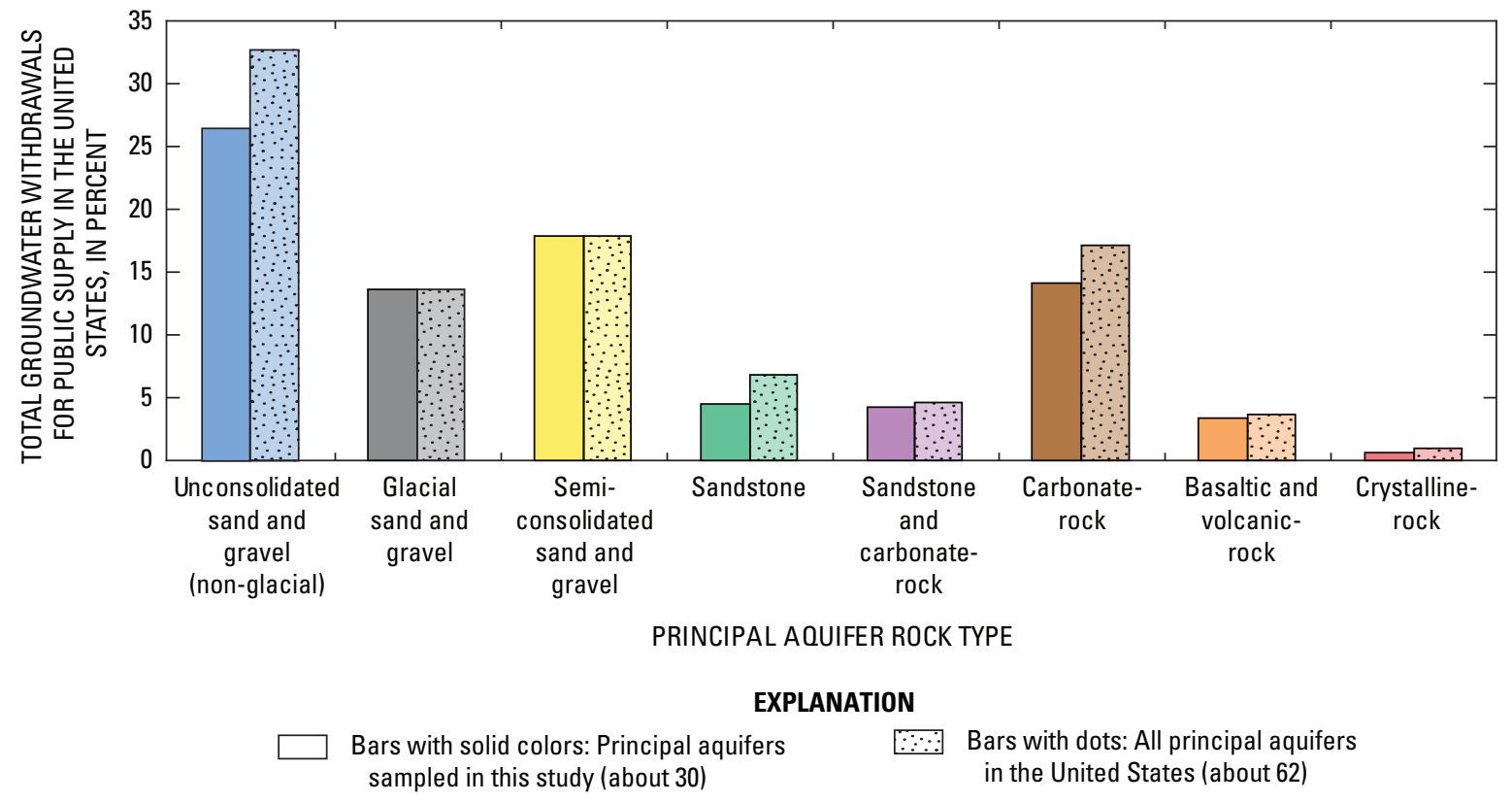

Figure 10. Comparisons among the distributions of groundwater withdrawals for public supply, by rock type, for all principal aquifers in the United States and for those principal aquifers represented by the public wells sampled during 1993-2007. Groundwater withdrawal data are from 2000, modified from Maupin and Barber (2005).

\section{Population}

In 1995, about 84 percent of the U.S. population obtained their drinking water from public suppliers (about 34 percent from groundwater sources and about 50 percent from surfacewater sources), and 16 percent of the U.S. population obtained their water from domestic wells (Solley and others, 1998). In 2008, an estimated 34 percent of the U.S. population still obtained drinking water from groundwater-supplied public water systems (U.S. Environmental Protection Agency, 2008c; U.S. Census Bureau, 2009).

Public wells supply drinking water to some portion of the population in every state (fig. 11), but USGS studies were not specifically designed as a national-scale assessment of public well water quality. As a result, the public wells sampled by USGS do not provide a statistically based sampling of all public wells in the United States. However, a national distribution of sampled wells shows that public wells were sampled in counties where both large and small percentages of the total county populations are served by public wells (fig. 11A), based on water-use data for 1995 (Solley and others, 1998). For about one-half of the counties in the United States, more than 10 people $/ \mathrm{mi}^{2}$ obtain their drinking water from public wells (Solley and others, 1998). Similarly, in this study, about one-half of the source-water samples from public wells were collected from these areas where relatively large populations are served by public wells, and about one-half of the samples were collected in counties where less than 10 people/ $/ \mathrm{mi}^{2}$ are served by public wells (fig. $11 B$ ). 
A. Population supplied by public wells, in percent of total county population

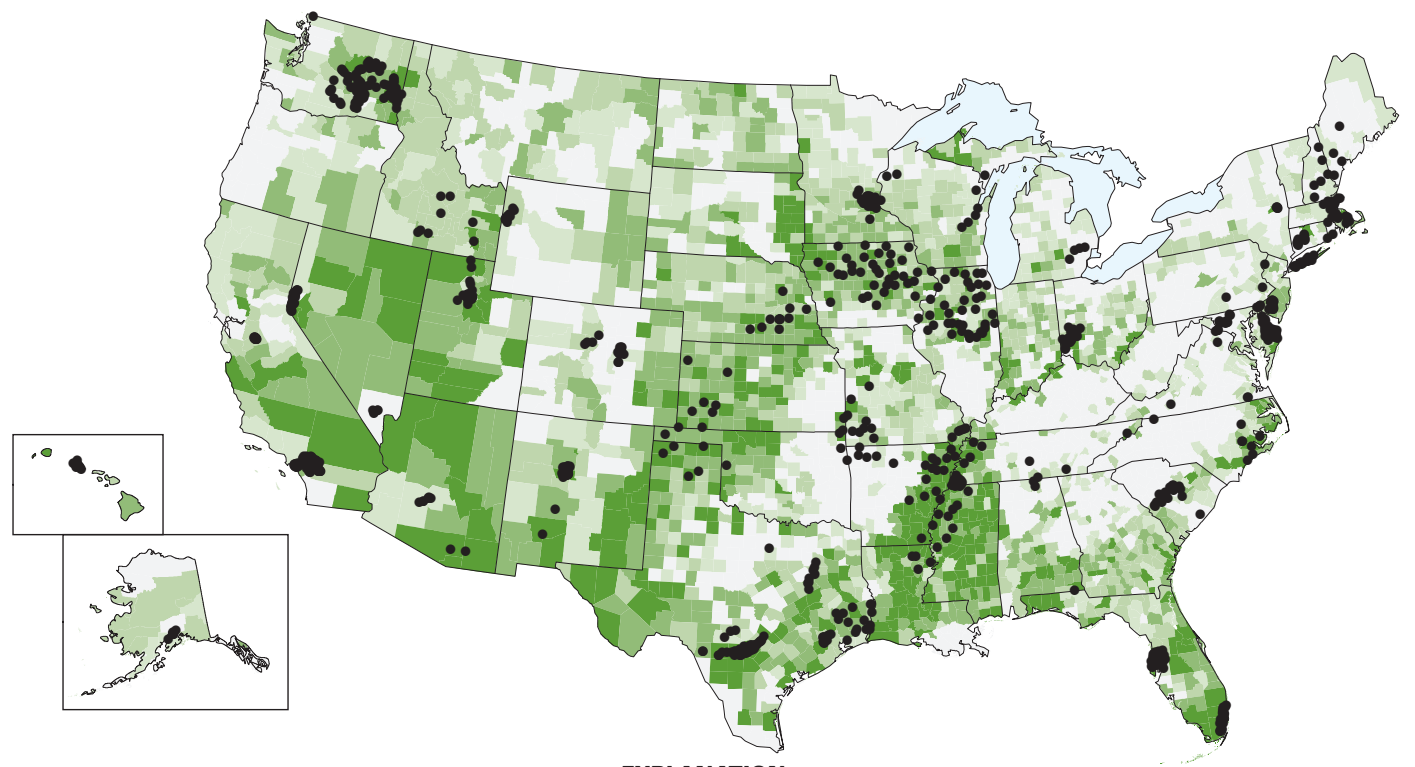

EXPLANATION

Population (1995) supplied by public wells,

- Public well in percent of total county population

\begin{tabular}{|c|c|}
\hline Greater than (>) 80 & 13.3 \\
\hline$>60$ to 80 & 17.4 \\
\hline$>40$ to 60 & 18.0 \\
\hline$>20$ to 40 & 15.9 \\
\hline Less than or equal to 20 & 35.5 \\
\hline
\end{tabular}

B. Population supplied by public wells, in people per square mile of land area

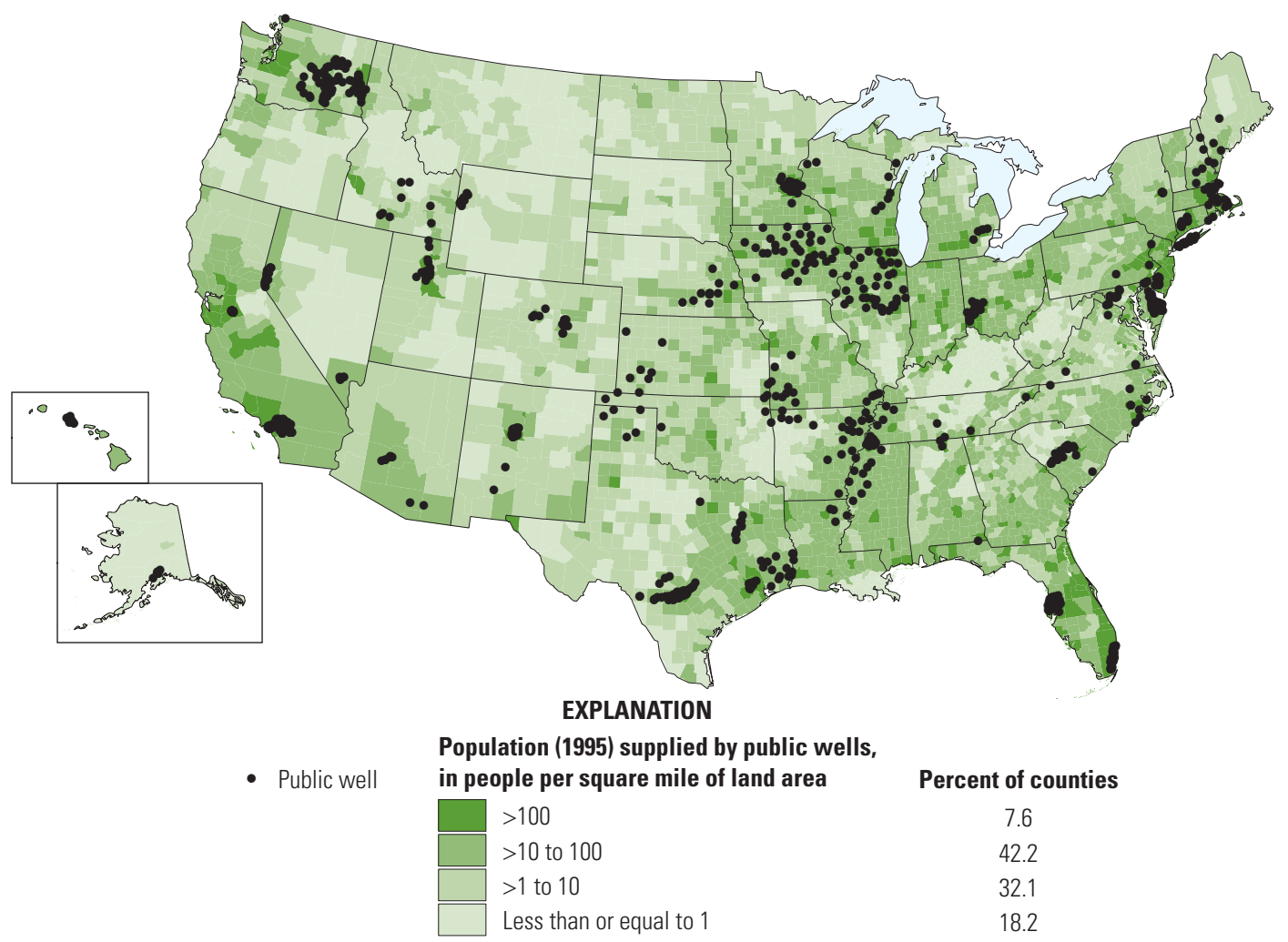

Figure 11. Population (1995) that uses groundwater from public wells for drinking water in $(A)$ percentage of total county population, and $(B)$ people per square mile of land area, by county. Water-use data are from Solley and others (1998). 


\section{Public Water Systems Sampled by the U.S. Geological Survey Compared to all Groundwater-Supplied Public Water Systems in the United States}

In this section of the report, the 932 public wells sampled by the USGS are described as public water systems, as opposed to individual public wells, to facilitate comparisons among the public water systems sampled as part of this study and all groundwater-supplied public water systems in the United States. The public wells sampled in this study represented 629 unique public water systems, using data from the USEPA SDWIS database (M.A. Horn, U.S. Geological Survey, written commun., November 2007 and August 2008). For most of these 629 public water systems, one well was sampled per system, but as many as 16 wells per system were sampled (table 7). One public well was sampled per system for all very small systems and for all Non-Transient and Transient Non-Community Water Systems. Only large and very large systems, all of which are CWSs, contained five or more wells sampled per system (table 7).

The 629 public water systems with one or more wells sampled in this study represent about one-half of 1 percent of the approximately 140,000 groundwater-supplied public water systems in the United States. In the United States in 2008, the vast majority of systems ( 86 percent) were very small (The National Academies, 2008; U.S. Environmental Protection Agency, 2008c), but 53 percent of people were customers of large and very large systems (fig. 12). The public water systems sampled in this study under-represented the very small systems in the United States and over-represented all other public water system sizes (fig. 12A).

In 2008, about 105 million people in the United States obtained their finished (treated) drinking water from groundwater-supplied public water systems (U.S. Environmental Protection Agency, 2008c). Although less than 1 percent of all groundwater-supplied public water systems in the United States were sampled in this study, samples from the 629 systems represent source water used by about 26 million people_-about 25 percent of the U.S. population served by groundwater-supplied public water systems (fig. 12B) - or about 9 percent of the entire U.S. population in 2008 . The population served by groundwatersupplied public water systems, as reported by USEPA, may be somewhat overestimated because some people are served by multiple systems and were counted more than once (U.S. Environmental Protection Agency, 2010d).

Samples from the 629 public water systems represented source water used by nearly one-quarter of the population served by groundwater-supplied public water systems in the United States because (1) most people are customers of large and very large publicly owned systems (U.S. Environmental Protection Agency, 2002a); (2) about one-half of the wells were associated with large and very large systems (fig. 3); and (3) most large and very large systems were sampled in urban areas (fig. 9) that tend to be densely populated (Grady, 2002). Further, about 84 percent of people who obtained their drinking water from groundwater-supplied public water systems in the United States in 2008 obtained their water from CWSs (U.S. Environmental Protection Agency, 2008c), and 92 percent of the public water systems sampled in this study were CWSs (ig. 12).

Table 7. Distribution of sizes and types for the 629 public water systems sampled during 1993-2007, by numbers of sampled wells per system.

[Public water system sizes and types are defined in tables 1 and 2. Data are from the U.S. Environmental Protection Agency Safe Drinking Water Information System (M.A. Horn, U.S. Geological Survey, written commun., November 2007 and August 2008). -, none]

\begin{tabular}{|c|c|c|c|c|c|c|c|c|c|}
\hline \multirow{2}{*}{$\begin{array}{l}\text { Number } \\
\text { of wells } \\
\text { sampled } \\
\text { per system }\end{array}$} & \multirow[b]{2}{*}{$\begin{array}{c}\text { Number of } \\
\text { systems }\end{array}$} & \multicolumn{5}{|c|}{ Number of systems by system size } & \multicolumn{3}{|c|}{ Number of systems by system type } \\
\hline & & $\begin{array}{l}\text { Very } \\
\text { small }\end{array}$ & Small & Medium & Large & $\begin{array}{l}\text { Very } \\
\text { large }\end{array}$ & $\begin{array}{l}\text { Community } \\
\text { water system } \\
\text { (CWS) }\end{array}$ & $\begin{array}{c}\text { Non- } \\
\text { transient } \\
\text { non-CWS }\end{array}$ & $\begin{array}{l}\text { Transient } \\
\text { non-CWS }\end{array}$ \\
\hline 1 & 531 & 103 & 176 & 98 & 138 & 16 & 483 & 17 & 31 \\
\hline 2 & 57 & - & 9 & 8 & 34 & 6 & 57 & - & - \\
\hline 3 & 14 & - & - & 1 & 9 & 4 & 14 & - & - \\
\hline 4 & 6 & - & - & 2 & 1 & 3 & 6 & - & - \\
\hline 5 & 4 & - & - & - & 4 & - & 4 & - & - \\
\hline 6 & 7 & - & - & - & 1 & 6 & 7 & - & - \\
\hline 7 & 2 & - & - & - & 1 & 1 & 2 & - & - \\
\hline 8 & 3 & - & - & - & 1 & 2 & 3 & - & - \\
\hline 9 & 1 & - & - & - & - & 1 & 1 & - & - \\
\hline 10 & 1 & - & - & - & 1 & - & 1 & - & - \\
\hline 14 & 1 & - & - & - & - & 1 & 1 & - & - \\
\hline 15 & 1 & - & - & - & - & 1 & 1 & - & - \\
\hline 16 & 1 & - & - & - & - & 1 & 1 & - & - \\
\hline Totals & 629 & 103 & 185 & 109 & 190 & 42 & 581 & 17 & 31 \\
\hline
\end{tabular}



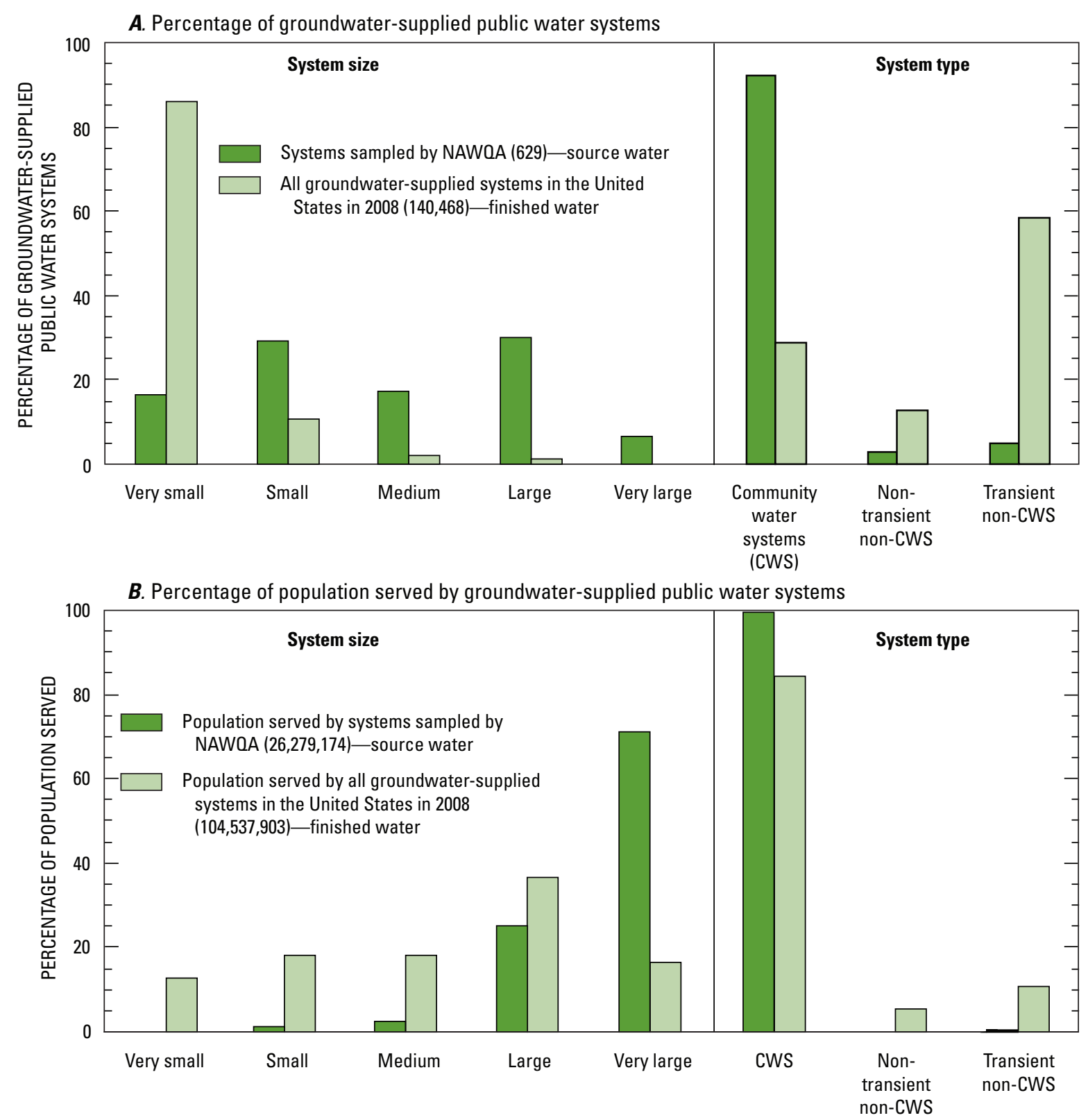

Figure 12. Comparisons among the percentage of $(A)$ groundwater-supplied systems and $(B)$ population served by groundwater-supplied systems, for public water systems sampled by the National Water-Quality Assessment (NAWQA) Program (1993-2007) and for all public water systems in the United States in 2008, by size and type of system. Public water system sizes and types are defined in tables 1 and 2. NAWQA data are from the USEPA Safe Drinking Water Information System (M.A. Horn, U.S. Geological Survey written commun., November 2007 and August 2008). National data are from the U.S. Environmental Protection Agency (2008c). 


\section{Results and Discussion-Individual Properties and Contaminants}

In this section of the report, water-quality properties and contaminant concentrations are summarized at the national scale for 932 public wells sampled by the USGS during 1993-2007. The six water-quality properties and 215 contaminants analyzed in the source-water samples from public wells are listed in Appendix 4 along with the numbers of samples analyzed, human-health benchmarks, and analytical information. Concentration statistics and detection frequencies for water-quality properties and contaminants are shown in Appendixes 8 to $\underline{13}$.

\section{Water-Quality Properties}

Source-water samples from public wells were analyzed for as many as six water-quality properties (such as $\mathrm{pH}$ and alkalinity). These water-quality properties are general indicators of the overall suitability of water for drinking and other uses, and affect how chemical contaminants behave in the water. Variability in these water-quality properties results from natural factors, such as precipitation chemistry, soil properties, and the physical and chemical characteristics of aquifer materials, and from the effects of human activity, such as irrigation and waste disposal. Statistics for water-quality properties are shown in Appendix 8. Human-health benchmarks have not been established for the water-quality properties, but USEPA SMCLs have been established for $\mathrm{pH}$ and total dissolved solids (TDS) (U.S. Environmental Protection Agency, 2006a) (table 8).

Table 8. Comparison of water-quality properties and contaminant concentrations to non-health guidelines in public-well samples collected during 1993-2007.

[No common assessment level was applied to these data. >, greater than; SMCL, Secondary Maximum Contaminant Level; mg/L, milligrams per liter; $\mu \mathrm{g} / \mathrm{L}$, micrograms per liter; N, nitrogen; <, less than]

\begin{tabular}{|c|c|c|c|c|c|c|c|}
\hline \multirow{2}{*}{$\begin{array}{l}\text { Water-quality property } \\
\text { or contaminant }\end{array}$} & \multirow{2}{*}{$\begin{array}{l}\text { Number of } \\
\text { samples }\end{array}$} & \multirow{2}{*}{$\begin{array}{l}\text { Number of } \\
\text { detections }\end{array}$} & \multirow{2}{*}{$\begin{array}{l}\text { Detection } \\
\text { frequency } \\
\text { (percent) }\end{array}$} & \multicolumn{2}{|c|}{ Non-health guideline ${ }^{1}$} & \multicolumn{2}{|c|}{$\begin{array}{c}\text { Samples with } \\
\text { concentrations > non- } \\
\text { health guideline }\end{array}$} \\
\hline & & & & $\begin{array}{c}\text { Value (in } \\
\text { units shown) }\end{array}$ & Type & Number & Percent \\
\hline \multicolumn{8}{|c|}{ Water-quality properties } \\
\hline pH (standard units) & 878 & 878 & 100 & 6.5 to 8.5 & SMCL & $163,{ }^{2} 14$ & $18.6,1.6$ \\
\hline Fluoride & 808 & 610 & 75.5 & 2 & SMCL & 22 & 2.7 \\
\hline Chloride & 809 & 808 & 99.9 & 250 & SMCL & 24 & 3.0 \\
\hline Sodium & 809 & 809 & 100 & 30 to 60 & Taste threshold & 155 to 318 & 19.2 to 39.3 \\
\hline Sulfate & 810 & 795 & 98.1 & 250 & SMCL & 29 & 3.6 \\
\hline \multicolumn{8}{|c|}{ Trace elements ( $\mu \mathrm{g} / \mathrm{L})$} \\
\hline Manganese & 808 & 543 & 67.2 & 50 & SMCL & 118 & 14.6 \\
\hline Silver & 606 & 4 & 0.7 & 100 & SMCL & 0 & 0 \\
\hline Zinc & 613 & 561 & 91.5 & 5,000 & SMCL & 0 & 0 \\
\hline \multicolumn{8}{|c|}{ Nutrients (mg/L) } \\
\hline Ammonia as $\mathrm{N}$ & 806 & 357 & 44.3 & 30 & Taste threshold & 0 & 0 \\
\hline \multicolumn{8}{|c|}{ Volatile organic compounds $(\mu \mathrm{g} / \mathrm{L})$} \\
\hline $\begin{array}{l}\text { Methyl tert-butyl ether } \\
\text { (MTBE) }\end{array}$ & 832 & 115 & 13.8 & 20 and 40 & $\begin{array}{c}\text { Odor }(20 \mu \mathrm{g} / \mathrm{L}) \\
\text { and taste } \\
(40 \mu \mathrm{g} / \mathrm{L}) \text { thresholds }\end{array}$ & 0 & 0 \\
\hline \multicolumn{8}{|c|}{ All water-quality properties and contaminants with non-health guidelines } \\
\hline $\begin{array}{l}\text { All properties and } \\
\text { contaminants with non- } \\
\text { health guidelines }\end{array}$ & 897 & 897 & 100 & Various & Various & $\begin{array}{l}{ }^{3} 476 \\
{ }^{4} 575\end{array}$ & $\begin{array}{l}{ }^{3} 53.1 \\
{ }^{4} 64.1\end{array}$ \\
\hline
\end{tabular}


The acidity of water is indicated by $\mathrm{pH}$ and is a key control on the solubility of many metals (Fortescue, 1980). $\mathrm{pH}$ values range from about 6.0 to 8.5 in most groundwaters in the United States (Hem, 1985). Highly acidic (low pH) or highly alkaline (high $\mathrm{pH}$ ) water can be corrosive to pipes and may have an unpleasant taste (World Health Organization, 2004). An SMCL has been established for $\mathrm{pH}$ between 6.5 and 8.5 (U.S. Environmental Protection Agency, 2006a). The pH was within the SMCL range for most source-water samples in this study (fig. 13A), but the $\mathrm{pH}$ was lower than the recommended SMCL range in 18.6 percent of samples (table 8). These low $\mathrm{pH}$ values (less than 6.5) were detected more frequently in the eastern United States (fig. 14A), and about two-thirds of the low-pH samples were in samples collected from unconfined aquifers. The $\mathrm{pH}$ of precipitation also is lowest in the eastern United States (National Atmospheric Deposition Program, 2007).
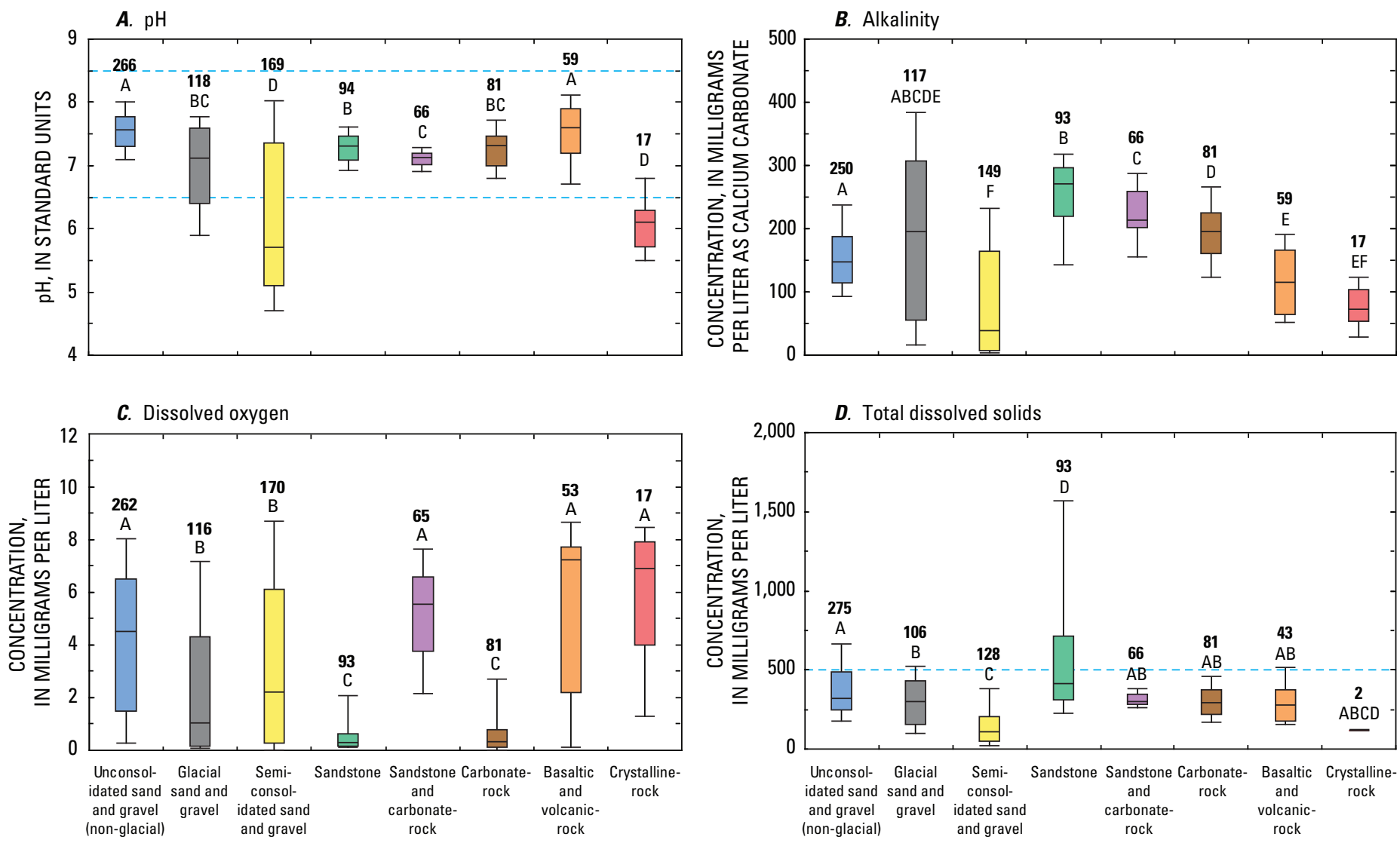

PRINCIPAL AQUIFER ROCK TYPE

PRINCIPAL AQUIFER ROCK TYPE

\section{EXPLANATION}

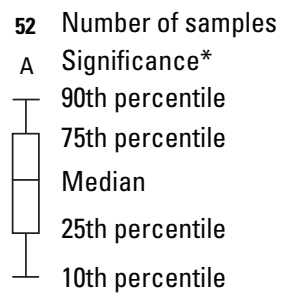

- - Secondary Maximum Contaminant Level (SMCL)-

SMCLs are not available for alkalinity or dissolved oxygen

*Distributions of groups that share the same letter

symbol are not significantly different at the

95-percent confidence level.

Figure 13. Distributions of $(A) \mathrm{pH},(B)$ alkalinity, $(C)$ dissolved oxygen, and $(D)$ total dissolved-solids concentrations, by principal aquifer rock type, in public-well samples collected during 1993-2007. 
A. $\mathrm{pH}-$ Secondary Maximum Contaminant Level $(\mathrm{SMCL})=6.5$ to 8.5

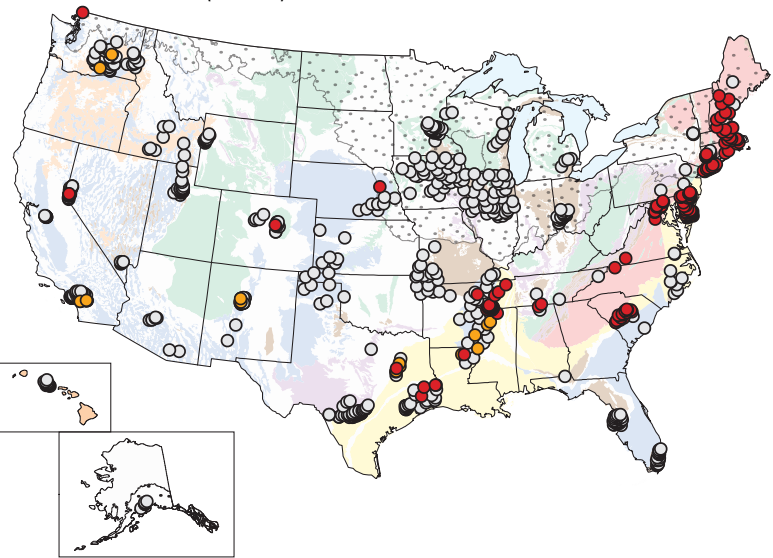

C. Dissolved oxygen-SMCL is not available

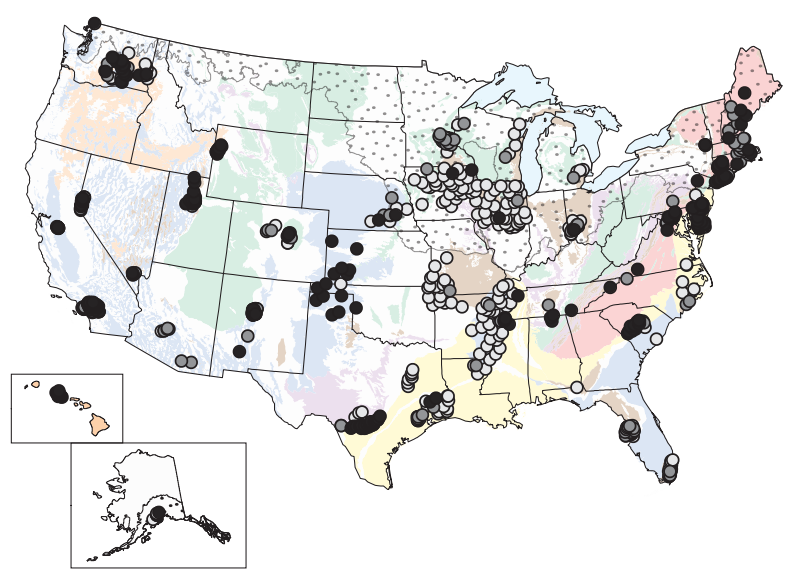

B. Alkalinity-SMCL is not available

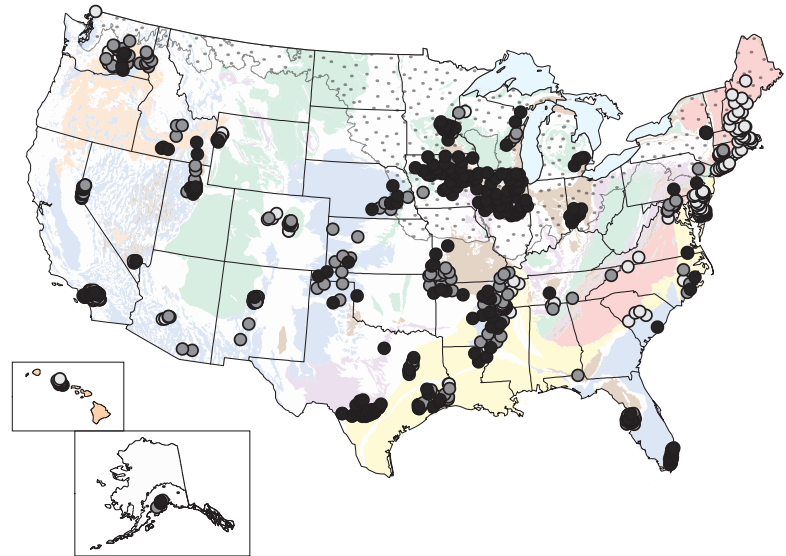

EXPLANATION

(A) $\mathrm{pH}$ (standard units)

- Less than $(<) 6.5$

○ $\quad 6.5$ to 8.5

- Greater than $(>) 8.5$

\section{(C) Dissolved-oxygen} concentration $(\mathrm{mg} / \mathrm{L})$

- $>5$

- 1 to 5

$\circ<1$

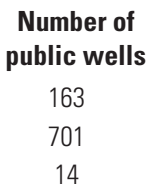

Number of public wells

283

235

347

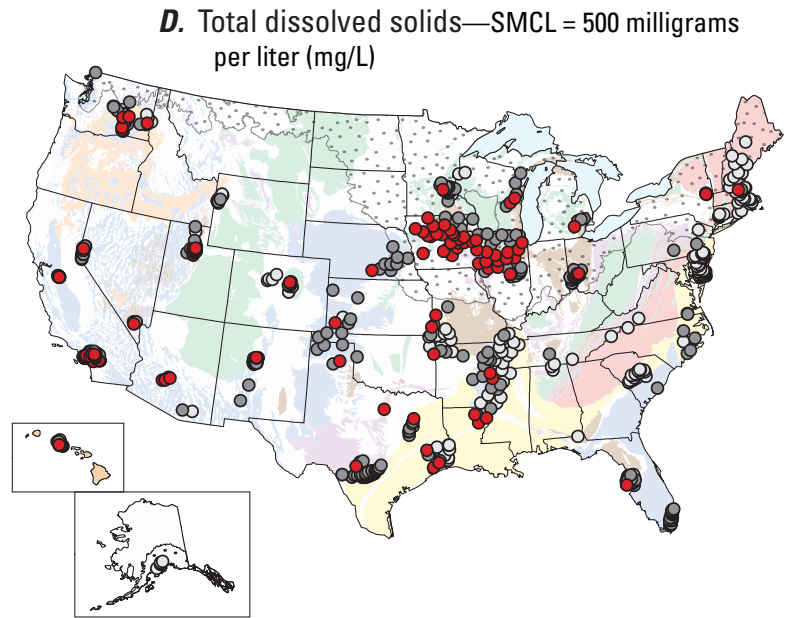

D. Total dissolved solids $-\mathrm{SMCL}=500$ milligrams eer liter $(\mathrm{mg} / \mathrm{L})$

(B) Alkalinity concentration (mg/L as calcium carbonate)

- $>200$

Number of

public wells

- 100 to 200

291

○ $<100$

332

217

(D) Total dissolved-solids concentration $(\mathrm{mg} / \mathrm{L})$

- $>500$

- 250 to 500

○ $<250$
Number of public wells

134

377

291

Figure 14. Geographic distributions of $(A) \mathrm{pH},(B)$ alkalinity, $(C)$ dissolved oxygen, and $(D)$ total dissolved-solids concentrations in public-well samples collected during 1993-2007. Data are from 878 samples measured for $\mathrm{pH}, 840$ samples for alkalinity, 865 samples for dissolved oxygen, and 802 samples analyzed for total dissolved solids. (See fig. $2 A$ for explanation of principal aquifer rock types.) 
The samples with the lowest $(\mathrm{p}<0.05) \mathrm{pH}$ values were from semi-consolidated sand and gravel aquifers and crystalline-rock aquifers (fig. 13A). These aquifers tend to have less capability to neutralize acid precipitation (lower alkalinity), and lower TDS as compared to other principal aquifer rock types (figs. $13 C$ and $\underline{13 D}$ ). $\mathrm{pH}$ was strongly positively correlated $(\mathrm{p}<0.05)$ with alkalinity $(r h o=0.92)$ and TDS $(r h o=0.84)$ in samples from semi-consolidated sand and gravel aquifers, and with alkalinity $(r h o=0.76)$ in samples from crystalline-rock aquifers. $\mathrm{pH}$ was negatively correlated $(r h o=-0.20$ to -0.62$)$ with alkalinity and TDS in samples from sandstone, sandstone and carbonate, and carbonate-rock aquifers where alkalinity was greatest $(\mathrm{p}<0.05)($ fig. $13 B)$.

Alkalinity is the capacity of a solution to react with and neutralize acid. In most natural waters, alkalinity is produced by the dissolved carbon dioxide species, bicarbonate and carbonate (Hem, 1985). The predominant carbon dioxide species depends on the $\mathrm{pH}$ of the water; the bicarbonate ion is the most abundant species when the $\mathrm{pH}$ is between about 6.3 and 10.3 (Hemond and Fechner, 1994). The median and maximum alkalinity values were 158 and $500 \mathrm{mg} / \mathrm{L}$ as $\mathrm{CaCO}_{3}$, respectively, in the source-water samples (Appendix 8). Benchmarks or guidelines are not available for alkalinity in drinking water (U.S. Environmental Protection Agency, 2006a), but low alkalinity water (less than $40 \mathrm{mg} / \mathrm{L}$ ) may contribute to corrosion of pipes in water distribution systems (World Health Organization, 2004).

Alkalinity was lowest $(\mathrm{p}<0.05)$ in samples from semiconsolidated sand and gravel, basaltic, and crystalline-rock aquifers where $\mathrm{pH}$ also tended to be lowest (figs. 13A and $\underline{13 B}$ ) and where $\mathrm{pH}$ and alkalinity were positively correlated ( $r h o=0.44$ to $0.92, \mathrm{p}<0.05$ ). Because of the influence of carbonate, alkalinity was highest $(\mathrm{p}<0.05)$ in samples from sandstone and (or) carbonate-rock aquifers. Alkalinity concentrations were highly variable in samples from glacial sand and gravel aquifers, but some concentrations in glacial aquifers were high relative to other rock types (fig. 13B), particularly in the midwestern states of Ohio, Illinois, and Minnesota. Geographically, alkalinity was highest in the midwestern and central United States, and in Texas (fig. 14B), indicating, in part, the general distribution of the various sampled aquifers composed of sandstone and (or) carbonate rock (fig. 2). Alkalinity was positively correlated with TDS in samples from all principal aquifer rock types ( $r h o=0.38$ to 0.90, $\mathrm{p}<0.05)$.

Dissolved oxygen in groundwater originates from the atmosphere. Benchmarks or guidelines are not available for dissolved oxygen in drinking water (U.S. Environmental Protection Agency, 2006a), but dissolved oxygen plays a key role in oxidation-reduction (redox) reactions, such as the control on the mobility of some metals and the biotransformation of organic compounds (Domenico and
Schwartz, 1990). Dissolved oxygen can serve as the terminal electron acceptor in microbial metabolism (Perry, 1979), and the availability of dissolved oxygen in groundwater depends on various factors, including rates of oxygen consumption by microorganisms and the presence of utilizable substrates that can lead to oxygen depletion (Bossert and Bartha, 1984). Dissolved oxygen usually is depleted along a groundwater flow path through reactions with organic materials and reduced minerals (Freeze and Cherry, 1979). As a result, shallow groundwater commonly contains more dissolved oxygen than older, deep groundwater. In this study, dissolvedoxygen concentrations generally were greater $(\mathrm{p}<0.05)$ in samples collected from shallower unconfined aquifers, where the median concentration was $3.9 \mathrm{mg} / \mathrm{L}$, than in samples collected from deeper confined aquifers, where the median concentration was $0.6 \mathrm{mg} / \mathrm{L}$ (fig. 15), but varied widely among most principal aquifer rock types. Dissolved oxygen was lowest $(\mathrm{p}<0.05)$ and least variable in samples from sandstone aquifers and in carbonate-rock aquifers (fig. 13C). Geographically, dissolved-oxygen concentrations were lowest in the east-central United States and highest in the eastern and western United States (fig. 14C).

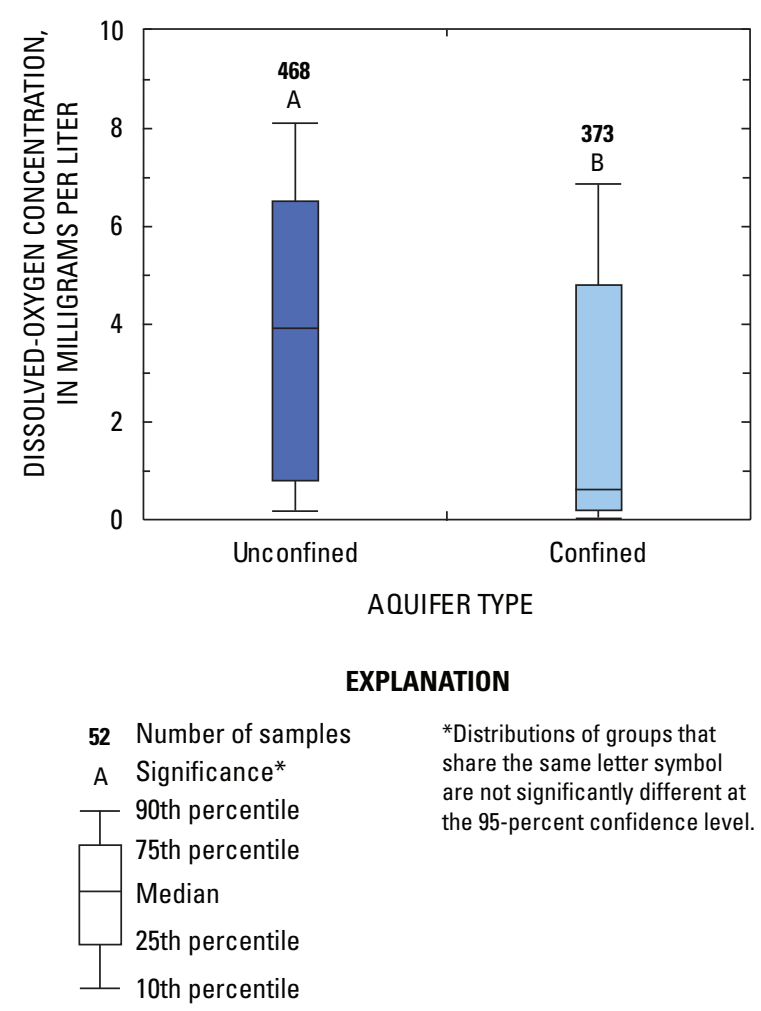

Figure 15. Distributions of dissolved-oxygen concentrations in relation to aquifer type in public-well samples collected during 1993-2007. 
Groundwater contains a wide variety of dissolved chemical constituents primarily because of interactions between groundwater and the geological material through which groundwater flows. TDS typically consists of inorganic constituents and small amounts of organic matter, and groundwater can be viewed as an electrolyte solution because nearly all of its dissolved constituents are present in ionic form (Freeze and Cherry, 1979). As a result, specific conductance can be used as a general indication of TDS (Freeze and Cherry, 1979; Hem, 1985), and specific conductance and TDS were very highly correlated in the public wells sampled in this study (rho $=0.98, \mathrm{p}<0.05)$.

TDS concentrations were greater than the SMCL of $500 \mathrm{mg} / \mathrm{L}$ (U.S. Environmental Protection Agency, 2006a) in 16.7 percent of the source-water samples from public wells (table 8); these samples were from all principal aquifer rock types except for crystalline-rock aquifers, and were, therefore, widely distributed across the United States. However, most samples with TDS concentrations greater than the SMCL were from unconsolidated sand and gravel aquifers in the southwestern United States, and from sandstone aquifers in the Cambrian-Ordovician aquifer system, mostly from confined aquifers in Iowa and Illinois (fig. 14D).

Overall, TDS concentrations were greatest $(p<0.05)$ in public-well samples from sandstone aquifers (fig. 13D), and were significantly greater in deeper confined aquifers than in shallower unconfined aquifers (data not shown). Groundwater samples from public wells in the Cambrian-Ordovician sandstone aquifer of eastern Wisconsin have previously been reported to commonly contain concentrations of dissolved solids greater than the SMCL, possibly from the dissolution of chloride-bearing minerals coupled with sorption reactions (Weaver and Bahr, 1991). TDS concentrations also have been shown to increase with depth in the Cambrian-Ordovician aquifer system to concentrations greater than the SMCL (Olcott, 1992; Andrews and others, 2005).

\section{Major lons}

Source-water samples from public wells were analyzed for as many as nine major ions. Major ions comprise most of the dissolved constituents in groundwater and occur naturally as a result of recharge composition and interactions between water and soil or rock (Bartos and others, 2004). Concentration statistics for the major ions analyzed in source-water samples are shown in Appendix 8. Major ions occur naturally, and, except for fluoride, were detected in nearly every sample in which they were analyzed
(Appendix 8). The bicarbonate anion was reported as alkalinity in section, "Water-Quality Properties" on page 29. Water hardness was calculated from calcium and magnesium concentrations (Appendix 7). Silica, an uncharged species, also is included in Appendix 8 as a major ion. Major-ion data were analyzed to evaluate the distribution of water types and hardness, and to evaluate the occurrence of several individual major ions - sodium, chloride, sulfate, and fluoride - to non-health guidelines and (or) human-health benchmarks.

\section{Water Types}

Major-ion data were plotted in trilinear diagrams to identify the relations among overall geochemical conditions and principal aquifer rock types. Trilinear diagrams were created for each principal aquifer rock type, using results for 733 public-well samples in which all required cations (calcium, magnesium, sodium, potassium) and anions (chloride, bicarbonate, and sulfate) were analyzed. Bicarbonate concentrations were calculated from alkalinity (Appendix 6) when measured bicarbonate concentrations were not available. Trilinear diagrams show the relative concentrations as percentages of the major cations and anions on two separate trilinear plots and a central diamond plot where the points from the two trilinear plots are projected (Güler and others, 2002). The central diamond-shaped field shows the overall chemical character of the water (Piper, 1944). Trilinear diagrams are useful for visually describing differences in major-ion chemistry in groundwater flow systems (Freeze and Cherry, 1979), and commonly are subdivided into hydrochemical facies, or identifiable groups or categories of water compositions (Back, 1961; Back and Hanshaw, 1965) (fig. 16).

The ionic composition of the groundwater samples evaluated in this study was quite variable within most principal aquifer rock types, consistent with the range of lithologies and geochemical processes in these broad rock-type categories (fig. 17); these results are consistent with previous findings from domestic-well samples (DeSimone, 2009). Mixed cation-bicarbonate water types were observed in unconsolidated sand and gravel, glacial, sandstone, and basaltic-rock aquifers (figs. 17A, $\underline{B}, \underline{D}$, and $\underline{G}$ ). Calcium was the most abundant cation and bicarbonate was the most abundant anion in most rock types. Calcium and bicarbonate especially were dominant in the carbonate-rock and sandstone and carbonate-rock aquifers (figs. $17 E$ and $\underline{F}$ ), in which calcite (calcium carbonate) dissolution strongly affects water chemistry (Domenico and Schwartz, 1990). 


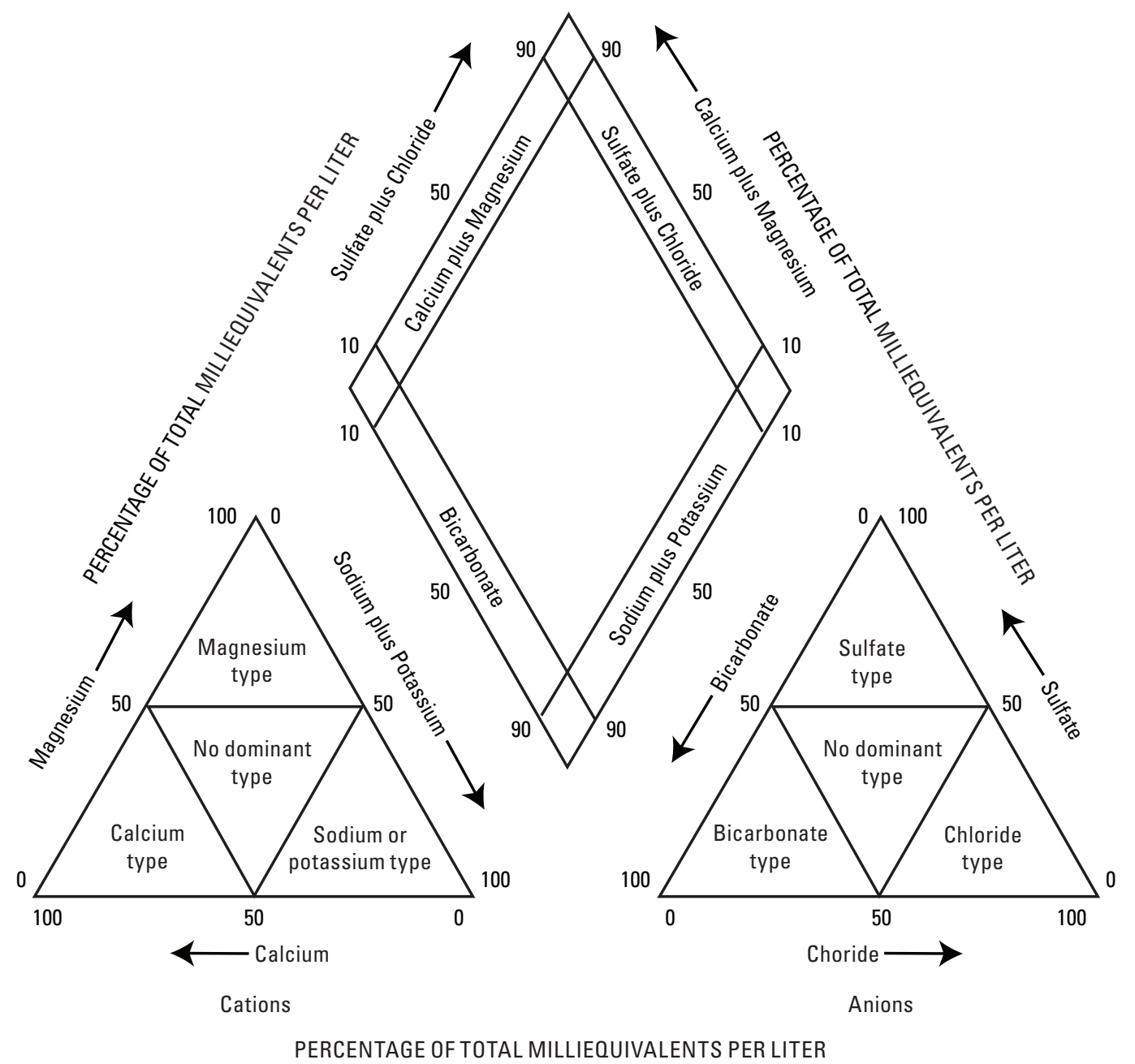

Figure 16. Water-type classification categories in terms of major-ion percentages. Water types are classified by the domain in which they occur on the diagram segments. Diagram was modified from Back and Hanshaw (1965).

The sodium-chloride water type was observed in some samples from semi-consolidated sand and gravel aquifers (fig. 17C), perhaps indicating the influence of sea spray, saltwater intrusion, or the non-reactive character of these coastal-plain aquifer sediments (Barlow, 2003; DeSimone, 2009). Sodium in the mixed-cation water types also may result from (1) mixing with brines; (2) the presence of sodium-containing minerals; (3) human activities, such as the application of road salt; and (4) cation exchange (where sodium replaces calcium or magnesium) (Weaver and Bahr, 1991; Bartos and others, 2004; Andrews and others, 2005).

Waters from deep aquifers are likely to have longer flow paths and, therefore, more contact with aquifer materials (longer residence time), and more time to exchange calcium and magnesium for sodium than waters from shallow aquifers (Bartos and others, 2004). 
A. Unconsolidated sand and gravel aquifers (non-glacial) (245 samples)

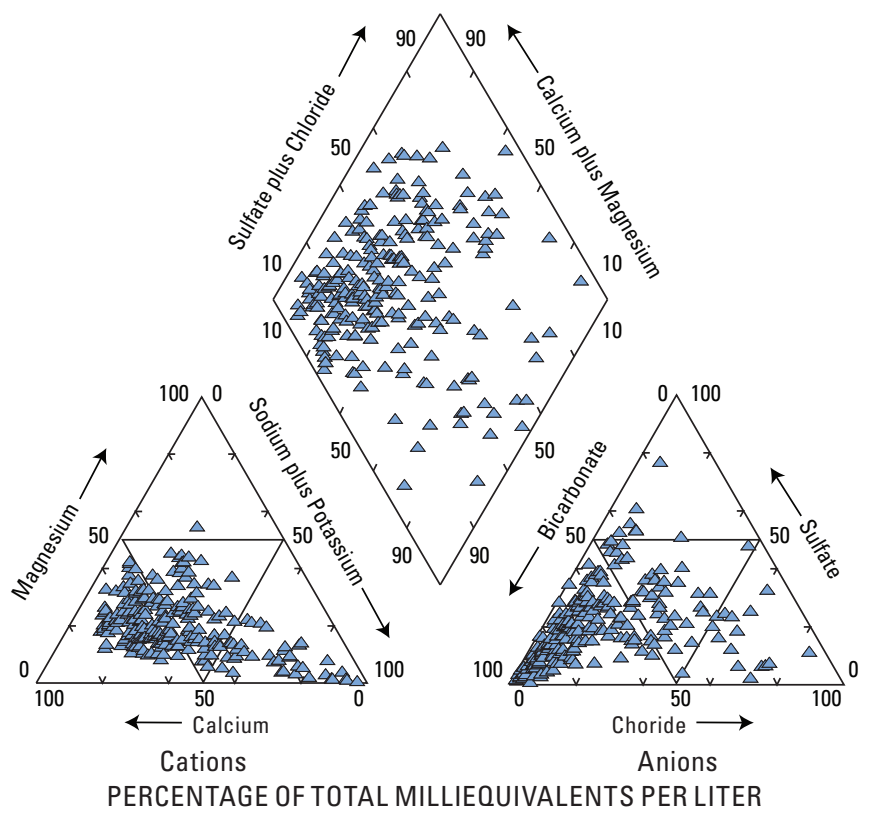

C. Semi-consolidated sand and gravel aquifers (102 samples)

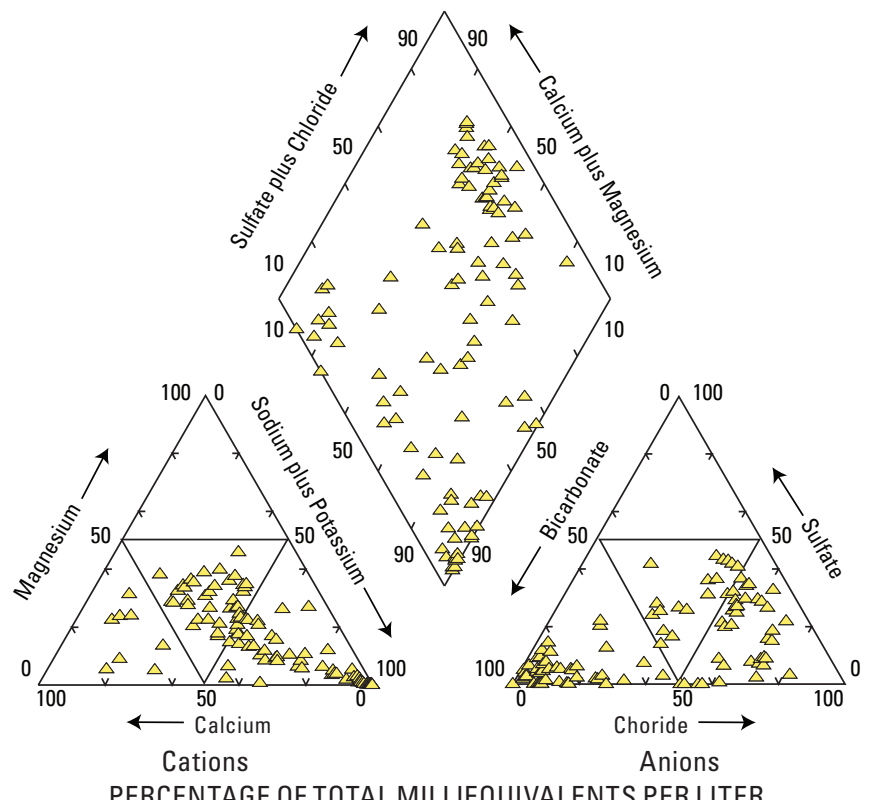

B. Glacial sand and gravel aquifers (100 samples)

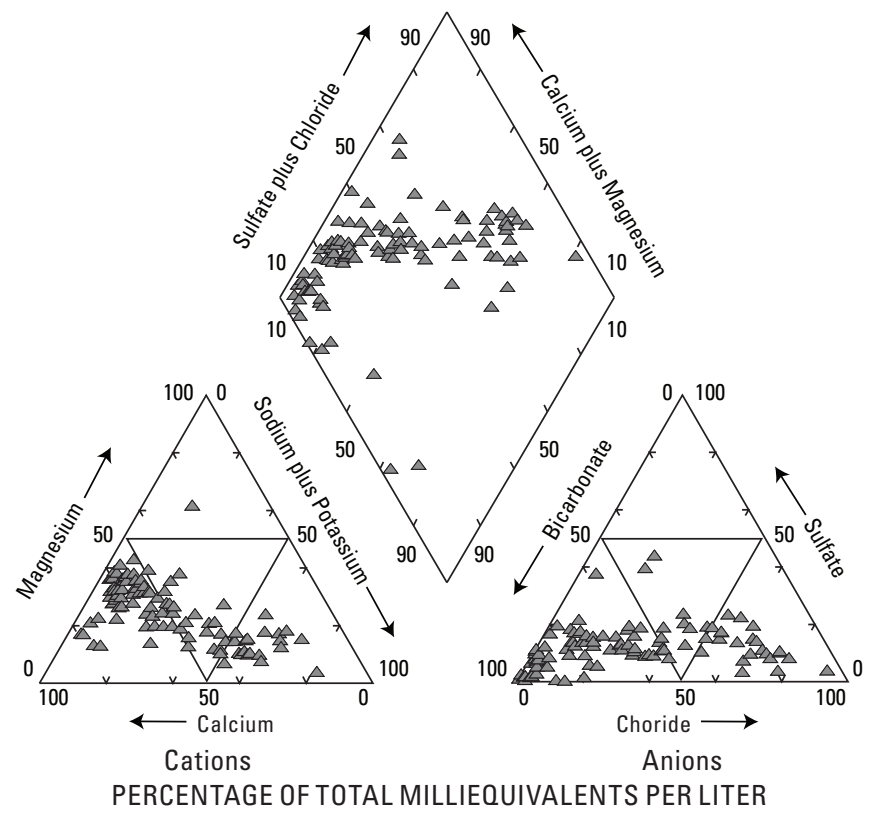

D. Sandstone aquifers (91 samples)

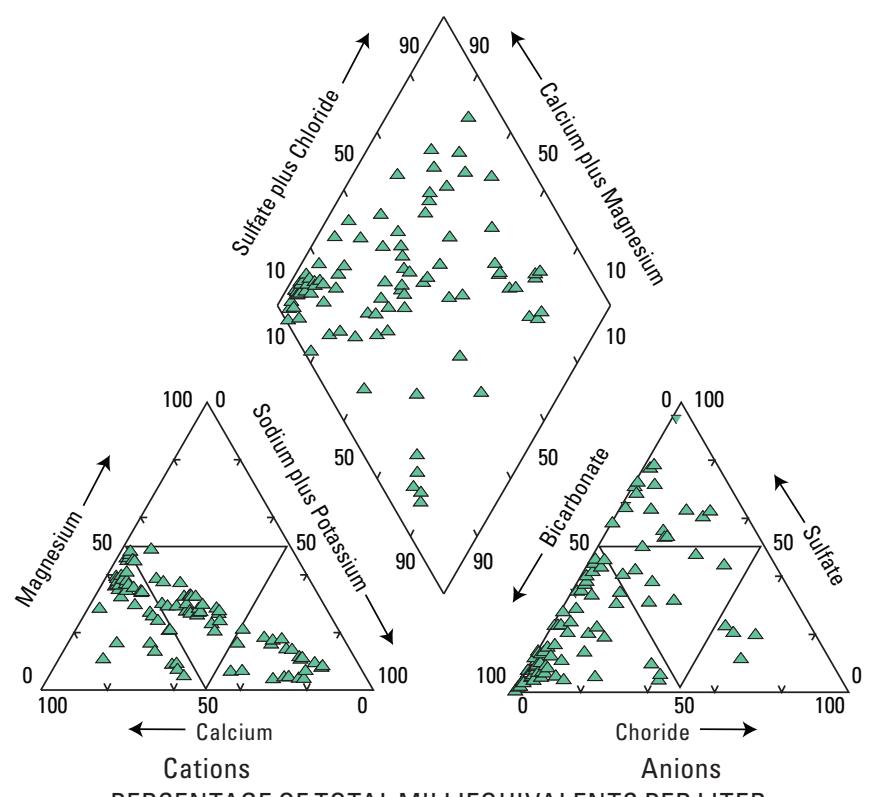

PERCENTAGE OF TOTAL MILLIEQUIVALENTS PER LITER

Figure 17. Ionic composition of source water from public-well samples collected during 1993-2007, by principal aquifer rock type. Data are from 733 samples in which all required cations (calcium, magnesium, sodium, potassium) and anions (chloride, bicarbonate, and sulfate) were analyzed. 
E. Sandstone and carbonate-rock aquifers (66 samples)

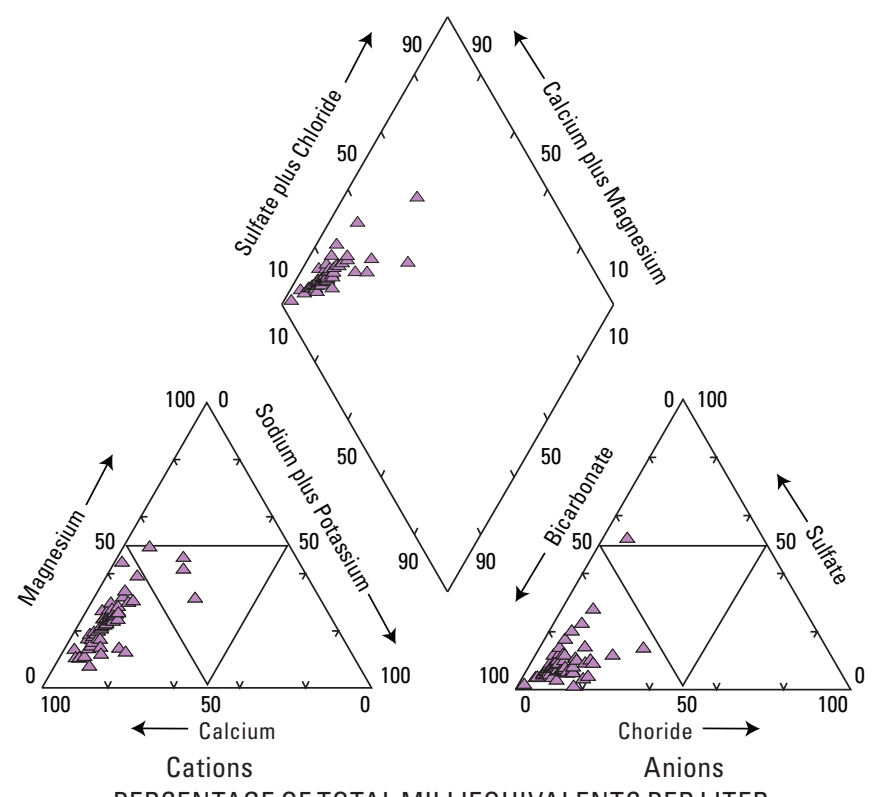

PERCENTAGE OF TOTAL MILLIEQUIVALENTS PER LITER

G. Basaltic and volcanic-rock aquifers (48 samples)

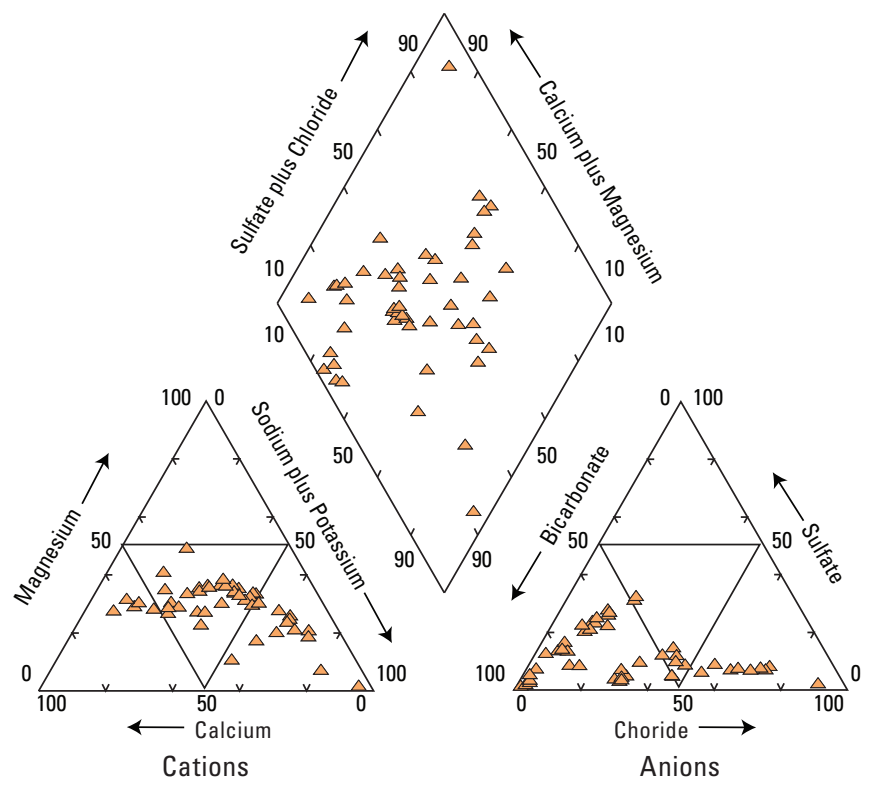

PERCENTAGE OF TOTAL MILLIEQUIVALENTS PER LITER
F. Carbonate-rock aquifers (79 samples)

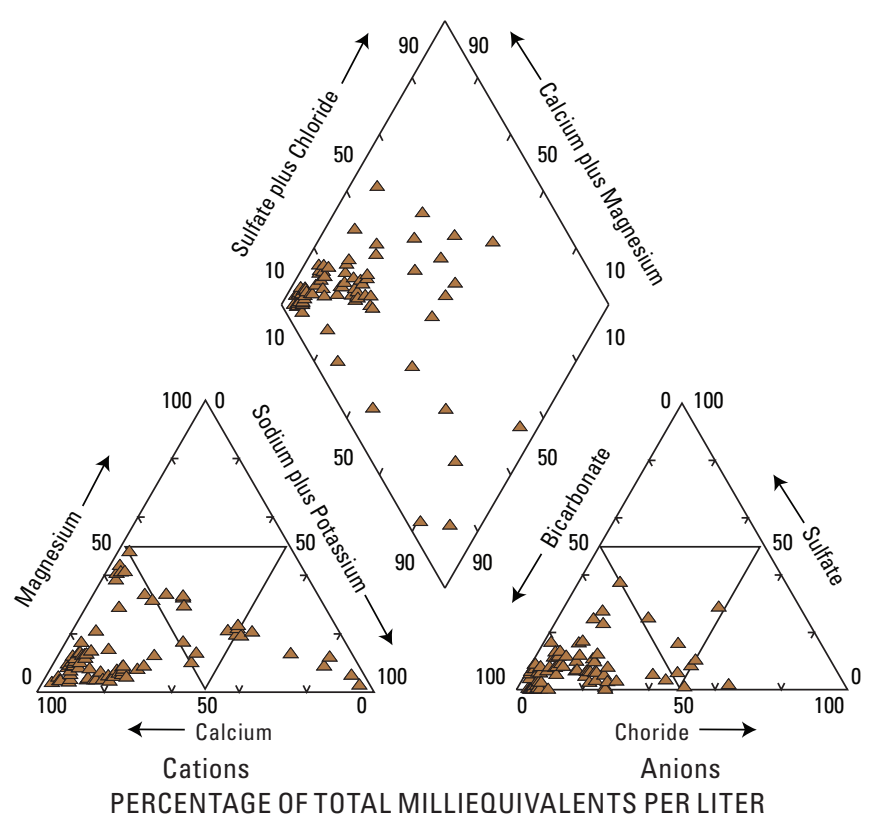

H. Crystalline-rock aquifers (2 samples)

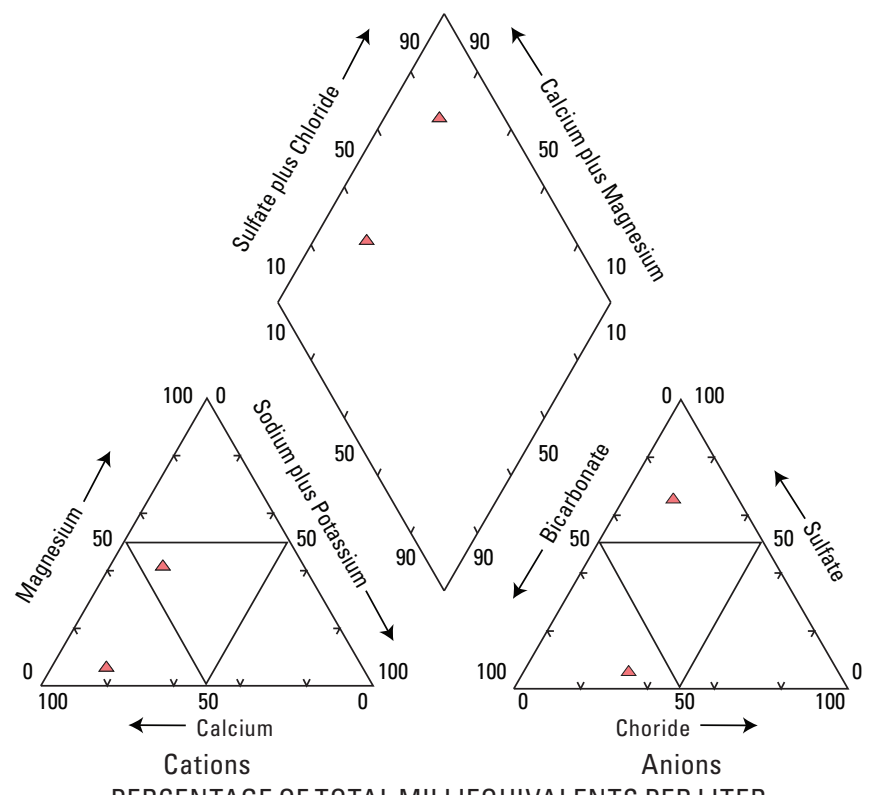

PERCENTAGE OF TOTAL MILLIEQUIVALENTS PER LITER

Figure 17. Ionic composition of source water from public-well samples collected during 1993-2007, by principal aquifer rock type. Data are from 733 samples in which all required cations (calcium, magnesium, sodium, potassium) and anions (chloride, bicarbonate, and sulfate) were analyzed.-Continued 


\section{Hardness}

Hardness is calculated from calcium and magnesium concentrations in water (Appendix 7) and is a qualitative indicator of how readily water forms insoluble residues with soaps and scale deposits in pipes and boilers and on plumbing fixtures (Hem, 1985). Water hardness is classified in different ways by different authors; in this report, the hardness classification scheme described by Durfor and Becker (1964) and reported by Hem (1985) was used (table 9). Benchmarks or guidelines are not available for hardness in drinking water (U.S. Environmental Protection Agency, 2006a), but soft water (low in hardness) can cause corrosion of metallic surfaces, whereas hard water requires excessive amounts of soap and detergents and forms insoluble scums in pipes (Durfor and Becker, 1964). Hard water can be treated with a water softener, through which dissolved calcium and magnesium are exchanged with sodium; this process is chemically similar to the naturally occurring cation exchange process described above, where sodium replaces calcium or magnesium in aquifers (Hem, 1985; Bartos and others, 2004).

The median water hardness in samples collected from public wells in this study was about $182 \mathrm{mg} / \mathrm{L}$ as $\mathrm{CaCO}_{3}$ (Appendix 8); water with hardness concentrations greater
Table 9. Water hardness classification scheme.

[Classification scheme from Durfor and Becker (1964). $\mathrm{mg} / \mathrm{L}$ as $\mathrm{CaCO}_{3}$, milligrams per liter as calcium carbonate; >, greater than]

\begin{tabular}{cl}
\hline $\begin{array}{c}\text { Hardness range } \\
\left(\mathbf{m g} / \mathbf{L} \text { as } \mathrm{CaCO}_{3}\right)\end{array}$ & Description \\
\hline $0-60$ & Soft \\
$60-120$ & Moderately hard \\
$121-180$ & Hard \\
$>180$ & Very hard \\
\hline
\end{tabular}

than $180 \mathrm{mg} / \mathrm{L}$ as $\mathrm{CaCO}_{3}$ is considered to be very hard (table 9). Very hard water was detected in samples from all principal aquifer rock types except crystalline-rock aquifers, where calcium and magnesium were only analyzed in two samples. Very hard water was, therefore, widely distributed across the United States. About one-half of the source-water samples from public wells with very hard water were from unconsolidated sand and gravel aquifers in the southwestern United States, and in sandstone aquifers in the CambrianOrdovician aquifer system in Illinois, Iowa, Minnesota, and Wisconsin (fig. 18), with a geographic distribution similar to

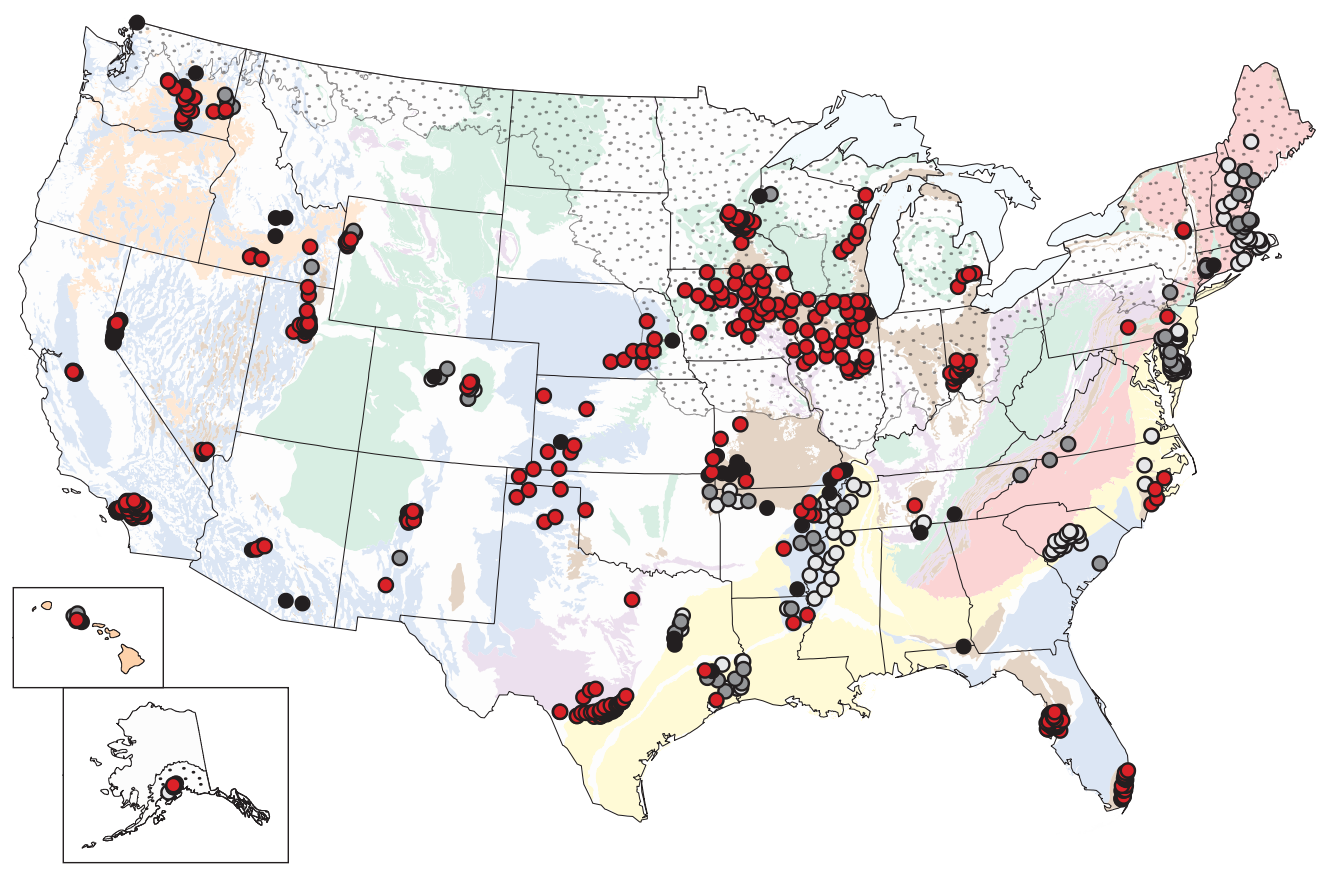

EXPLANATION

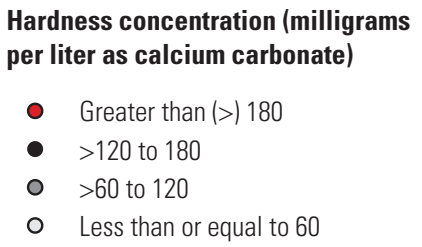

$\begin{array}{cc}\begin{array}{c}\text { Hardness } \\ \text { classification }\end{array} & \begin{array}{c}\text { Number of } \\ \text { public wells }\end{array} \\ \text { Very hard } & 407 \\ \text { Hard } & 114 \\ \text { Moderately hard } & 123 \\ \text { Soft } & 165\end{array}$

Figure 18. Geographic distribution of water hardness concentrations in 809 public-well samples collected during 1993-2007. Water hardness classifications are from Durfor and Becker (1964). (See fig. $2 A$ for explanation of principal aquifer rock types.) 
that of alkalinity and TDS (figs. $14 B$ and $\underline{D}$ ). Water hardness was positively correlated with alkalinity and TDS in most principal aquifer rock types ( $r h o=0.47$ to $0.91, \mathrm{p}<0.05$ ). The hardest waters $(\mathrm{p}<0.05)$ were detected in samples from sandstone and sandstone and carbonate-rock aquifers that contain calcium- and magnesium-bearing minerals, such as calcium carbonate. The softest waters $(p<0.05)$ were detected in samples from semi-consolidated sand and gravel aquifers (fig. 19), where pH, alkalinity, and TDS were lowest (ig. 13). The results for water hardness in this study are consistent with findings from a recent national USGS study of groundwater data from domestic wells (DeSimone, 2009).

\section{Sodium, Chloride, and Sulfate}

Sodium concentrations were greater than USEPA's taste threshold range of 30 to $60 \mathrm{mg} / \mathrm{L}$ in about 20 to 40 percent of the source-water samples from public wells (table 8). The median sodium concentration in all samples was $21 \mathrm{mg} / \mathrm{L}$ (Appendix 8). Potential sources of sodium in groundwater were discussed above.
Concentrations of chloride and sulfate greater than $250 \mathrm{mg} / \mathrm{L}$ (USEPA SMCL for each anion) can impart an unpleasant taste to drinking water, and both may contribute to corrosion of distribution systems (World Health Organization, 2004). Chloride and sulfate concentrations each were greater than their USEPA SMCLs in less than 4 percent of source-water samples from public wells (table 8). Chloride concentrations greater than the SMCL were distributed across the United States in samples from six different principal aquifer rock types in a mix of confined and unconfined aquifers (data not shown). Natural sources of chloride in groundwater include dissolution of sodium chloride from sedimentary rocks. Chloride also may be present in these rocks as a result of the presence of brine, or sedimentary rock formation via deposition in the sea or a closed drainage basin (Hem, 1985). Anthropogenic sources of chloride in groundwater include road-salt application and wastewater disposal.

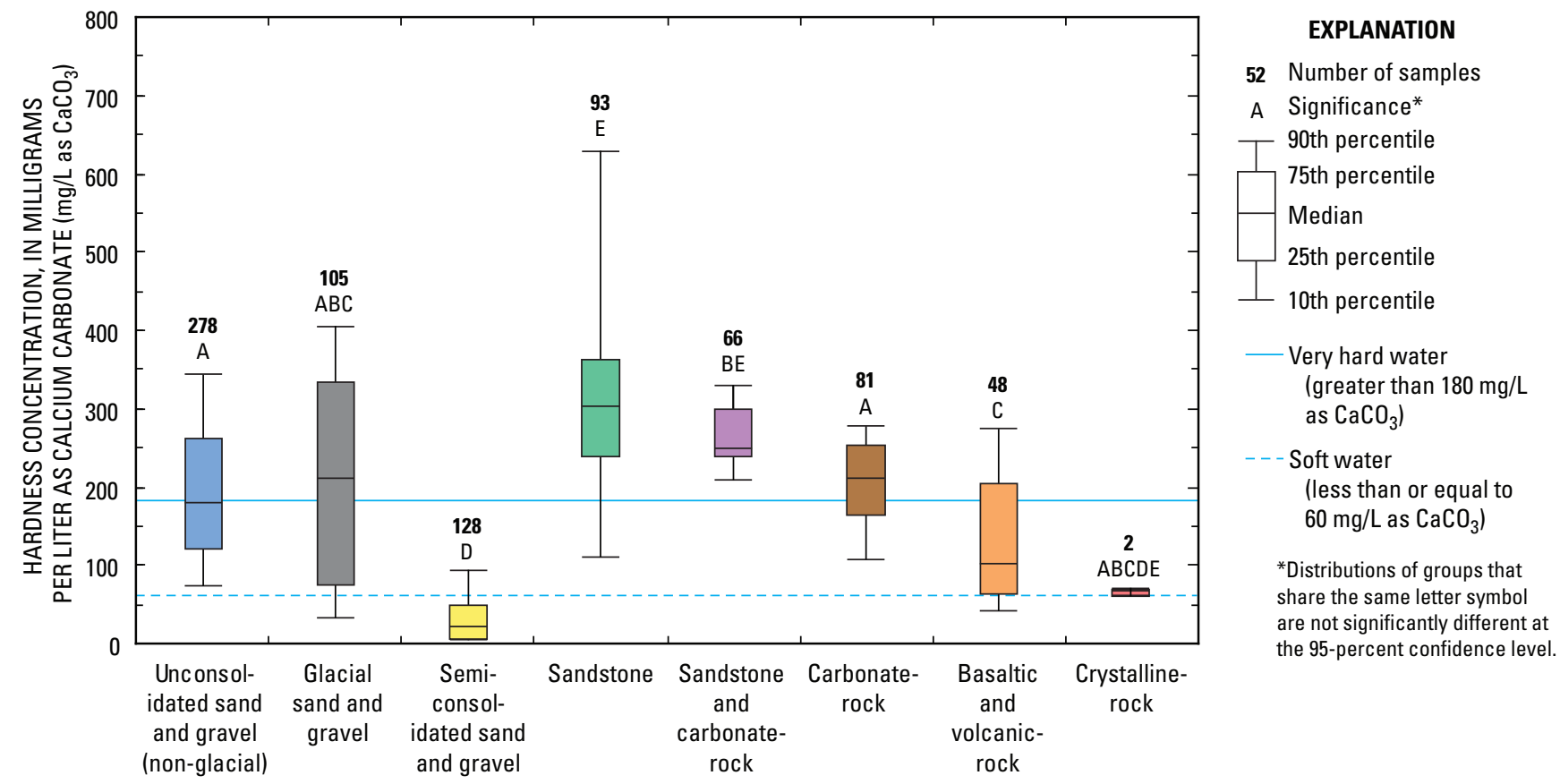

PRINCIPAL AQUIFER ROCK TYPE

Figure 19. Distributions of water hardness, by principal aquifer rock type, in public-well samples collected during 1993-2007. Water hardness classifications are from Durfor and Becker (1964). 
Most sulfate concentrations greater than the SMCL were detected in public-well samples from confined sandstone aquifers in Iowa and Illinois (data not shown). Natural sources of sulfate in groundwater include gypsum dissolution and the oxidation of pyrite (iron sulfide) or other sulfides common in igneous and sedimentary rocks; these processes also can be affected by human activities (Hem, 1985). Fertilizer application is a common anthropogenic source of sulfate in groundwater (Bartos and others, 2004). Depletion of dissolved oxygen in water supplies can cause sulfate reduction to sulfide (Madigan and others, 1997).

\section{Fluoride}

Many public-health agencies endorse adding fluoride to drinking water as a way to prevent tooth decay in communities where natural fluoride concentrations are lower than those needed to help prevent tooth decay (National Research Council, 2006a). More than 40 years ago, the U.S. Public Health Service recommended that community drinking water be adjusted to contain between 0.7 and $1.2 \mathrm{mg} / \mathrm{L}$ of fluoride to help prevent tooth decay (U.S. Centers for Disease Control and Prevention, 2001). In 2000, about 162 million people in the United States received artificially fluoridated water. The U.S. Public Health Service recommended range for artificial fluoridation is less than the USEPA drinking-water standard (MCL of $4 \mathrm{mg} / \mathrm{L}$ ) and non-health guideline (SMCL of $2.0 \mathrm{mg} / \mathrm{L}$ ) for fluoride in drinking water, but was designed for a different purpose (National Research Council, 2006a; U.S. Environmental Protection Agency, 2006a).

Fluoride concentrations greater than the MCL in drinking water may cause mottled teeth (enamel fluorosis), especially in children, and bone disease (U.S. Environmental Protection Agency, 2009b). A 2006 review by the National Academies concluded that the MCL is not protective of health because exposure to fluoride at $4 \mathrm{mg} / \mathrm{L}$ places children at risk of developing severe enamel fluorosis and also can weaken bone, which increases the risk of fractures. The National Academies recommended that USEPA update its risk assessment of fluoride to include new data on health risks and new estimates of total exposure for individuals. The safety and effectiveness of the practice of water fluoridation was not evaluated in the National Academies report (National Research Council, 2006a, b).

Fluoride was detected in about 75 percent of the source-water samples from public wells (Appendix 8). Fluoride concentrations were less than the MCL in 99.5 percent of samples (table 10) and were less than the SMCL in 97.3 percent of samples (table 8). Three of the four samples with fluoride concentrations greater than the MCL were from confined carbonate-rock aquifers. Fluoride concentrations greater than the SMCL were distributed across the United States in samples from most principal aquifer rock types (fig. 20) in a mix of confined and unconfined aquifers. The number of samples with fluoride concentrations greater than one-tenth of the MCL (BQ>0.1) was not determined because fluoride at this concentration $(0.4 \mathrm{mg} / \mathrm{L})$ is less than the range of concentrations in drinking water recommended for the prevention of tooth decay (U.S. Centers for Disease Control and Prevention, 2001). Fluoride concentrations were less than $1.2 \mathrm{mg} / \mathrm{L}$ (the upper end of the recommended range to prevent tooth decay) in 92 percent of the source-water samples. This finding is consistent with previous reportsfluoride concentrations in most natural waters are less than 1.0 mg/L (Hem, 1985; DeSimone, 2009).

In this study, fluoride concentrations were positively correlated with TDS in samples from most principal aquifer rock types $(r h o=0.30$ to $0.78, \mathrm{p}<0.05)$, which is consistent with the fact that fluoride in groundwater usually originates from the dissolution of minerals, such as fluorite $\left(\mathrm{CaF}_{2}\right)$ and fluoroapatite $\left(\mathrm{Ca}_{3}\left(\mathrm{PO}_{4}\right)_{2} \cdot \mathrm{CaF}_{2}\right)$ in sedimentary rock (Freeze and Cherry, 1979; Hem, 1985). Fluoride also can enter water resources from various anthropogenic industrial discharges and emissions (National Research Council, 2006a). Fluoride concentrations were negatively correlated with dissolved oxygen in samples from most principal aquifer rock types $(r h o=-0.18$ to $-0.67, \mathrm{p}<0.05)$, perhaps because of groundwater age; older waters are more likely to have high solute concentrations (Bartos and others, 2004) and potentially less dissolved oxygen (DeSimone, 2009) than younger waters. 
Table 10. Number of detections and comparison of concentrations to human-health benchmarks for water-quality properties, major ions, nutrients, radionuclides, and fecal-indicator microorganisms in public-well samples collected during 1993-2007.

[No common assessment level was applied to these data. BQ, Benchmark Quotient (ratio of concentration to human-health benchmark); >, greater than; $\leq$ less than or equal to; $\mathrm{CaCO}_{3}$, calcium carbonate; $\mathrm{mg} / \mathrm{L}$, milligrams per liter; - , not available; $\mu \mathrm{S} / \mathrm{cm}$, microsiemens per centimeter; ${ }^{\circ} \mathrm{C}$, degrees Celsius; $\mathrm{MCL}$, Maximum Contaminant Level; N, nitrogen; P, phosphorus; pCi/L, picocuries per liter; AMCL, Alternative Maximum Contaminant Level; col/100 mL; colonies per 100 milliliters; \%, percent]

\begin{tabular}{|c|c|c|c|c|c|c|c|c|}
\hline \multirow[b]{2}{*}{ Contaminant } & \multirow{2}{*}{$\begin{array}{l}\text { Number of } \\
\text { samples }\end{array}$} & \multirow{2}{*}{$\begin{array}{l}\text { Number of } \\
\text { detections }\end{array}$} & \multicolumn{2}{|c|}{ Human-health benchmark ${ }^{1}$} & \multicolumn{2}{|c|}{ Samples with B0>1 } & \multicolumn{2}{|c|}{$\begin{array}{l}\text { Samples with } \\
\text { B }>0.1 \text { and } \leq 1\end{array}$} \\
\hline & & & $\begin{array}{c}\text { Value } \\
\text { (in units } \\
\text { shown) }\end{array}$ & Type & Number & Percent & Number & Percent \\
\hline \multicolumn{9}{|c|}{ Water-quality properties } \\
\hline Alkalinity as $\mathrm{CaCO}_{3}(\mathrm{mg} / \mathrm{L})^{2}$ & 840 & 838 & - & - & - & - & - & - \\
\hline Dissolved oxygen (mg/L) & 865 & 803 & - & - & - & - & - & - \\
\hline $\mathrm{pH}$, in standard units & 878 & 878 & - & - & - & - & - & - \\
\hline Specific conductance $\left(\mu \mathrm{S} / \mathrm{cm}\right.$ at $\left.25^{\circ} \mathrm{C}\right)$ & 896 & 896 & - & - & - & - & - & - \\
\hline Temperature $\left({ }^{\circ} \mathrm{C}\right)$ & 893 & 884 & - & - & - & - & - & - \\
\hline Total dissolved solids (mg/L) & 802 & 802 & - & - & - & - & - & - \\
\hline \multicolumn{9}{|c|}{ Major ions (mg/L) } \\
\hline Bromide & 787 & 749 & - & - & - & - & - & - \\
\hline Calcium & 809 & 809 & - & - & - & - & - & - \\
\hline Chloride & 809 & 808 & - & - & - & - & - & - \\
\hline Fluoride & 808 & 610 & 4 & MCL & 4 & 0.5 & - & - \\
\hline Magnesium & 809 & 809 & - & - & - & - & - & - \\
\hline Potassium & 810 & 810 & - & - & - & - & - & - \\
\hline Silica & 809 & 809 & - & - & - & - & - & - \\
\hline Sodium & 809 & 809 & - & - & - & - & - & - \\
\hline Sulfate & 810 & 795 & - & - & - & - & - & - \\
\hline Hardness as $\mathrm{CaCO}_{3}{ }^{3}$ & 809 & 809 & - & - & - & - & - & - \\
\hline All analyzed major ions & 810 & 810 & various & various & 4 & 0.5 & - & - \\
\hline \multicolumn{9}{|c|}{ Nutrients (mg/L) } \\
\hline Ammonia as $\mathrm{N}$ & 806 & 357 & - & - & - & - & - & - \\
\hline Ammonia plus organic nitrogen as $\mathrm{N}$ & 603 & 206 & - & - & - & - & - & - \\
\hline Dissolved organic carbon & 817 & 735 & - & - & - & - & - & - \\
\hline Nitrate plus nitrite as $\mathrm{N}^{4}$ & 806 & 578 & 10 & MCL & 15 & 1.9 & 346 & 42.9 \\
\hline Nitrite as $\mathrm{N}$ & 807 & 83 & 1 & MCL & 0 & 0 & 1 & 0.1 \\
\hline Orthophosphate as $\mathrm{P}$ & 804 & 521 & - & - & - & - & - & - \\
\hline Phosphorus, dissolved as P & 454 & 285 & - & - & - & - & - & - \\
\hline $\begin{array}{l}\text { Total nitrogen as } \mathrm{N}(\text { nitrate }+ \text { nitrite }+ \\
\text { ammonia }+ \text { organic } \mathrm{N})\end{array}$ & 201 & 194 & - & - & - & - & - & - \\
\hline All analyzed nutrients & 895 & 880 & various & various & 15 & 1.7 & 346 & 38.7 \\
\hline \multicolumn{9}{|c|}{ Radionuclides (pCi/L) } \\
\hline Gross alpha-particle radioactivity & 84 & 61 & 15 & $\mathrm{MCL}^{5}$ & 4 & 4.8 & 41 & 48.8 \\
\hline Gross beta-particle radioactivity & 86 & 69 & 50 & $\begin{array}{l}\text { Screening } \\
\text { level }^{6}\end{array}$ & 0 & 0 & 39 & 45.3 \\
\hline Radium-226 plus radium-228 & 191 & 176 & 5 & MCL & 36 & 18.8 & 83 & 43.5 \\
\hline Radon-222 & 506 & 497 & 4,000 & $\begin{array}{l}\text { Proposed } \\
\text { AMCL }\end{array}$ & 3 & 0.6 & ${ }^{7} 274$ & ${ }^{7} 54.2$ \\
\hline Radon-222 & 506 & 497 & 300 & $\begin{array}{l}\text { Proposed } \\
\text { MCL }\end{array}$ & 277 & 54.7 & -8 & $-{ }^{8}$ \\
\hline All analyzed radionuclides & 514 & 505 & various & various & 939 & 97.6 & ${ }^{7} 309$ & ${ }^{7} 60.1$ \\
\hline All analyzed radionuclides & 514 & 505 & various & various & ${ }^{10} 308$ & ${ }^{10} 59.9$ & 840 & 87.8 \\
\hline
\end{tabular}


Table 10. Number of detections and comparison of concentrations to human-health benchmarks for water-quality properties, major ions, nutrients, radionuclides, and fecal-indicator microorganisms in public-well samples collected during 1993-2007.—Continued

[No common assessment level was applied to these data. BQ, Benchmark Quotient (ratio of concentration to human-health benchmark); >, greater than; $\leq$ less than or equal to; $\mathrm{CaCO}_{3}$, calcium carbonate; $\mathrm{mg} / \mathrm{L}$, milligrams per liter; -, not available; $\mu \mathrm{S} / \mathrm{cm}$, microsiemens per centimeter; ${ }^{\circ} \mathrm{C}$, degrees Celsius; $\mathrm{MCL}$, Maximum Contaminant Level; N, nitrogen; P, phosphorus; pCi/L, picocuries per liter; AMCL, Alternative Maximum Contaminant Level; col/100 mL; colonies per 100 milliliters; \%, percent]

\begin{tabular}{|c|c|c|c|c|c|c|c|c|}
\hline \multirow[b]{2}{*}{ Contaminant } & \multirow{2}{*}{$\begin{array}{l}\text { Number of } \\
\text { samples }\end{array}$} & \multirow{2}{*}{$\begin{array}{l}\text { Number of } \\
\text { detections }\end{array}$} & \multicolumn{2}{|c|}{ Human-health benchmark ${ }^{1}$} & \multicolumn{2}{|c|}{ Samples with B0>1 } & \multicolumn{2}{|c|}{$\begin{array}{l}\text { Samples with } \\
\text { B0 }>0.1 \text { and } \leq 1\end{array}$} \\
\hline & & & $\begin{array}{l}\text { Value } \\
\text { (in units } \\
\text { shown) }\end{array}$ & Type & Number & Percent & Number & Percent \\
\hline \multicolumn{9}{|c|}{ Fecal-indicator microorganisms } \\
\hline Coliphage, presence/absence & 294 & 7 & - & $-11,12$ & - & - & - & - \\
\hline $\begin{array}{l}\text { Escherichia coli, all methods, in } \\
\quad \mathrm{col} / 100 \mathrm{~mL}\end{array}$ & 330 & 8 & $\begin{array}{l}\text { See total } \\
\text { coliforms }\end{array}$ & $\mathrm{MCL}^{12,13}$ & - & $-{ }^{14}$ & - & -14 \\
\hline $\begin{array}{l}\text { Total coliforms, all methods, in } \\
\text { col/100 mL }\end{array}$ & 343 & 36 & $\begin{array}{l}5 \% \text { of } \\
\text { samples }\end{array}$ & $\mathrm{MCL}^{12,13}$ & - & $-{ }^{14}$ & - & $-{ }^{14}$ \\
\hline $\begin{array}{l}\text { All analyzed fecal-indicator } \\
\text { microorganisms }\end{array}$ & 353 & 42 & various & various & - & $-{ }^{14}$ & - & $-{ }^{14}$ \\
\hline \multicolumn{9}{|c|}{$\begin{array}{l}{ }^{1} \text { Human-health benchmark values were current as of September 2009. MCL values were obtained from U.S. Environmental Protection Agency (2006a) } \\
\text { unless otherwise indicated. }\end{array}$} \\
\hline \multicolumn{9}{|c|}{${ }^{2}$ Alkalinity was calculated from bicarbonate concentrations in 69 samples ( $\underline{\text { Appendix } 6}$ ), and was directly analyzed in 771 samples. } \\
\hline \multicolumn{9}{|c|}{${ }^{3}$ Hardness was calculated from calcium and magnesium concentrations (․ppendix 7$)$} \\
\hline \multicolumn{9}{|c|}{${ }^{4}$ The median nitrite concentration was about 1 percent of the nitrate plus nitrite concentrations in individual samples. } \\
\hline \multicolumn{9}{|c|}{$\begin{array}{l}{ }^{5} \text { The MCL for gross alpha-particle radioactivity excludes alpha-particle radioactivity from radon and uranium (U.S. Environmental Protection Agency, } \\
2000 \text { b). Gross alpha-particle radioactivity values for public-well samples in this study were not corrected for radon or uranium. }\end{array}$} \\
\hline \multicolumn{9}{|c|}{$\begin{array}{l}{ }^{6} \mathrm{MCL}=4 \mathrm{mrem} / \mathrm{yr} \text {, but because gross beta-particle radioactivity was measured in } \mathrm{pCi} / \mathrm{L} \text {, activities were compared to USEPA's screening level for gross beta- } \\
\text { particle radioactivity of } 50 \mathrm{pCi} / \mathrm{L} \text { (U.S. Environmental Protection Agency, 2000b). }\end{array}$} \\
\hline \multicolumn{9}{|c|}{${ }^{7}$ Samples with radon activities greater than the proposed MCL value $(300 \mathrm{pCi} / \mathrm{L})$ but less than or equal to the proposed $\mathrm{AMCL}(4,000 \mathrm{pCi} / \mathrm{L})$ were counted. } \\
\hline \multicolumn{9}{|c|}{${ }^{8}$ Samples with radon activities greater than one-tenth of the proposed MCL value were not counted in this category. } \\
\hline \multicolumn{9}{|c|}{${ }^{9}$ Radon activities were compared to the proposed AMCL of $4,000 \mathrm{pCi} / \mathrm{L}$. } \\
\hline \multicolumn{9}{|c|}{${ }^{10}$ Radon activities were compared to the proposed MCL of $300 \mathrm{pCi} / \mathrm{L}$, which is about one-tenth of the proposed AMCL. } \\
\hline \multicolumn{9}{|c|}{${ }^{11}$ There is no MCL for coliphage. The MCL for viruses is a treatment technique requiring that 99.99 percent of viruses be removed or inactivated. } \\
\hline \multicolumn{9}{|c|}{${ }^{12}$ Additional information about benchmarks for fecal-indicator microorganisms is available from U.S. Environmental Protection Agency (2009b). } \\
\hline \multicolumn{9}{|c|}{$\begin{array}{l}{ }^{13} \text { No more than } 5 \text { percent of samples per month may have total coliforms present. Sampling frequencies vary with the system size. Repeat sampling and } \\
\text { analysis for fecal coliforms or Escherichia coli are required when total coliform bacteria are detected; no fecal coliforms or Escherichia coli bacteria are } \\
\text { allowed. }\end{array}$} \\
\hline${ }^{14}$ Because the MCL for Escherich & total coli & is based & ionthly sa & (see footnote & & & & \\
\hline
\end{tabular}




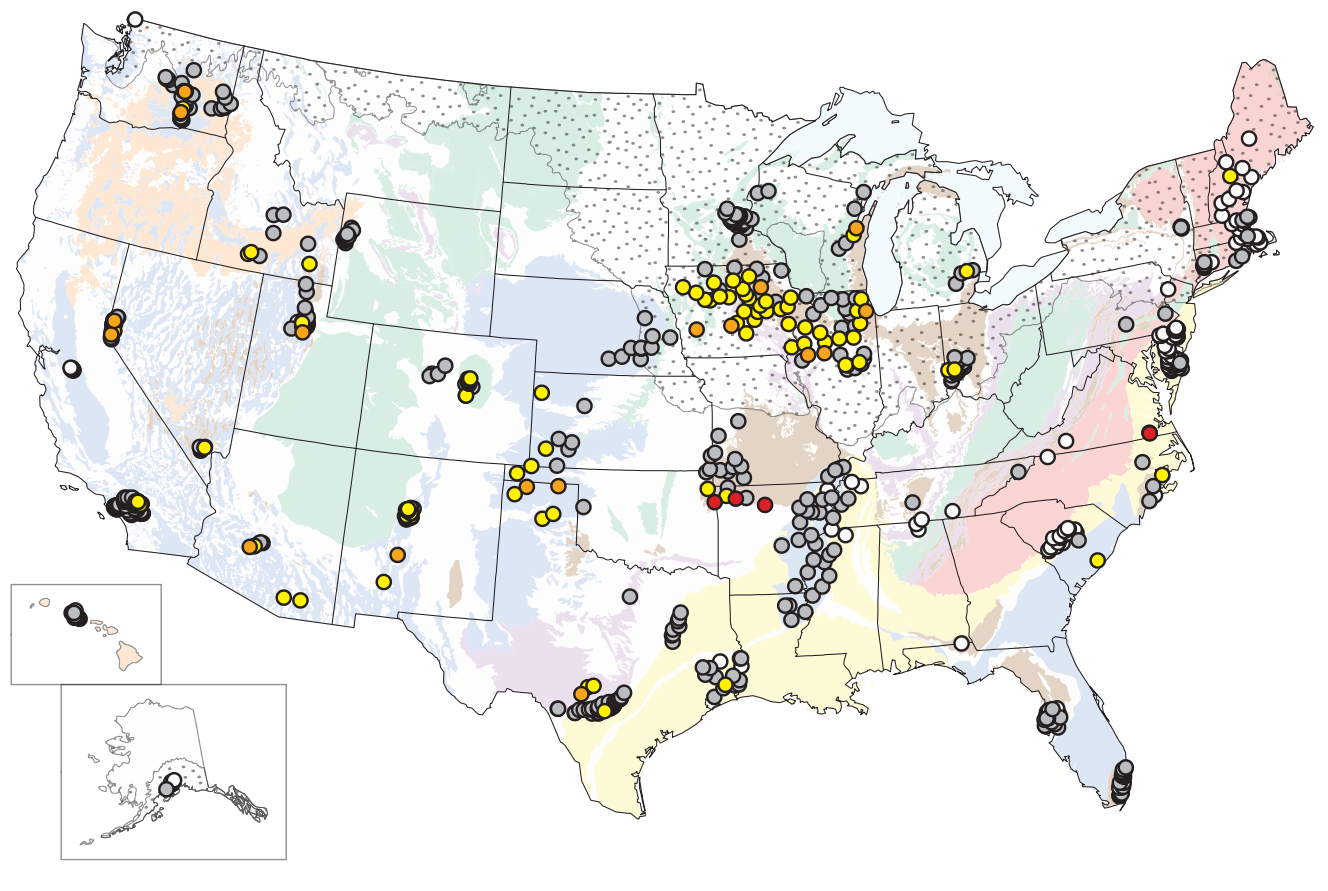

EXPLANATION

Maximum Contaminant Level for fluoride $=4$ milligrams per liter (mg/L); Secondary Maximum Contaminant Level = $2 \mathrm{mg} / \mathrm{L}$; U.S. Centers for Disease Control and Prevention (2001) recommended range for prevention of tooth decay $=0.7$ to $1.2 \mathrm{mg} / \mathrm{L}$

Fluoride concentration (mg/L)

- Greater than $(>) 4$

$0>2$ to 4

$0>0.7$ to 2

- Less than or equal to 0.7

o Not detected
Number of public wells

$$
\begin{gathered}
4 \\
18 \\
97 \\
491 \\
198
\end{gathered}
$$

Figure 20. Geographic distribution of fluoride concentrations in 808 public-well samples collected during 1993-2007. No common assessment level was applied to these data. (See fig. 2A for explanation of principal aquifer rock types.) 


\section{Trace Elements}

Total concentrations of as many as 23 trace elements were analyzed in source-water samples from public wells (Appendix 9). Trace elements include metals and semi-metallic elements that typically occur in natural waters at concentrations less than $1 \mathrm{mg} / \mathrm{L}$ because of constraints imposed by the solubility of minerals and adsorption onto clay, hydrous oxides of iron and manganese, or organic matter (Freeze and Cherry, 1979). Trace elements occur naturally in rocks, and their concentrations, oxidation states, and their speciation and complexation in groundwater are influenced by their abundance in aquifer materials; geochemical conditions, such as redox conditions and $\mathrm{pH}$; concentrations of other dissolved species, such as chloride, sulfate and bicarbonate; and attenuation processes, such as adsorption (Freeze and Cherry, 1979; Hem, 1985). The speciation of metals influences not only the mobility of metals, but also their bioavailability and toxicity. Although total concentrations were analyzed in this study, total dissolved metal concentrations provide much less information about metal transport, reactivity, and bioavailability than do data on metal speciation (Hering and Kraemer, 1998). Human activities, such as mining and industrial discharges, can have a particularly strong influence on the occurrence of many trace elements in water (Hem, 1985). The potential effect of well construction on concentrations of trace elements in public-well samples was not evaluated in this study, but wells constructed of steel and other metals can affect concentrations of some trace elements (Lapham and others, 1995, 1997).

Concentration statistics and detection frequencies for the trace elements analyzed in source-water samples from public wells are shown in Appendix 9. Detection frequencies for trace elements using no common assessment level and a common assessment level of $1 \mu \mathrm{g} / \mathrm{L}$ (except for boron and iron, for which higher common assessment levels were used) are shown in Appendix 10. Trace elements were not analyzed in all samples. Twenty-one trace elements were analyzed in about one-half to two-thirds of the samples, and two trace elements were analyzed in about 90 percent of the samples. Most trace elements were frequently detected in source-water samples, and detection frequencies ranged from about 50 to 100 percent. Antimony, beryllium, cadmium, silver, and thallium were detected in about 20 percent or fewer samples, and were infrequently detected or not detected at a common assessment level of $1 \mu \mathrm{g} / \mathrm{L}$ (Appendix 10). These findings are consistent with a recent national USGS study of water quality from domestic wells (DeSimone, 2009).

MCLs or HBSLs are available for most trace elements (table 11) because of the potential for adverse human-health effects from exposure through drinking water. Trace-element concentrations were less than MCLs or HBSLs in at least 99 percent of the source-water samples except for arsenic, boron, manganese, and strontium, which each were detected at concentrations greater than MCLs or HBSLs in about 3 to 10 percent of samples (table 11). Arsenic is regulated in drinking water under the SDWA (U.S. Environmental Protection Agency, 2006a). Boron and manganese have undergone USEPA's regulatory determination process under the SDWA, but were not selected for regulation in drinking water (U.S. Environmental Protection Agency, 2003a, 2008b), and strontium is listed on USEPA's most recent (third) CCL (U.S. Environmental Protection Agency, 2010a).

Arsenic, boron, manganese, and strontium concentrations greater than human-health benchmarks were detected in samples collected from unconfined and confined aquifers, consistent with the fact that these contaminants originate primarily from aquifer materials, rather than from man made sources at the land surface. Overall, one or more trace elements with concentrations greater than human-health benchmarks were detected in about 16 percent of sourcewater samples from public wells. In addition, one or more trace elements with concentrations less than, but within onetenth of, human-health benchmarks were detected in about 57 percent of samples (table 11).

\section{Arsenic}

Arsenic was detected in about 70 percent of source-water samples from public wells (Appendix 10). Arsenic also was frequently detected in previous studies. For example, arsenic concentrations greater than or equal to $0.5 \mu \mathrm{g} / \mathrm{L}$ were detected in 58 percent of groundwater sources in United States drinking-water supplies in the National Arsenic Occurrence Survey (Frey and Edwards, 1997). Arsenic concentrations were greater than the MCL of $10 \mu \mathrm{g} / \mathrm{L}$ (U.S. Environmental Protection Agency, 2006a) in about 10 percent of source-water samples in this study (table 11). The MCL for arsenic changed from $50 \mu \mathrm{g} / \mathrm{L}$ to $10 \mu \mathrm{g} / \mathrm{L}$ in 2001 , and the new MCL became effective in January 2006 (U.S. Environmental Protection Agency, 2001b). As a result, source-water samples collected prior to January 2006 with arsenic concentrations greater than $10 \mu \mathrm{g} / \mathrm{L}$ (but less than $50 \mu \mathrm{g} / \mathrm{L}$ ) did not represent concentrations greater than the MCL at that time. Numerous aquifers worldwide contain arsenic concentrations greater than $10 \mu \mathrm{g} / \mathrm{L}$ (Nordstrom, 2002). Almost all samples in this study with arsenic concentrations greater than the MCL were associated with unconsolidated sand and gravel aquifers and glacial aquifers, and arsenic concentrations were greatest $(\mathrm{p}<0.05)$ in unconsolidated sand and gravel aquifers (fig. 21A) . 
Table 11. Number of detections and comparison of concentrations to human-health benchmarks for trace elements in public-well samples collected during 1993-2007.

[No common assessment level was applied to these data. $\mu \mathrm{g} / \mathrm{L}$, micrograms per liter; BQ, Benchmark Quotient (ratio of concentration to humanhealth benchmark); >, greater than; $\leq$ less than or equal to; MCL, Maximum Contaminant Level; HBSL, Health-Based Screening Level; -, not available]

\begin{tabular}{|c|c|c|c|c|c|c|c|c|}
\hline \multirow{2}{*}{ Trace element } & \multirow{2}{*}{$\begin{array}{c}\text { Number } \\
\text { of } \\
\text { samples }\end{array}$} & \multirow{2}{*}{$\begin{array}{c}\text { Number } \\
\text { of } \\
\text { detections }\end{array}$} & \multicolumn{2}{|c|}{ Human-health benchmark ${ }^{1}$} & \multicolumn{2}{|c|}{ Samples with B0>1 } & \multicolumn{2}{|c|}{$\begin{array}{l}\text { Samples with } \\
\text { BQ }>0.1 \text { and } \leq 1\end{array}$} \\
\hline & & & $\begin{array}{l}\text { Value } \\
(\mu \mathrm{g} / \mathrm{L})\end{array}$ & Type & Number & Percent & Number & Percent \\
\hline Aluminum & 598 & 299 & - & - & - & - & - & - \\
\hline Antimony & 619 & 105 & 6 & MCL & 1 & 0.2 & 5 & 0.8 \\
\hline Arsenic & 638 & 444 & 10 & MCL & 63 & 9.9 & 206 & 32.3 \\
\hline Barium & 630 & 627 & 2,000 & MCL & 1 & 0.2 & 49 & 7.8 \\
\hline Beryllium & 622 & 37 & 4 & MCL & 0 & 0 & 1 & 0.2 \\
\hline Boron & 501 & 497 & 1,000 & HBSL & 14 & 2.8 & 126 & 25.1 \\
\hline Cadmium & 631 & 109 & 5 & MCL & 0 & 0 & 1 & 0.2 \\
\hline Chromium & 626 & 309 & 100 & MCL & 0 & 0 & 13 & 2.1 \\
\hline Cobalt & 627 & 396 & - & - & - & - & - & - \\
\hline Copper & 625 & 497 & 1,300 & $\mathrm{MCL}^{2}$ & 0 & 0 & 0 & 0 \\
\hline Iron & 809 & 449 & - & - & - & - & - & - \\
\hline Lead & 630 & 348 & 15 & $\mathrm{MCL}^{2}$ & 3 & 0.5 & 70 & 11.1 \\
\hline Lithium & 458 & 448 & - & - & - & - & - & - \\
\hline Manganese & 808 & 543 & 300 & HBSL & 37 & 4.6 & 125 & 15.5 \\
\hline Molybdenum & 628 & 485 & 40 & HBSL & 4 & 0.6 & 131 & 20.9 \\
\hline Nickel & 629 & 444 & 100 & HBSL & 0 & 0 & 7 & 1.1 \\
\hline Selenium & 632 & 299 & 50 & MCL & 1 & 0.2 & 17 & 2.7 \\
\hline Silver & 606 & 4 & 100 & HBSL & 0 & 0 & 0 & 0 \\
\hline Strontium & 503 & 503 & 4,000 & HBSL & 15 & 3.0 & 231 & 45.9 \\
\hline Thallium & 437 & 93 & 2 & MCL & 0 & 0 & 5 & 1.1 \\
\hline Uranium & 650 & 467 & 30 & MCL & 5 & 0.8 & 148 & 22.8 \\
\hline Vanadium & 457 & 404 & - & - & - & - & - & - \\
\hline Zinc & 613 & 561 & 2,000 & HBSL & 1 & 0.2 & 5 & 0.8 \\
\hline $\begin{array}{l}\text { All analyzed } \\
\text { trace elements }\end{array}$ & 810 & 787 & various & various & 133 & 16.4 & 458 & 56.5 \\
\hline
\end{tabular}

\footnotetext{
${ }^{1}$ Human-health benchmark values were current as of September 2009. MCL values were obtained from U.S. Environmental Protection Agency (2006a) and HBSL values were obtained from the HBSL website (Toccalino and others, 2008).

${ }^{2} \mathrm{MCL}$ is a treatment technique. Copper action level $=1,300 \mu \mathrm{g} / \mathrm{L}$ (at tap); lead action level $=15 \mu \mathrm{g} / \mathrm{L}$ (at tap).
} 


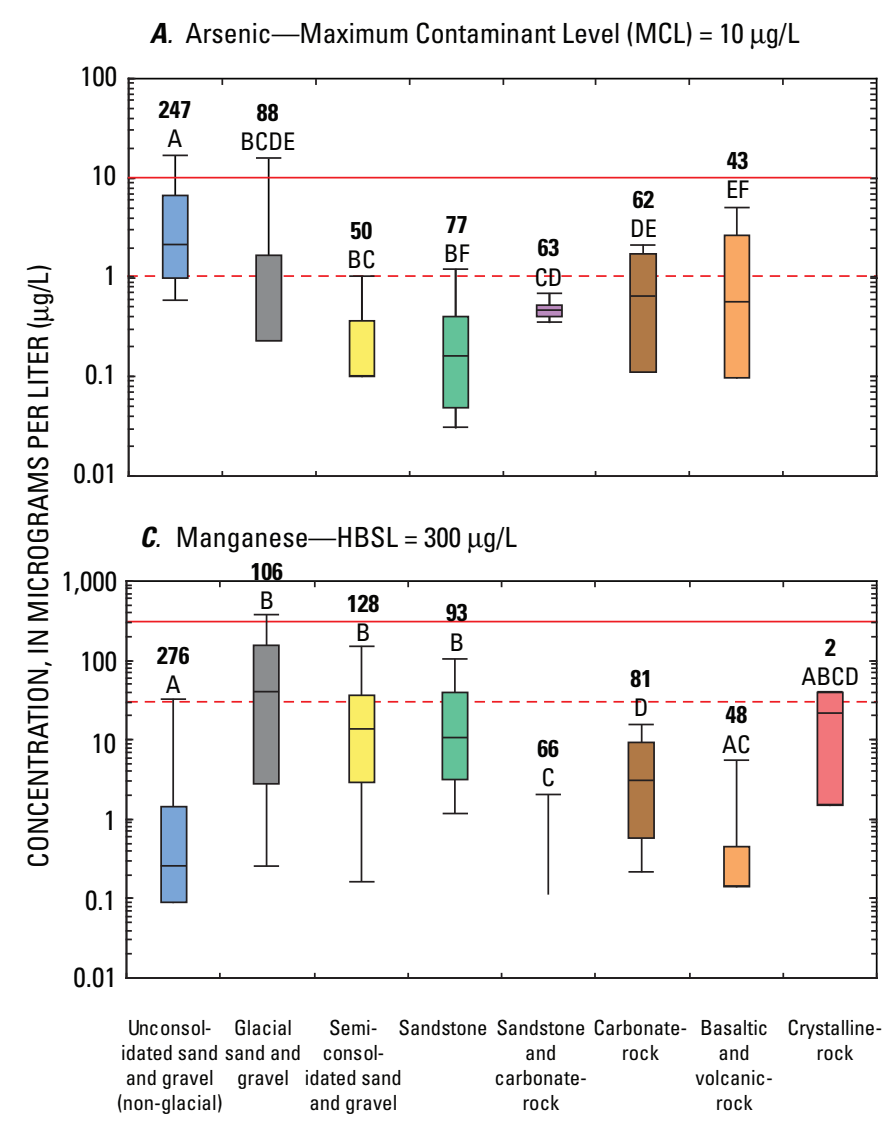

PRINCIPAL AQUIFER ROCK TYPE
B. Boron-Health-Based Screening Level (HBSL) $=1,000 \mu \mathrm{g} / \mathrm{L}$

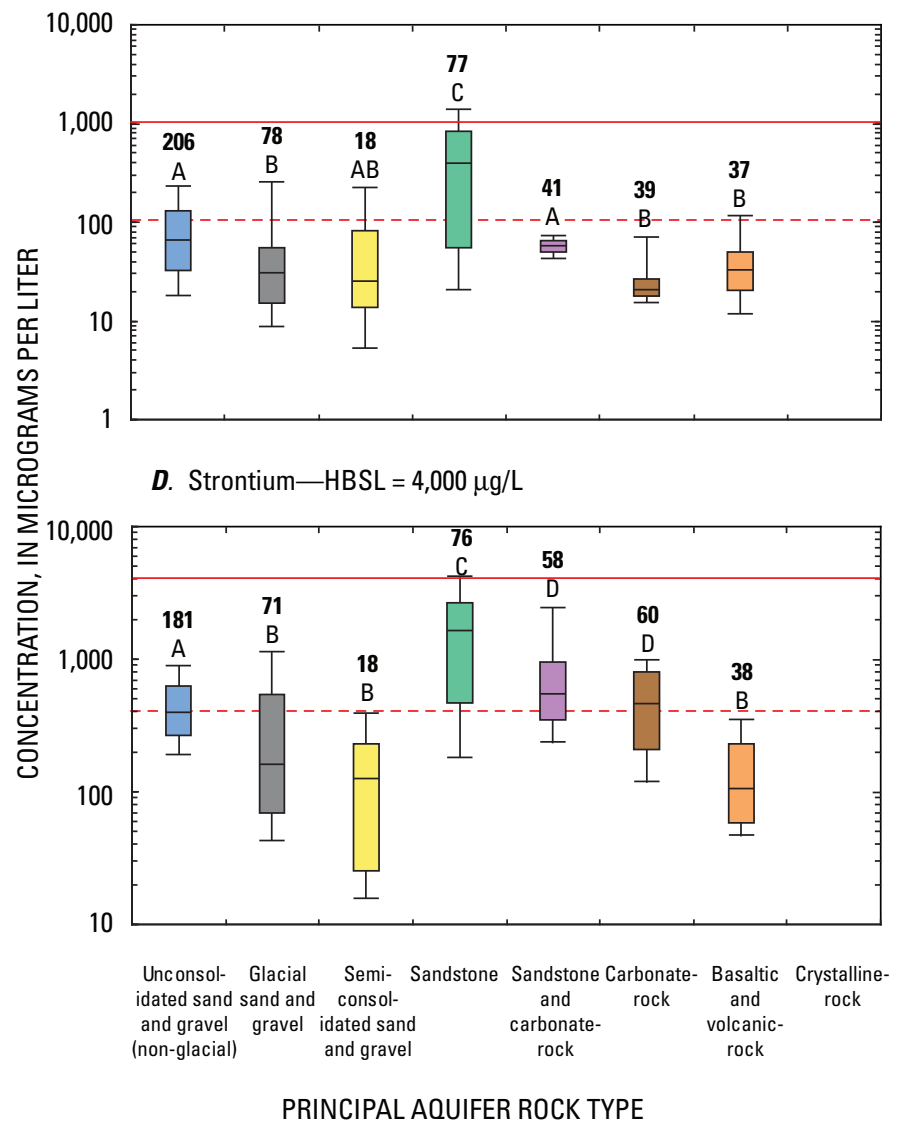

EXPLANATION

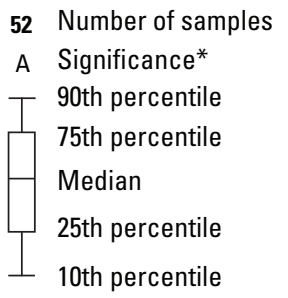

Human-health benchmarks

- MCL or HBSL

- - - One-tenth of MCL or HBSL

*Distributions of groups that share the same letter

symbol are not significantly different at the

95-percent confidence level.

Figure 21. Distributions of $(A)$ arsenic, $(B)$ boron, $(C)$ manganese, and $(D)$ strontium concentrations, by principal aquifer rock type, in public-well samples collected during 1993-2007. No common assessment level was applied to these data.

Although arsenic concentrations greater than the MCL were distributed across the United States in samples from unconfined and confined aquifers, about three-quarters of these samples were from public wells in the western United States (fig. 22). Previous national-scale studies also have reported that arsenic concentrations in groundwater generally were highest in the western United States (Focazio and others, 2000; Welch and others, 2000; Ryker, 2001). Regional-scale studies, however, have reported arsenic concentrations in groundwater greater than $10 \mu \mathrm{g} / \mathrm{L}$ in other areas of the United
States, such as eastern New England (Ayotte and others, 2003). Arsenic concentrations were greater than $10 \mu \mathrm{g} / \mathrm{L}$ in about 8 to 10 percent of the samples in previous national-scale studies (Focazio and others, 2000; Welch and others, 2000), which is consistent with the findings in this study, even though the earlier studies included many more groundwater samples (about 18,850 to 30,000 samples) from multiple types of wells (for example, wells used for observation, industrial purposes, private supply, and public supply). 


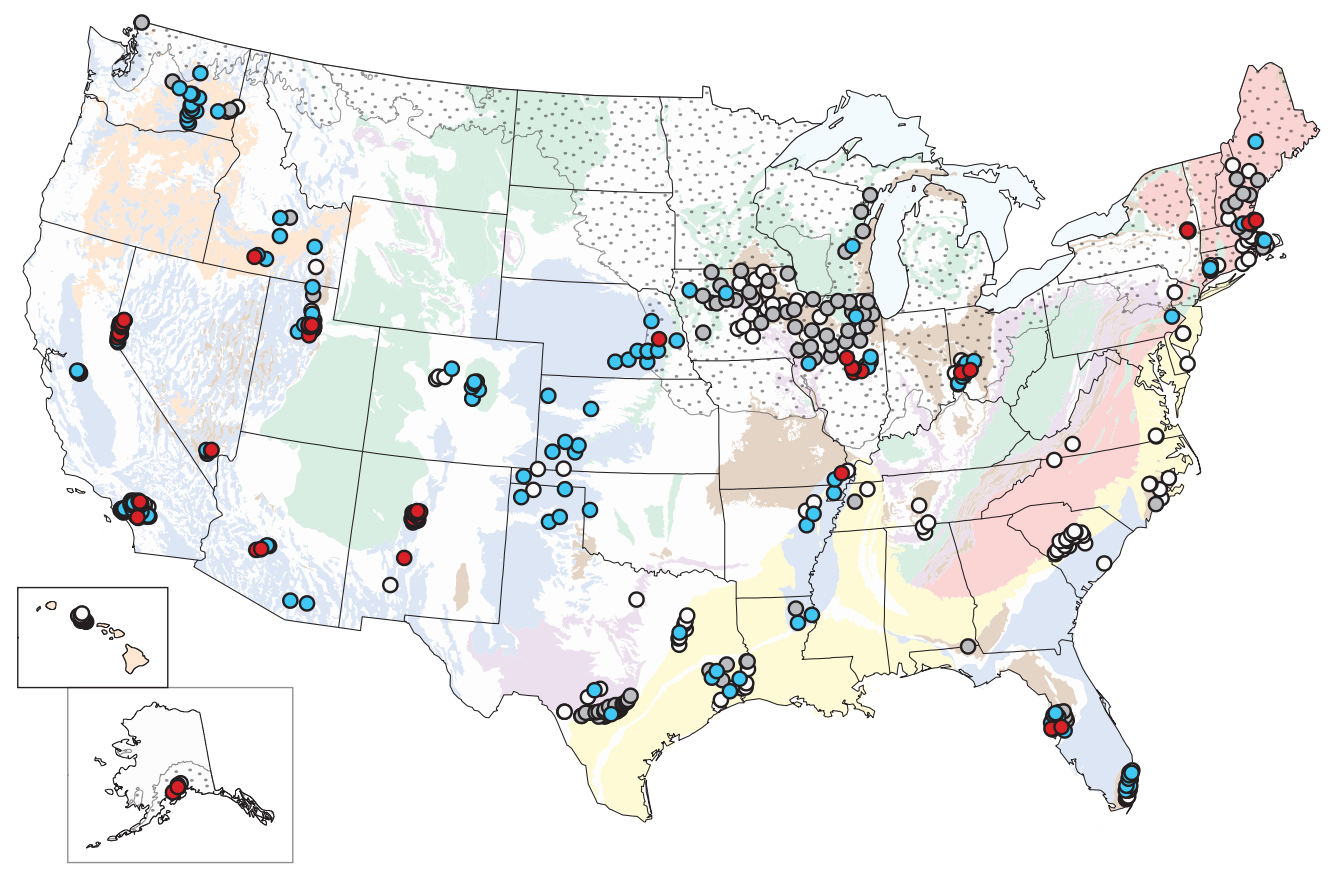

EXPLANATION

Maximum Contaminant Level $(\mathrm{MCL})$ for arsenic $=10$ micrograms per liter $(\mu \mathrm{g} / \mathrm{L})$
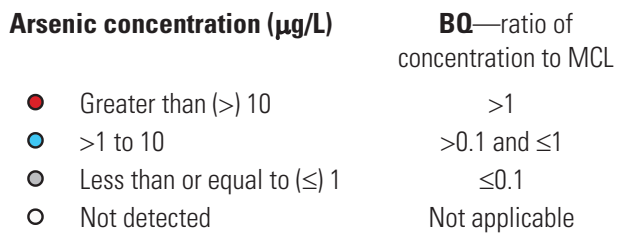

$\begin{gathered}\text { Number of } \\ \text { public wells }\end{gathered}$
63
206
175
194

Figure 22. Geographic distribution of arsenic concentrations and Benchmark Quotients (B0) in 638 public-well samples collected during 1993-2007. No common assessment level was applied to these data. (See fig. $2 A$ for explanation of principal aquifer rock types.)

Arsenic concentrations greater than the MCL were detected in public-well samples from all system sizes, but about one-half of the samples with arsenic concentrations greater than the MCL were collected from large and very large systems (data not shown). Similarly, Frey and Edwards (1997) reported that arsenic concentrations were highest in large groundwater-supplied public water systems serving more than 10,000 people. System size may be related to multiple factors, such as well capacity (pumping rate), groundwater contributing area, usage patterns, and well drilling and maintenance practices. Such factors affect the vulnerability of public wells to anthropogenic contaminants, but the relation between these factors and natural contaminants, such as arsenic, have been shown to be highly dependent on local conditions (Ryker, 2003). Welch and others (2000b) reported that arsenic releases from iron oxide, on which arsenic may be adsorbed, apparently are the most common cause of widespread arsenic concentrations greater than $10 \mu \mathrm{g} / \mathrm{L}$ in groundwater. Additionally, sulfide minerals are a source and a sink for arsenic, and geothermal water with high evaporation rates is associated with arsenic concentrations greater than $10 \mu \mathrm{g} / \mathrm{L}$ in groundwater, particularly in the western United States (Welch and others, 2000). In glacial aquifers in the northern United States, arsenic concentrations greater than $10 \mu \mathrm{g} / \mathrm{L}$ in groundwater were associated with factors such as strongly reducing conditions and old groundwater recharged before 1953 (Thomas, 2007).

In addition to the approximately 10 percent of sourcewater samples with concentrations greater than the MCL, arsenic concentrations approached the $\mathrm{MCL}(0.1<\mathrm{BQ} \leq 1)$ in about 32 percent of the samples (table 11); these samples were widely distributed across the United States (fig. 22). About two-thirds of these samples were from unconsolidated sand and gravel aquifers, although arsenic concentrations were greater than one-tenth of the MCL in some samples from all principal aquifer rock types, except for crystalline-rock aquifers from which arsenic was analyzed in only two samples (fig. 21A). 
Arsenic is a naturally occurring nonmetallic element in rocks, soils, and waters in contact with them (Hem, 1985; Focazio and others, 2000). Anthropogenic sources of arsenic include agricultural pesticide applications, wood preservation, glass production, mining activities, and livestock feed additives (Welch and others, 2000; Nordstrom, 2002). Recognized as a toxic element for centuries, arsenic is still a human-health concern because it can contribute to a wide variety of adverse health effects, including several types of cancers (National Research Council, 2001). Arsenic has been classified as a weakly mobile element in aquatic systems (Fortescue, 1980), and the mobility and solubility of arsenic in groundwater is increased by reducing conditions, high $\mathrm{pH}(>8.5)$, and the presence of oxyanions, such as organic carbon and iron oxides (Welch and others, 2000; Nordstrom, 2002; Kelly and others, 2005). Arsenic concentrations were positively correlated with $\mathrm{pH}$ and TDS in samples from some principal aquifer rock types in this study ( $r h o=0.17$ to 0.57 , $\mathrm{p}<0.05$ ), but the relations between these correlations and arsenic occurrence by principal aquifer rock type (fig. 21A) were not clear in most cases. A broad relation between high arsenic concentrations (greater than $10 \mu \mathrm{g} / \mathrm{L}$ ) and alkaline groundwater $(\mathrm{pH}>8)$ has been noted in eastern New England (Ayotte and others, 2003) and across the United States (Welch and others, 2000). The $\mathrm{pH}$ of groundwater increases with groundwater age and possibly with the presence of calcite in bedrock (Ayotte and others, 2003).

\section{Boron}

Boron was detected in about 99 percent of sourcewater samples from public wells (Appendix 10). Boron concentrations were greater than the HBSL of $1,000 \mu \mathrm{g} / \mathrm{L}$ in about 3 percent of samples (table 11). All of these samples were associated with sandstone aquifers; overall, boron concentrations were highest $(\mathrm{p}<0.05)$ in sandstone aquifers (fig. 21B). All 14 samples with boron concentrations greater than the HBSL were collected from confined aquifers in the Cambrian-Ordovician aquifer system in Iowa and Illinois (data not shown). Boron concentrations in the CambrianOrdovician aquifer system previously have been shown to be elevated, especially in groundwater with high TDS concentrations (Olcott, 1992).

In addition to the approximately 3 percent of sourcewater samples with concentrations greater than the HBSL, boron concentrations approached the $\operatorname{HBSL}(0.1<\mathrm{BQ} \leq 1)$ in about 25 percent of the samples (table 11). These samples were associated with most principal aquifer rock types (fig. 21B) and were therefore widely distributed across the United States.

Boron in groundwater may originate from natural sources, such as leaching of geologic materials and mixing of groundwater (Kendall and others, 2004; Buszka and others,
2007), and boron concentrations were positively correlated with TDS in samples from several principal aquifer rock types ( $r h o=0.54$ to $0.81, \mathrm{p}<0.05$ ). Sources of boron affected by human activities include coal combustion, wastewater effluent, and laundry detergent (Kendall and others, 2004; Buszka and others, 2007). Because the more prevalent boron solute species are anionic or uncharged, boron can be transported in groundwater with little attenuation or adsorption onto other mineral surfaces (Hem, 1985), hence boron is very mobile in aquatic systems (Fortescue, 1980).

\section{Manganese}

Manganese was detected in about 67 percent of source-water samples from public wells (Appendix 10). Manganese concentrations were greater than the HBSL of $300 \mu \mathrm{g} / \mathrm{L}$ in about 5 percent of samples (table 11). Samples with manganese concentrations greater than the HBSL were associated with four principal aquifer rock types, primarily glacial sand and gravel aquifers and unconsolidated sand and gravel aquifers (fig. 21C). In unconsolidated sand and gravel aquifers, all manganese concentrations greater than the HBSL also were greater than the $90^{\text {th }}$ percentile for manganese, and therefore are not shown on the boxplot in figure $21 \mathrm{C}$. Manganese concentrations greater than the HBSL were detected in samples from most principal aquifer rock types in a recent national USGS study of water quality from domestic wells (DeSimone, 2009).

In addition to the approximately 5 percent of sourcewater samples with concentrations greater than the HBSL, manganese concentrations approached the $\operatorname{HBSL}(0.1<\mathrm{BQ} \leq 1)$ in about 16 percent of the samples (table 11). These samples were associated with all principal aquifer rock types except for sandstone and carbonate-rock aquifers (fig. 21C) and were therefore widely distributed across the United States.

Manganese is a metallic element that is a component of many rock types (Hem, 1985). The solubility of manganese in groundwater depends on redox conditions and $\mathrm{pH}$ (Hem, 1985; Hemond and Fechner, 1994). Manganese can precipitate as manganese oxides under aerobic conditions and occurs as dissolved species under reducing conditions (Hem, 1985). In this study, manganese concentrations were negatively correlated with dissolved oxygen ( $r h o=-0.36$ to -0.62 , $\mathrm{p}<0.05$ ), and positively correlated with TDS ( $r h o=0.25$ to $0.39, \mathrm{p}<0.05)$ in samples from several principal aquifer rock types.

\section{Strontium}

Strontium was detected in 100 percent of sourcewater samples from public wells (Appendix 10). Strontium concentrations were greater than the HBSL of $4,000 \mu \mathrm{g} / \mathrm{L}$ in about 3 percent of samples (table 11). About one-half of 
the samples with strontium concentrations greater than the HBSL were associated with confined sandstone aquifers in the Cambrian-Ordovician aquifer system in Illinois, Iowa, and Wisconsin; overall, strontium concentrations were highest $(\mathrm{p}<0.05)$ in sandstone aquifers ( $\underline{\text { fig. } 21 D}$ ). About one-quarter of the samples with strontium concentrations greater than the HBSL were collected from sandstone and carbonate-rock aquifers in the Edwards-Trinity aquifer system in Texas.

In addition to the approximately 3 percent of sourcewater samples with concentrations greater than the HBSL, strontium concentrations approached the HBSL $(0.1<\mathrm{BQ} \leq 1)$ in about 46 percent of the samples (table 11); these samples were associated with all principal aquifer rock types, except for crystalline-rock aquifers in which strontium was not analyzed (fig. 21D).

Strontium, an alkaline-earth metal, is geochemically similar to calcium, and the carbonate and sulfate forms are common in sediments (Hem, 1985). Strontium is classified as a mobile element in aquatic systems (Fortescue, 1980). Strontium concentrations were positively correlated with TDS ( $r h o=0.63$ to $0.82, \mathrm{p}<0.05$ ) in samples from most principal aquifer rock types in this study.

\section{Other Trace Elements}

Six trace elements - aluminum, copper, iron, manganese, silver, and zinc - have SMCLs because of potential aesthetic or nuisance problems (table 8); all except aluminum and iron also have MCLs or HBSLs (table 11). Copper, silver, and zinc concentrations were less than the SMCL in all source-water samples from public wells, and aluminum concentrations were greater than the SMCL range in about 0.3 to 1.5 percent of the samples. Concentrations of iron and manganese each were greater than SMCLs in about 15 percent of samples (table 8).

Iron and manganese can stain plumbing fixtures and laundry with red oxyhydroxide precipitates and black manganese oxides, respectively (Hem, 1985). The chemical behavior of iron and manganese, and their species and solubility in groundwater, depend strongly on the redox potential and $\mathrm{pH}$ of groundwater (Hem, 1985; Pankow, 1991; Hemond and Fechner, 1994). Manganese concentrations were negatively correlated with dissolved oxygen in samples from the various sand and gravel aquifers and in the basaltic aquifers ( $r h o=-0.36$ to $-0.62, \mathrm{p}<0.05$ ), but were not correlated with $\mathrm{pH}$ in most rock types. Manganese concentrations were positively correlated with iron concentrations in samples from all principal aquifer rock types in this study ( $r h o=0.73, \mathrm{p}<0.05)$, likely because the chemical behavior of iron and manganese is similar in groundwater.

In an American Water Works Association (AWWA) survey of 67 public water systems, the most commonly identified issues for inorganic contaminants were iron and manganese, which have historically been problematic for many water utilities (American Water Works Association
Inorganics Committee and Inorganic Contaminants Research Committee, 2009) because their presence at concentrations greater than their SMCLs can have significant economic implications (U.S. Environmental Protection Agency, 1992c). Increasing attention has been given to these contaminants as the water industry expands the use of poor-quality source waters to meet increasing demands (American Water Works Association Inorganics Committee and Inorganic Contaminants Research Committee, 2009). Conventional water treatment technologies can effectively remove iron and manganese (U.S. Environmental Protection Agency, 1992c), and 45 percent of the groundwater-supplied public water systems in the United States treat groundwater to remove or sequester iron or manganese (U.S. Environmental Protection Agency, 2002a). Information about which treatment technologies were used at most of the sampled systems in this study, however, was not available.

\section{Nutrients and Dissolved Organic Carbon}

Source-water samples from public wells were analyzed for as many as seven nitrogen and phosphorus species, and dissolved organic carbon (DOC) (Appendix 8). Nitrogen and phosphorus species in groundwater originate from various natural sources, including precipitation, degradation of organic matter, and aquifer materials (Freeze and Cherry, 1979; Hem, 1985). Human activities, such as agricultural and urban uses of fertilizer, agricultural uses of manure, and combustion of fossil fuels, contribute to nitrogen and phosphorus in groundwater (Nolan and others, 1997; U.S. Geological Survey, 1999). Nitrogen speciation and mobility in groundwater are mediated by microorganisms and redox conditions (Freeze and Cherry, 1979; Madigan and others, 1997). In the presence of sufficient nutrients and dissolved oxygen in groundwater, microorganisms will ultimately convert many organic contaminants to carbon dioxide, water, and microbial cell mass, but inadequate concentrations of nutrients often limit biodegradation processes (Madigan and others, 1997).

Nitrate is the primary nitrogen species detected in groundwater (U.S. Geological Survey, 1999), and nitrate was detected in about 72 percent of the source-water samples from public wells (Appendix 8). About two-thirds of the samples in which nitrate was detected were from unconfined aquifers and one-third of the samples were from confined aquifers (data not shown). Shallow groundwater (such as from unconfined aquifers), because of its proximity to the land surface, is more vulnerable to contamination from human activities, such as fertilizer application, than deep groundwater (U.S. Geological Survey, 1999). Nitrate concentrations were positively correlated with dissolved oxygen in samples from most principal aquifer rock types ( $r h o=0.27$ to $0.65, \mathrm{p}<0.05$ ), which is consistent with nitrate occurrence under the oxidizing conditions commonly observed in unconfined aquifers. 
Because nitrate is water soluble and mobile, it tends to leach through soils with infiltrating water (Nolan and Hitt, 2006). Nitrate can persist in groundwater for decades and accumulate as more nitrogen is applied to the land surface each year (Nolan and others, 1997). In this report, nitrate refers to the sum of nitrate plus nitrite, as reported by the USGS NWQL. Nitrite contributions to nitrate plus nitrite were negligible; the median nitrite concentration was about 1 percent of the nitrate plus nitrite concentrations in individual samples. Nitrate and nitrite are the only nutrients for which human-health benchmarks have been established (table 10). Infants who ingest water with concentrations of nitrate or nitrite greater than the MCL may develop methemoglobinemia (blue-baby syndrome and shortness of breath) (U.S.

Environmental Protection Agency, 2009b).

Nitrate concentrations were greater than the MCL of $10 \mathrm{mg} / \mathrm{L}$ as nitrogen in about 2 percent of the source-water samples from public wells (table 10). Similarly, USEPA estimated that 1.2 percent of public wells contain nitrate at concentrations greater than the MCL in finished water (U.S. Environmental Protection Agency, 1990). In this study, all except for two of the 15 samples with nitrate concentrations greater than the MCL were collected from public wells that withdraw water from unconsolidated sand and gravel aquifers in the western United States, specifically in California, Arizona, and Washington (fig. 23). This finding is consistent with a review of nitrate in groundwater in the United States which showed that most areas in the United States with nitrate concentrations greater than the MCL were west of the Missouri River, where irrigation is a necessity (Spalding and Exner, 1993).

All 15 samples with nitrate concentrations greater than the MCL were collected from public wells that withdraw water from unconfined aquifers, and primarily were associated with unconsolidated sand and gravel aquifers, which is one of the principal aquifer rock types with the highest $(\mathrm{p}<0.05)$ nitrate concentrations (figs. $24 A$ and $\underline{B}$ ).

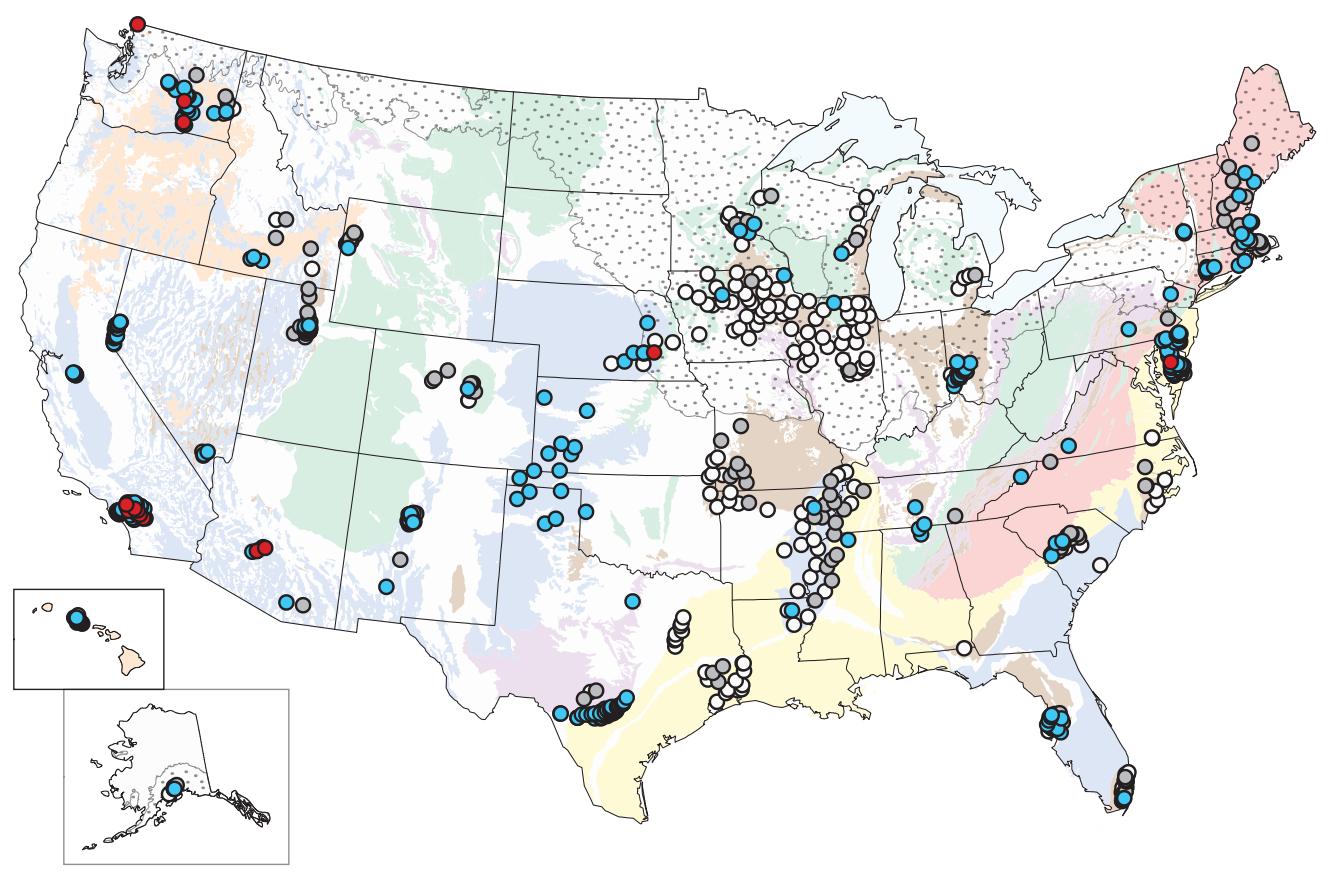

EXPLANATION

Maximum Contaminant Level (MCL) for nitrate $=10$ milligrams per liter as nitrogen (mg/L as N)

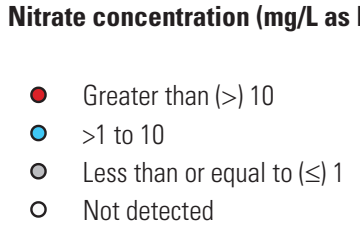
806 public-well samples collected during 1993-2007. No common assessment level was applied to these data. (See fig. $2 A$ for explanation of principal aquifer rock types.) 


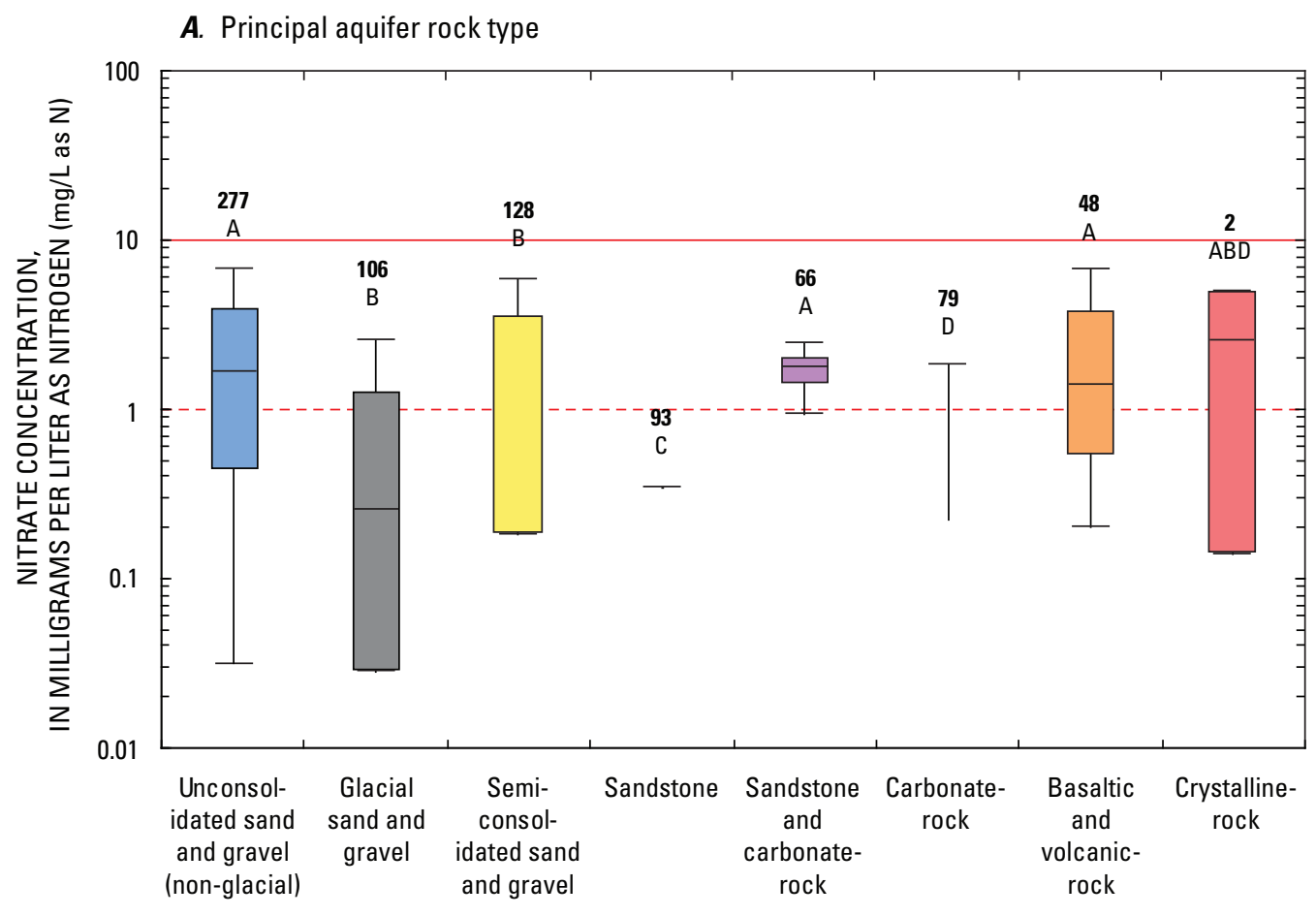

PRINCIPAL AQUIFER ROCK TYPE

B. Aquifer type

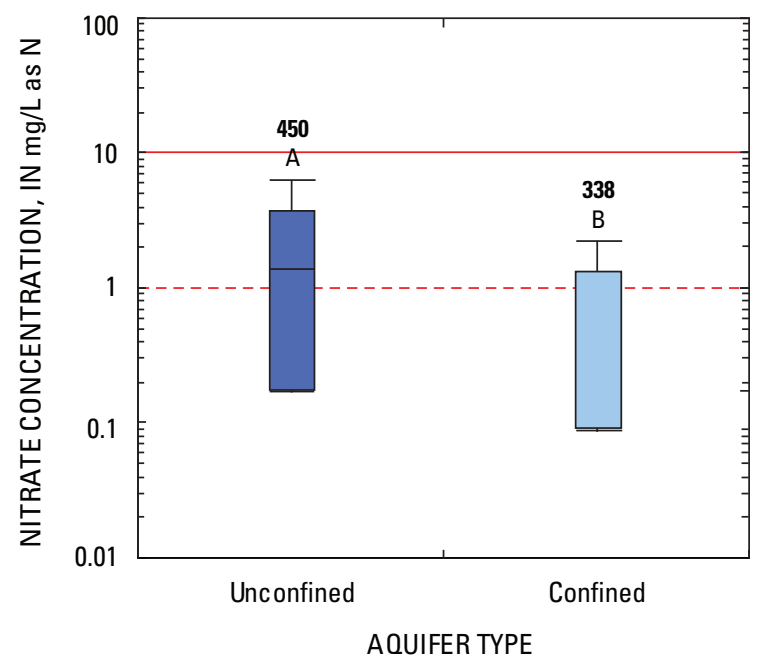

C. Land use

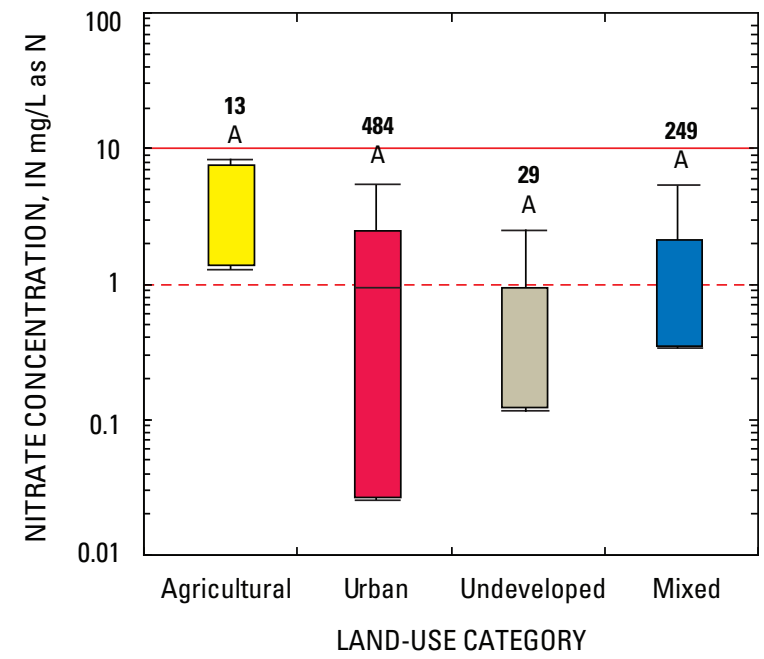

\section{EXPLANATION}

52 Number of samples

A Significance*

T 90th percentile

7 75th percentile

Median

25th percentile

$\perp$ 10th percentile
Human-health benchmark

- Maximum Contaminant Level $(\mathrm{MCL})=10 \mathrm{mg} / \mathrm{L}$ as N

- - - One-tenth of MCL

*Distributions of groups that share the same letter symbol are not significantly different at the 95-percent confidence level.

Figure 24. Distributions of nitrate concentrations by $(A)$ principal aquifer rock type, $(B)$ aquifer type, and $(C)$ land use in public-well samples collected during 1993-2007. No common assessment level was applied to these data. 
This result is consistent with previous studies that indicate that rock types with high effective porosities (such as sand and gravel aquifers or rocks with high interconnected porosity or solution channels, such as karst features, that can readily transmit water and contaminants to groundwater) are most vulnerable to nitrate contamination (Mueller and others, 1995; Nolan and Hitt, 2006; Lindsey and others, 2009). Nitrate concentrations were significantly greater in samples from unconfined aquifers than from confined aquifers; the median nitrate concentration in unconfined and confined aquifers was 1.4 and $0.09 \mathrm{mg} / \mathrm{L}$ as $\mathrm{N}$, respectively (fig. 24B). This finding is consistent with previous studies that show that nitrate concentrations decrease with depth (Spalding and Exner, 1993), and that nitrate concentrations were rarely greater than the MCL in samples from confined aquifers from any well type (Lindsey and others, 2009).

In a recent national study of water quality from domestic wells, nitrate concentrations were greater than the MCL in 4.4 percent of domestic-well samples (DeSimone, 2009), about twice the percentage of samples as in this study (1.9 percent of public-well samples). Nitrate concentrations in domestic-well samples previously have been detected at greater concentrations than in public-well samples (Nolan and others, 1997; Lindsey and others, 2009), partly because public wells tend to be screened in deeper aquifers than domestic wells, and nitrate contamination is less likely to occur in deep groundwater (Mueller and others, 1995). In this study, nitrate concentrations were lowest $(\mathrm{p}<0.05)$ in samples from sandstone aquifers (fig. 24A), and most samples from this rock type were collected from deep confined aquifers (figs. 4 and 7). Nitrate concentrations in all public-well samples in the southern United States also were less than the MCL (fig. 23), consistent with previous findings reported in deep confined aquifers in Mississippi, Louisiana, Arkansas, Missouri, Tennessee, and Kentucky (Kleiss and others, 2000). Sandstone aquifers in Iowa and Illinois (fig. 23) are part of the corn-belt states where tile drainage, in, part, has kept nitrate concentrations in groundwater less than the MCL (Spalding and Exner, 1993). Several factors explain why nitrate concentrations tend to decrease with depth. Reducing or low-oxygen conditions at depth in some aquifers do not favor nitrate formation or accumulation. Deep groundwater also is older and can pre-date recent periods of increased fertilizer use in younger, shallow groundwater. Lastly, groundwater at depth can be protected by intervening, less permeable geologic units that can impede the downward migration of nitrate (Nolan and others, 1997; Nolan and Hitt, 2006).

In addition to the 1.9 percent of source-water samples with concentrations greater than the MCL, nitrate concentrations approached the MCL $(0.1<\mathrm{BQ} \leq 1)$ in 42.9 percent of the samples (table 10). These samples were associated with all principal aquifer rock types (fig. 24A), and were widely distributed across the United States (fig. 23).
Nitrate concentrations greater than $1 \mathrm{mg} / \mathrm{L}$ as nitrogen $(\mathrm{BQ}>0.1)$ are considered indicative of human influence in many parts of the United States (Nolan and Hitt, 2003). Human factors shown to be associated with the highest nitrate concentrations in groundwater include high nitrogen application rates and irrigation, such as would be associated with agricultural land-use areas (Nolan and Hitt, 2006). In this study, distributions of nitrate concentrations did not vary significantly by land use ( $\mathrm{p}>0.05)$, but this probably is because (1) few public-well samples were collected in agricultural and undeveloped areas (fig. 24C), and (2) this study did not focus on shallow groundwater resources that are more vulnerable to nitrate contamination.

Ammonia is a reduced form of nitrogen that tends to be less common than nitrate in groundwater (U.S. Geological Survey, 1999). Ammonia was detected in about 44 percent of the source-water samples from public wells, with a median concentration of $0.01 \mathrm{mg} / \mathrm{L}$ as nitrogen (Appendix 8); all concentrations were less than the USEPA taste threshold of $30 \mathrm{mg} / \mathrm{L}$ (table 8). Ammonia may be removed from groundwater by nitrification (ammonia oxidation to nitrate) when dissolved oxygen is present and by adsorption to aquifer material (Freeze and Cherry, 1979). In this study, ammonia concentrations were negatively correlated with dissolved oxygen in samples from most principal aquifer rock types (rho $=-0.23$ to $-0.74, \mathrm{p}<0.05$ ), which is consistent with ammonia occurring under reducing conditions. The occurrence of nitrate and ammonia were negatively correlated in samples from most principal aquifer rock types ( $r h o=-0.40$ to -0.72 , $\mathrm{p}<0.05$ ) because these nitrogen species occur under different redox conditions. Nitrate concentrations were greatest $(\mathrm{p}<0.05)$ when ammonia was not detected, and decreased with increasing ammonia concentrations (fig. 25).

Phosphates are the most common forms of phosphorus in groundwater, but phosphates dissolve less readily than nitrate, and are not as mobile in groundwater because they tend to attach to soil and aquifer particles. Most dissolved phosphates typically are orthophosphates, a readily bioavailable form of phosphorus (U.S. Geological Survey, 1999). Orthophosphate was detected in about 65 percent of source-water samples from public wells, with a median concentration of $0.01 \mathrm{mg} / \mathrm{L}$ as phosphorus (Appendix 8).

DOC is composed of humic substances (fulvic and humic acids), hydrophilic organic acids, and various organic compounds, including amino acids and simple sugars (Macalady and Ranville, 1998). Sources of DOC include natural organic matter, waste disposal, and leachate from landfills (Hem, 1985). DOC plays a key role in the transport and transformation of metals (Macalady and Ranville, 1998), and organic ligands can increase and decrease metal adsorption (Hering and Kraemer, 1998). The presence of a complexing ligand can alter how much total metal dissolves because the ligand can affect the speciation of a 


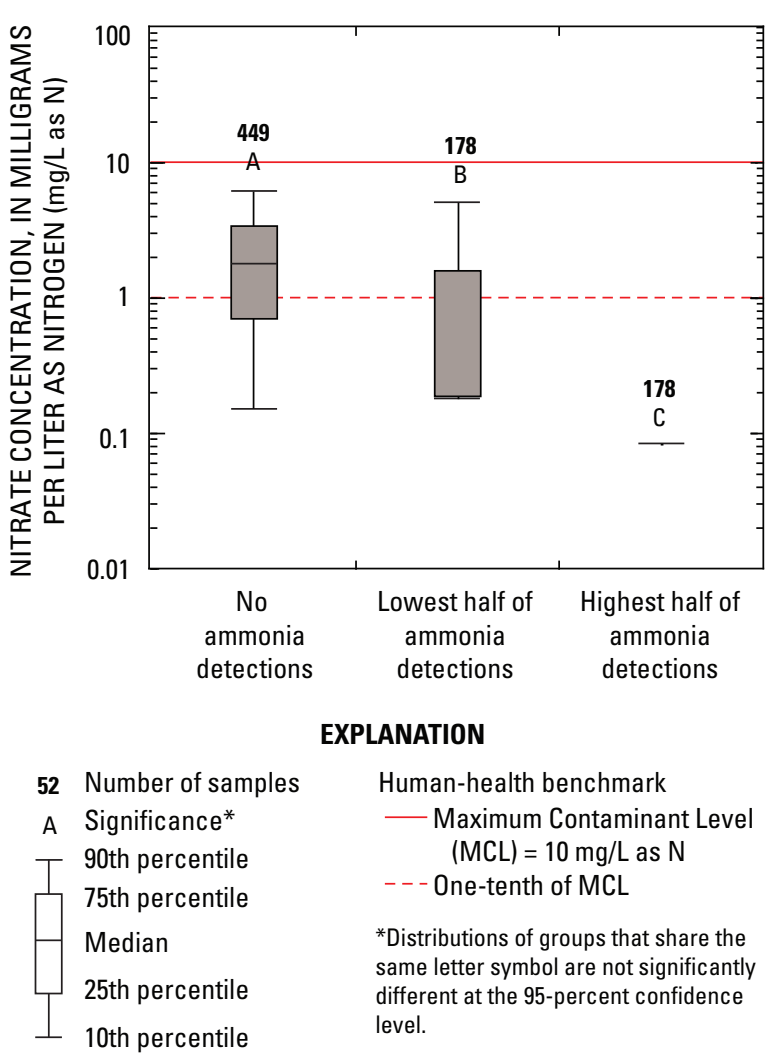

Figure 25. Distributions of nitrate concentrations in relation to increasing ammonia concentrations in publicwell samples collected during 1993-2007. No common assessment level was applied to these data.

metal ion in solution (Pankow, 1991). DOC also contributes to biogeochemical redox processes by shuttling electrons from donors to acceptors through redox-active groups, such as complexed metals and quinone moieties (Nurmi and Tratnyek, 2002). During water treatment, DOC can react with disinfectants, such as chlorine, to form disinfection by-products (DBPs), such as trihalomethanes (THMs) (Richardson and others, 2002), some of which are likely to be carcinogenic to humans (U.S. Environmental Protection Agency, 2006a).

DOC was detected in 90 percent of the source-water samples from public wells, and the median concentration was $0.4 \mathrm{mg} / \mathrm{L}$ (Appendix 8). DOC was positively correlated with TDS in samples from most principal aquifer rock types ( $r h o=0.13$ to $0.62, \mathrm{p}<0.05$ ), and was negatively correlated with dissolved oxygen in one-half of the principal aquifer rock types ( $r h o=-0.18$ to $-0.60, \mathrm{p}<0.05$ ), perhaps because microorganisms in groundwater may assimilate some DOC and consume dissolved oxygen in the process (Bitton, 1994).

\section{Radionuclides}

Source-water samples from public wells were analyzed for as many as four radionuclides (Appendix 8). Radionuclides were not analyzed in all samples. Radon (radon-222) was analyzed in 54 percent of the samples, and the other radionuclides (radium-226 plus radium-228, and gross alphaand beta-particle radioactivities) were analyzed in about 10 to 20 percent of the samples. When analyzed, however, radionuclides commonly were detected, and detection frequencies ranged from about 73 to 98 percent (Appendix 8).

Radionuclides occur naturally in most rocks and soils (Zapecza and Szabo, 1986), and anthropogenic sources include nuclear facilities and power plants, and institutional and industrial sources, such as hospitals and laboratories (U.S. Environmental Protection Agency, 2000b). Radionuclides are formed primarily by the radioactive decay of their parent elements, which occurs by the emission of an alpha particle (a nucleus of a helium atom) or a beta particle (electron). The geochemical behavior of parent and daughter elements in groundwater may differ, but the parent tends to govern the occurrence and distribution of the daughter element (Zapecza and Szabo, 1986). Geologic setting strongly influences the occurrence of natural radionuclides in drinking water (Hess and others, 1985). The radionuclides analyzed in this study are some of the most common radionuclides in groundwater. Radon and radium-226 form from the decay of uranium-238, and both emit alpha particles. Radium-228 forms from the decay of thorium-232 and emits beta particles. All radionuclide measurements in this study were reported in activity units $(\mathrm{pCi} / \mathrm{L})$. One $\mathrm{pCi} / \mathrm{L}$ is equal to 0.037 disintegrations of the radionuclide per second per liter of fluid (Zapecza and Szabo, 1986).

\section{Radon}

Radon is a soluble inert gas in groundwater (Ayotte and others, 2007) with a half-life of about 3.8 days (Zapecza and Szabo, 1986). Radon activities in groundwater can be affected by the distribution of uranium-bearing rocks, the physical characteristics of aquifers, and geochemical conditions that affect uranium-238 and radium-226 from which radon originates. Radon activities in groundwater can be many orders of magnitude greater than the activities of its parent source, uranium-238 (Ayotte and others, 2007). In this study, radon activities were positively correlated with uranium concentrations in samples from most principal aquifer rock types ( $r h o=0.30$ to $0.75, \mathrm{p}<0.05$ ), potentially indicating uranium-bearing rocks as a source of radon. Uranium was measured in concentration units $(\mu \mathrm{g} / \mathrm{L})$ and not in activity units, which is consistent with the concentration-based MCL for uranium. 
USEPA classifies all radionuclides analyzed in this study as human carcinogens (U.S. Environmental Protection Agency, 2006a), but of the radioisotopes that contribute to natural radiation, radon has the largest potential risk to human health (National Research Council, 1999b). Radon contributes to lung-cancer deaths through exposure to radon and its decay products in indoor air. Because radon is a gas, many uses of water, such as showering, readily release radon from water into indoor air. Radon in water typically adds only a small increment to the indoor air concentration, but ingestion of radon in drinking water may contribute to adverse effects in the gastrointestinal tract and other organs (National Research Council, 1999b).

USEPA has proposed an MCL of $300 \mathrm{pCi} / \mathrm{L}$ and an AMCL of 4,000 pCi/L for public water systems (U.S.

Environmental Protection Agency, 2006a). Some states also have established their own standards or guidelines for radon in drinking water, including New Hampshire $(2,000 \mathrm{pCi} / \mathrm{L})$, Maine (4,000 pCi/L), Connecticut (5,000 pCi/L), and Massachusetts $(10,000 \mathrm{pCi} / \mathrm{L})$ (New Hampshire Department of Environmental Services, 2008; Maine Center for Disease Control and Prevention, 2006; Connecticut Department of
Public Health, 2005; Commonwealth of Massachusetts, 2009). States may set radon guidelines higher than USEPA's proposed MCL or AMCL because USEPA's proposed benchmarks for radon are not final, and are therefore not yet legally enforceable. Under the SDWA, individual states may set and enforce drinking-water standards that are more stringent than USEPA's national standards (U.S. Code, 1996).

In this study, radon activities were greater than the proposed AMCL of 4,000 $\mathrm{pCi} / \mathrm{L}$ in less than 1 percent of source-water samples from public wells (three samples), but were greater than the proposed MCL of $300 \mathrm{pCi} / \mathrm{L}$ in about 55 percent of samples (table 10). Public wells yielding water with radon activities greater than $300 \mathrm{pCi} / \mathrm{L}$ were geographically distributed across the United States and included wells that withdraw water from every principal aquifer rock type (figs. 26 and 27). Samples with radon activities greater than $30 \mathrm{pCi} / \mathrm{L}$ (greater than one-tenth of the proposed MCL) were not counted in any analyses in this study because, as discussed above, standards or guidelines for radon adopted by several states tend to be greater than $300 \mathrm{pCi} / \mathrm{L}$, making it unreasonable to use one-tenth of the proposed $\mathrm{MCL}$ (30 pCi/L).

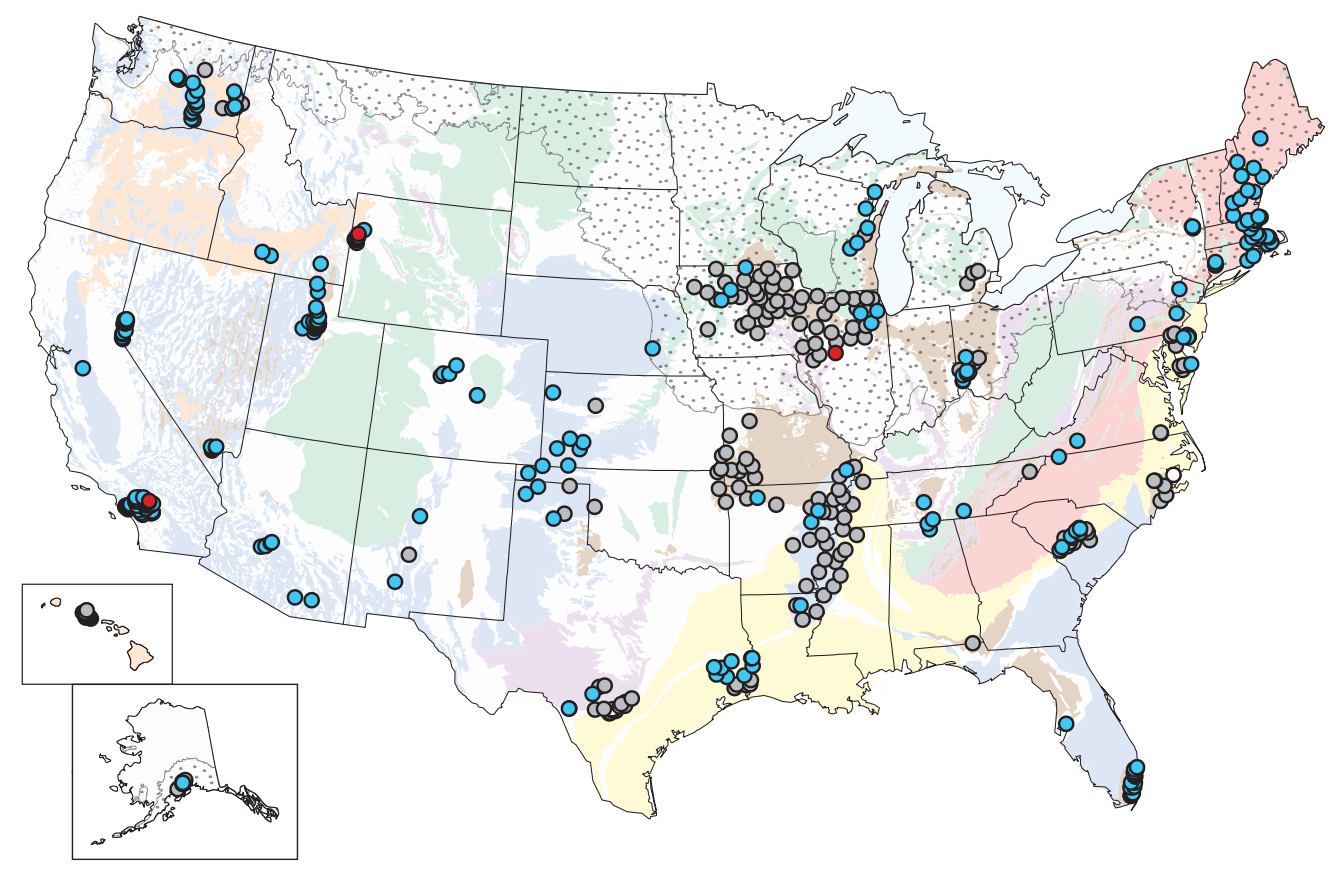

EXPLANATION

Proposed Maximum Contaminant Level $(\mathrm{MCL})$ for radon $=300$ picocuries per liter (pCi/L); proposed Alternative MCL for radon $=4,000 \mathrm{pCi} / \mathrm{L}$

$\begin{array}{clc}\text { Radon activities (pCi/L) } & \text { Number of public wells } \\ \circ & \text { Greater than }(>) \text { 4,000 } & 3 \\ 0 & >300 \text { to } 4,000 & 274 \\ 0 & \text { Less than or equal to } 300 & 220 \\ 0 & \text { Not detected } & 9\end{array}$

Figure 26. Geographic distribution of radon activities, and activities in relation to proposed Maximum Contaminant Levels, in 506 public-well samples collected during 1993-2007. No common assessment level was applied to these data. (See fig. $2 A$ for explanation of principal aquifer rock types.) 


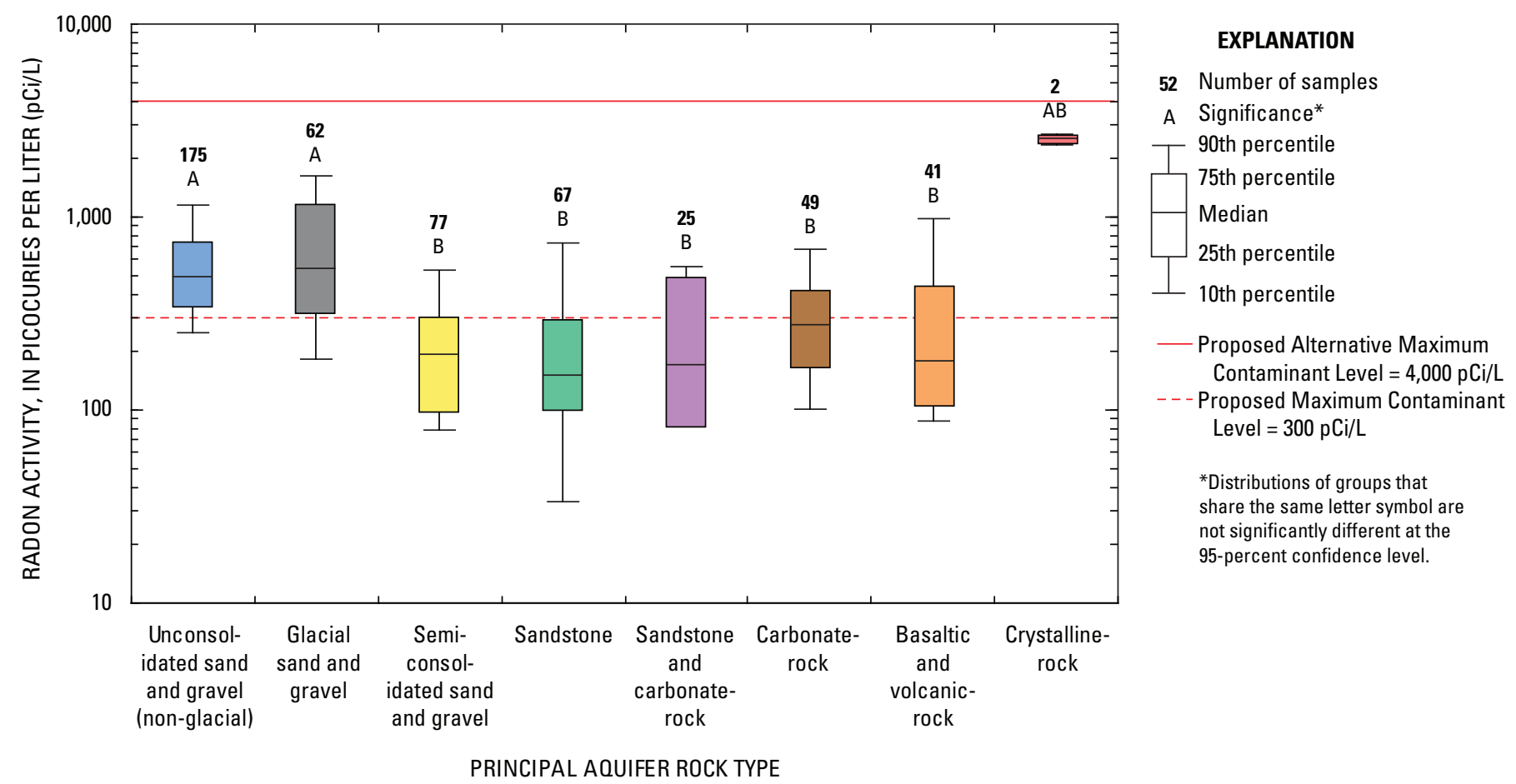

Figure 27. Distributions of radon activities, by principal aquifer rock type, in public-well samples collected during 1993-2007. No common assessment level was applied to these data.

Radon activities were greater than $300 \mathrm{pCi} / \mathrm{L}$ in publicwell samples collected from unconfined and confined aquifers, and from all system sizes, consistent with the fact that radon originates primarily from aquifer materials, rather than from man-made sources at the land surface. With the exception of crystalline-rock aquifers, from which there were only two samples, radon activities were greatest $(\mathrm{p}<0.05)$ in samples from unconsolidated sand and gravel and glacial aquifers (fig. 27). Radon activities generally were lowest in public wells in the central United States and among a few smaller sampled areas, such as eastern North Carolina, where radon either was not detected or activities were less than $300 \mathrm{pCi} / \mathrm{L}$ (fig. 26); in these areas, samples primarily were collected from sandstone and (or) carbonate-rock, and semi-consolidated sand and gravel aquifers (fig. 27).

Several previous studies have reported high radon activities in samples from crystalline-rock aquifers, particularly in the northeastern United States. For example, Ayotte and others (2007) calculated a median radon activity of about $2,100 \mathrm{pCi} / \mathrm{L}$ in samples from crystalline aquifers in New York and New England, and DeSimone (2009) calculated a median radon activity of about $2,300 \mathrm{pCi} / \mathrm{L}$ in samples from crystalline-rock aquifers, primarily in the northeastern United States. In this study, radon was analyzed in only two samples from crystalline-rock aquifers, so substantive comparisons to previous studies could not be made, but radon activities were about 2,500 pCi/L in each of those two samples (fig. 27).
Previous investigations have examined the occurrence of radon in public water supplies in the United States (Horton, 1983; Hess and others, 1985; Longtin, 1988; National Research Council, 1999b). One study (Hess and others, 1985) examined 9,000 measurements of radon in groundwater and surface water from national and state surveys; data were compiled for all but 10 states by geologic provinces. Radon activities from all sources were highest in the New England and the Appalachian Highland-Piedmont provinces (Hess and others, 1985). In this study, radon activities generally were highest in the northeastern and western United States (fig. 26). Hess and others (1985) also reported that radon activities were highest for water utilities that serve small populations. In this study, however, radon activities did not vary significantly among most system sizes ( $\mathrm{p}>0.05)$, but were significantly lower in samples collected from small systems than from large and very large systems (fig. 28). This difference may be a result of the fact that small systems were sampled less frequently in the study by Hess and others (1985), whereas in this study, small systems were not greatly under-represented as compared to other system sizes sampled for radon (fig. 28), and radon was analyzed in samples from small systems in all principal aquifer rock types across the United States. Longtin (1988) also examined radon activities as a function of system size, but about 93 percent of 990 groundwater-supplied public water systems were very small or small, preventing substantive comparisons to radon activities in samples from larger system sizes. 


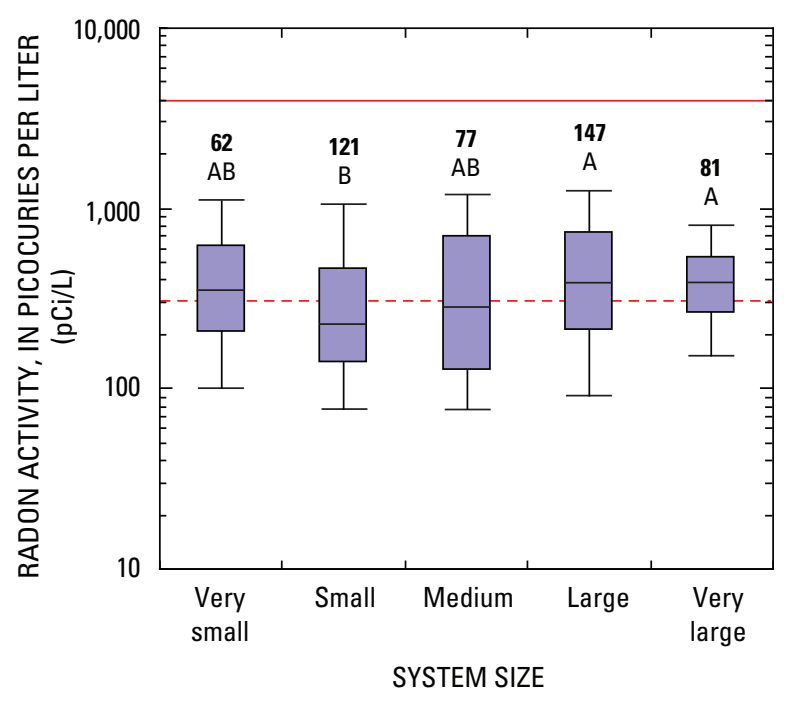

EXPLANATION

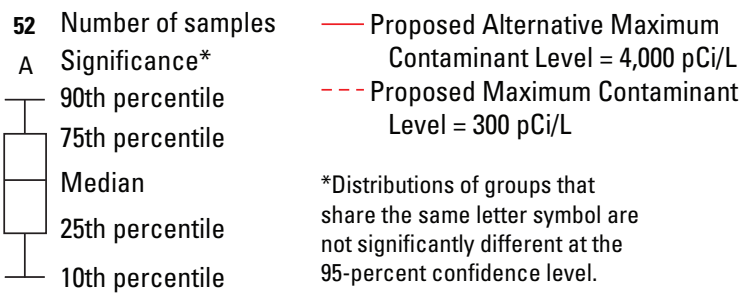

Figure 28. Distributions of radon activities, by system size, in public-well samples collected during 1993-2007. No common assessment level was applied to these data.

USEPA also has national databases for radioactivity in public water supplies (Horton, 1983; Longtin, 1988). Beginning in November 1980, USEPA sampled more than 2,500 groundwater-supplied public water systems in 35 states (Horton, 1983). One finished drinking-water sample was collected per water system that served more than 1,000 people; composite samples were collected instead of individual well samples. The systems sampled represented about 45 percent of water consumed by United States groundwater consumers. Radon activities were highest in waters of the New England states, North and South Carolina, Georgia, Virginia, and some western states (Horton, 1983). The national mean radon activity reported by Horton (1983) was $340 \mathrm{pCi} / \mathrm{L}$, which was similar to the median radon activity of $326 \mathrm{pCi} / \mathrm{L}$ in this study (Appendix 8).

Between 1984 and 1986, USEPA conducted the National Inorganics and Radionuclides Survey using 990 randomly distributed groundwater samples from 49 states from the inventory of public water systems in the Federal Reporting Data System (Longtin, 1988). The random samples represented finished water in the distribution system, and generally were collected at the tap. Radon was detected in about 72 percent of groundwater samples, the median of detections was $289 \mathrm{pCi} / \mathrm{L}$ (median of all samples was not calculated), and the overall mean radon activity was about $650 \mathrm{pCi} / \mathrm{L}$ (Longtin, 1988). This mean radon activity reported by Longtin (1988) was presumably greater than the mean activity reported by Horton (1983) because radon was detected at activities greater than $5,000 \mathrm{pCi} / \mathrm{L}$ in a larger percentage of the samples in the Longtin study (about 2.2 percent) than in the Horton study ( 0.4 percent). In addition, the maximum radon activity was $25,700 \mathrm{pCi} / \mathrm{L}$ in the Longtin (1988) study.

\section{Radium-226 and Radium-228}

The half-lives of radium-226 and radium-228 are 1,622 years and 5.75 years, respectively-much longer than the half-life of radon (Zapecza and Szabo, 1986). The MCL for combined radium-226 and radium-228 is $5 \mathrm{pCi} / \mathrm{L}$ (U.S. Environmental Protection Agency, 2006a). Combined radium was analyzed in only 191 source-water samples from public wells in this study, but activities were greater than the MCL in about 19 percent of these samples, and activities approached the MCL $(0.1<\mathrm{BQ} \leq 1)$ in about an additional 44 percent of samples (table 10). All except for three of 36 samples with combined radium activities greater than $5 \mathrm{pCi} / \mathrm{L}$ were from public wells that withdraw water from confined sandstone aquifers in Iowa and Illinois in the Cambrian-Ordovician aquifer system; the remaining three samples were from unconfined semi-consolidated sand and gravel aquifers in New Jersey in the Northern Atlantic Coastal Plain aquifer system (data not shown). These findings are consistent with a national review of radionuclide measurements in public water supplies that showed two geologic regions where more than 75 percent of radium concentrations greater than the MCL were detected. These regions were the Piedmont and Coastal Plain provinces in New Jersey, North Carolina, South Carolina, and Georgia; and a north-central region, consisting of parts of Minnesota, Iowa, Illinois, Missouri, and Wisconsin (Hess and others, 1985).

A previous study showed that combined radium activities were greater than $5 \mathrm{pCi} / \mathrm{L}$ in more than 100 of 129 public wells sampled in the Cambrian-Ordovician aquifer system, primarily in confined aquifers (Gilkeson and Cowart, 1987). A key source of radium-228 in the Cambrian-Ordovician aquifer system was thought to be thorium-rich minerals in the sandstone bedrock (Gilkeson and Cowart, 1987). Radium-228 will not migrate large distances in groundwater from its site of generation because of its relatively short half-life, and because its thorium-232 parent is highly insoluble and does not mobilize in most groundwater environments (Focazio and others, 2001). A key source of radium-226 in groundwater in confined Cambrian-Ordovician aquifers is the accumulation of the precursor radionuclides (uranium-238 and -234 and 
thorium-230) on the sandstone matrix as a result of various mobilization mechanisms (Gilkeson and Cowart, 1987). In this study, radium was not correlated with uranium concentrations in samples from any individual principal aquifer rock types $(\mathrm{p}>0.05)$.

In the national public-well study by Horton (1983), total radium activities were greater than the MCL in 79 percent of 91 samples from public supplies, and the mean activity was $8.5 \mathrm{pCi} / \mathrm{L}$. It is unclear why the percentage of samples with activities greater than the MCL, and the mean activity of total radium, were so much higher in the Horton (1983) study than in this study, where activities were greater than the MCL in about 19 percent of samples (table 10) and the median combined radium activity was $0.8 \mathrm{pCi} / \mathrm{L}$ (Appendix 8 ). The results from this study, however, were similar to those from Hess and others (1985), where the geometric means for radium-226 and for radium-228 were about 0.1 to $2.2 \mathrm{pCi} / \mathrm{L}$ in groundwater samples from the Atlantic Plain and Piedmont provinces.

\section{Gross Alpha- and Gross Beta-Particle Radioactivities}

Gross alpha- and beta-particle radioactivities each were analyzed in only about 85 source-water samples from public wells in this study (table 10). As a result, correlations between gross alpha- and beta-particle radioactivities and other radionuclides could not be made in samples from most principal aquifer rock types. Gross alpha-particle radioactivity is a measure of the total amount of radioactivity in a water sample that is attributable to the radioactive decay of alpha-emitting radioactive elements (Szabo and DePaul, 1998), without identifying the specific radionuclides responsible for the activity. The MCL for gross alpha-particle radioactivity is $15 \mathrm{pCi} / \mathrm{L}$, excluding activities caused by radon and uranium (U.S. Environmental Protection Agency, 2000b). Gross alpha-particle radioactivities reported in this study were not corrected for contributions for radon or uranium, and are, therefore, conservatively high estimates. Corrections for radon or uranium were not made because radon typically volatilizes before analysis (U.S. Environmental Protection Agency, 2000a) and uranium was reported as a concentration (not an activity), which is consistent with the current mass-based MCL for uranium. Uranium concentrations $(\mu \mathrm{g} / \mathrm{L})$, however, can be converted to activities ( $\mathrm{pCi} / \mathrm{L}$ ) by using a conversion factor of 0.67 to $1.5 \mathrm{pCi} / \mu \mathrm{g}$ for sources of drinking water (U.S. Environmental Protection Agency, 2000a), but uranium was not analyzed in all samples in which gross alpha-particle radioactivity was analyzed.

Gross alpha-particle radioactivities were greater than the MCL in about 5 percent of source-water samples, and activities approached the MCL $(0.1<\mathrm{BQ} \leq 1)$ in about an additional 49 percent of samples (table 10). Uranium was not analyzed in the four samples in which gross alpha-particle radioactivities were greater than the MCL, but uranium was analyzed in 35 of the 41 samples in which gross-alpha particle radioactivities were greater than one-tenth of the MCL. Correcting gross alpha-particle radioactivities for those 35 samples by applying the uranium conversion factors suggests that 13 to 31 percent of samples (instead of 49 percent) may have contained gross alpha-particle radioactivities approaching the $\mathrm{MCL}(0.1<\mathrm{BQ} \leq 1)$.

All public-well samples with gross alpha-particle radioactivities greater than the MCL were from unconfined semi-consolidated sand and gravel aquifers in New Jersey in the Northern Atlantic Coastal Plain aquifer system (data not shown). This finding is consistent with previous studies that report gross alpha-particle radioactivities greater than $15 \mathrm{pCi} / \mathrm{L}$ in samples from an unconfined aquifer system in southern New Jersey (Szabo and DePaul, 1998; Szabo and others, 2005). In the national public-well study by Horton (1983), gross alpha-particle radioactivities were greater than the MCL in about 2 percent of public-well samples, and the mean activity was $1.8 \mathrm{pCi} / \mathrm{L}$. In this study, the median gross alpha-particle radioactivity was $1.8 \mathrm{pCi} / \mathrm{L}$ (Appendix 8).

Gross beta-particle radioactivity is a measure of the total radioactivity caused by beta-particle emissions in a water sample (U.S. Environmental Protection Agency, 2000b). The MCL for gross beta-particle radioactivity is 4 millirems per year (mrem/yr) (U.S. Environmental Protection Agency, 2006a). A rem is a dose equivalent measurement from ionizing radiation to the body or organs; it is an absorbed dose that accounts for different types of radiation (U.S. Environmental Protection Agency, 2000b). Because gross beta-particle radioactivity was measured in activity units $(\mathrm{pCi} / \mathrm{L})$ and not dose units (mrem/yr), gross beta-particle radioactivities analyzed in this study were compared to the USEPA gross beta-particle radioactivity screening level of $50 \mathrm{pCi} / \mathrm{L}$. Gross beta-particle radioactivities were less than $50 \mathrm{pCi} / \mathrm{L}$ in all of the source-water samples from public wells (table 10). This finding is consistent with a USEPA study that suggests that gross beta-particle radioactivities rarely will exceed $50 \mathrm{pCi} / \mathrm{L}$ in water from public water systems (U.S. Environmental Protection Agency, 2000b).

Gross beta-particle radioactivities were greater than one-tenth of the screening level in about 45 percent of public-well samples (table 10), mostly from unconfined aquifers. One-half of these samples were collected from unconsolidated sand and gravel aquifers in the central United States, and one-quarter of these samples were collected from semi-consolidated sand and gravel aquifers in Delaware and New Jersey in the Northern Atlantic Coastal Plain aquifer system (data not shown). In the national public-well study by Horton (1983), gross beta-particle radioactivities were greater than $5 \mathrm{pCi} / \mathrm{L}$ (corresponding to a $\mathrm{BQ}>0.1$ ) in about 19 percent of public-well samples and the mean activity was $3.4 \mathrm{pCi} / \mathrm{L}$. In this study, the median gross-beta particle activity was $4.8 \mathrm{pCi} / \mathrm{L}$ (Appendix 8). 


\section{Organic Contaminants}

Most contaminants analyzed in this study (168 of 215) were organic contaminants. As many as 83 pesticides or pesticide degradation products and as many as 85 VOCs were analyzed in source-water samples from public wells (Appendix 4). Not all organic contaminants were analyzed in all samples. VOCs and about one-half of the pesticide compounds analyzed using GCMS were analyzed in most (81 to 96 percent) samples; pesticides analyzed using GCMS are shown as Schedule 2010 in Appendix 4. The remaining pesticide compounds (the other one-half of those analyzed using GCMS and most analyzed using HPLC) were analyzed in 54 to 69 percent of samples; those analyzed using HPLC are shown as Schedule 2050 in Appendix 4.

All organic contaminants analyzed in this study originate from anthropogenic sources, although a few also have natural sources. The primary use groups and sources of pesticide compounds and VOCs are listed in Appendix 5. The potential for pesticide compounds and VOCs to affect drinking-water quality is influenced by their sources and pathways in the hydrologic system, their volatility, mobility and persistence in soils and groundwater, and their toxicity to humans (Barbash and Roberts, 1986; Gilliom and others, 2006; Zogorski and others, 2006). Pesticides are released into the environment primarily through their application to agricultural lands, such as croplands, and to non-agricultural areas, such as lawns, golf courses, and commercial areas (Gilliom and others, 2006). VOCs are a broad class of organic contaminants that have numerous uses in industry, commerce, households, and military sites. For example, VOCs are used in gasoline, as solvents and degreasers, in the synthesis of other compounds, as fumigants, in personal care products, and are created during the disinfection of water and wastewater (Appendix 5). As their name implies, VOCs tend to be more volatile than other organic contaminants, and therefore tend to partition from water into air (Zogorski and others, 2006). Conversely, atmospheric inputs of VOCs have been observed in untreated groundwater from public wells (Shapiro and others, 2004).

\section{Detection Frequency}

One or more pesticide compounds or VOCs were detected in about 64 percent of source-water samples from public wells when all detections were considered, and in about 34 percent of samples at a common assessment level of $0.2 \mu \mathrm{g} / \mathrm{L}$. VOCs were detected in more samples than pesticide compounds at all common assessment levels (fig. 29). Considering all detections, pesticide compounds and VOCs were detected in about 41 and 60 percent of samples, respectively (fig. 29). Detection frequencies of all individual pesticide compounds and VOCs at various

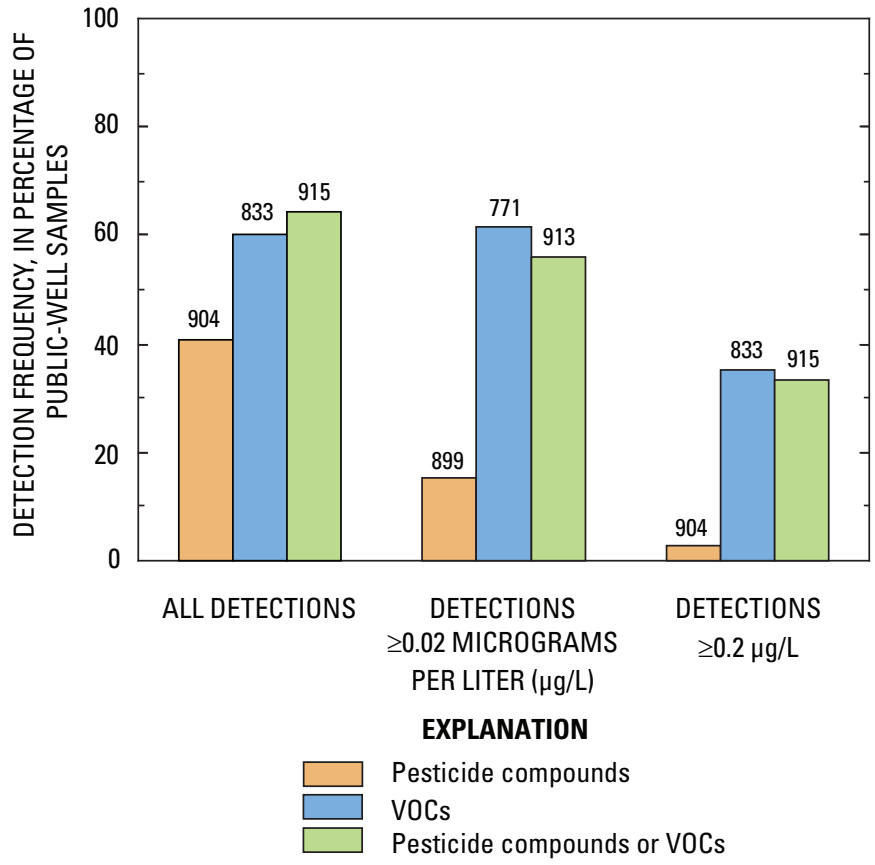

\begin{abstract}
The common assessment level of $0.02 \mu \mathrm{g} / \mathrm{L}$ was not applied to (1) VOC measurements prior to April 1996 or (2) 36 pesticide compounds analyzed using high performance liquid chromatography, because the laboratory reporting levels for those contaminants were greater than $0.02 \mu \mathrm{g} / \mathrm{L}$.
\end{abstract}

Figure 29. Detection frequencies of pesticide compounds and volatile organic compounds (VOCs) at different common assessment levels in public-well samples collected during 1993-2007. Detections are concentrations greater than or equal to $(\geq)$ a common assessment level. Numbers above bars indicate the number of samples in which organic contaminants were analyzed.

common assessment levels are shown in Appendix 11 and Appendix 12, respectively. Concentration statistics are shown in Appendix 13 for those pesticide compounds and VOCs that were detected in at least 1 percent of the samples using no common assessment level. The 58 organic contaminants not detected in any sample are shown in Appendix 14.

The detection frequencies of pesticide compounds and VOCs in this study generally are consistent with previous USGS national-scale studies, in part because about one-third of the public wells evaluated in this study were included in USGS national assessments of pesticide compounds (Gilliom and others, 2006) and VOCs (Zogorski and others, 2006). For example, in a recent national assessment of 83 pesticide compounds in 364 public wells, pesticide compounds were detected in about one-third of groundwater samples from major aquifers (Gilliom and others, 2006). In this study, the occurrence of the same 83 pesticide compounds was assessed in as many as 904 public wells, and pesticide compounds were detected in about 41 percent of public-well samples (fig. 29). 
In a recent national assessment of 55 VOCs in 1,096 public wells, VOCs were detected in about 26 percent of samples at a common assessment level of $0.2 \mu \mathrm{g} / \mathrm{L}$ (Zogorski and others, 2006). In this study where 85 VOCs were analyzed in as many as 833 public-well samples, VOCs were detected in about 35 percent of the public-well samples at the same common assessment level (fig. 29). VOCs may have been more frequently detected in this study because 30 additional VOCs were analyzed in this study ( 85 versus 55 ).

Geographic patterns of the overall occurrence of organic contaminants in public-well samples were not evident.

However, when occurrence was examined by the number of organic contaminants detected in each sample, more organic contaminants per sample generally were detected along the East Coast and in California than in other areas of the country (fig. 30).

More pesticide compounds and VOCs were detected in samples from the various sand and gravel aquifers than in other principal aquifer rock types (fig. 31A). About 60 and 70 percent of the samples with detections of pesticide compounds and VOCs, respectively, were from the three sand and gravel aquifers - unconsolidated, glacial, and semi-consolidated. Public wells in sand and gravel aquifers generally more often withdraw water from shallower unconfined aquifers than from deeper confined aquifers (fig. 7). Accordingly, pesticide compounds and VOCs were detected more frequently in samples from unconfined aquifers than from confined aquifers; this difference was more notable for pesticide compounds. About two-thirds of the samples in which pesticide compounds were detected were from unconfined aquifers and one-third of the samples were from confined aquifers (fig. 31B). This finding is consistent with previous studies that show that shallow groundwater (such as from unconfined aquifers), because of its proximity to the land surface, is more vulnerable to contamination from human activities, such as pesticide application, than deep groundwater (U.S. Geological Survey, 1999). Rock types with high effective porosities (such as sand and gravel aquifers) also are more vulnerable to contamination from the land surface than other rock types (Mueller and others, 1995; Nolan and Hitt, 2006).

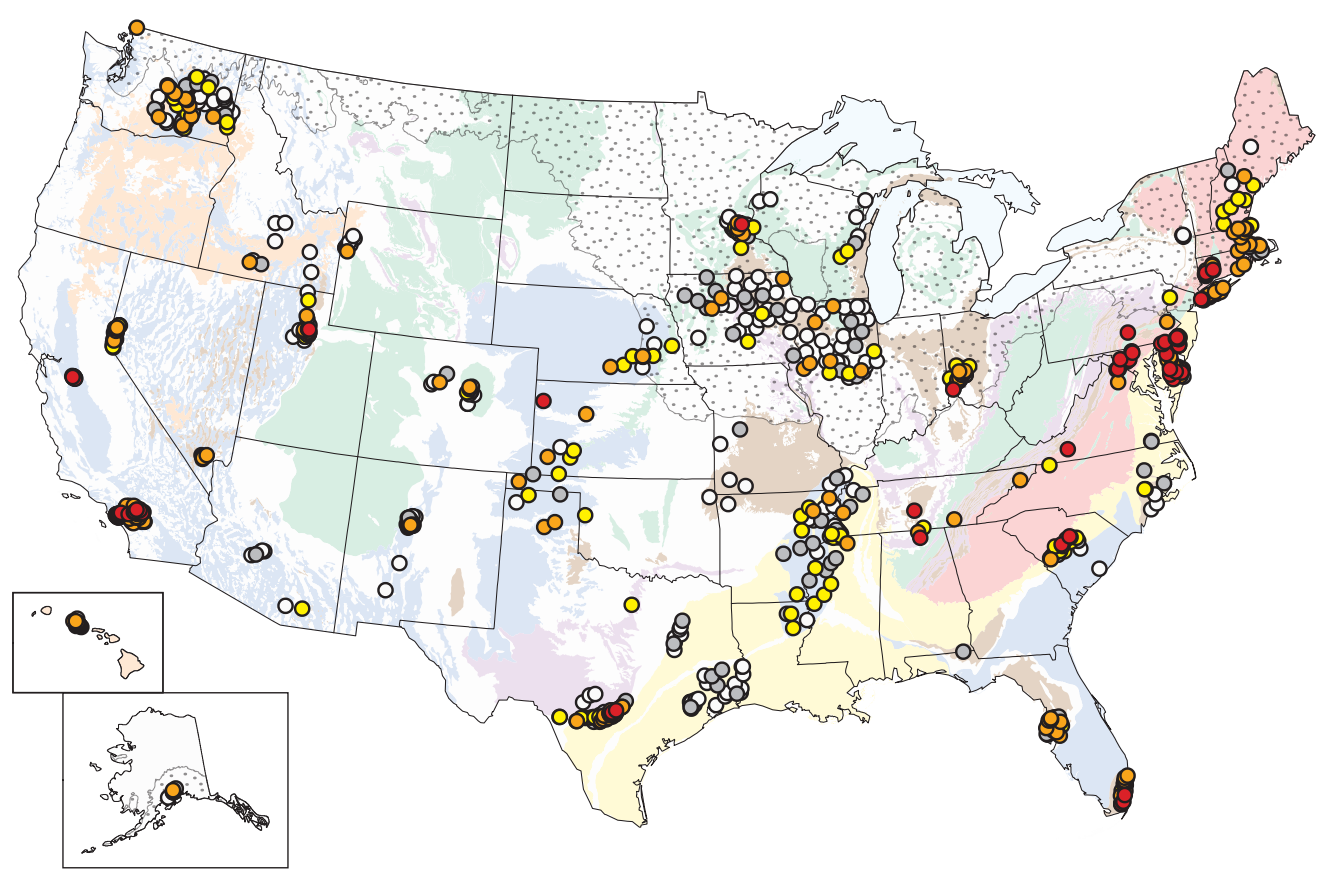

EXPLANATION

Number of organic contaminants detected
$\begin{array}{ll}\text { - } & \text { Greater than } 10 \\ \text { O } & 4 \text { to } 10 \\ \text { O } & 2 \text { to } 3 \\ \text { O } & 1 \\ \text { O } & 0\end{array}$

Number of public wells

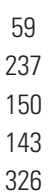

Figure 30. Geographic distribution of the number of pesticide compounds and volatile organic compounds detected in 915 public-well samples collected during 1993-2007. No common assessment level was applied to these data. (See fig. $2 A$ for explanation of principal aquifer rock types.) 
A. Principal aquifer rock type

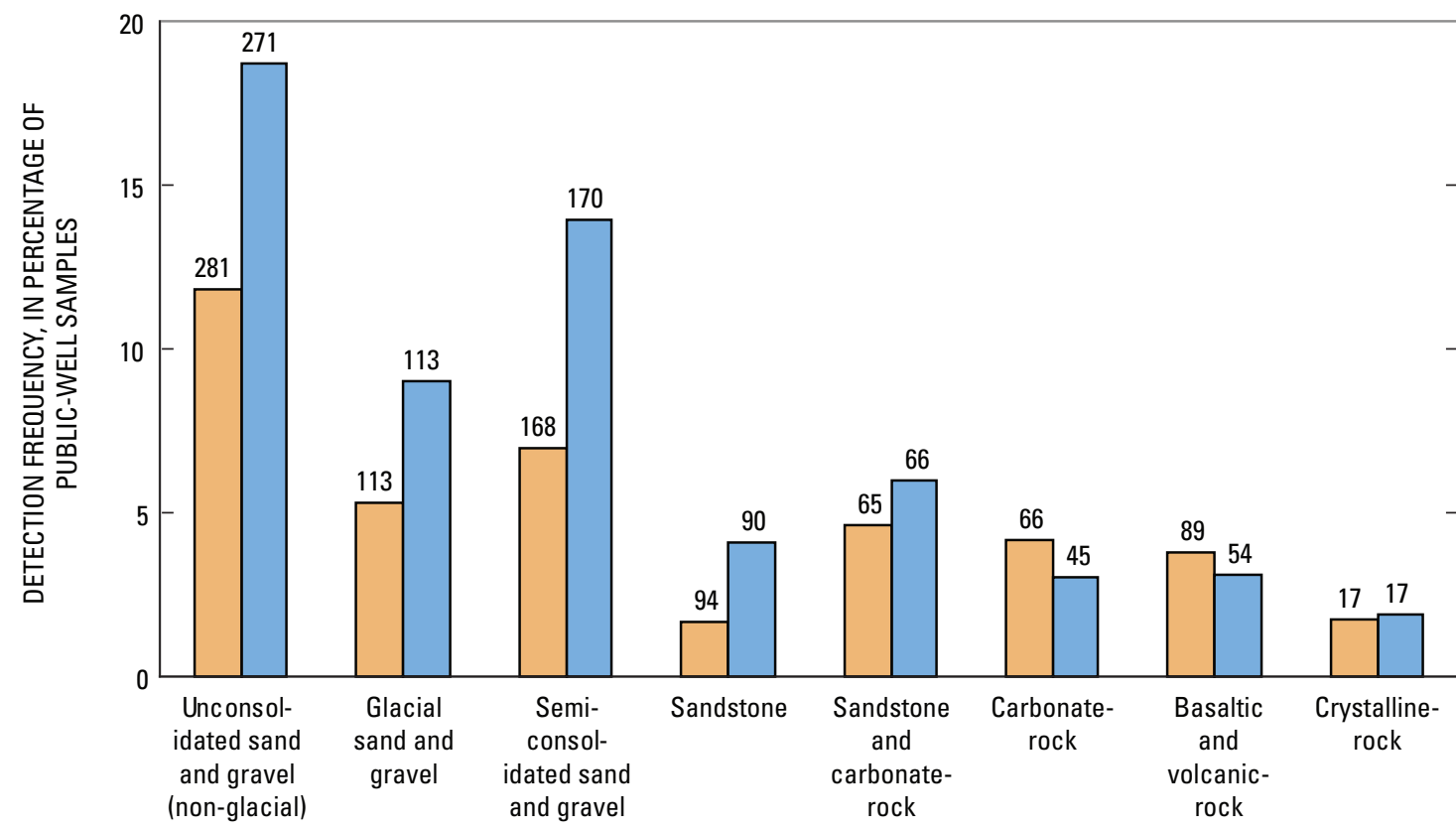

PRINCIPAL AQUIFER ROCK TYPE

B. Aquifer type

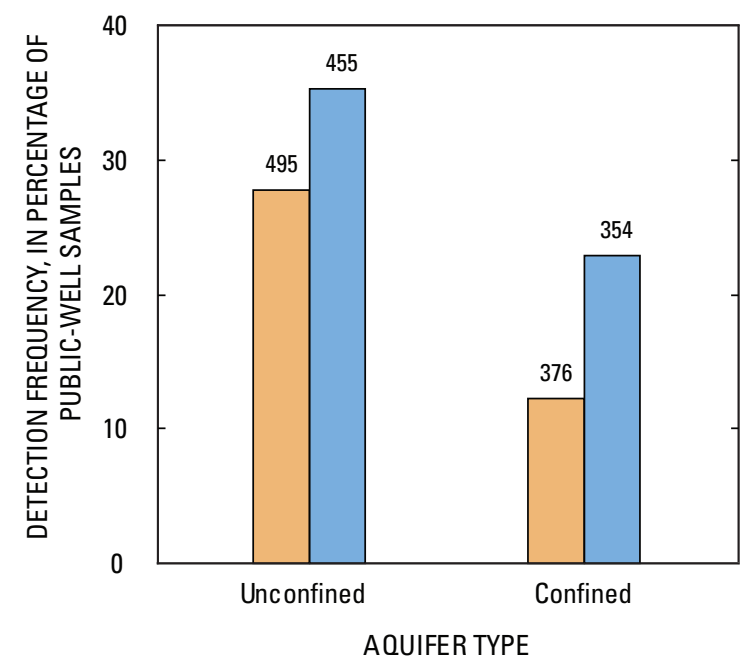

C. System size

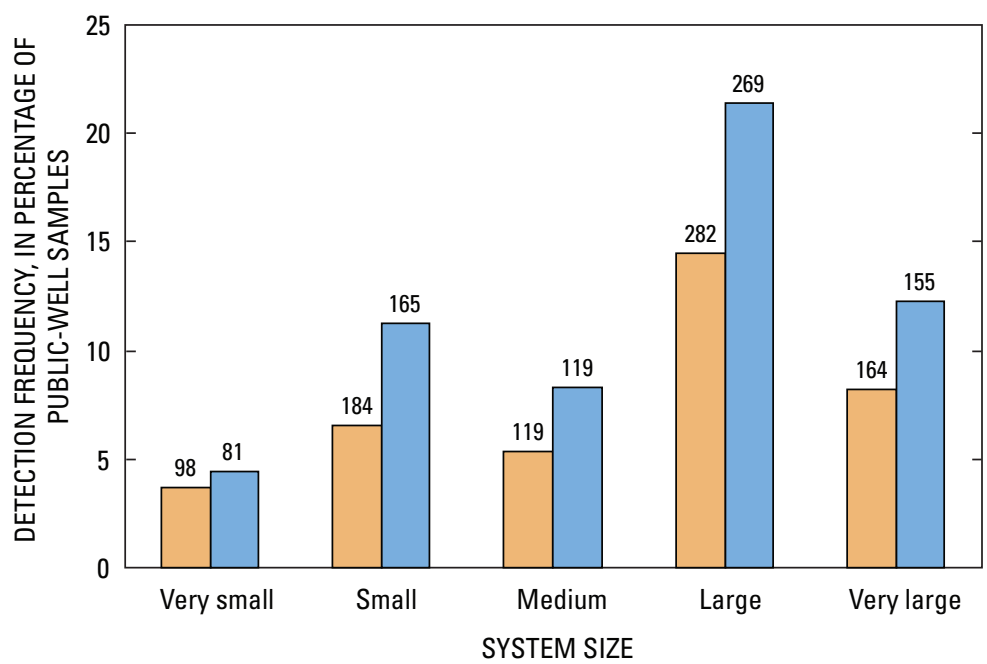

EXPLANATION

Pesticide compounds VOCs

Figure 31. Detection frequencies of pesticide compounds and volatile organic compounds (VOCs) by $(A)$ principal aquifer rock type, $(B)$ aquifer type, and $(C)$ system size, for public-well samples collected during 1993-2007. Numbers above bars indicate the number of samples in which pesticide compounds or VOCs were analyzed. No common assessment level was applied to these data. 
More than one-half of the source-water samples from public wells with detections of pesticide compounds or VOCs were from large and very large systems (fig. 31C). VOCs previously have been reported to be detected more frequently in drinking water supplied by large systems than by small systems (Westrick and others, 1984; Grady and Casey, 2001; Grady, 2002). Large and very large systems, including those with deep wells, can intercept and accelerate groundwater flowing along extensive flow paths because they have substantial withdrawal rates. Such large systems may, therefore, capture water from various land-use settings that may contain degradation products from parent compounds (Gilliom and others, 2006; Zogorski and others, 2006). The more frequent occurrence of organic contaminants in source waters used by larger public water systems also likely reflects the greater proximity of larger systems to high-population density, urban areas as compared to smaller systems (Grady, 2002).

A wide variety of organic contaminants, encompassing many uses, were detected in public wells. The most frequently detected organic contaminants were DBPs, herbicides and herbicide degradates, and solvents (fig. 32), when examined by primary use groups or sources of contaminants (Appendix 5). In a national random survey of VOCs analyzed in untreated water from 579 groundwater CWSs (Grady, 2002), it was observed that, when examined by primary use groups, DBPs were detected most frequently, followed by solvents and gasoline hydrocarbons (including oxygenates), which is consistent with the VOC results from this study (fig. 32), and a national assessment of VOCs in public wells (Zogorski and others, 2006).

The 10 most frequently detected individual organic contaminants at a common assessment level of $0.02 \mu \mathrm{g} / \mathrm{L}$ were chloroform and bromodichloromethane (DBPs); perchloroethene (PCE), trichloroethene (TCE), 1,1,1-trichloroethane, cis-1,2-dichloroethene, and 1,1-dichloroethane (solvents); atrazine and deethylatrazine (herbicides and herbicide degradates); and methyl-tert-butyl ether (MTBE) (gasoline oxygenate) (fig. 33). Most of these pesticide compounds and VOCs also were among the most frequently detected organic contaminants in a recent USGS SWQA study of anthropogenic organic contaminants in public wells (Hopple and others, 2009) and in national assessments of pesticide compounds (Gilliom and others, 2006) and VOCs (Zogorski and others, 2006). About one-quarter of the public wells evaluated in this study were included in the SWQA study. In the USEPA groundwater supply survey, chloroform also was the most frequently detected VOC; after the DBPs, TCE, PCE, and 1,1,1-trichloroethane were most frequently detected (Westrick and others, 1984).

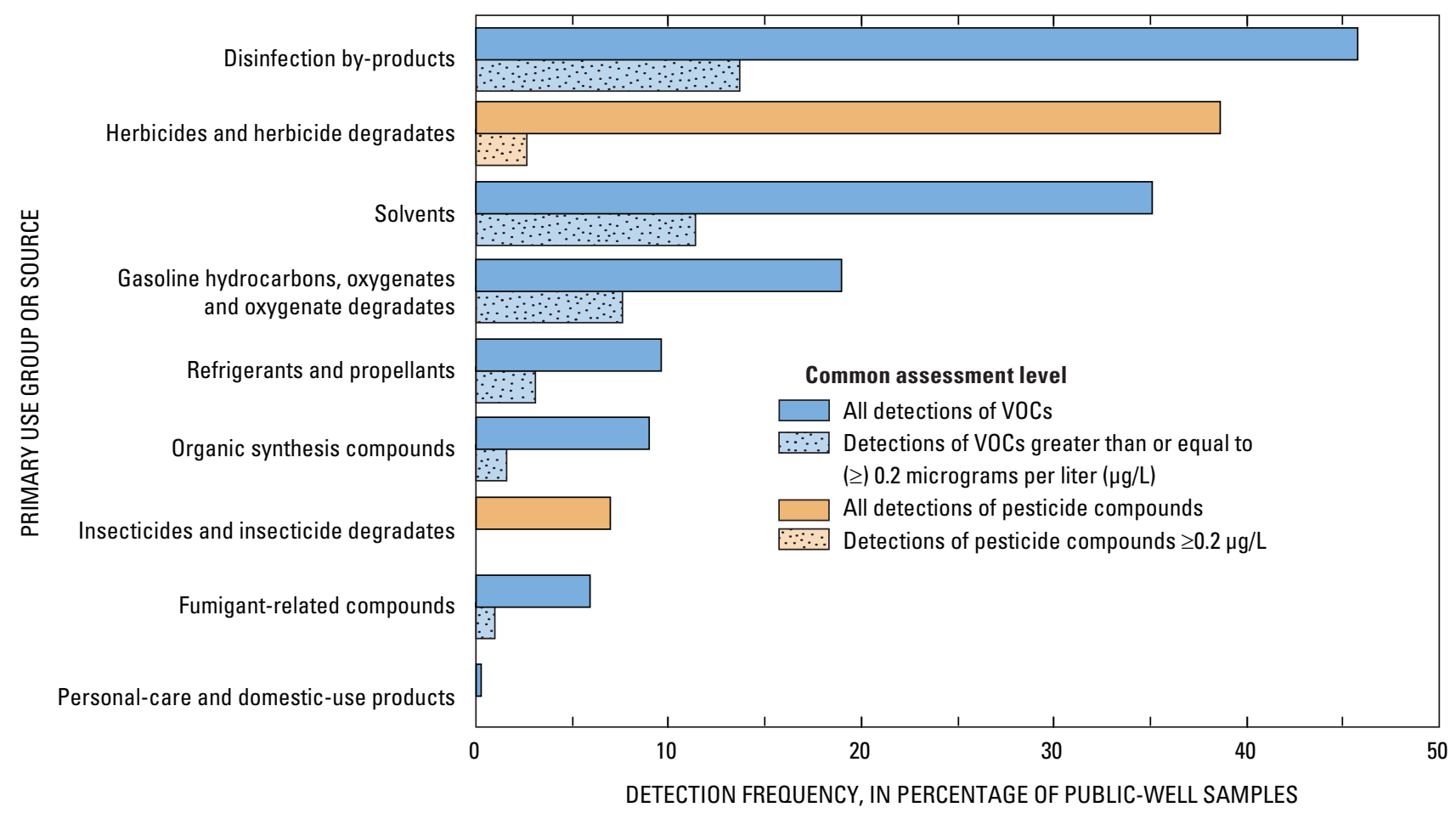

Figure 32. Detection frequencies of pesticide compounds and volatile organic compounds (VOCs), by primary use group or source, for public-well samples collected during 1993-2007. 


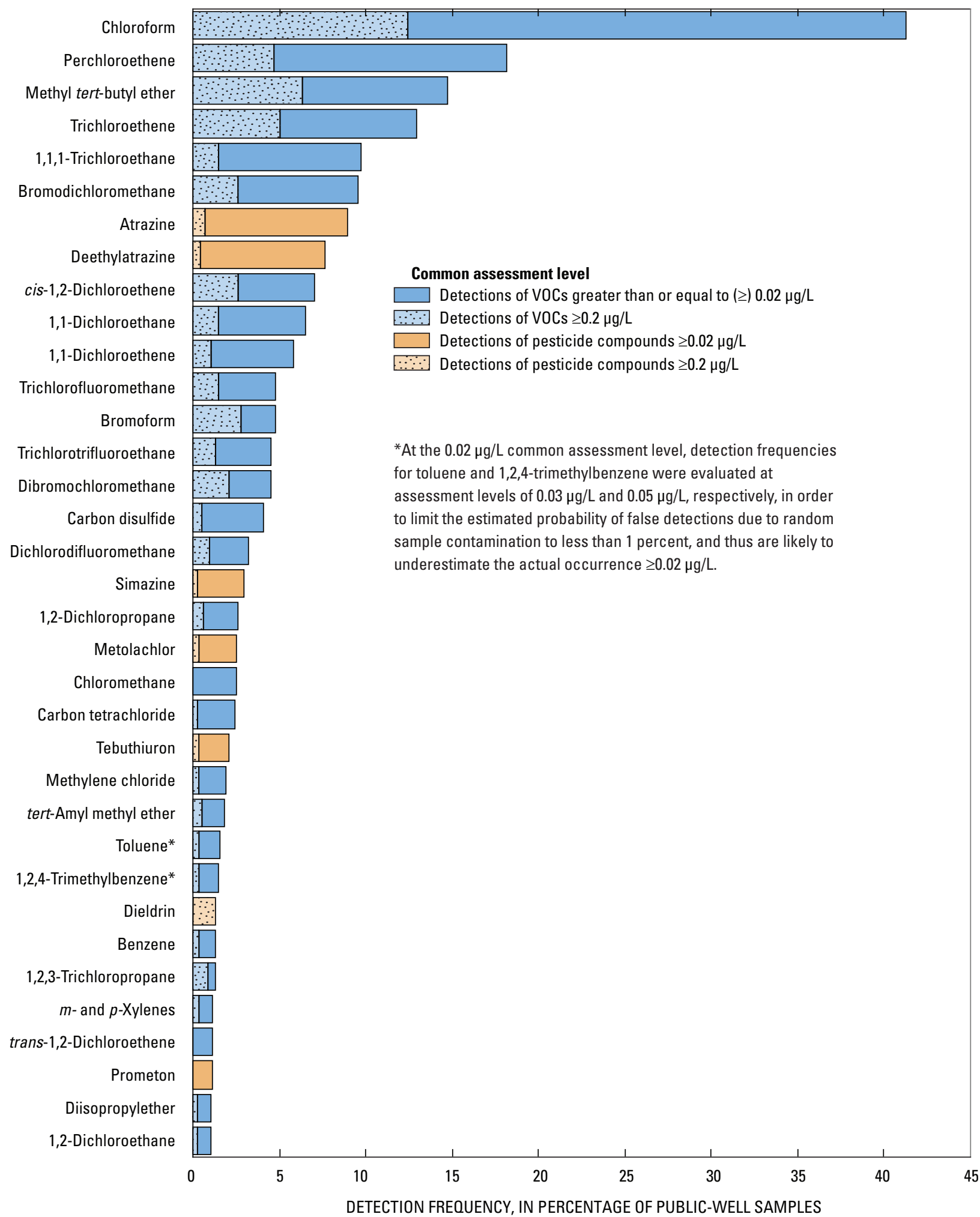

Figure 33. Detection frequencies of individual pesticide compounds and volatile organic compounds (VOCs) in relation to common assessment levels of 0.02 and 0.2 micrograms per liter ( $\mu \mathrm{g} / \mathrm{L}$ ) in public-well samples collected during 1993-2007. All organic contaminants detected in at least 1 percent of public-well samples at a $0.02 \mu \mathrm{g} / \mathrm{L} \mathrm{common}$ assessment level are shown. 


\section{Comparison to Human-Health Benchmarks}

Human-health benchmarks were available for 74 of the 83 pesticide compounds and 53 of the 85 VOCs that were analyzed in this study (Appendix 4). Overall, one or more pesticide compounds were detected at concentrations greater than benchmarks in about 3 percent of source-water samples from public wells (table 12), and one or more VOCs were detected at concentrations greater than benchmarks in about 2 percent of samples (table 13). These findings are consistent with recent national assessments of pesticides and VOCs in public wells. Gilliom and others (2006) reported that pesticide concentrations were greater than benchmarks in 2 percent of public wells in major aquifers. Zogorski and others (2006) reported that VOC concentrations were greater than benchmarks in 1.5 percent of public wells. About one-third of the public wells evaluated in this study were included in these previous national assessments of pesticide compounds (Gilliom and others, 2006) and VOCs (Zogorski and others, 2006).

Concentrations of seven organic contaminants were greater than their human-health benchmarks in at least one source-water sample from public wells (tables 12 and 13). All together, concentrations of organic contaminants were greater than benchmarks in samples from 41 public wells (4.5 percent of all samples); 28 of these samples (68 percent) were collected from public wells in states bordering the East Coast, primarily in semi-consolidated sand and gravel aquifers that underlie the Coastal Plains (fig. 34). About 22 percent of the samples with concentrations of organic contaminants greater than benchmarks were collected from public wells in the western states of California, Washington, and Hawaii (fig. 34). Concentrations of dieldrin were greater than the HBSL in 3 percent of samples (table 12), and concentrations of PCE and TCE each were greater than the MCLs in about 1 percent of samples (table 13). The remaining four organic contaminants with concentrations greater than benchmarks in at least one sample - alpha-hexachlorocyclohexane (alpha-HCH), acrylonitrile, DBCP, and ethylene dibromide(1) were infrequently detected ( 0.5 percent or less of samples) (Appendixes 11 and 12), (2) were detected only once or twice with $\mathrm{BQ}>1$ (tables 12 and 13 ), and (3) have higher uncertainty regarding concentrations greater than benchmarks than other contaminants, except for alpha-HCH. Concentrations of the seven organic contaminants with $\mathrm{BQ}>1$ in this study, except for alpha-HCH and DBCP, also were greater than benchmarks in a recent SWQA examination of anthropogenic organic contaminants in public wells (Hopple and others, 2009), but alpha-HCH was not analyzed in that study.
In addition to the seven organic contaminants with concentrations greater than human-health benchmarks in 4.5 percent of source-water samples from public wells, concentrations of 16 organic contaminants were greater than one-tenth of benchmarks in 5.4 percent of samples (tables 12 and $\underline{13}$ and fig. 34). Overall, one or more pesticide compounds with concentrations less than, but within one-tenth of, human-health benchmarks $(0.1<\mathrm{BQ} \leq 1)$ were detected in 1.3 percent of samples (table 12), and one or more VOCs with concentrations approaching benchmarks were detected in 5 percent of samples (table 13). Samples with concentrations greater than one-tenth of benchmarks were distributed throughout the United States, but nearly three-quarters of these samples were collected from public wells in unconsolidated and semi-consolidated sand and gravel aquifers. In much of the central and west-central United States, concentrations were less than one-tenth of benchmarks or no human-health benchmarks were available for detected organic contaminants (fig. 34).

Figure 35 shows the distributions of BQ values for the 23 organic contaminants with concentrations greater than onetenth of human-health benchmarks $(\mathrm{BQ}>0.1)$ in at least one source-water sample. Maximum MRL or LT-MDL values were greater than human-health benchmarks for four of the seven organic contaminants with $\mathrm{BQ}>1$ - dieldrin, acrylonitrile, DBCP, and ethylene dibromide (table 5 and fig. 35). As a result, the percentage of samples with concentrations greater than benchmarks for these four contaminants may be underestimated (see section, "Comparison of Analytical Reporting Levels to Benchmarks" on page 16).

Although there is some uncertainty about concentrations of dieldrin greater than the HBSL as described above, dieldrin stands out because concentrations were greater than the low end of the HBSL range $(0.002 \mu \mathrm{g} / \mathrm{L})$ for 27 of the 28 samples in which dieldrin was detected (table 12). As a result, as many as two-thirds (27 of 41) of the source-water samples with concentrations greater than benchmarks for organic contaminants shown in figure 34 correspond to dieldrin detections, although concentrations of more than one organic contaminant were greater than benchmarks in some samples. This finding is consistent with a previous study, where Gilliom and others (2006) reported that concentrations of one or more pesticide compounds were greater than benchmarks in eight of 364 public-well samples (six were from dieldrin concentrations). The low end of the HBSL range corresponds to a $10^{-6}$ ( 1 in 1 million) cancer risk (Toccalino, 2007). None of the dieldrin concentrations were greater than the high end of the HBSL range $(0.2 \mu \mathrm{g} / \mathrm{L})$ that corresponds to a $10^{-4}(1$ in 10 thousand) cancer risk; the high end of the HBSL range would plot as $\mathrm{BQ}=100$ in figure 35 . 
Table 12. Number of detections and comparison of concentrations to human-health benchmarks for pesticide compounds in publicwell samples collected during 1993-2007.

[No common assessment level was applied to these data. Only those pesticide compounds detected in at least one sample are included in this table. $\mu \mathrm{g} / \mathrm{L}$, micrograms per liter; BQ, Benchmark Quotient (ratio of concentration to human-health benchmark); >, greater than; $\leq$ less than or equal to; HBSL, HealthBased Screening Level; MCL, Maximum Contaminant Level; -, not available; DWLOC, Drinking Water Level of Comparison]

\begin{tabular}{|c|c|c|c|c|c|c|c|c|}
\hline \multirow{2}{*}{$\begin{array}{l}\text { Pesticide } \\
\text { compound }\end{array}$} & \multirow{2}{*}{$\begin{array}{l}\text { Number of } \\
\text { samples }\end{array}$} & \multirow{2}{*}{$\begin{array}{l}\text { Number of } \\
\text { detections }\end{array}$} & \multicolumn{2}{|c|}{$\begin{array}{c}\text { Human-health } \\
\text { benchmark }^{1}\end{array}$} & \multicolumn{2}{|c|}{ Samples with B0>1 } & \multicolumn{2}{|c|}{$\begin{array}{l}\text { Samples with } \\
\text { BQ }>0.1 \text { and } \leq 1\end{array}$} \\
\hline & & & Value ( $\mu \mathrm{g} / \mathrm{L})$ & Type & Number & Percent & Number & Percent \\
\hline Acetochlor & 800 & 2 & 1 & HBSL low $^{2}$ & 0 & 0 & 1 & 0.1 \\
\hline Alachlor & 869 & 16 & 2 & MCL & 0 & 0 & 1 & 0.1 \\
\hline Aldicarb sulfone & 569 & 3 & 7 & $\mathrm{HBSL}^{3}$ & 0 & 0 & 0 & 0 \\
\hline Aldicarb sulfoxide & 569 & 2 & 7 & $\mathrm{HBSL}^{3}$ & 0 & 0 & 0 & 0 \\
\hline Atrazine & 853 & 227 & 3 & MCL & 0 & 0 & 4 & 0.5 \\
\hline Bentazon & 589 & 16 & 200 & HBSL & 0 & 0 & 0 & 0 \\
\hline Bromacil & 590 & 30 & 70 & HBSL & 0 & 0 & 0 & 0 \\
\hline Bromoxynil & 590 & 1 & 10 & HBSL & 0 & 0 & 0 & 0 \\
\hline Butylate & 511 & 1 & 400 & HBSL & 0 & 0 & 0 & 0 \\
\hline Carbaryl & 898 & 6 & 40 & HBSL low ${ }^{2}$ & 0 & 0 & 0 & 0 \\
\hline Carbofuran & 644 & 13 & 40 & MCL & 0 & 0 & 0 & 0 \\
\hline Chloramben methyl ester & 580 & 1 & - & - & - & - & - & - \\
\hline Chlorpyrifos & 898 & 2 & 2 & HBSL & 0 & 0 & 0 & 0 \\
\hline Clopyralid & 586 & 1 & - & - & - & - & - & - \\
\hline Cyanazine & 634 & 3 & 1 & HBSL & 0 & 0 & 0 & 0 \\
\hline $2,4-\mathrm{D}$ & 590 & 2 & 70 & MCL & 0 & 0 & 0 & 0 \\
\hline Dacthal & 898 & 3 & 70 & HBSL & 0 & 0 & 0 & 0 \\
\hline$p, p^{\prime}-\mathrm{DDE}$ & 512 & 14 & 0.1 & HBSL low $^{2}$ & 0 & 0 & 0 & 0 \\
\hline Deethylatrazine & 853 & 257 & - & - & - & - & - & - \\
\hline Diazinon & 897 & 3 & 1 & HBSL & 0 & 0 & 0 & 0 \\
\hline Dieldrin & 896 & 28 & 0.002 & HBSL low $^{2}$ & 27 & 3.0 & 1 & 0.1 \\
\hline 2,6-Diethylaniline & 898 & 1 & - & - & - & - & - & - \\
\hline Dinoseb & 590 & 5 & 7 & MCL & 0 & 0 & 0 & 0 \\
\hline Diuron & 587 & 31 & 2 & HBSL low $^{2}$ & 0 & 0 & 4 & 0.7 \\
\hline EPTC & 646 & 2 & 200 & HBSL & 0 & 0 & 0 & 0 \\
\hline Ethoprop & 647 & 1 & 1 & HBSL low $^{2}$ & 0 & 0 & 0 & 0 \\
\hline Fenuron & 587 & 6 & - & - & - & - & - & - \\
\hline Fluometuron & 590 & 6 & 4 & HBSL & 0 & 0 & 1 & 0.2 \\
\hline alpha-HCH & 512 & 1 & 0.006 & HBSL low $^{2}$ & 1 & 0.2 & 0 & 0 \\
\hline gamma-HCH & 512 & 2 & 0.2 & MCL & 0 & 0 & 1 & 0.2 \\
\hline Linuron & 512 & 1 & 5 & HBSL & 0 & 0 & 0 & 0 \\
\hline Metolachlor & 870 & 75 & 700 & HBSL & 0 & 0 & 0 & 0 \\
\hline Metribuzin & 898 & 11 & 90 & HBSL & 0 & 0 & 0 & 0 \\
\hline Molinate & 635 & 3 & 0.7 & HBSL & 0 & 0 & 0 & 0 \\
\hline Norflurazon & 585 & 6 & 10 & HBSL & 0 & 0 & 0 & 0 \\
\hline Parathion-methyl & 889 & 1 & 1 & HBSL & 0 & 0 & 0 & 0 \\
\hline Picloram & 585 & 2 & 500 & MCL & 0 & 0 & 0 & 0 \\
\hline Prometon & 885 & 93 & 400 & HBSL & 0 & 0 & 0 & 0 \\
\hline Propoxur & 586 & 1 & 9 & HBSL low ${ }^{2}$ & 0 & 0 & 0 & 0 \\
\hline Simazine & 884 & 126 & 4 & MCL & 0 & 0 & 0 & 0 \\
\hline Tebuthiuron & 859 & 40 & 1,000 & HBSL & 0 & 0 & 0 & 0 \\
\hline Terbacil & 508 & 4 & 90 & HBSL & 0 & 0 & 0 & 0 \\
\hline Total chlorotriazines & 886 & 293 & 12.5 & DWLOC $^{4}$ & 0 & 0 & 1 & 0.1 \\
\hline $\begin{array}{l}\text { All detected pesticide } \\
\text { compounds }\end{array}$ & 904 & 368 & Various & Various & 28 & 3.1 & 12 & 1.3 \\
\hline
\end{tabular}

\footnotetext{
${ }^{1}$ Human-health benchmark values were current as of September 2009. MCL values were obtained from U.S. Environmental Protection Agency (2006a) and HBSL values were obtained from the HBSL website (Toccalino and others, 2008).

${ }^{2}$ Low end of HBSL range corresponding to a $10^{-6}$ ( 1 in 1 million) cancer risk. The HBSL range corresponds to a $10^{-6}$ to $10^{-4}$ cancer risk range.

${ }^{3}$ The USEPA Office of Water recommends that the concentration of any combination of two or more of the three aldicarb compounds should not be greater than $7 \mu \mathrm{g} / \mathrm{L}$ because of similar mode of action.

${ }^{4}$ The DWLOC was applied to the sum of atrazine, deethylatrazine, and simazine concentrations. The DWLOC value is from the U.S. Environmental Protection Agency, Office of Pesticide Programs (U.S. Environmental Protection Agency, 2003e).
} 
Table 13. Number of detections and comparison of concentrations to human-health benchmarks for volatile organic compounds in public-well samples collected during 1993-2007.

[No common assessment level was applied to these data. Only those volatile organic compounds detected in at least one sample are included in this table. $\mu \mathrm{g} / \mathrm{L}$, micrograms per liter; BQ, Benchmark Quotient (ratio of concentration to human-health benchmark); >, greater than; $\leq$ less than or equal to; HBSL, HealthBased Screening Level; MCL, Maximum Contaminant Level; -, not available]

\begin{tabular}{|c|c|c|c|c|c|c|c|c|}
\hline \multirow{2}{*}{$\begin{array}{l}\text { Volatile organic } \\
\text { compound }\end{array}$} & \multirow{2}{*}{$\begin{array}{l}\text { Number of } \\
\text { samples }\end{array}$} & \multirow{2}{*}{$\begin{array}{l}\text { Number of } \\
\text { detections }\end{array}$} & \multicolumn{2}{|c|}{$\begin{array}{c}\text { Human-health } \\
\text { benchmark }^{1}\end{array}$} & \multicolumn{2}{|c|}{ Samples with BQ>1 } & \multicolumn{2}{|c|}{$\begin{array}{l}\text { Samples with } \\
\text { BO }>0.1 \text { and } \leq 1\end{array}$} \\
\hline & & & $\begin{array}{l}\text { Value } \\
(\mu \mathrm{g} / \mathrm{L})\end{array}$ & Type & Number & Percent & Number & Percent \\
\hline Acetone & 771 & 5 & 6,000 & HBSL & 0 & 0 & 0 & 0 \\
\hline Acrylonitrile & 771 & 1 & 0.06 & HBSL low ${ }^{2}$ & 1 & 0.1 & 0 & 0 \\
\hline tert-Amyl methyl ether & 771 & 14 & - & - & - & - & - & - \\
\hline Benzene & 831 & 21 & 5 & MCL & 0 & 0 & 1 & 0.1 \\
\hline Bromobenzene & 832 & 1 & - & - & - & - & - & - \\
\hline Bromochloromethane & 832 & 2 & 90 & HBSL & 0 & 0 & 0 & 0 \\
\hline Bromodichloromethane & 831 & 92 & 80 & $\mathrm{MCL}^{3}$ & 0 & 0 & 1 & 0.1 \\
\hline Bromoform & 832 & 37 & 80 & $\mathrm{MCL}^{3}$ & 0 & 0 & 0 & 0 \\
\hline$n$-Butylbenzene & 831 & 1 & - & - & - & - & - & - \\
\hline sec-Butylbenzene & 831 & 3 & - & - & - & - & - & - \\
\hline tert-Butylbenzene & 832 & 1 & - & - & - & - & - & - \\
\hline Carbon disulfide & 765 & 44 & 700 & HBSL & 0 & 0 & 0 & 0 \\
\hline Carbon tetrachloride & 832 & 28 & 5 & MCL & 0 & 0 & 1 & 0.1 \\
\hline Chlorobenzene & 832 & 11 & 100 & MCL & 0 & 0 & 0 & 0 \\
\hline Chloroform & 831 & 381 & 80 & $\mathrm{MCL}^{3}$ & 0 & 0 & 10 & 1.2 \\
\hline Chloromethane & 806 & 22 & 30 & HBSL & 0 & 0 & 0 & 0 \\
\hline Dibromochloromethane & 832 & 38 & 80 & $\mathrm{MCL}^{3}$ & 0 & 0 & 0 & 0 \\
\hline Dibromochloropropane & 832 & 2 & 0.2 & MCL & 2 & 0.2 & 0 & 0 \\
\hline Dibromomethane & 832 & 6 & - & - & - & - & - & - \\
\hline 1,2-Dichlorobenzene & 831 & 9 & 600 & MCL & 0 & 0 & 0 & 0 \\
\hline 1,3-Dichlorobenzene & 832 & 4 & 600 & HBSL & 0 & 0 & 0 & 0 \\
\hline 1,4-Dichlorobenzene & 831 & 21 & 75 & MCL & 0 & 0 & 0 & 0 \\
\hline Dichlorodifluoromethane & 832 & 27 & 1,000 & HBSL & 0 & 0 & 0 & 0 \\
\hline 1,1-Dichloroethane & 832 & 64 & - & - & - & - & - & - \\
\hline 1,2-Dichloroethane & 825 & 8 & 5 & MCL & 0 & 0 & 1 & 0.1 \\
\hline 1,1-Dichloroethene & 832 & 63 & 7 & MCL & 0 & 0 & 5 & 0.6 \\
\hline cis-1,2-Dichloroethene & 832 & 67 & 70 & MCL & 0 & 0 & 2 & 0.2 \\
\hline trans-1,2-Dichloroethene & 832 & 13 & 100 & MCL & 0 & 0 & 0 & 0 \\
\hline 1,2-Dichloropropane & 830 & 27 & 5 & MCL & 0 & 0 & 2 & 0.2 \\
\hline 1,3-Dichloropropane & 832 & 1 & - & - & - & - & - & - \\
\hline 1,1-Dichloropropene & 832 & 1 & - & - & - & - & - & - \\
\hline Diethyl ether & 771 & 2 & 1,000 & HBSL & 0 & 0 & 0 & 0 \\
\hline Diisopropyl ether & 758 & 8 & - & - & - & - & - & - \\
\hline Ethyl tert-butyl ether & 771 & 1 & - & - & - & - & - & - \\
\hline Ethylbenzene & 830 & 8 & 700 & MCL & 0 & 0 & 0 & 0 \\
\hline Ethylene dibromide & 832 & 4 & 0.05 & MCL & 2 & 0.2 & 2 & 0.2 \\
\hline 2-Ethyltoluene & 770 & 3 & - & - & - & - & - & - \\
\hline Hexachlorobutadiene & 831 & 1 & 0.9 & HBSL low $^{2}$ & 0 & 0 & 0 & 0 \\
\hline Iodomethane & 771 & 1 & - & - & - & - & - & - \\
\hline Isopropylbenzene & 830 & 6 & 700 & HBSL & 0 & 0 & 0 & 0 \\
\hline$n$-Isopropyltoluene & 831 & 2 & - & - & - & - & - & - \\
\hline Methyl ethyl ketone & 769 & 13 & 4,000 & HBSL & 0 & 0 & 0 & 0 \\
\hline Methyl isobutyl ketone & 769 & 3 & - & - & - & - & - & - \\
\hline Methyl tert-butyl ether & 832 & 115 & - & - & - & - & - & - \\
\hline Methylene chloride & 832 & 22 & 5 & MCL & 0 & 0 & 1 & 0.1 \\
\hline Naphthalene & 831 & 1 & 100 & HBSL & 0 & 0 & 0 & 0 \\
\hline Perchloroethene & 829 & 187 & 5 & $\mathrm{MCL}^{4}$ & 8 & 1.0 & 18 & 2.2 \\
\hline$n$-Propylbenzene & 831 & 1 & - & - & - & - & - & - \\
\hline
\end{tabular}


Table 13. Number of detections and comparison of concentrations to human-health benchmarks for volatile organic compounds in public-well samples collected during 1993-2007.-Continued

[No common assessment level was applied to these data. Only those volatile organic compounds detected in at least one sample are included in this table. $\mu \mathrm{g} / \mathrm{L}$, micrograms per liter; BQ, Benchmark Quotient (ratio of concentration to human-health benchmark); >, greater than; $\leq$ less than or equal to; HBSL, HealthBased Screening Level; MCL, Maximum Contaminant Level; -, not available]

\begin{tabular}{|c|c|c|c|c|c|c|c|c|}
\hline \multirow{2}{*}{$\begin{array}{l}\text { Volatile organic } \\
\text { compound }\end{array}$} & \multirow{2}{*}{$\begin{array}{l}\text { Number of } \\
\text { samples }\end{array}$} & \multirow{2}{*}{$\begin{array}{l}\text { Number of } \\
\text { detections }\end{array}$} & \multicolumn{2}{|c|}{$\begin{array}{c}\text { Human-health } \\
\text { benchmark }^{1}\end{array}$} & \multicolumn{2}{|c|}{ Samples with BQ>1 } & \multicolumn{2}{|c|}{$\begin{array}{l}\text { Samples with } \\
\text { B0>0.1 and } \leq 1\end{array}$} \\
\hline & & & $\begin{array}{l}\text { Value } \\
\text { ( } \mu \mathrm{g} / \mathrm{L})\end{array}$ & Type & Number & Percent & Number & Percent \\
\hline Styrene & 829 & 2 & 100 & MCL & 0 & 0 & 0 & 0 \\
\hline 1,1,1.2-Tetrachloroethane & 832 & 3 & 70 & HBSL & 0 & 0 & 0 & 0 \\
\hline Tetrahydrofuran & 771 & 6 & - & - & - & - & - & - \\
\hline 1,2,3,4-Tetramethylbenzene & 770 & 3 & - & - & - & - & - & - \\
\hline 1,2,3,5-Tetramethylbenzene & 770 & 1 & - & - & - & - & - & - \\
\hline Toluene & 818 & 12 & 1,000 & MCL & 0 & 0 & 0 & 0 \\
\hline 1,2,3-Trichlorobenzene & 832 & 1 & - & - & - & - & - & - \\
\hline 1,2,4-Trichlorobenzene & 831 & 1 & 70 & MCL & 0 & 0 & 0 & 0 \\
\hline 1,1,1-Trichloroethane & 832 & 100 & 200 & MCL & 0 & 0 & 0 & 0 \\
\hline 1,1,2-Trichloroethane & 829 & 5 & 5 & MCL & 0 & 0 & 0 & 0 \\
\hline Trichloroethene & 832 & 122 & 5 & $\mathrm{MCL}^{4}$ & 7 & 0.8 & 18 & 2.2 \\
\hline Trichlorofluoromethane & 832 & 42 & 2,000 & HBSL & 0 & 0 & 0 & 0 \\
\hline 1,2,3-Trichloropropane & 832 & 10 & 40 & HBSL & 0 & 0 & 0 & 0 \\
\hline Trichlorotrifluoroethane & 832 & 38 & 200,000 & HBSL & 0 & 0 & 0 & 0 \\
\hline 1,2,3-Trimethylbenzene & 770 & 2 & - & - & - & - & - & - \\
\hline 1,2,4-Trimethylbenzene & 828 & 11 & - & - & - & - & - & - \\
\hline $1,3,5$-Trimethylbenzene & 831 & 2 & - & - & - & - & - & - \\
\hline Vinyl chloride & 832 & 3 & 2 & MCL & 0 & 0 & 2 & 0.2 \\
\hline$o$-Xylene & 769 & 7 & 10,000 & $\mathrm{MCL}^{5}$ & 0 & 0 & 0 & 0 \\
\hline$m$ - and $p$-Xylenes & 769 & 10 & 10,000 & $\mathrm{MCL}^{5}$ & 0 & 0 & 0 & 0 \\
\hline Total trihalomethanes & 832 & 381 & 80 & $\mathrm{MCL}^{3}$ & 0 & 0 & 11 & 1.3 \\
\hline Total xylenes & 769 & 11 & 10,000 & $\mathrm{MCL}^{5}$ & 0 & 0 & 0 & 0 \\
\hline $\begin{array}{l}\text { All detected volatile } \\
\text { organic compounds }\end{array}$ & 833 & 500 & Various & Various & 17 & 2.0 & 42 & 5.0 \\
\hline
\end{tabular}

${ }^{1}$ Human-health benchmark values were current as of September 2009. MCL values were obtained from U.S. Environmental Protection Agency (2006a) and HBSL values were obtained from the HBSL website (Toccalino and others, 2008).

${ }^{2}$ Low end of HBSL range corresponding to a $10^{-6}$ ( 1 in 1 million) cancer risk. The HBSL range corresponds to a $10^{-6}$ to $10^{-4}$ cancer risk range.

${ }^{3}$ The MCL is for total trihalomethanes; bromodichloromethane, bromoform, chlorodibromomethane, and chloroform.

${ }^{4} \mathrm{MCL}$ is under review by the U.S. Environmental Protection Agency.

${ }^{5}$ The MCL is for total xylenes (o-, $m$-, and $p$-xylene). 


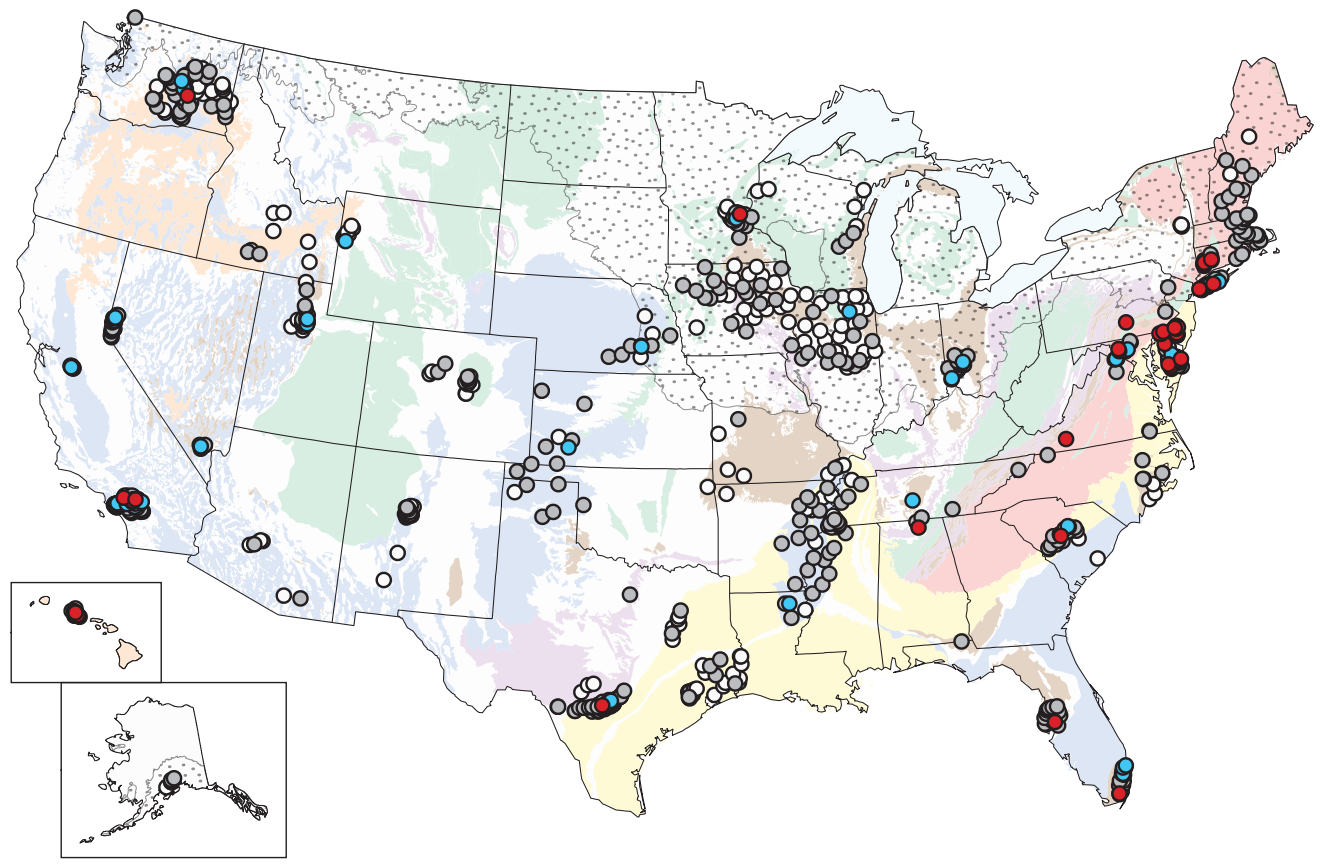

EXPLANATION

Concentrations of organic contaminants relative to human-health benchmarks

Number of (BO; ratio of concentration to human-health benchmark; $>$, greater than; $\leq$, less than or equal to) public wells

- One or more pesticide compounds or VOCs with $\mathrm{BO}>1$

41

- One or more pesticide compounds or VOCs with $\mathrm{BO}>0.1$ and $\leq 1$

- One or more pesticide compounds or VOCs with $\mathrm{BO} \leq 0.1$ or no human-health benchmark available

499

○ Not detected

326

Figure 34. Geographic distribution of Benchmark Quotients (BQ) for pesticide compounds and volatile organic compounds (VOCs) for 915 public-well samples collected during 1993-2007. No common assessment level was applied to these data. (See fig. $2 A$ for explanation of principal aquifer rock types.) 


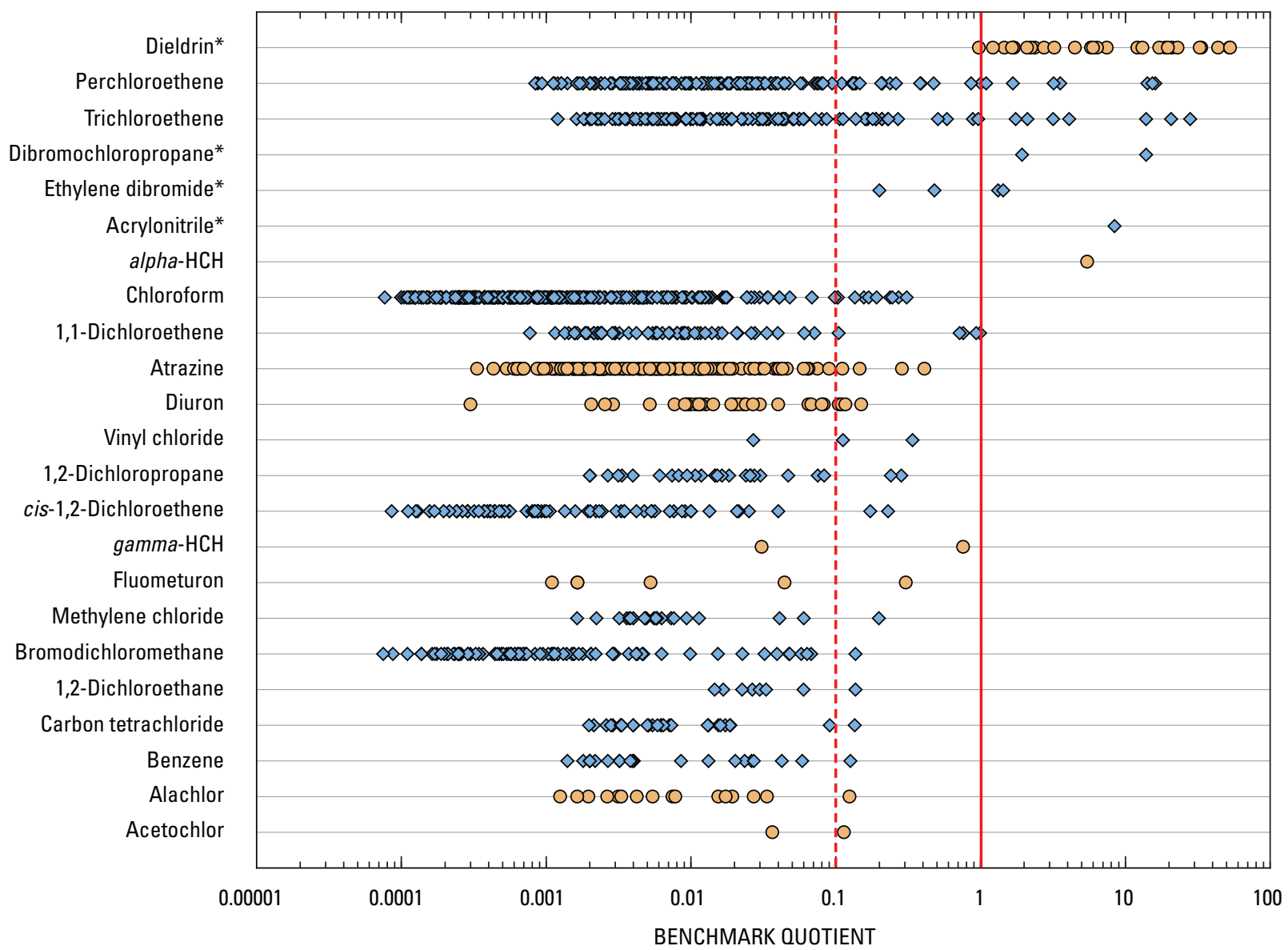

\section{EXPLANATION}

- $\mathrm{BO}=1$ (concentration equals human-health benchmark) - - - - BO $=0.1$ (concentration equals one-tenth of benchmark)

Pesticide compounds $\diamond \mathrm{VOCs}$

*For four contaminants, the ratio of the maximum reporting level to the human-health benchmark is greater than 1 (see section "Comparison of Analytical Reporting Levels to Benchmarks" on page 16). $\mathrm{HCH}$, hexachlorocyclohexane

Figure 35. Distributions of Benchmark Quotients (BO) for all pesticide compounds and volatile organic compounds (VOCs) with concentrations greater than (>) one-tenth of human-health benchmarks in one or more public-well samples collected during 1993-2007. No common assessment level was applied to these data. Contaminants are listed in order of most to least numbers of detections with $\mathrm{B} 0>1$, then in order of most to least numbers of detections with $\mathrm{B} 0>0.1$. 
Dieldrin is an organochlorine insecticide, which is a highly persistent class of insecticides used extensively in the United States during the 1950s and 1960s (Nowell and others, 1999). Dieldrin also is a degradation product formed from aldrin. Historically, dieldrin was used to control soil insects, to control corn pests, and in the citrus industry. By 1974, all uses of aldrin and dieldrin were banned, except for a few uses, such as subsurface termite control (U.S. Environmental Protection Agency, 1980); USEPA banned all uses in 1987 (Agency for Toxic Substances and Disease Registry, 2002a). Dieldrin has undergone USEPA's regulatory determination process under the SDWA, but was not selected for regulation in drinking water (U.S. Environmental Protection Agency, 2003a). Most dieldrin detections (61 percent) were in samples from unconfined aquifers in the Northern Atlantic Coastal Plain aquifer system (semi-consolidated sand and gravel aquifer) in Delaware, New Jersey, and New York (fig. 36). Dieldrin also was detected in samples from several other principal aquifer rock types in confined and unconfined aquifers, primarily in the southeastern United States and Hawaii (fig. 36).
Five organic contaminants were frequently detected (detected in at least 10 percent of source-water samples from public wells) and were detected at concentrations greater than one-tenth of human-health benchmarks in at least one sample. These contaminants were PCE and TCE (solvents that also were detected at concentrations greater than benchmarks), chloroform and bromodichloromethane (DBPs), and atrazine (an herbicide) (fig. 35, Appendixes 11 and 12). Most detections of these organic contaminants were less than one-tenth of human-health benchmarks, and some detections were several orders of magnitude less than benchmarks (fig. 35). Two additional organic contaminantsdeethylatrazine and MTBE-were detected in more than 10 percent of samples, but human-health benchmarks are not currently (April 2010) available for these contaminants, so their occurrence could not be evaluated in the context of potential human-health significance.

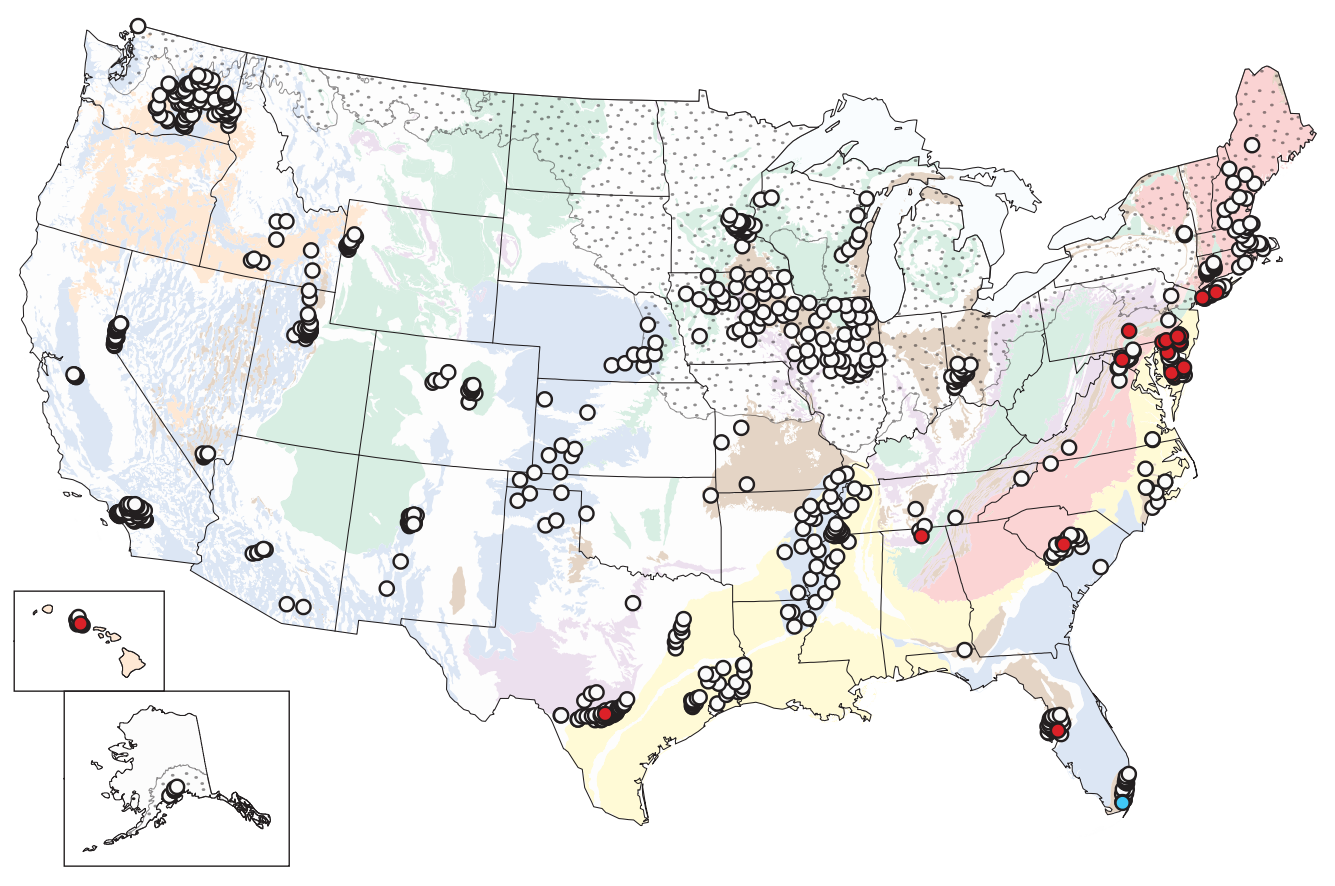

EXPLANATION

Low end of Health-Based Screening Level (HBSL) range for dieldrin $=0.002$ micrograms per liter $(\mu \mathrm{g} / \mathrm{L})$

\begin{tabular}{cccc}
\multicolumn{2}{c}{ Dieldrin concentration $(\boldsymbol{\mu g} / \mathbf{L})$} & BO- ratio of concentration to HBSL & Number of public wells \\
$\circ$ & Greater than $(>) 0.002$ & $>1$ & 27 \\
$\circ$ & $>0.0002$ to 0.002 & $>0.1$ and less than or equal to 1 & 1 \\
0 & Not detected & Not applicable & 868
\end{tabular}

Figure 36. Geographic distribution of dieldrin concentrations and Benchmark Quotients (BQ) for 896 public-well samples collected during 1993-2007. No common assessment level was applied to these data. (See fig. $2 A$ for explanation of principal aquifer rock types.) 
PCE and TCE were among the four most frequently detected VOCs, and were detected in about 23 and 15 percent of source-water samples from public wells, respectively (Appendix 12). This finding is consistent with previous studies that also reported that PCE and TCE were among the four most frequently occurring VOCs in the Nation's aquifers (Squillace and others, 1999; Zogorski and others, 2006; Hopple and others, 2009). In this study, concentrations of PCE and TCE each were greater than the MCLs of $5 \mu \mathrm{g} / \mathrm{L}$ in about 1 percent of samples (table 13). In previous studies, percentages of samples with PCE and TCE concentrations greater than MCLs were similar (Zogorski and others, 2006; Hopple and others, 2009) or slightly higher (Moran, 2006) than percentages of samples with concentrations greater than MCLs in this study. PCE and TCE concentrations also were greater than MCLs in groundwater samples from a national random survey of VOCs in CWSs (Grady, 2002). In this study, concentrations of PCE and TCE each were greater than one-tenth of their MCLs in about 25 samples (about 3 percent of samples, including those in which concentrations were greater than MCLs) (table 13 and fig. 37). In a previous study, PCE and TCE ranked high in terms of the frequencies of concentrations greater than or approaching MCLs in groundwater from various well types (Moran and others, 2007).

All samples with PCE and TCE concentrations greater than the MCLs were collected from unconfined aquifers, mostly from various sand and gravel aquifers (unconsolidated, glacial, and semi-consolidated). Geographically, about one-third of the samples with PCE or TCE concentrations greater than one-tenth of the MCLs were collected from semi-consolidated sand and gravel aquifers in Delaware, New Jersey, and New York in the Northern Atlantic Coastal Plain aquifer system (fig. 37). PCE and TCE were infrequently detected in public-well samples collected from sandstone aquifers in Illinois, Iowa, and Wisconsin, or from semi-consolidated sand and gravel aquifers in the south central United States (fig. 37). PCE and TCE are chlorinated solvents that are more dense than water, and as a result, can steadily migrate downwards in an aquifer, especially as pure solvents (Hemond and Fechner, 1994). PCE and TCE are not known to occur naturally in the environment. PCE is a manufactured chemical that is widely used for dry cleaning of fabrics and for metal-degreasing, whereas TCE is used primarily as a solvent to remove grease from metal parts, although both solvents have several additional uses (Agency for Toxic Substances and Disease Registry, 1997, 2003). PCE also can be degraded to TCE in groundwater, and then to other contaminants, such as dichloroethene, under anoxic conditions through reductive dechlorination, a process that is mediated by microorganisms (Madigan and others, 1997).

Chloroform was the most frequently detected organic contaminant and was detected in 45.8 percent of sourcewater samples from public wells (Appendix 12). Chloroform was identified as the most frequently detected VOC in the Nation's public and domestic wells in numerous other studies (Westrick and others, 1984; Squillace and others, 1999; U.S. Environmental Protection Agency, 2002b; Zogorski and others, 2006; Rowe and others, 2007; Carter and others, 2008; DeSimone, 2009; Hopple and others, 2009). Chloroform is used as a solvent, an extractant, an intermediate product in organic synthesis, and is a by-product of chlorination of drinking water and wastewater (Zogorski and others, 2006). Chloroform concentrations were less than the MCL of $80 \mu \mathrm{g} / \mathrm{L}$ in all source-water samples, but concentrations were greater than one-tenth of the MCL in 10 samples (1.2 percent of samples) (table 13 and figs. 35 and $\underline{38}$ ). This finding is consistent with previous national studies that reported that chloroform concentrations were less than the MCL in untreated water samples from public wells (Schaap and Zogorski, 2006; Zogorski and others, 2006). Geographically, seven of the 10 samples with chloroform concentrations greater than one-tenth of the MCL were collected from the Basin and Range basin-fill aquifers (unconsolidated sand and gravel aquifers) in Nevada and Utah (fig. 38). Chloroform was infrequently detected in samples collected from sandstone aquifers in Illinois, Iowa, and Wisconsin, or in semi-consolidated sand and gravel aquifers in the southcentral United States (fig. 38).

Chloroform may enter groundwater from direct industrial releases, intentional or inadvertent inputs of chlorinated water, dehalogenation of carbon tetrachloride, and various natural sources (Ivahnenko and Barbash, 2004; Ivahnenko and Zogorski, 2006). Chloroform and three other THMsbromodichloromethane, dibromochloromethane, and bromoform - are DBPs (Appendix 5) commonly produced during the chlorination of water and wastewater (Ivahnenko and Zogorski, 2006) when chlorine reacts with natural organic matter (Gallard and von Gunten, 2002; Woo and others, 2002). The USEPA regulates these four THMs together in drinking water; the MCL for total trihalomethanes (TTHM) is $80 \mu \mathrm{g} / \mathrm{L}$ (U.S. Environmental Protection Agency, 2006a). TTHM concentrations were less than the MCL in all sourcewater samples from public wells, but concentrations were greater than one-tenth of the MCL in 11 samples (1.3 percent of samples) (table 13), primarily because of chloroform concentrations. 

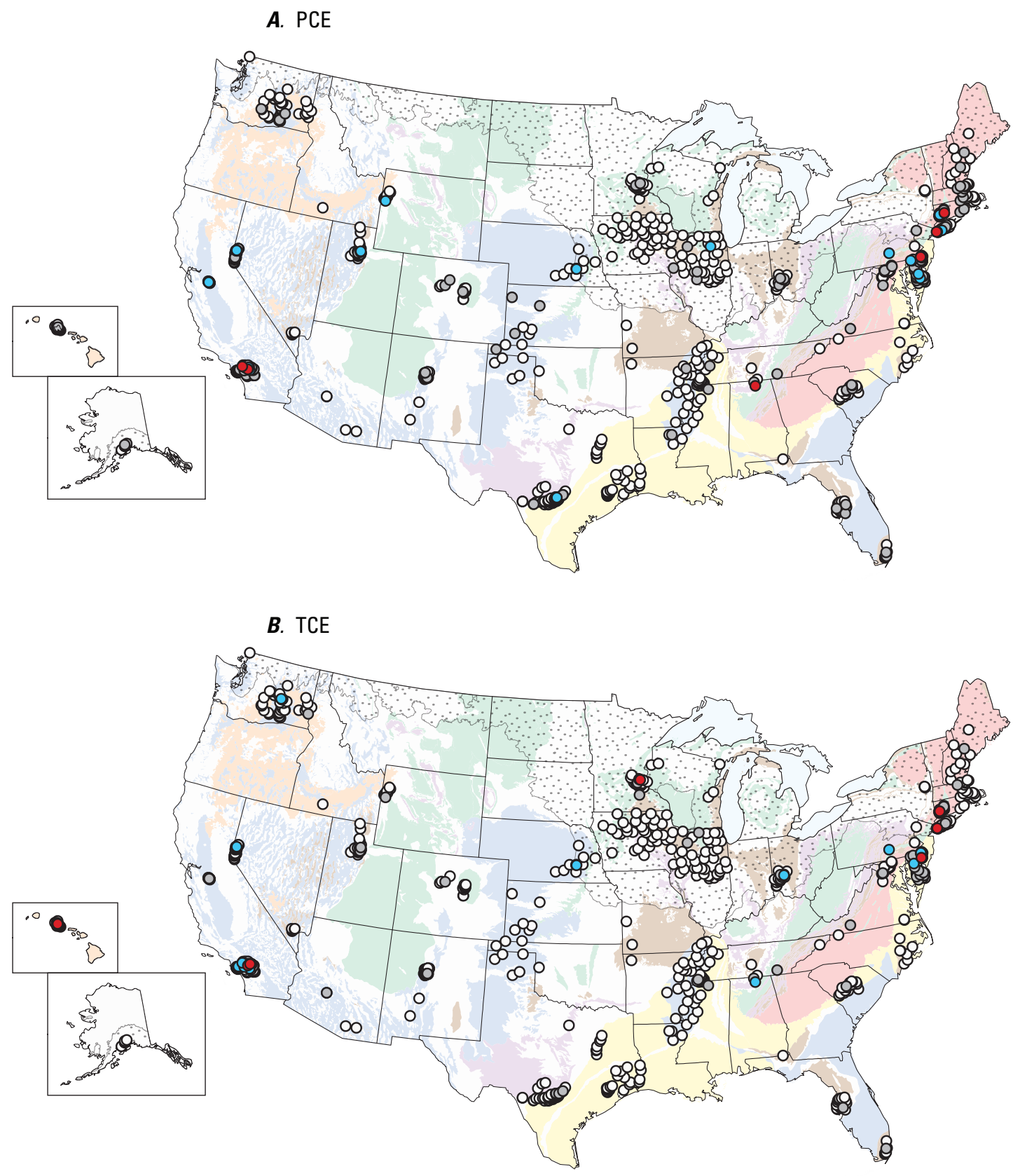

EXPLANATION

Maximum Contaminant Level (MCL) for PCE = 5 micrograms per liter $(\mu \mathrm{g} / \mathrm{L})$; MCL for TCE $=5 \mu \mathrm{g} / \mathrm{L}$

\begin{tabular}{|c|c|c|c|c|c|c|c|}
\hline \multicolumn{2}{|c|}{ PCE concentration ( $\mu \mathrm{g} / \mathrm{L})$} & \multirow{2}{*}{$\begin{array}{c}\text { BQ_-ratio of } \\
\text { concentration to } \mathrm{MCL} \\
>1\end{array}$} & \multirow{2}{*}{$\begin{array}{c}\text { Number of } \\
\text { public wells } \\
8\end{array}$} & \multicolumn{2}{|c|}{ TCE concentration $(\mu \mathrm{g} / \mathrm{L})$} & \multirow{2}{*}{$\begin{array}{l}\text { B0 } \\
>1\end{array}$} & \multirow{2}{*}{$\begin{array}{c}\text { Number of } \\
\text { public wells } \\
7\end{array}$} \\
\hline ○ & Greater than $(>) 5$ & & & ○ & $>5$ & & \\
\hline o & $>0.5$ to 5 & $>0.1$ and $\leq 1$ & 18 & 0 & $>0.5$ to 5 & $>0.1$ and $\leq 1$ & 18 \\
\hline ० & Less than or equal to $(\leq) 0.5$ & $\leq 0.1$ & 161 & o & $\leq 0.5$ & $\leq 0.1$ & 97 \\
\hline ० & Not detected & Not applicable & 642 & o & Not detected & Not applicable & 710 \\
\hline
\end{tabular}

Figure 37. Geographic distributions of $(A)$ perchloroethene (PCE) and $(B)$ trichloroethene (TCE) concentrations and Benchmark Quotients (BO) in public-well samples collected during 1993-2007. Data are from 829 samples analyzed for PCE and 832 samples analyzed for TCE. No common assessment level was applied to these data. (See fig. $2 A$ for explanation of principal aquifer rock types.) 


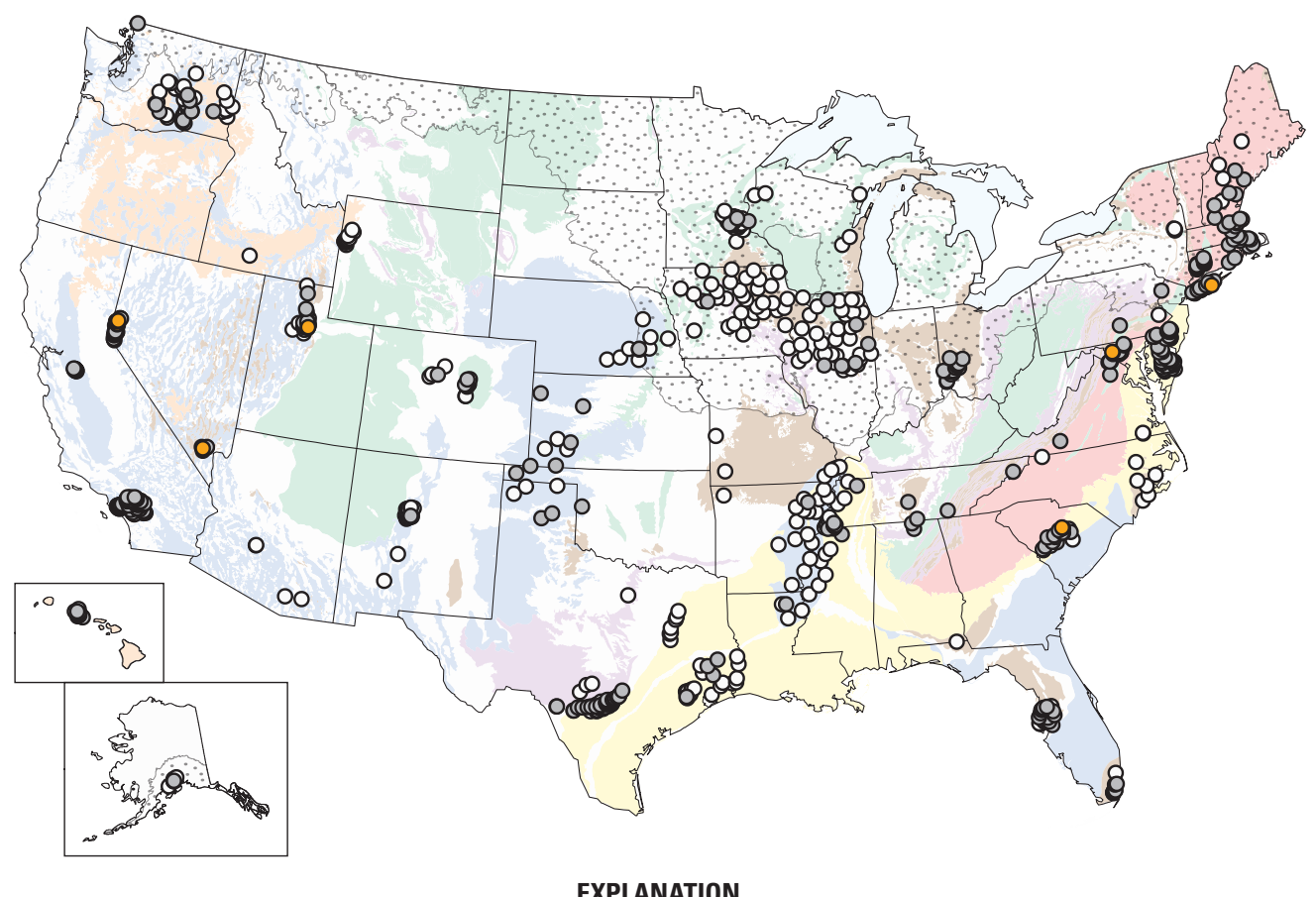

EXPLANATION

Maximum Contaminant Level (MCL) for chloroform = 80 micrograms per liter ( $\mu \mathrm{g} / \mathrm{L})$; this is the MCL for total trihalomethanes

Chloroform concentration $(\boldsymbol{\mu g} / \mathbf{L})$
○ Greater than $(>) 8$ to 80
$\circ$ Less than or equal to $(\leq) 8$
$\circ$ Not detected

Figure 38. Geographic distribution of chloroform concentrations and Benchmark Quotients (B0) for 831 public-well samples collected during 1993-2007. No common assessment level was applied to these data. (See fig. $2 A$ for explanation of principal aquifer rock types.)
When more than one THM is produced in water from chlorination, the relative concentrations (or relative detection frequencies for a uniform reporting limit) among the different contaminants usually decrease with increasing bromination (chloroform $>$ bromodichloromethane $>$ dibromochloromethane $>$ bromoform). This occurrence pattern could provide a means for distinguishing between chlorinated water and other potential sources of chloroform in groundwater (Ivahnenko and Barbash, 2004). A similar pattern was observed in public-well samples from this study (chloroform $>$ bromodichloromethane $>$ dibromochloromethane $\approx$ bromoform) using no common assessment level and at common assessment levels of 0.02 and $0.1 \mu \mathrm{g} / \mathrm{L}$ (Appendix 12 and fig. 33), suggesting that some of the chloroform detected in this study may have originated from the chlorination of water. TTHM concentrations generally did not vary significantly by principal aquifer rock type or land use, but were greater $(p<0.05)$ in samples from unconfined aquifers than from confined aquifers (data not shown). THM detections in source-water samples from public wells may be attributed to the capture of recycled water with a history of chlorination. Artificial recharge of chlorinated water containing THMs is becoming more common, especially in the western United States, in part because of limited drinking-water supplies (Zogorski and others, 2006). The occurrence of THMs in public-well samples may result from the practice of using treated water to lubricate turbine pump shafts (L.S. Fahlquist, U.S. Geological Survey, written commun., May 2008). Filters at some public water supplies also may be back-flushed with chlorinated (treated) water that is discharged back into the source waters (Grady, 2002). Once introduced to groundwater, THMs may persist and move long distances in some aquifers (Zogorski and others, 2006).

The herbicide atrazine, and deethylatrazine, a degradation product of atrazine, were the most frequently detected pesticide compounds and were detected in 26.6 and 30.1 percent of source-water samples from public wells, respectively (Appendix 11). Because deethylatrazine is a degradation product of atrazine, it generally tended to be detected in the same samples as atrazine (fig. 39). 

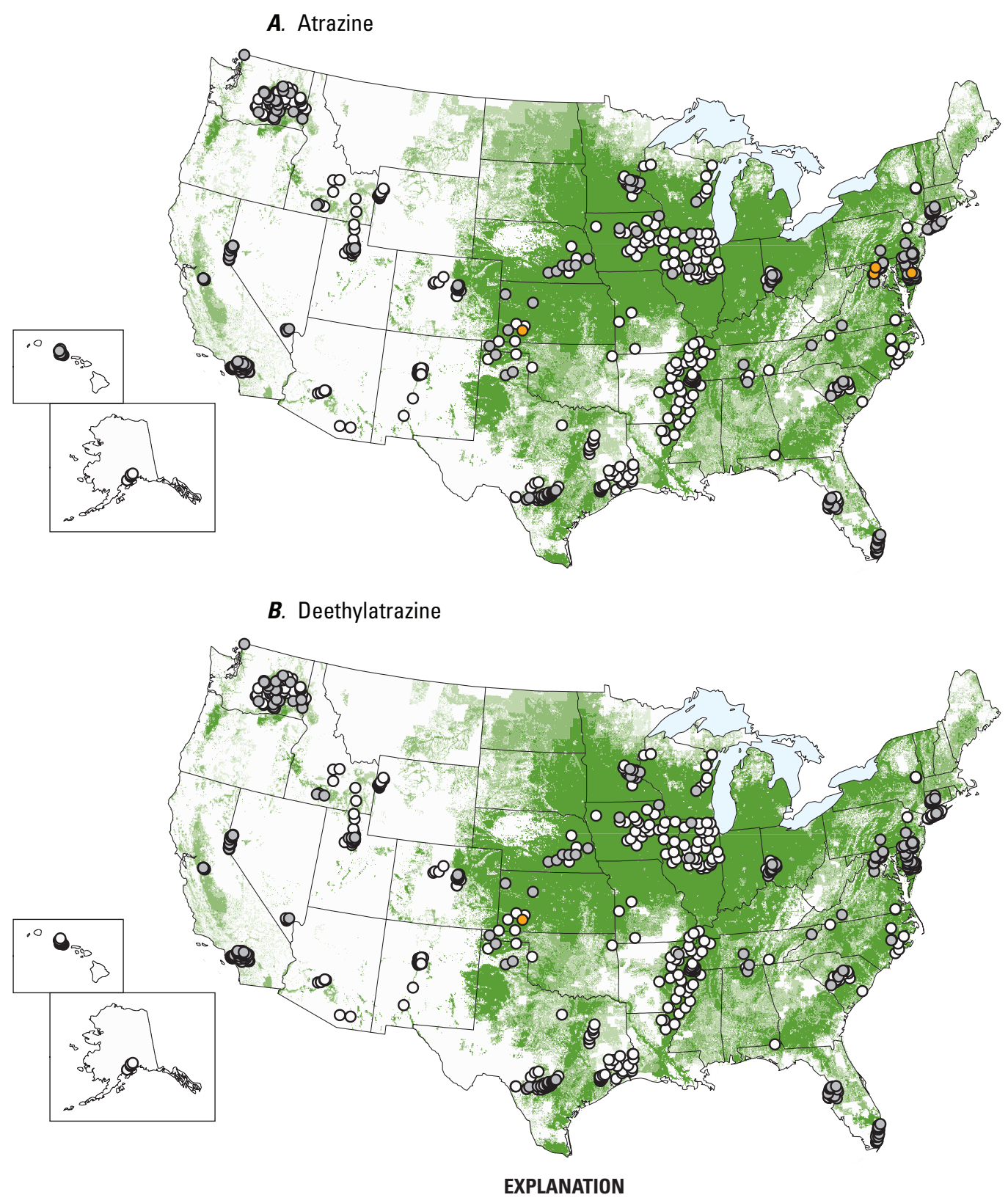

Estimated 1997 agricultural use intensity of atrazine, in pounds per square mile per year

\begin{tabular}{|c|c|c|c|c|c|c|c|}
\hline & Greater than $(>) 0$ and less th & $n 0.01$ & 0.01 & & & $>5$ & \\
\hline Data & on use intensity are not availab & for Ala & awaii & & & & \\
\hline Maxi & Im Contaminant Level (MCL) & atrazir & & $r$ liter $(\mu \mathrm{g}$ & he & ark i & rdeoth \\
\hline Atra & ine concentration $(\mu \mathrm{g} / \mathrm{L})$ & $\begin{array}{r}\text { BO } \\
\text { concen }\end{array}$ & $\mathrm{f}$ & $\begin{array}{l}\text { Number of } \\
\text { public wells }\end{array}$ & $\begin{array}{l}\text { Deet } \\
\text { conc }\end{array}$ & $\begin{array}{l}\text { ilatrazine } \\
\text { entration ( } \mu \mathrm{g} / \mathrm{L} \text { ) }\end{array}$ & $\begin{array}{c}\text { Number of } \\
\text { public wells }\end{array}$ \\
\hline 0 & $>0.3$ to 3 & & & 4 & 0 & $>0.3$ to 3 & 1 \\
\hline 0 & Less than or equal to $(\leq) 0.3$ & & & 223 & o & $\leq 0.3$ & 256 \\
\hline 0 & Not detected & & & 626 & 0 & Not detected & 596 \\
\hline
\end{tabular}

Figure 39. Geographic distributions of $(A)$ atrazine and $(B)$ deethylatrazine concentrations and Benchmark Quotients (BO) for 853 public-well samples collected during 1993-2007. No common assessment level was applied to these data. 
Atrazine has been one of the most heavily used herbicides in the United States since the 1990s, on the basis of total pounds applied (Thelin and Stone, 2010). Most agricultural use of atrazine was associated with corn production, but it also has some nonagricultural uses. Atrazine is highly soluble, mobile, and moderately persistent in water (Gilliom and others, 2006). Geographically, atrazine and deethylatrazine were detected in public wells throughout the United States, but were not most frequently detected in regions of highest atrazine use, such as in Illinois and Iowa (fig. 39). This same distinct regional pattern - that atrazine was not most frequently detected in areas of highest use - has been noted in several previous studies (Hallberg, 1989; Kolpin and others, 1994; Gilliom and others, 2006). This pattern may be the result of (1) the widespread use of subsurface drainage systems (tile drains) in areas of highest atrazine use; tile drains move shallow groundwater rapidly to streams and reduce transport to deep groundwater, and (2) the presence of low-permeability glacial till (Burkart and others, 2001; Gilliom and others, 2006).

Atrazine concentrations were less than the MCL of $3 \mu \mathrm{g} / \mathrm{L}$ (U.S. Environmental Protection Agency, 2006a) in all source-water samples from public wells, and concentrations were greater than one-tenth of the MCL in four samples (0.5 percent of samples) (table 12 and figs. 35 and $\underline{39}$ ). An MCL or HBSL is not available for deethylatrazine. As part of the FIFRA reregistration of atrazine in 2003, however, the USEPA developed Drinking Water Levels of Comparison (DWLOCs) for the sum of atrazine and its three chlorinated degradates (deethylatrazine, deisopropylatrazine, and deethyldeisopropyl atrazine), referred to as total chlorotriazines (TCT), in public water systems (U.S. Environmental Protection Agency, 2003e). DWLOCs are the maximum concentrations in drinking water that, when considered together with other dietary exposure, do not exceed a level of concern. Because of the relatively slow movement of groundwater, changes in contaminant concentrations over time generally were not expected to be large. As a result, the DWLOC for TCT used in this analysis is a 90-day moving average of $12.5 \mu \mathrm{g} / \mathrm{L}$, which applies when source-water samples are collected from a water system less than weekly during the high-use season (U.S. Environmental Protection Agency, 2003e). Concentrations greater than the DWLOC indicate a need for further analysis and monitoring.

The USEPA no longer uses the DWLOC approach for dietary risk assessment (E. Behl, U.S. Environmental Protection Agency, written commun., December 2009). Since the reregistration of atrazine in 2003, many studies have examined the health effects of atrazine. In order to evaluate this new science, the USEPA announced in October 2009 the beginning of a year-long, comprehensive scientific re-evaluation of the potential human-health impacts of atrazine by using information about atrazine's mode of action and by carefully considering the potential for cancer and non-cancer effects based on the available data from laboratory animal and human epidemiology studies (U.S. Environmental Protection Agency, 2009c). Although this re-evaluation of atrazine will change future assessments, TCT concentrations detected in this study were compared to the DWLOC as a preliminary assessment. Approximate TCT concentrations were calculated as the sum of atrazine and deethylatrazine (the two other chlorinated degradates were not analyzed) and simazine. Simazine was included with TCT because USEPA's recent cumulative risk assessment for triazines concluded that simazine should be included with TCT in a common mechanism group for cumulative risk assessment (U.S. Environmental Protection Agency, 2006c).

TCT concentrations were less than the DWLOC in all source-water samples from public wells, and concentrations were greater than one-tenth of the DWLOC in only one sample (table 12). This sample was one of the four samples with an atrazine concentration greater than one-tenth of the MCL, and was from an unconfined aquifer in unconsolidated sand and gravel in Kansas (fig. 39). TCT concentrations generally did not vary significantly by principal aquifer rock type or land use, but were greater $(p<0.05)$ in samples from unconfined aquifers than from confined aquifers (data not shown).

MTBE was among the four most frequently detected VOCs, and was detected in 13.8 percent of source-water samples from public wells (Appendix 12). MTBE is almost exclusively used as a fuel additive (gasoline oxygenate) to raise the oxygen content of gasoline, which in turn helps gasoline to burn more completely (U.S. Environmental Protection Agency, 2008d). MTBE was the most commonly used oxygenate in gasoline to help meet the requirements of the Clean Air Act Amendments of 1990 (Moran and others, 2005). As a result, MTBE was detected much more frequently in this study than other gasoline oxygenates, such as tert-amyl methyl ether or ethyl tert-butyl ether (Appendix 12), which is consistent with results from other studies (Grady, 2002; Carter and others, 2006; DeSimone, 2009). MTBE also was detected more frequently than any of the gasoline hydrocarbons, such as the BTEX contaminants benzene, toluene, ethylbenzene, and xylenes (Appendix 12), which was consistent with the statewide occurrence of MTBE and gasoline hydrocarbons in Maine's drinking-water supplies (State of Maine, 1998) and a national survey of MTBE and other VOCs in drinking-water sources (Grady, 2002). MTBE is more soluble, less likely to sorb to aquifer materials, and more resistant to biodegradation than most other gasoline components, making MTBE very mobile in groundwater systems (Squillace and others, 1997; Johnson and others, 2000). 
Currently, an MCL or HBSL is not available for MTBE, but the USEPA odor and taste thresholds are 20 and $40 \mu \mathrm{g} / \mathrm{L}$, respectively (U.S. Environmental Protection Agency, 2006a). MTBE concentrations were less than these thresholds in all samples (table 8). In previous national- and state-scale studies, MTBE concentrations in public-well samples also were less than $20 \mu \mathrm{g} / \mathrm{L}$ (Grady, 2002; Zogorski and others, 2006) or $35 \mu \mathrm{g} / \mathrm{L}$ (State of Maine, 1998). MTBE detections primarily were concentrated in the northeastern United States, the mid-Atlantic regions, and California, which are areas of high MTBE use (fig. 40). This finding is consistent with a previous study where the frequency of MTBE detections in drinking water was significantly related to high MTBE-use patterns (Grady and Casey, 2001). In Maine, MTBE was most frequently detected in areas with high population densities and in areas where reformulated gasoline was used (State of Maine, 1998). In 2000, the USEPA announced the beginning of regulatory action to significantly reduce or eliminate MTBE use in gasoline (U.S. Environmental Protection
Agency, 2008e). As of 2004, MTBE in gasoline was partially or completely banned in 19 states (U.S. Environmental Protection Agency, 2004b).

\section{Fecal-Indicator Microorganisms}

Waterborne diseases are the most widespread and acute threat to health from drinking water (U.S. Environmental Protection Agency, 2008c). However, as many as 98 percent of drinking-water utilities report that they provide disinfected water (American Water Works Association Disinfection Systems Committee, 2008) that is specifically treated to prevent waterborne diseases. Because analyzing the wide variety of microorganisms that may be present in water resources is costly and time consuming for water utilities, fecal-indicator microorganisms typically are analyzed instead of specific pathogens (Bitton, 1994). The fecal-indicator microorganisms analyzed in this study were total coliforms,

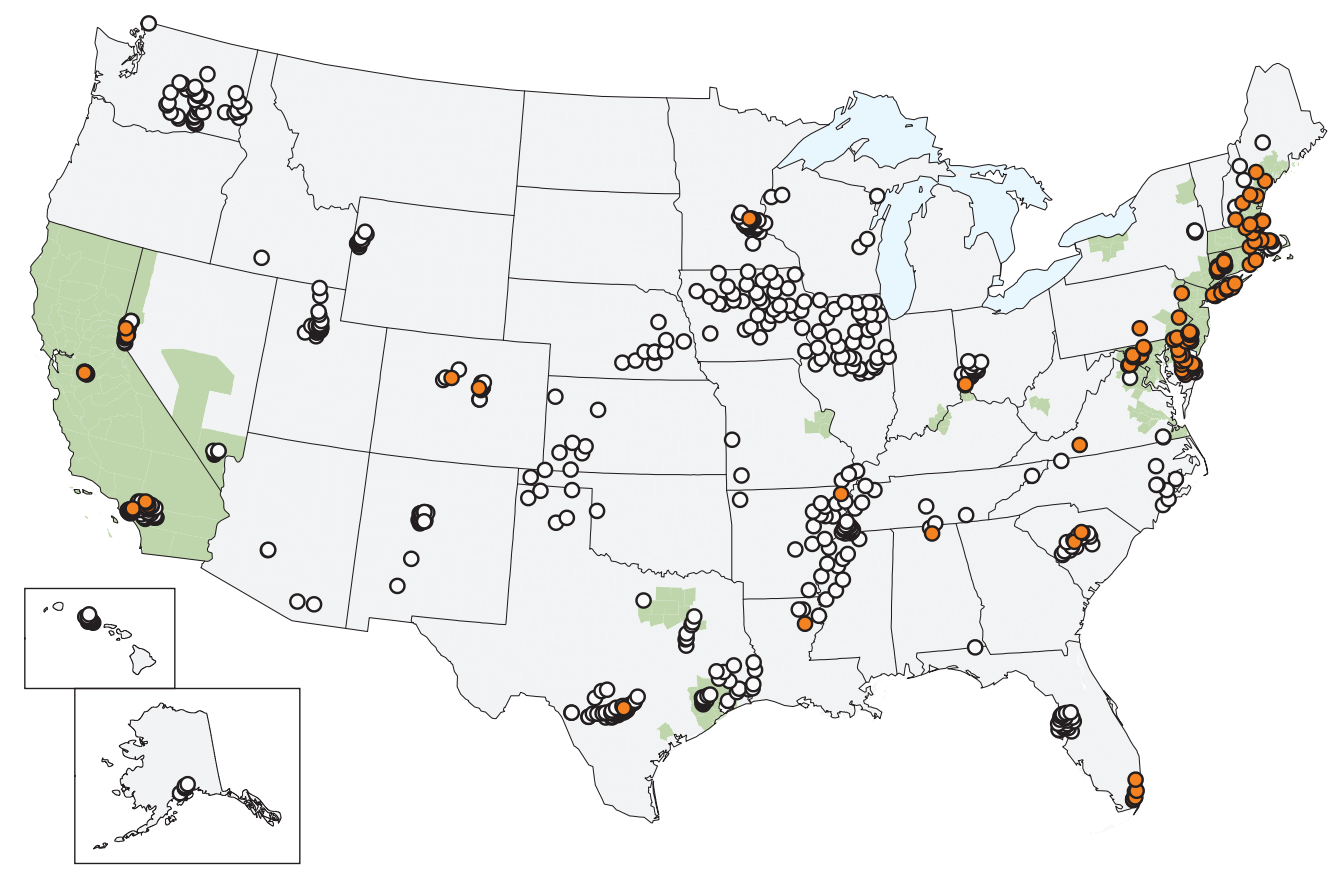

EXPLANATION

A human-health benchmark is not available for MTBE

\begin{tabular}{|c|c|c|}
\hline Area of high MTBE use & MTBE detection & Number of public wells \\
\hline & - Detected & 115 \\
\hline & ○ Not detected & 717 \\
\hline
\end{tabular}

Figure 40. Geographic distribution of methyl tert-butyl ether (MTBE) detections in 832 public-well samples collected during 1993-2007. No common assessment level was applied to these data. 
Escherichia coli (E. coli), and coliphage (table 10). Overall, fecal-indicator microorganisms were detected in about 12 percent of 353 source-water samples from public wells. A complete description of NAWQA's microbiological sampling program and national results for groundwater samples collected from various well types during 1993-2004 was provided by Embrey and Runkle (2006). About two-thirds of the samples analyzed for fecal-indicator microorganisms in this study were included in the study by Embrey and Runkle (2006), so the results from these two studies are similar.

Fecal-indicator microorganisms usually are associated with the intestinal tract and their presence in water indicates that the water has received contamination of an intestinal origin (Madigan and others, 1997). The most widely used indicator is the total coliform group of organisms, which includes various organisms including E. coli. Coliforms are good indicators of fecal contamination because they are common inhabitants and are present in large numbers in the intestinal tract of humans and other warm-blooded animals. Coliforms also die at a slower rate than some pathogenic bacteria, yet behave similarly to pathogens during water purification processes. Therefore, if coliforms are detected in water, then it is likely that water has received fecal contamination (Madigan and others, 1997). Fecal contamination can reach groundwater sources, including public wells, from livestock wastes, failed septic systems, leaking sewer lines, land application of sewage, and improperly constructed wells (Freeze and Cherry, 1979; U.S. Environmental Protection Agency, 2006b).

The Total Coliform Rule of 1989 was established to reduce fecal pathogens in public water systems to minimal levels through the control of total coliform bacteria, including fecal coliforms and E. coli (U.S. Environmental Protection Agency, 2001d). The MCL established by the Total Coliform Rule is based on the presence or absence of total coliforms in a percentage of samples collected each month. All samples testing positive for total coliforms must also be tested for fecal coliforms or E. coli; fecal coliforms or E. coli are not allowed (U.S. Environmental Protection Agency, 2001d, 2006a). In 2006, USEPA issued the Ground Water Rule to further protect groundwater sources of public drinking water supplies from disease-causing viruses and bacteria. The Ground Water Rule requires identification of deficiencies in water systems that could lead to contamination and requires corrective actions to reduce risks resulting from these deficiencies (U.S. Environmental Protection Agency, 2006b). Detections of total coliforms and E. coli from this study could not be compared to MCLs because the MCLs are based on monthly sampling and only one sample was collected per public well in this study. Instead, fecal-indicator microorganisms are reported as 'present' or 'absent'.

Total coliform bacteria and E. coli were detected in 10.5 and 2.4 percent of the source-water samples from public wells, respectively (table 10). Embrey and Runkle (2006) noted similar detection frequencies of total coliform bacteria (15.9 percent) and E. coli (2.7 percent) in public-well samples. Total coliforms were detected in samples from all principal aquifer rock types in which coliforms were analyzed, and their occurrence, therefore, was widely distributed across the United States (fig. 41). Total coliforms were most frequently detected in crystalline-rock and carbonate-rock aquifers, which is consistent with the findings of previous studies (Embrey and Runkle, 2006; DeSimone, 2009). The highest percentage of $E$. coli detections was in samples from sandstone and carbonate-rock aquifers in the southern and eastern United States (fig 41).

Nationally, total coliform bacteria and E. coli were detected about 3-fold more frequently in domestic wells (33.5 and 7.9 percent, respectively) than in public wells (DeSimone, 2009), in part because domestic wells tend to be shallower than public wells and therefore more vulnerable to contamination from the land surface (Embrey and Runkle, 2006). Further, domestic wells also are less likely than public wells to have stringent wellhead protection practices, so fecal contamination may be introduced into domestic wells from surface sources near the wellhead, especially if the well is not sealed or its casing is not intact (DeSimone, 2009).

More than 100 types of human pathogenic viruses may be present in water with fecal contamination (Havelaar and others, 1993), but because monitoring of these enteric viruses is difficult and time consuming, coliphages have been considered as possible indicator organisms for enteric viruses in surface water and groundwater contaminated with fecal material (Brion and others, 2002). Coliphages are bacteriophages, specifically viruses that infect and replicate in coliform bacteria, including E. coli (Bitton, 1994; Francy and others, 2000). Coliphages are being considered as potential indicators of fecal contamination because they are similar to enteric viruses, they are more easily and rapidly detected in water than enteric viruses, and they are detected in higher numbers than enteric viruses in various environments (Bitton, 1994). The detection of coliphages in public-well samples does not indicate that pathogenic viruses also will be detected in the water; rather, coliphage detection indicates the potential for the transport of other viruses into the subsurface (Embrey and Runkle, 2006). 


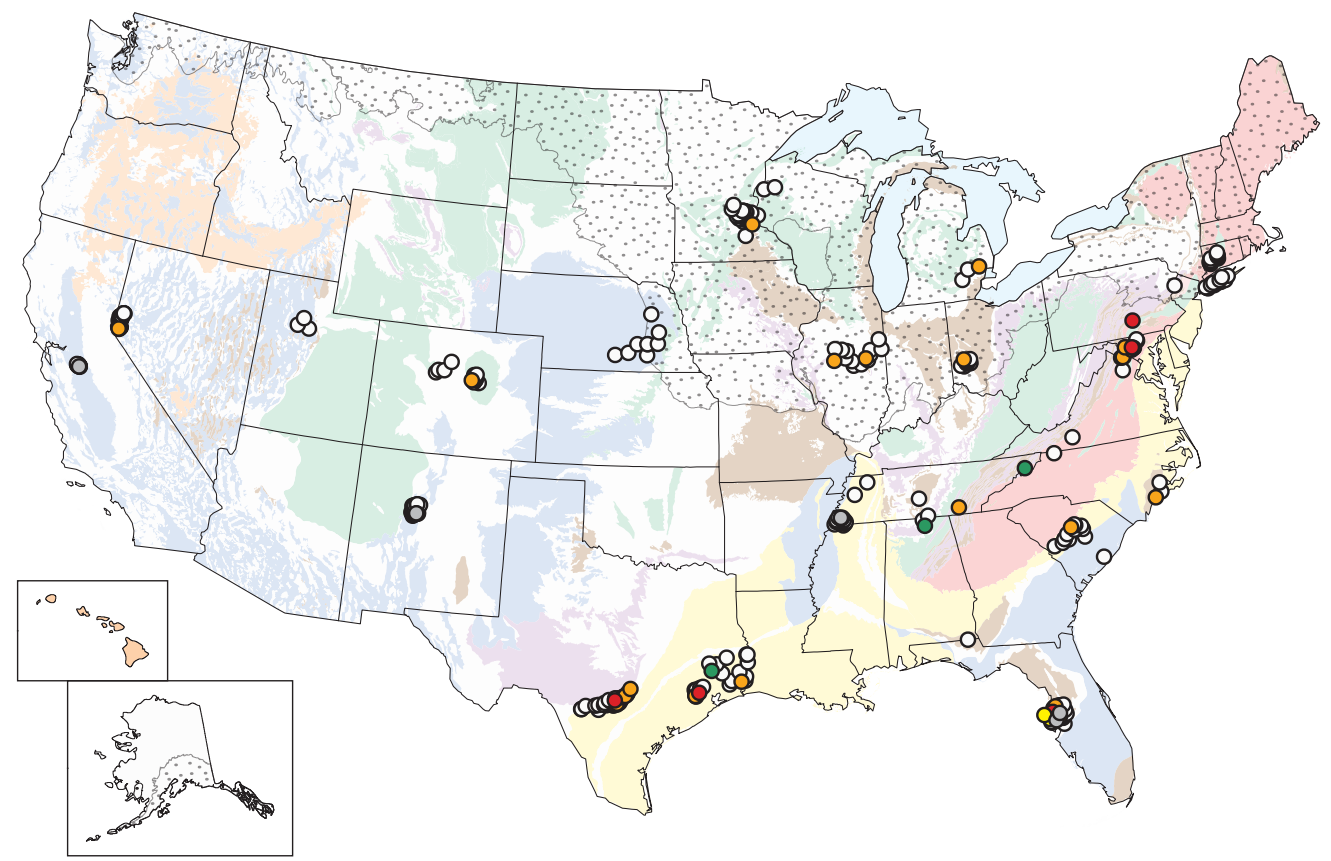

EXPLANATION

Detections of fecal-indicator microorganisms

Number of public wells

- Total coliform and Escherichia coli detected

5

- Total coliform only detected

29

- Total coliform and coliphage detected

- Escherichia coli only detected

○ Coliphage only detected

o No microorganisms detected — not all microorganisms were analyzed in all samples

Figure 41. Geographic distribution of detections of fecal-indicator microorganisms in 353 publicwell samples collected during 1993-2007. (See fig. 2A for explanation of principal aquifer rock types.)

Coliphages were detected in 2.4 percent of 294 source-water samples from public wells (table 10), and four of the seven coliphage detections were in samples from confined carbonate-rock aquifers in the Floridan aquifer system (fig. 41). These coliphage results are consistent with Embrey and Runkle (2006) who reported that coliphages were detected in 2.7 percent of 183 public-well samples, with three of the five detections in samples from the Floridan (carbonate-rock) aquifer system. The presence of coliphages in public-well samples was not related to the presence of total coliforms or E. coli; coliphages co-occurred with total coliforms in two samples (fig. 41). This lack of co-occurrence between detections of coliform bacteria and coliphage has been observed in previous studies (Francy and others, 2004; Embrey and Runkle, 2006).

\section{Summary of Comparison of Contaminant Concentrations to Human-Health Benchmarks}

Human-health benchmarks were available for 108 of the 157 naturally occurring and anthropogenic contaminants that were detected in one or more source-water samples from public wells (table 14). The potential human-health relevance of the occurrence of 49 contaminants without benchmarksalmost one-third of detected contaminants - cannot, therefore, be evaluated at this time. One-half of the detected contaminants without available benchmarks were VOCs (Appendix 15). 
Table 14. Summary of contaminant occurrence and comparisons of concentrations to human-health benchmarks, by contaminant group, for public wells sampled during 1993-2007.

[No common assessment level was applied to these data. MCL, Maximum Contaminant Level; HBSL, Health-Based Screening Level; BQ, Benchmark Quotient (ratio of concentration to human-health benchmark); >, greater than; $\leq$ less than or equal to; -, not available; mrem/yr; millirem per year; pCi/L, picocuries per liter]

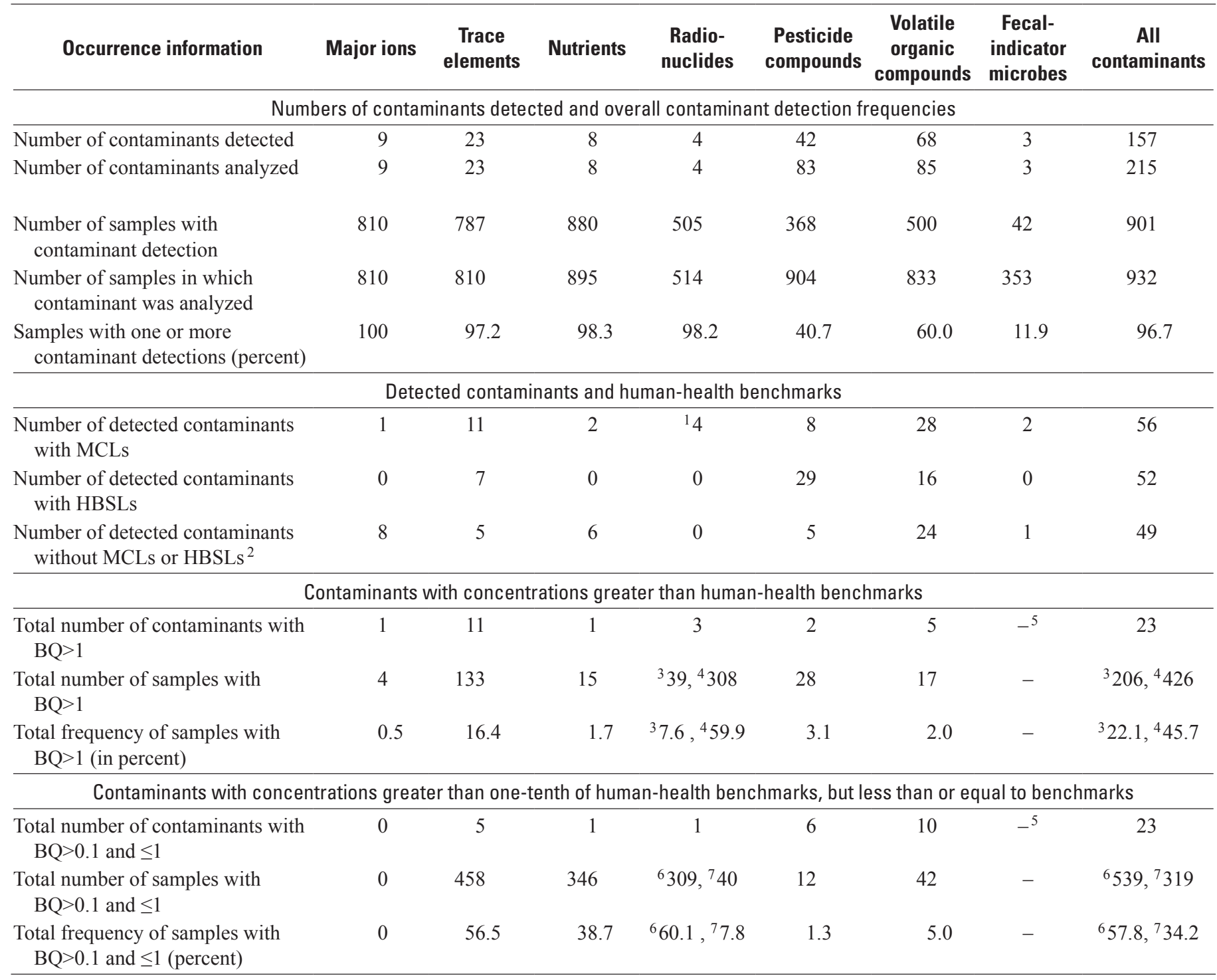

${ }^{1} \mathrm{MCL}=4 \mathrm{mrem} / \mathrm{yr}$, but because gross beta-particle radioactivity was measured in $\mathrm{pCi} / \mathrm{L}$, activities were compared to USEPA's screening level for gross betaparticle radioactivity of $50 \mathrm{pCi} / \mathrm{L}$ (U.S. Environmental Protection Agency, 2000b).

${ }^{2}$ Non-health guidelines are available for some detected contaminants (see table 8 ).

${ }^{3}$ Radon activities were compared to the proposed Alternative MCL (AMCL) of 4,000 pCi/L.

${ }^{4}$ Radon activities were compared to the proposed MCL of $300 \mathrm{pCi} / \mathrm{L}$, which is about one-tenth of the proposed AMCL.

${ }^{5}$ Because the MCL for Escherichia coli and total coliforms is based on monthly sampling, and because one sample was collected per public well in this study, the percentage of samples with $\mathrm{BQ}>1$ or $\mathrm{BQ}>0.1$ for fecal-indicator microorganisms could not be calculated. Escherichia coli and total coliforms were detected in 2.4 and 10.5 percent of public-well samples, respectively.

${ }^{6}$ Samples with radon activities greater than the proposed MCL value $(300 \mathrm{pCi} / \mathrm{L})$ but less than or equal to the proposed $\mathrm{AMCL}(4,000 \mathrm{pCi} / \mathrm{L})$ were counted.

${ }^{7}$ Samples with radon activities greater than one-tenth of the proposed MCL value were not counted in this category. 
Concentrations were less than MCLs or HBSLs for 85 of the 108 detected contaminants with human-health benchmarks (table 14). Concentrations of the remaining 23 contaminants were greater than MCLs or HBSLs in 0.1 to 55 percent of source-water samples from public wells if the lower proposed MCL for radon was used, or in 0.1 to 19 percent of samples if the higher proposed AMCL for radon was used (fig. 42). About one-half of the 23 contaminants with concentrations greater than human-health benchmarks - all inorganic contaminants - also were frequently detected (more than 10 percent of samples) at concentrations greater than one-tenth of benchmarks (ig. 42).

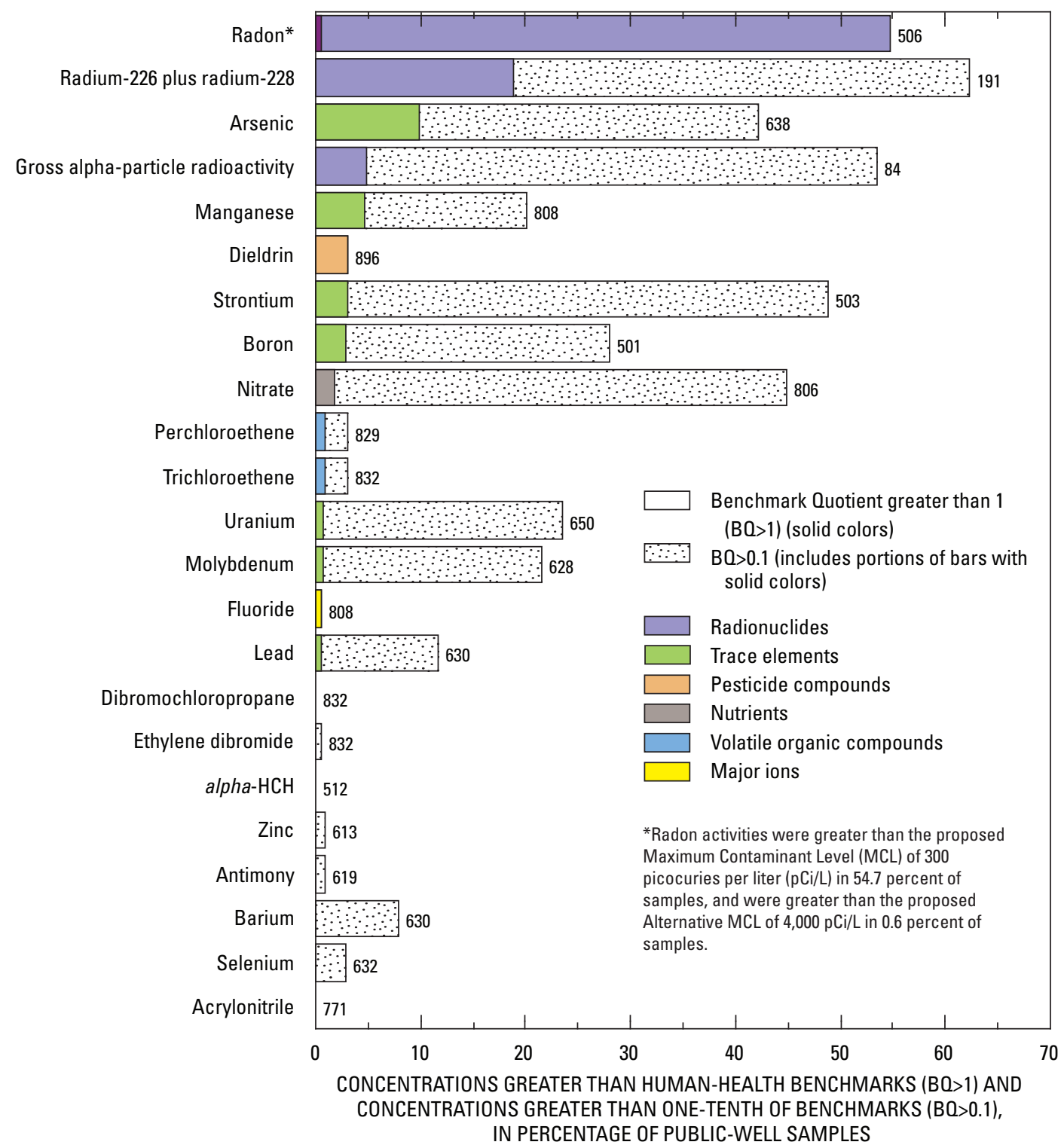

Figure 42. Percentage of source-water samples with concentrations greater than human-health benchmarks and concentrations greater than one-tenth of benchmarks. Data are for each of 23 contaminants with concentrations greater than benchmarks in one or more public-well samples collected during 1993-2007. Numbers at the end of bars indicate the number of samples in which a contaminant was analyzed. No common assessment level was applied to these data. 
All together, more than one in five (22 percent) source-water samples from public wells contained one or more contaminants at concentrations greater than human-health benchmarks (tables 14 and 15 and fig. 43). These results are based on comparing radon activities to the proposed AMCL of $4,000 \mathrm{pCi} / \mathrm{L}$. Relative to specific types of benchmarks, concentrations of at least one chemical contaminant were greater than an MCL in 15 percent of the source-water samples and were greater than an HBSL in 10 percent of the source-water samples; contaminant concentrations were greater than both MCLs and HBSLs in some samples (table 15). Collectively, contaminants regulated in drinking water accounted for 60 percent of concentrations greater than human-health benchmarks, and unregulated contaminants accounted for 40 percent of concentrations greater than benchmarks. If radon activities were compared to the proposed
MCL of $300 \mathrm{pCi} / \mathrm{L}$, then concentrations of one or more contaminants were greater than benchmarks in a total of about 46 percent of samples (tables 14 and $\underline{15}$ and fig. 43 ).

A total of 80 percent of source-water samples contained at least one contaminant at concentrations greater than one-tenth of human-health benchmarks, regardless of which proposed MCL or AMCL was applied to radon activities (tables 14 and $\underline{15}$ and figs. 43 and $\underline{44}$ ). Most individual contaminant detections, however, were less than one-tenth of human-health benchmarks, and many detections were several orders of magnitude less than benchmarks. Public wells yielding water in which contaminant concentrations were greater than benchmarks, as well as those in which concentrations were greater than one-tenth of benchmarks, were distributed throughout the United States and include wells that withdraw water from all principal aquifer rock types included in this study (fig. 44).

Table 15. Overall summary of comparison of contaminant concentrations to human-health benchmarks for 932 public-well samples collected during 1993-2007.

[No common assessment level was applied to these data. BQ, Benchmark Quotient (ratio of concentration to human-health benchmark); $>$, greater than; $\leq$ less than or equal to; AMCL, Alternate Maximum Contaminant Level; MCL, Maximum Contaminant Level; pCi/L, picocuries per liter; HBSL, Health-Based Screening Level; mg/L, milligrams per liter. Numbers for MCLs and HBSLs do not sum to totals because some samples have concentrations greater than more than one type of benchmark. Fecal-indicator microorganisms were excluded from this table because samples were not collected in a manner that allows for comparisons to benchmarks.]

\begin{tabular}{|c|c|c|c|c|}
\hline \multirow{2}{*}{ Human-health benchmark } & \multicolumn{2}{|c|}{ Samples with BO>1 } & \multicolumn{2}{|c|}{ Samples with $B 0>0.1$ and $\leq 1^{1}$} \\
\hline & Number & Percent & Number & Percent \\
\hline \multicolumn{5}{|c|}{ Benchmarks used for radon: proposed $A M C L$ of $4,000 \mathrm{pCi} / \mathrm{L}$ for $\mathrm{BO}>1$ and proposed $\mathrm{MCL}$ of $300 \mathrm{pCi} / \mathrm{L}$ for $\mathrm{B} 0>0.1$ and $\leq 1$} \\
\hline MCLs & ${ }^{2} 142$ & ${ }^{2} 15.2$ & ${ }^{3} 533$ & ${ }^{3} 57.2$ \\
\hline HBSLs & 97 & 10.4 & 401 & 43.0 \\
\hline All human-health benchmarks (MCLs and HBSLs) & 206 & 22.1 & 539 & 57.8 \\
\hline \multicolumn{5}{|c|}{ Benchmarks used for radon: proposed $\mathrm{MCL}$ of $300 \mathrm{pCi} / \mathrm{L}$ for $\mathrm{B} 0>1$. Radon excluded from $\mathrm{B} 0>0.1$ and $\leq 1$ category } \\
\hline MCLs & 3375 & ${ }^{3} 40.2$ & ${ }^{4} 300$ & ${ }^{4} 32.2$ \\
\hline HBSLs & 97 & 10.4 & 401 & 43.0 \\
\hline All human-health benchmarks (MCLs and HBSLs) & 426 & 45.7 & 319 & 34.2 \\
\hline \multicolumn{5}{|c|}{$\begin{array}{l}{ }^{1} \text { Fluoride was excluded from this category because fluoride at this level }(0.4 \mathrm{mg} / \mathrm{L}) \text { is less than the range of concentrations in drinking } \\
\text { water recommended for the prevention of tooth decay (U.S. Centers for Disease Control and Prevention, 2001). }\end{array}$} \\
\hline \multicolumn{5}{|c|}{$\begin{array}{l}{ }^{2} \mathrm{Radon} \text { activities were compared to the proposed } \mathrm{AMCL} \text { of } 4,000 \mathrm{pCi} / \mathrm{L} \text { (three public-well samples had radon activities greater than } \\
4,000 \mathrm{pCi} / \mathrm{L} \text { ). }\end{array}$} \\
\hline \multicolumn{5}{|c|}{$\begin{array}{l}{ }^{3} \text { Radon activities were compared to the proposed MCL of } 300 \mathrm{pCi} / \mathrm{L} \text {, which is about one-tenth of the proposed AMCL ( } 277 \text { public-well } \\
\text { samples had radon activities greater than } 300 \mathrm{pCi} / \mathrm{L} \text { ). }\end{array}$} \\
\hline
\end{tabular}




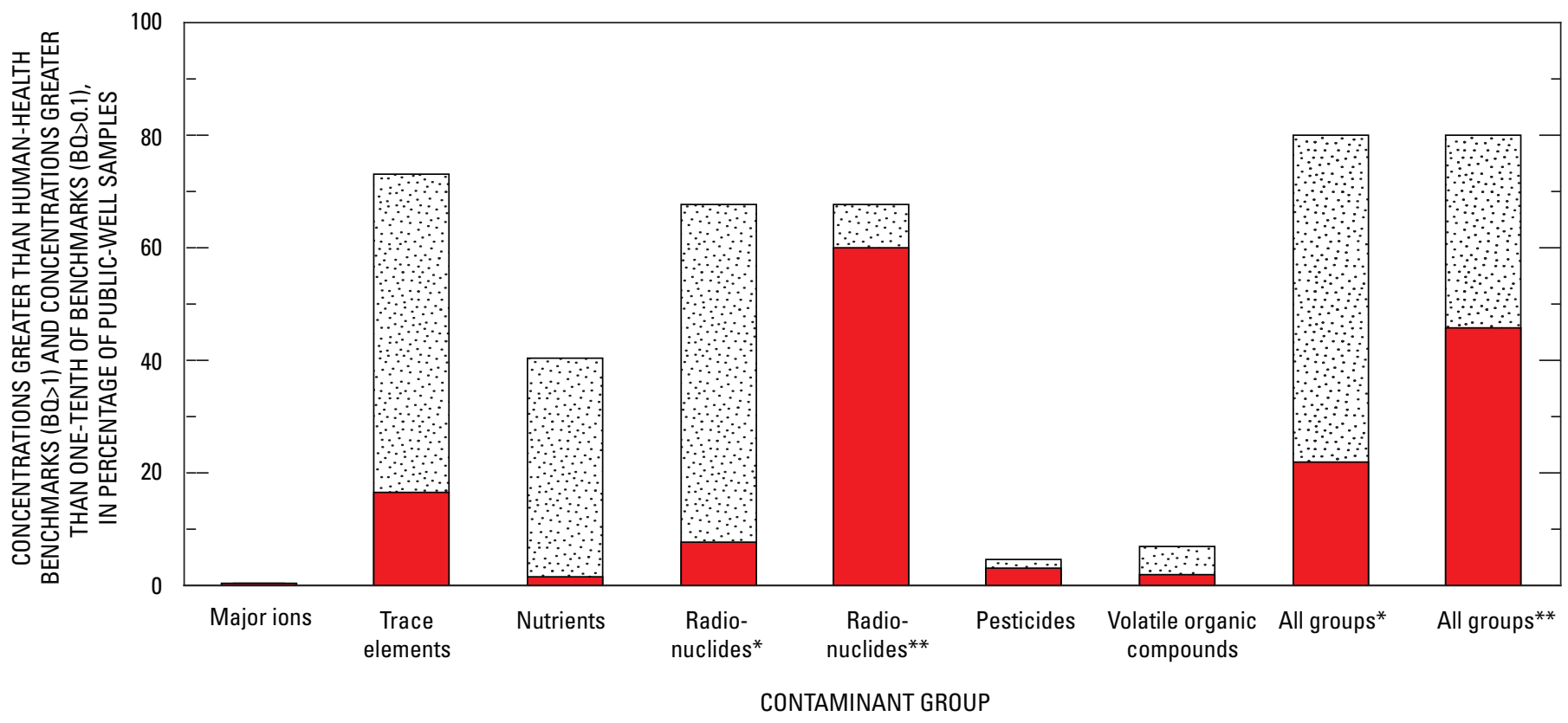

\section{EXPLANATION}

Benchmark Quotient greater than $1(\mathrm{~B} 0>1)$

$\mathrm{BO}>0.1$ (includes portion of bars with solid color)

*For radon, the proposed Alternative Maximum Contaminant Level of 4,000 picocuries per liter (pCi/L) was used for the $\mathrm{B} 0>1 \mathrm{category}$, and the proposed Maximum Contaminant Level (MCL) of $300 \mathrm{pCi} / \mathrm{L}$ was used for the B0>0.1 category.

**For radon, the proposed $\mathrm{MCL}$ of $300 \mathrm{pCi} / \mathrm{L}$ was used for the $\mathrm{B} 0>1$ category, and radon was excluded from the $\mathrm{B} 0>0.1 \mathrm{category}$.

Figure 43. Summary of percentage of source-water samples with one or more contaminants with concentrations greater than human-health benchmarks and concentrations greater than one-tenth of benchmarks, by contaminant group, for public-well samples collected during 1993-2007. No common assessment level was applied to these data. 
A. Distribution of Benchmark Quotient (BO) values when the higher proposed Alternative Maximum Contaminant Level (AMCL) is applied to radon activities

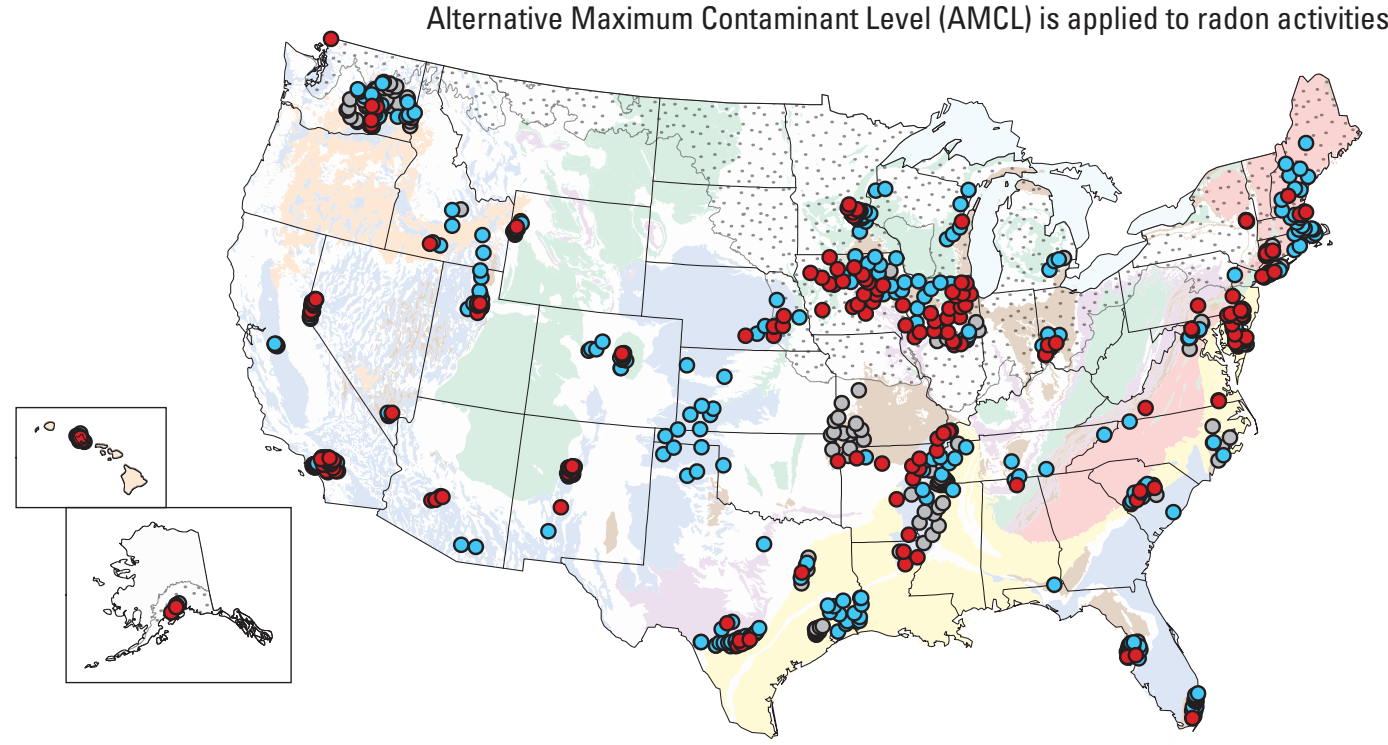

B. Distribution of $\mathrm{BO}$ values when the lower proposed Maximum Contaminant Level

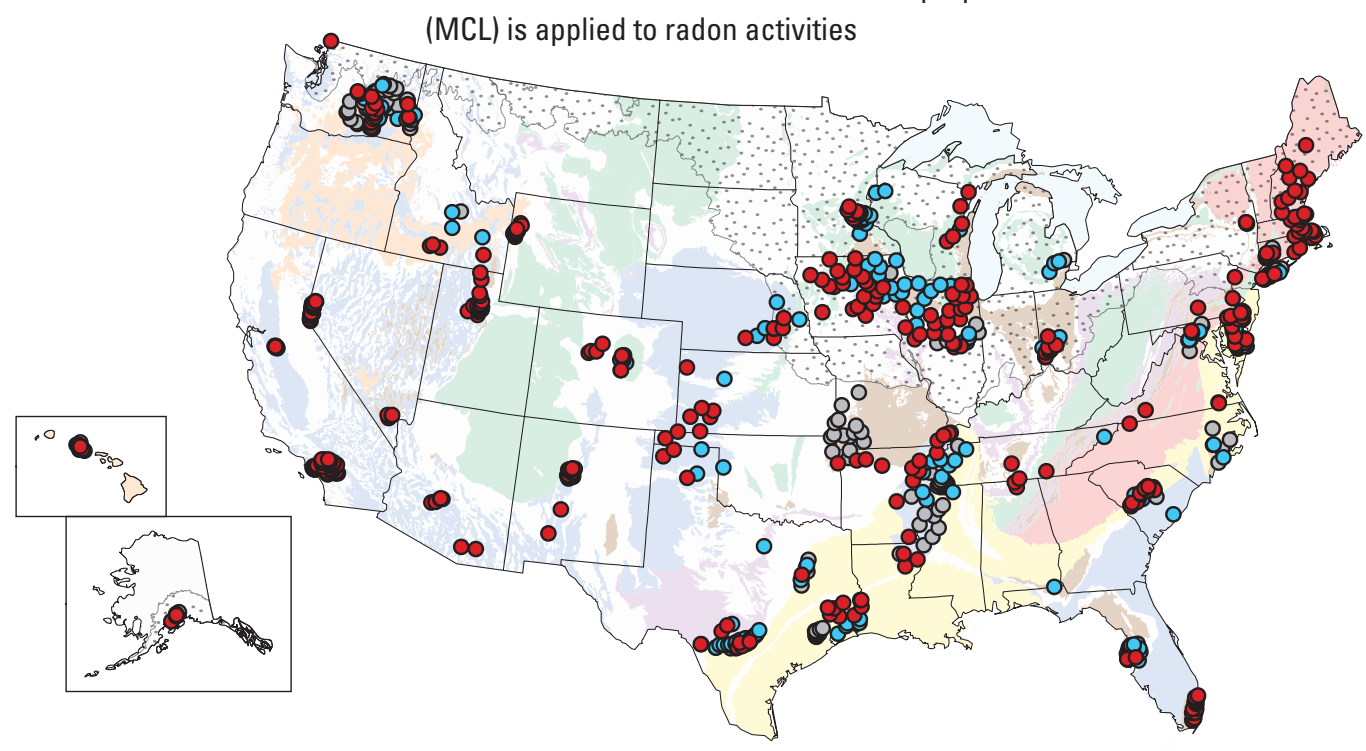

EXPLANATION

Concentrations of individual contaminants relative to human-health benchmarks-proposed AMCL of 4,000 picocuries per liter ( $\mathrm{pCi} / \mathrm{L}$ ) used for radon activities)

- One or more contaminant with $\mathrm{B} 0$ greater than $(>) 1$ or radon activities $>4,000 \mathrm{pCi} / \mathrm{L}$

- One or more contaminant with $\mathrm{BO}>0.1$ and less than or equal to $(\leq) 1$ or radon activities $>300$ and $\leq 4,000 \mathrm{pCi} / \mathrm{L}$

- No contaminants with $\mathrm{B} 0>0.1$, or radon activities $\leq 300 \mathrm{pCi} / \mathrm{L}$, or no contaminants detected

\section{Number of public wells}

206

539

187
Concentrations of individual contaminants relative to human-health benchmarks - proposed MCL of $300 \mathrm{pCi} / \mathrm{L}$ used for radon activities)

- One or more contaminant with $\mathrm{BO}>1$ or radon activities $>300 \mathrm{pCi} / \mathrm{L}$

- One or more contaminant with $\mathrm{BO}>0.1$ and $\leq 1$

- No contaminants with $\mathrm{BO}>0.1$, or radon activities $\leq 300 \mathrm{pCi} / \mathrm{L}$, or no contaminants detected
Number of public wells

426

187

Figure 44. Geographic distribution of contaminant concentrations relative to human-health benchmarks for 932 publicwell samples collected during 1993-2007. No common assessment level was applied to these data. (See fig. 2A for explanation of principal aquifer rock types.) 
Concentrations of 10 contaminants were greater than MCLs or HBSLs in at least 1 percent of source-water samples from public wells, including seven naturally occurring contaminants and three primarily from anthropogenic sources (table 16 and fig. 42). Concentrations greater than benchmarks are of potential human-health concern, but do not necessarily indicate that adverse effects will occur if water with such concentrations were ingested. MCLs and HBSLs generally are contaminant concentrations at which adverse effects are not expected over a lifetime of exposure (see discussion in the Methods sub-section, "Human-Health Benchmarks" on page 14). The potential health effects associated with the ingestion of water containing any of these 10 contaminants at concentrations greater than benchmarks include an increased risk of cancer (for six of the contaminants), various neurological, developmental, and reproductive effects, liver problems, and blue-baby syndrome (table 16).

Five of the 10 contaminants that were detected at concentrations greater than benchmarks in at least 1 percent of source-water samples (radium, gross alpha-particle radioactivity, arsenic, nitrate, and PCE) are regulated in drinking water by the USEPA under the SDWA, and therefore managed, in finished drinking water; radon has proposed MCLs (U.S. Environmental Protection Agency, 2006a). Manganese, boron, and dieldrin have undergone USEPA's regulatory determination process under the SDWA. After evaluating available occurrence, exposure, and health-effects information, USEPA determined that no regulatory action was appropriate for these contaminants because they infrequently occur at health levels of concern in public water systems, and regulating these contaminants in drinking water would not "present a meaningful opportunity for health risk reduction" (U.S. Environmental Protection Agency, 2003a, 2008b). Strontium is listed on USEPA's most recent (third) CCL (U.S. Environmental Protection Agency, 2010a).

Naturally occurring trace elements and radionuclides accounted for about three-quarters of all contaminant concentrations greater than MCLs or HBSLs in source-water samples from public wells. Four trace elements (arsenic, manganese, strontium, and boron) and three radionuclides (radon, radium, and gross alpha-particle radioactivity) each were detected at concentrations greater than human-health benchmarks in at least 1 percent of source-water samples. Radon activities were greater than the higher proposed AMCL of $4,000 \mathrm{pCi} / \mathrm{L}$ in less than 1 percent of samples, but were greater than the lower proposed MCL of $300 \mathrm{pCi} / \mathrm{L}$ in about 55 percent of samples. Each of the remaining six trace elements and radionuclides were detected at concentrations greater than human-health benchmarks in about 3 to 19 percent of samples (table 16 and fig. 42). These seven inorganic contaminants also were frequently detected - in two-thirds to all of the samples.
Overall, concentrations of one or more trace elements were greater than human-health benchmarks in about 16 percent of source-water samples, and were greater than one-tenth of benchmarks in a total of 73 percent of samples. One or more radionuclide activities were greater than benchmarks in about 8 percent of samples when radon activities were compared to the higher proposed AMCL of $4,000 \mathrm{pCi} / \mathrm{L}$, and were greater than one-tenth of benchmarks in a total of 68 percent of samples (table 14 and figs. 43 and 45). Many trace elements and radionuclides were detected at concentrations greater than benchmarks in samples from both unconfined and confined aquifers (fig. 45), consistent with the fact that these naturally occurring inorganic contaminants originate from aquifer materials, rather than anthropogenic sources at the land surface.

Nitrate, pesticide compounds, and VOCs (contaminants that originate entirely or primarily from anthropogenic sources) accounted for about one-quarter of all contaminant concentrations greater than MCLs or HBSLs in source-water samples from public wells. Nitrate (a nutrient), dieldrin (an insecticide), and PCE (a solvent) each were detected at concentrations greater than MCLs or HBSLs in 1 to 3 percent of source-water samples (table 16 and fig. 42). PCE and nitrate also were frequently detected - in nearly one-quarter and three-quarters of the samples, respectively.

Nitrate was detected at concentrations greater the MCL in about 2 percent of the source-water samples from public wells, and at concentrations greater than one-tenth of the MCL in a total of 45 percent of samples (table 16 and fig. 42). All samples with nitrate concentrations greater than the MCL were collected from unconfined aquifers (fig. 45), consistent with the fact that nitrate originates at the land surface.

Only seven of the 168 pesticide compounds or VOCs analyzed in most source-water samples were detected at concentrations greater than human-health benchmarks in at least one public-well sample. These organic contaminants were dieldrin, alpha-HCH, PCE, TCE, DBCP, ethylene dibromide, and acrylonitrile. All together, one or more pesticide compounds were detected at concentrations greater than MCLs or HBSLs in 3 percent of source-water samples from public wells, and one or more VOCs were detected at concentrations greater than MCLs or HBSLs in 2 percent of samples (table 14 and figs. 43 and $\underline{45}$ ).

Collectively, concentrations of one or more pesticide compounds or VOCs were greater than human-health benchmarks in 4.5 percent of source-water samples and were greater than one-tenth of benchmarks in a total of 10 percent of samples. Almost all (86 to 94 percent) of the pesticide compound and VOC concentrations greater than human-health benchmarks were detected in samples from public wells that withdraw water from unconfined aquifers, consistent with the fact that these contaminants originate at the land surface (fig. 45). 


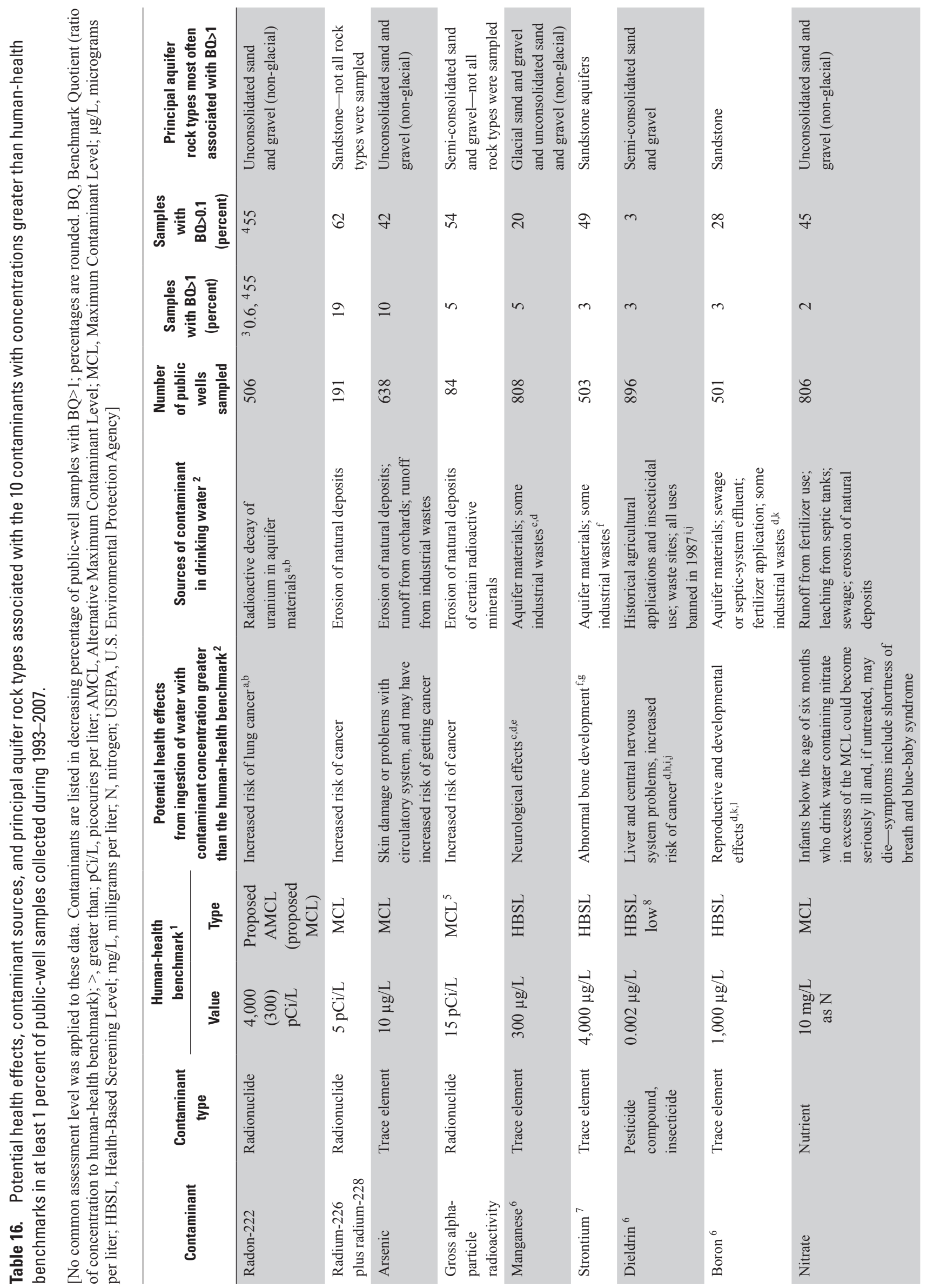




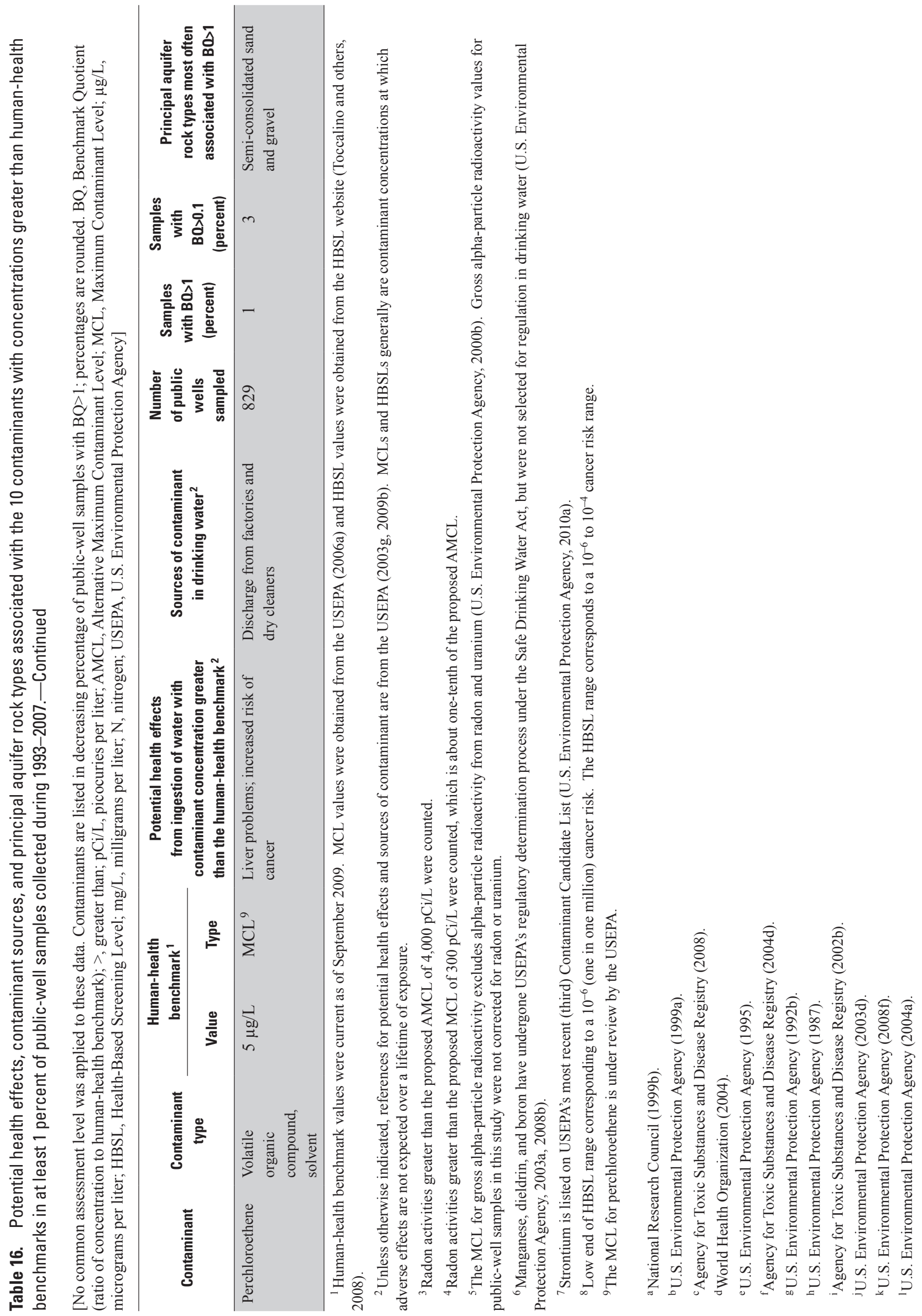




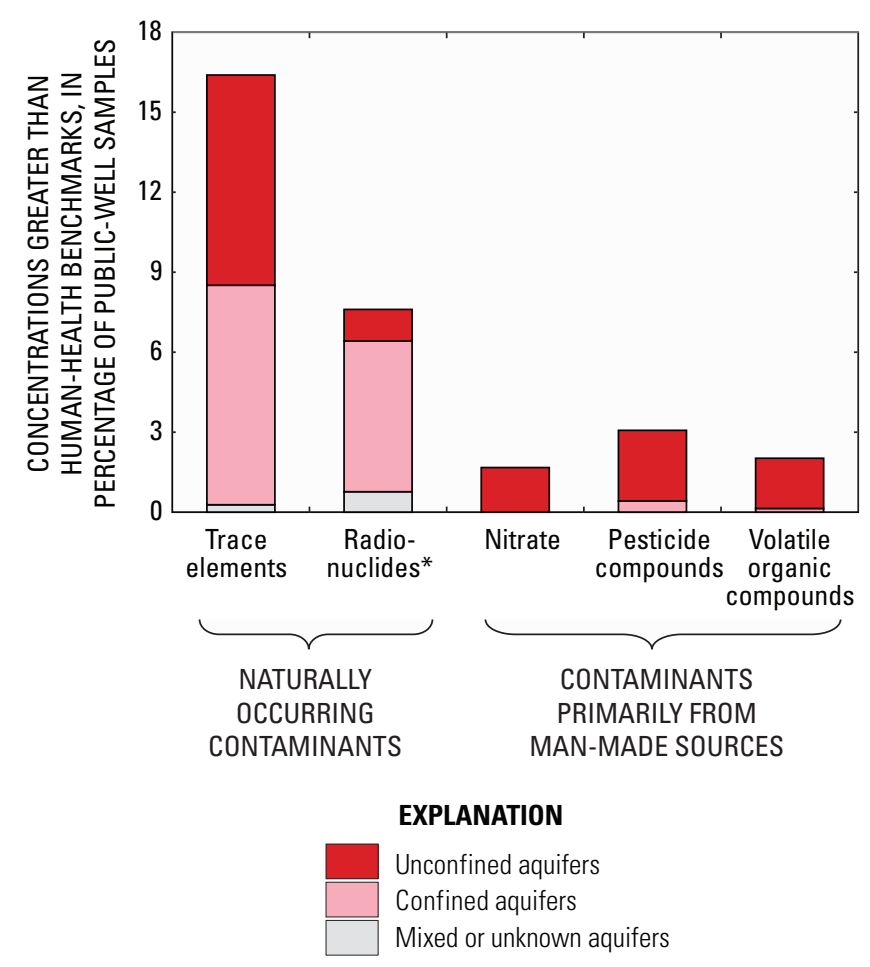

*Radon activities were compared to the proposed Alternative Maximum Contaminant Level of 4,000 picocuries per liter (pCi/L).

If radon activities were compared to the proposed Maximum Contaminant Level of $300 \mathrm{pCi} / \mathrm{L}$, then radionuclide activities were greater than benchmarks in a total of 60 percent of samples36 percent in unconfined aquifers, 22 percent in confined aquifers, and 2 percent in mixed or unknown aquifers (data not shown).

Figure 45. Percentage of source-water samples with one or more contaminants with concentrations greater than humanhealth benchmarks, by aquifer type and contaminant group, for public-well samples collected during 1993-2007. No common assessment level was applied to these data.

Some contaminants detected at concentrations approaching or greater than human-health benchmarks are not currently regulated by USEPA in drinking water under the SDWA (tables 11, 12, and 13). Occurrence data for such contaminants in water resources, and for frequently detected unregulated contaminants without human-health benchmarks, such as MTBE, deethylatrazine, and several trace elements and nutrients (Appendix 15), are used by the USEPA to fulfill part of the SDWA requirements for determining whether specific contaminants should be regulated in drinking water in the future (U.S. Environmental Protection Agency, 2010a).

Collectively, one or more properties or contaminants were detected at concentrations outside of USEPA's recommended SMCL or taste-threshold ranges in about one-half (53 percent) of the source-water samples from public wells (when the high end of the non-health guideline was applied to sodium and aluminum concentrations). Values or concentrations of $\mathrm{pH}$, TDS, sodium, iron, and manganese were individually outside the ranges defined by USEPA non-health guidelines in about 15 to 20 percent of samples (table 8). In addition, groundwater from about 50 percent of the samples in which calcium and magnesium were analyzed, mostly in the southeastern and midwestern United States, generally was considered to be "very hard" (ig. 18), although the USEPA has not established a non-health guideline for water hardness (U.S. Environmental Protection Agency, 2006a). Undesirable effects associated with these properties or contaminants include corrosion or scale deposition in pipes and plumbing, laundry staining, and unpleasant water color or taste.

\section{Results and Discussion-0ccurrence and Characteristics of Contaminant Mixtures}

In addition to assessing the occurrence of individual properties and contaminants in source-water samples from public wells, described above, the occurrence and characteristics of contaminant mixtures in these samples also were evaluated. Human exposure to contaminants is rarely limited to a single contaminant, but most toxicologic studies have been carried out with single, pure chemicals (Yang, 1994), and most drinking-water regulations are for single contaminants (U.S. Environmental Protection Agency, 2006a). In recent years, however, several United States agencies have focused more attention on health risks from exposure to contaminant mixtures, including the USEPA, ATSDR, the National Institute of Occupational Safety and Health, and the Argonne National Laboratory (Hertzberg and MacDonell, 2002). The 1996 Amendments to the SDWA direct USEPA to develop new approaches for the study of complex mixtures, such as mixtures detected in drinking water, and to determine the types of interactions that may affect the shape of the dose-response relationship of individual contaminants (U.S. Code, 1996). Since 1996, groups of contaminants that have been regulated as mixtures include various DBPs and gross alpha- and gross beta-particle radioactivities (U.S. Environmental Protection Agency, 2000a, 2006a).

This increased attention on contaminant mixtures is warranted because contaminants generally are not detected in isolation in groundwater (Squillace and others, 2002; Gilliom and others, 2006; Zogorski and others, 2006; DeSimone, 2009). Groundwater originates from many sources, such as recharge from precipitation or irrigation and infiltration of surface water, and each groundwater source may contain multiple contaminants. Analysis of individual contaminants, as described above for this study, is needed to identify those contaminants that are detected at concentrations of potential human-health concern, and to assess where and why they occur. Most people, however, are exposed to mixtures of anthropogenic organic and naturally occurring inorganic contaminants at concentrations less than concentrations known to cause adverse effects (Carpenter and others, 2002). 
Little is known about the potential health effects associated with exposure to multiple contaminants at low concentrations ( $\mu \mathrm{g} / \mathrm{L}$ or parts per billion), yet toxicologic interactions that can result in adverse effects are possible at these concentrations (Hasegawa and others, 1994; Yang, 1994).

Identifying and characterizing all possible contaminant mixtures in drinking water and assessing their toxicity is not practical (Squillace and others, 2002; Ryker and Small, 2008). Evaluating the toxicity of mixtures is complicated by the possibility of multiple types of interactions among the contaminants (such as additive, synergistic, antagonist, or no interactions), and by the fact that many individual contaminants can affect multiple sites in the body (Carpenter and others, 2002). Many contaminant combinations are possible, and which combinations are most important to human health often is unknown (Carpenter and others, 2002). Studies that systematically evaluate the occurrence of a wide range of contaminants, such as evaluated in this study, can help to identify those contaminant mixtures that are most commonly detected in the Nation's water resources and which contaminants in those mixtures are detected at concentrations greater than or approaching individual human-health benchmarks.

Several large datasets have recently become available on the occurrence of specific chemicals and mixtures in sources of drinking water in the United States (Squillace and others, 2002; Gilliom and others, 2006; Zogorski and others, 2006; Ryker and Small, 2008; DeSimone, 2009). Data from this study enhance these previous studies by examining the co-occurrence of a larger number of contaminants in source water from public wells and by assessing the occurrence of mixtures relative to human-health benchmarks. Humanhealth researchers can use information about which mixtures most frequently are detected in sources of drinking water to prioritize which mixtures to assess for potential toxicity. The combination of occurrence and toxicity information can be used to identify priorities for future research on mixture effects (Ryker and Small, 2008).

In this study, the occurrence and composition of unique contaminant mixtures in two subsets of samples were assessed: (1) 383 public-well samples in which most contaminants were analyzed, and (2) 814 samples in which organic contaminants were analyzed (see discussion in the Methods sub-section, "Evaluation of Contaminant Mixtures" on page 17). Mixtures in the subset of 383 samples were examined in three categories: (1) mixtures with $\mathrm{BQ}>1$, (2) mixtures with $\mathrm{BQ}>0.1$, and (3) mixtures with $\mathrm{BQ}>0.1$ plus any organic contaminant detection. Each category of mixtures builds on the previous category such that more contaminants were included in each subsequent category. Because very large numbers of unique mixtures were identified in some categories of mixtures, only unique mixtures that met a minimum detection frequency were examined in this study (table 17).

\section{Occurrence, Complexity, and Distribution of Mixtures}

Although 22 percent of source-water samples from public wells contained at least one contaminant at concentrations greater than human-health benchmarks, mixtures of two or more contaminants in which the concentration of each contaminant was greater than its individual benchmark (BQ $>1$ ), were detected less frequently - in 4 percent (16 of 383) of source-water samples. A total of 84 percent of sourcewater samples, however, contained two or more contaminants in which the concentration of each contaminant was greater than one-tenth of its individual benchmark (BQ>0.1) (figs. 46 and 47). Mixtures that also considered detections of any pesticide compound or VOC, without regard to the availability of benchmarks or concentrations relative to individual benchmarks, were detected in 92 percent of samples (fig. 47).

The complexity of the mixtures and the number of unique mixtures increased as the mixtures categories were made more inclusive (table 17). For example, none of the samples included a mixture with five contaminants in the $\mathrm{BQ}>1$ category, but mixtures with five or more contaminants in the $\mathrm{BQ}>0.1$ category were detected in about 17 percent of samples, and mixtures with five or more contaminants in the $\mathrm{BQ}>0.1$ plus any organic contaminant detection category were detected in about 53 percent of samples (fig. 47). Public wells yielding water in which contaminant concentrations in mixtures were greater than individual benchmarks, as well as those in which concentrations were greater than one-tenth of individual benchmarks, were distributed throughout the United States with no strong geographic pattern (ig. 46).

Mixtures with the largest number of contaminants ( 5 to 10) detected at concentrations greater than one-tenth of individual human-health benchmarks were distributed among a number of sampled areas throughout the United States, but were most common in public wells sampled in parts of the western United States. About three-quarters of the public wells with five or more contaminants with $\mathrm{BQ}>0.1$ withdraw water from unconsolidated sand and gravel aquifers in the western United States, mostly in California, Utah, Nevada, and Arizona (fig. 48).

TDS concentrations generally increased with increasing complexity of the mixtures, although the significance of this pattern was not strong (generally, $p>0.05$, data not shown). This finding indicates that the unique mixtures in the $\mathrm{BQ}>1$ and $\mathrm{BQ}>0.1$ categories frequently included naturally occurring trace elements and other inorganic contaminants that contribute to, or are correlated with, TDS concentrations, and is consistent with the findings of DeSimone (2009) in groundwater from domestic wells. 
Table 17. Contaminant mixture categories, criteria for examination of unique mixtures, and number of unique mixtures examined in public-well samples collected during 1993-2007.

[No common assessment level was applied to these data. GCMS, gas chromatography/mass spectrometry; VOC, volatile organic compound; BQ, Benchmark Quotient (ratio of concentration to human-health benchmark); >, greater than]

\begin{tabular}{|c|c|c|c|c|}
\hline Mixture category & $\begin{array}{c}\text { Number of } \\
\text { public-well } \\
\text { samples }\end{array}$ & $\begin{array}{l}\text { Total number } \\
\text { of unique } \\
\text { mixtures } \\
\text { detected }\end{array}$ & $\begin{array}{c}\text { Criteria for examination } \\
\text { of unique mixtures } \\
\text { (minimum detection } \\
\text { frequency) }\end{array}$ & $\begin{array}{l}\text { Number } \\
\text { of unique } \\
\text { mixtures } \\
\text { examined in } \\
\text { this study }\end{array}$ \\
\hline
\end{tabular}

Mixtures that were assessed relative to individual human-health benchmarks. Mixtures included samples in which major ions, trace elements, nitrate, radon, pesticide compounds (analyzed using GCMS), and VOCs were analyzed

\begin{tabular}{lllll}
\hline BQ $>$ 1. Mixtures of contaminants with & 383 & 21 & All mixtures & 21
\end{tabular}

concentrations greater than individual human-

health benchmarks. ${ }^{1}$ Only contaminants with

benchmarks are considered.

BQ>0.1. Mixtures of contaminants with

Each mixture detected in

concentrations greater than one-tenth of individual human-health benchmarks. ${ }^{2}$ Includes all mixtures in the first category. Only contaminants with benchmarks are considered.

$B Q>0.1$ plus any organic contaminant detection. Mixtures of contaminants with concentrations greater than one-tenth of individual human-health benchmarks ${ }^{2}$, plus the detection of any pesticide compound or VOC. ${ }^{3}$ Includes all mixtures in the first and second categories.

\begin{tabular}{llll}
\hline \multicolumn{4}{c}{ Mixtures that were not assessed relative to individual human-health benchmarks } \\
\hline $\begin{array}{l}\text { Any organic contaminant detection. Mixtures of } \\
\text { any detected pesticide compound (analyzed }\end{array}$ & 814 & $4,030,225$ & $\begin{array}{l}\text { Each mixture detected in } \\
\text { at least 10 percent of } \\
\text { samples }\end{array}$ \\
$\begin{array}{l}\text { using GCMS) or VOC. } \\
\text { sing }\end{array}$ & & 23 \\
\hline
\end{tabular}

\footnotetext{
${ }^{1}$ Radon activities were compared to the proposed Alternative Maximum Contaminant Level of 4,000 picocuries per liter (pCi/L).

${ }^{2}$ Radon activities were compared to the proposed Maximum Contaminant Level of $300 \mathrm{pCi} / \mathrm{L}$, which is about one-tenth of the proposed Alternative Maximum Contaminant Level.

${ }^{3}$ Organic contaminants were assessed regardless of the availability of human-health benchmarks or the concentrations relative to individual benchmarks.
} 


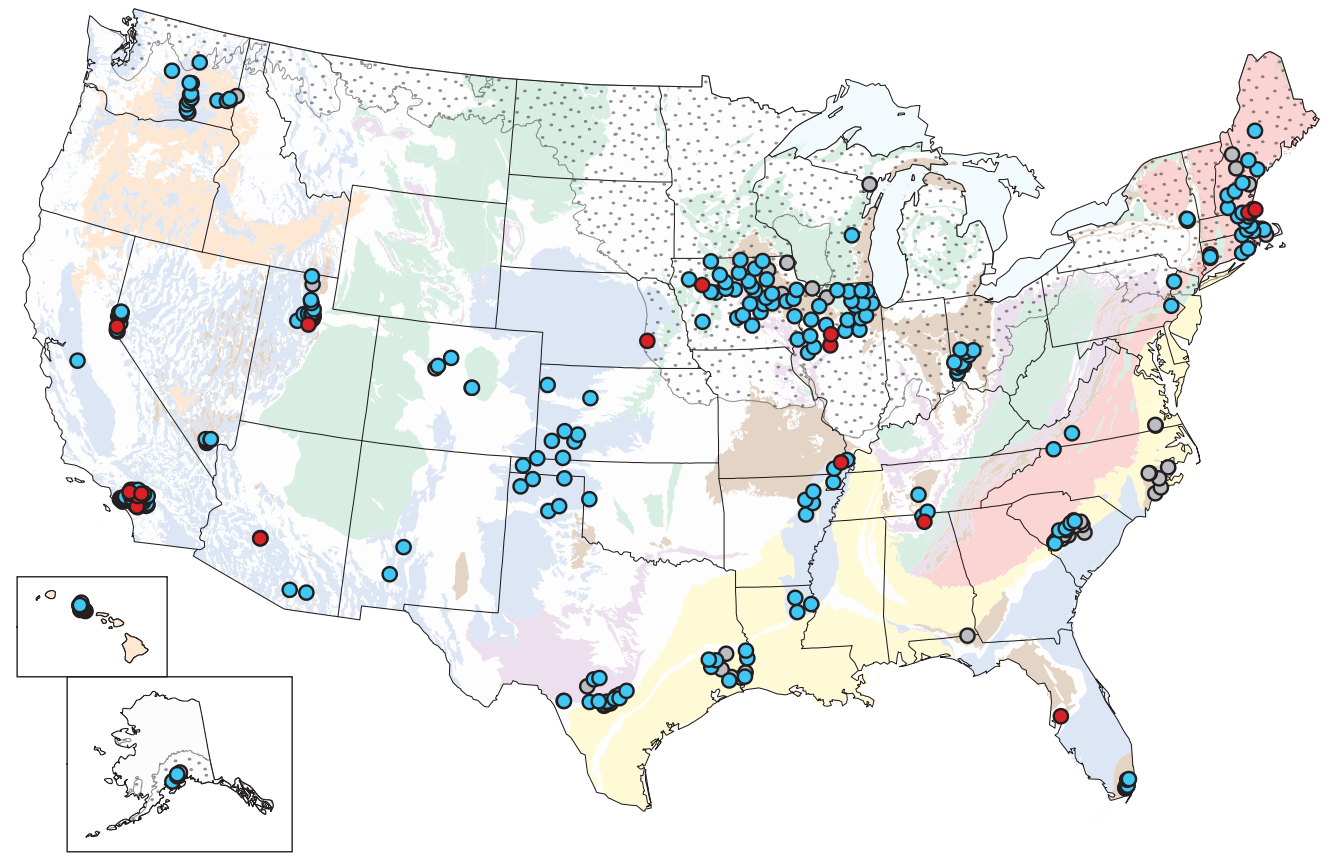

EXPLANATION

Concentrations of contaminants in mixtures relative to individual human-health benchmarks

- Two or more contaminants with Benchmark Quotients greater than $1(\mathrm{~B} 0>1)$-radon activities were compared to the proposed Alternative Maximum Contaminant Level of 4,000 picocuries per liter (pCi/L)

- Two or more contaminants with $\mathrm{B} 0>0.1$ —radon activities were compared to the proposed Maximum Contaminant Level of $300 \mathrm{pCi} / \mathrm{L}$

Number of
public wells

16

305

62

- Less than two contaminants with $\mathrm{BQ}>0.1$, or no contaminants detected

Figure 46. Geographic distribution of contaminant mixtures, relative to individual human-health benchmarks, for public-well samples collected during 1993-2007. Data are from 383 samples in which major ions, trace elements, nutrients, radon, and organic contaminants were analyzed. No common assessment level was applied to these data. (See fig. $2 A$ for explanation of principal aquifer rock types.)

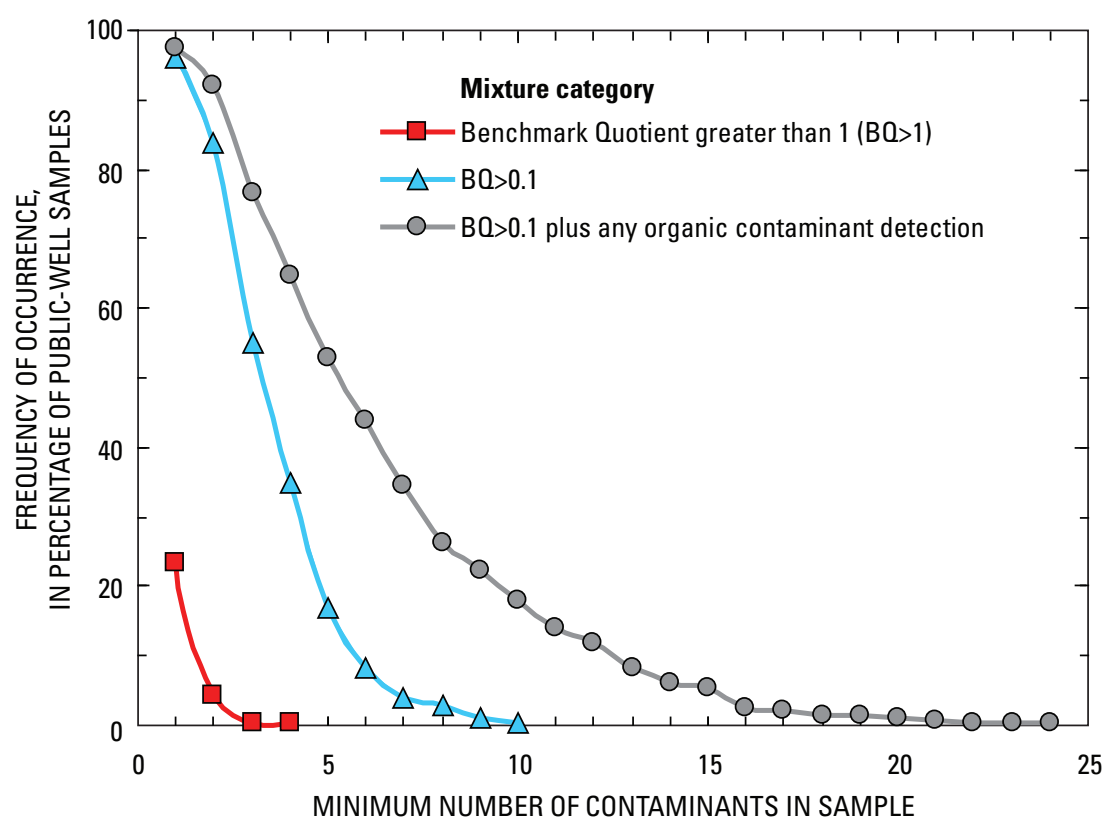

Figure 47. Frequency of contaminant occurrence in mixtures, for each of three mixtures categories, for public-well samples collected during 1993-2007. Table 17 lists the criteria for the evaluation of unique mixtures in each mixture category. Data are from 383 samples in which major ions, trace elements, nitrate, radon, and organic contaminants were analyzed. No common assessment level was applied to these data. 
A. Number of contaminants with concentrations greater than individual human-health benchmarks-Benchmark Quotient greater than $1(\mathrm{~B} 0>1)$

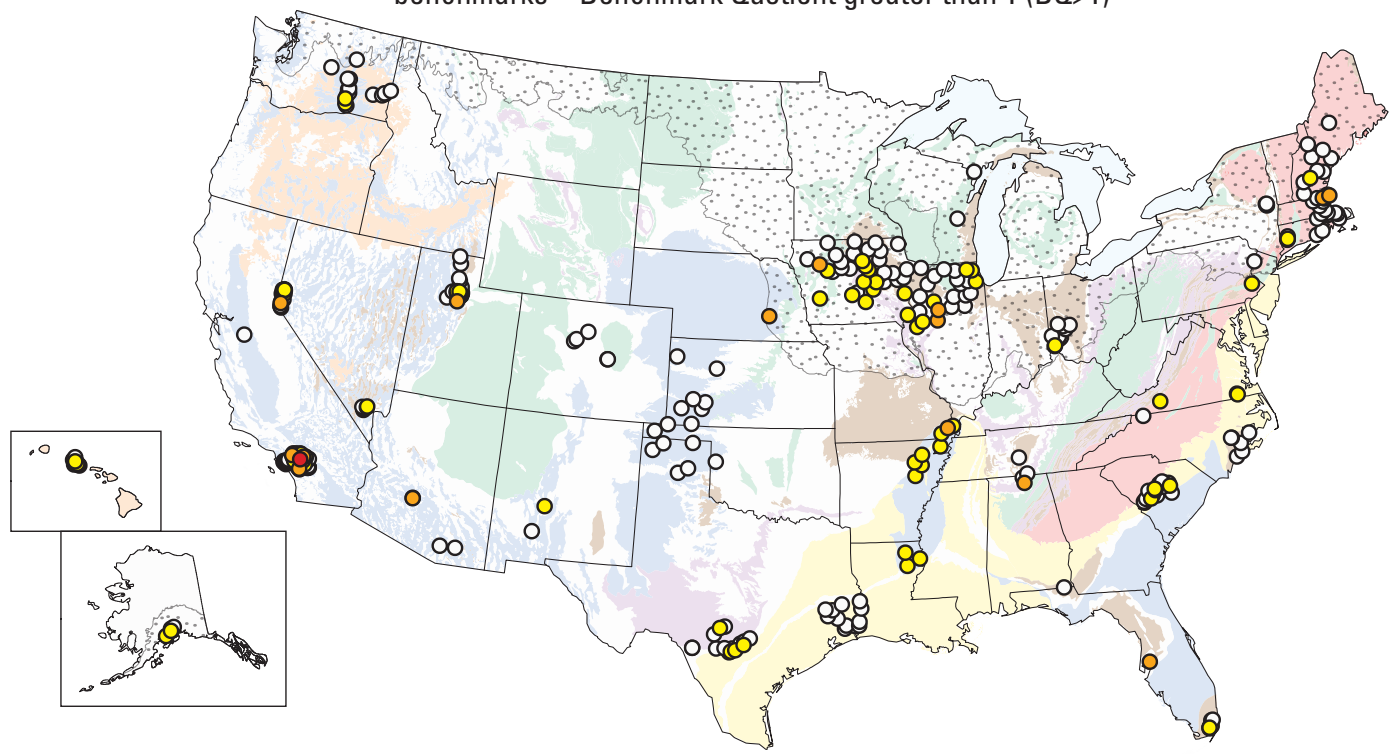

B. Number of contaminants with concentrations greater than one-tenth of individual

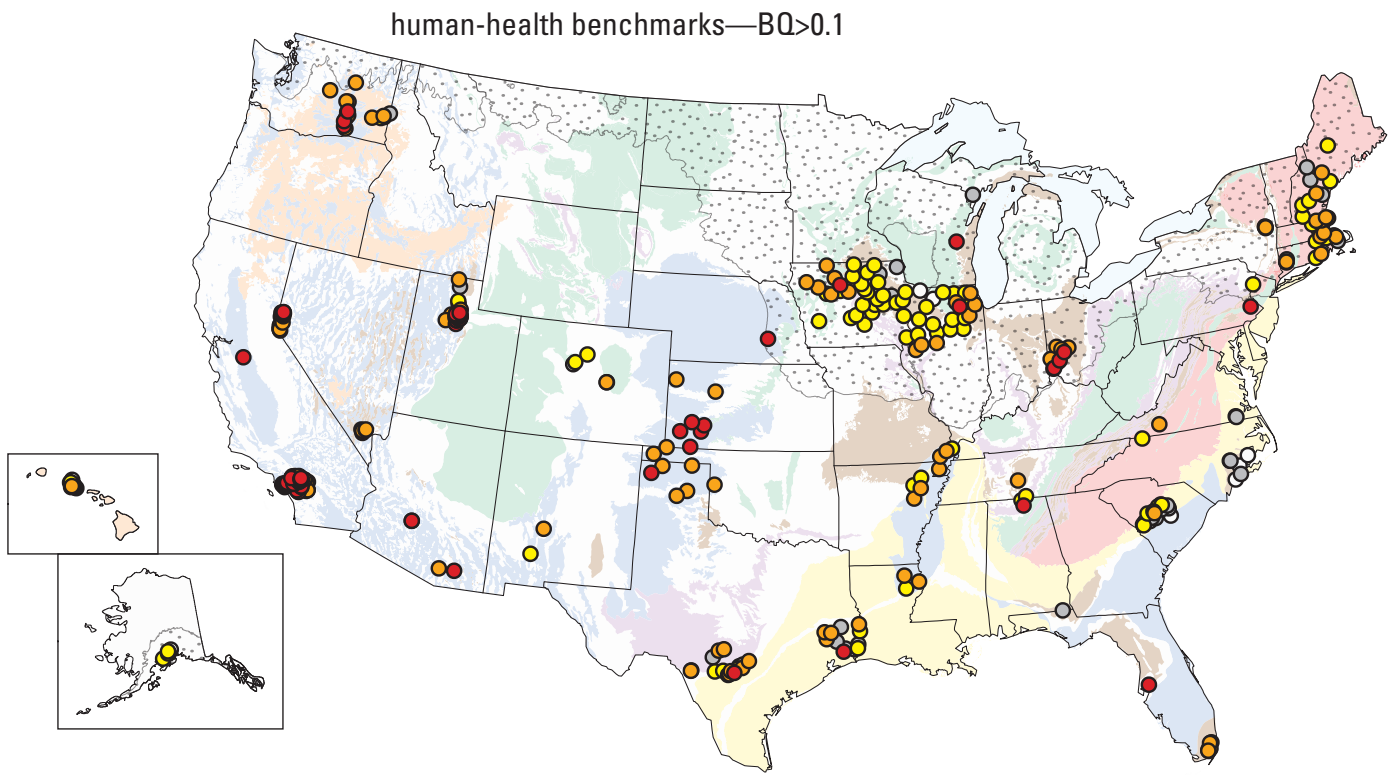

EXPLANATION

Number of contaminants with $\mathrm{B} 0>1-$ radon activities were compared to the proposed Alternative Maximum Contaminant Level of 4,000 picocuries per liter (pCi/L)

- 4

○ 2

○ 1

○ 0 Number of
public wells

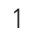

15

74

293
Number of contaminants with $\mathrm{B} 0>0.1-$ radon activities were compared to the proposed Maximum Contaminant Level of $300 \mathrm{pCi} / \mathrm{L}$

- 5 to 10

- 3 to 4

○ 2

$\begin{array}{lll}\circ & 1 & 47\end{array}$

$\circ 0$
Number of Number of 146
110
47
15

Figure 48. Geographic distribution of the numbers of contaminants in mixtures with $(A)$ concentrations greater than individual human-health benchmarks and $(B)$ concentrations greater than one-tenth of individual benchmarks, for public-well samples collected during 1993-2007. Data are from 383 samples in which major ions, trace elements, nitrate, radon, and organic contaminants were analyzed. No common assessment level was applied to these data. (See fig. $2 A$ for explanation of principal aquifer rock types.) 
The most complex mixtures of contaminants in sourcewater samples from public wells - those mixtures with the greatest number of contaminants - were detected more often in samples from shallower unconfined aquifers than in samples from deeper confined aquifers. For mixtures of contaminants at concentrations greater than one-tenth of individual humanhealth benchmarks $(\mathrm{BQ}>0.1)$, the proportion of samples from the more vulnerable unconfined aquifers increased as the complexity of the mixtures increased (fig. 49).

About one-half of the samples containing two or more contaminants at concentrations greater than one-tenth of individual benchmarks were from unconfined aquifers, and about one-half were from confined aquifers (fig. 49). This finding was expected because simple mixtures containing two or three contaminants were dominated by inorganic contaminants (see section, "Composition of Mixtures" below), which occur in samples from both confined and unconfined aquifers. By contrast, about two-thirds of samples containing four to six contaminants with $\mathrm{BQ}>0.1$, and more than three-quarters of samples containing seven to 10 contaminants with $\mathrm{BQ}>0.1$, were from unconfined aquifers (fig. 49). The more complex mixtures occurred more often in unconfined aquifers because the proportion of samples containing organic contaminants increased in those complex mixtures, and organic contaminants that originate from man-made sources at the land surface were detected more frequently in unconfined aquifers than in confined aquifers (fig. 31B).

Similarly, mixtures of pesticide compounds and (or) VOCs that were evaluated without regard to the availability of benchmarks or the concentrations relative to benchmarks were frequently detected and complex. One-half of the source-water samples from public wells contained mixtures of two or more pesticide compounds or VOCs, and 27 percent of the samples contained five or more pesticide compounds or VOCs (fig. 50). For mixtures of pesticide compounds and VOCs, the proportion of samples from the more vulnerable unconfined aquifers increased as the complexity of the mixtures increased. About two-thirds of the samples containing mixtures of two or more pesticide compounds or VOCs were from unconfined aquifers, whereas 90 percent of the samples containing mixtures of 10 or more pesticide compounds or VOCs were from unconfined aquifers (fig. 50).

\section{Composition of Mixtures}

For each category of mixtures examined in the subset of 383 samples, table 18 summarizes the composition of the 10 most commonly occurring unique mixtures, including the most

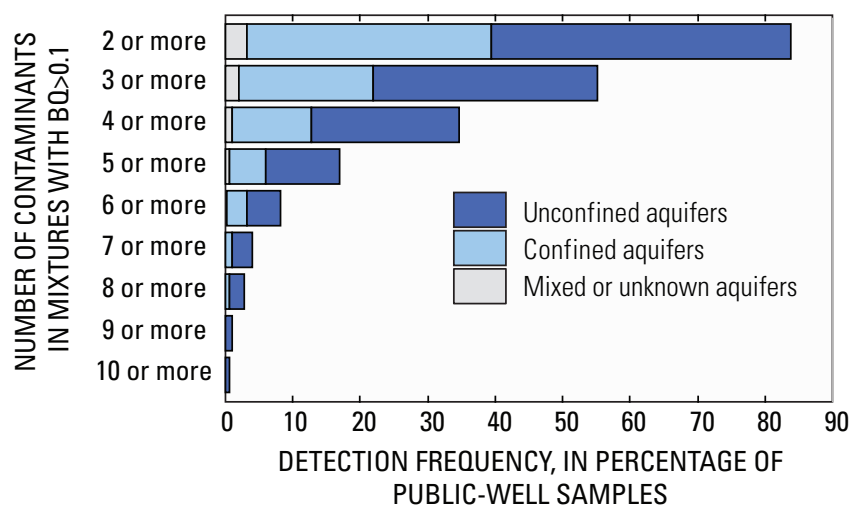

Figure 49. Proportion of contaminant mixtures with concentrations greater than one-tenth of individual human-health benchmarks $(B 0>0.1)$ in unconfined and confined aquifers, in relation to the complexity of the mixtures. Data are from 383 public-well samples in which major ions, trace elements, nitrate, radon, pesticide compounds, and volatile organic compounds were analyzed. Radon activities were compared to the proposed Maximum Contaminant Level of 300 picocuries per liter.

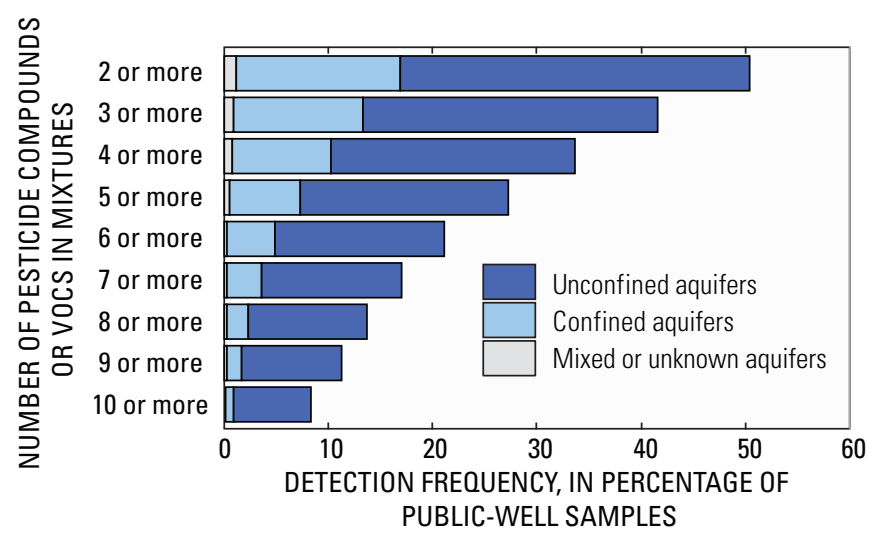

Figure 50. Proportion of mixtures of pesticide compounds and volatile organic compounds (VOCs) in unconfined and confined aquifers, in relation to the complexity of the mixtures. Data are from 814 public-well samples in which as many as 47 pesticide compounds and 85 VOCs were analyzed.

common contaminant groups and individual contaminants in the unique mixtures. Nutrients (specifically nitrate) and trace elements were among the most common contaminant groups in all three mixtures categories (table 18). The most common contaminants in the unique mixtures were those contaminants that were most frequently detected individually. 
Table 18. Summary of composition of the most common unique mixtures, by contaminant mixture category, for 383 public-well samples collected during 1993-2007.

[BQ, Benchmark Quotient (ratio of concentration to human-health benchmark); >, greater than; PCE, perchloroethene; TCE, trichloroethene; DBCP, dibromochloropropane; DBP, disinfection by-product. Bold type indicates the five most common individual contaminants and the three most common contaminant groups in the unique mixtures in each mixtures category; each of the most common contaminants and contaminant groups were bolded only once. Data are from 383 public-well samples in which major ions, trace elements, nitrate, radon, and organic contaminants were analyzed. No common assessment level was applied to these data.]

\begin{tabular}{|c|c|c|c|c|}
\hline \multicolumn{3}{|c|}{ Composition of 10 most common unique mixtures } & $\begin{array}{c}\text { Detection } \\
\text { frequency } \\
\text { (percent of } \\
\text { samples) }\end{array}$ & Use groups represented in mixture ${ }^{1}$ \\
\hline \multicolumn{5}{|c|}{ Mixtures of contaminants with $\mathrm{B} 0>1^{2}$} \\
\hline Boron & Strontium & & 0.8 & Trace elements \\
\hline Arsenic & Manganese & & 0.8 & Trace elements \\
\hline Nitrate & PCE & & 0.5 & Nutrient, solvent \\
\hline Arsenic & Molybdenum & & 0.5 & Trace elements \\
\hline Boron & Radon & & 0.4 & Trace element, radionuclide \\
\hline Nitrate & Strontium & & 0.4 & Nutrient, trace element \\
\hline Arsenic & Strontium & & 0.4 & Trace elements \\
\hline PCE & Dieldrin & & 0.3 & Solvent, insecticide \\
\hline Nitrate & PCE & TCE & 0.3 & Nutrient, solvents \\
\hline Nitrate & PCE & DBCP & 0.3 & Nutrient, solvent, fumigant \\
\hline \multicolumn{5}{|c|}{ Mixtures of contaminants with $\mathrm{BO}>0.1^{3}$} \\
\hline Nitrate & Radon & & 32.5 & Nutrient, radionuclide \\
\hline Arsenic & Radon & & 28.5 & Trace element, radionuclide \\
\hline Boron & Strontium & & 26.5 & Trace elements \\
\hline Strontium & Radon & & 22.0 & Trace element, radionuclide \\
\hline Uranium & Radon & & 19.8 & Trace element, radionuclide \\
\hline Nitrate & Strontium & & 19.5 & Nutrient, trace element \\
\hline Nitrate & Arsenic & & 19.4 & Nutrient, trace element \\
\hline Nitrate & Uranium & & 17.8 & Nutrient, trace element \\
\hline Nitrate & Arsenic & Radon & 16.3 & Nutrient, trace element, radionuclide \\
\hline Arsenic & Uranium & & 16.0 & Trace elements \\
\hline \multicolumn{5}{|c|}{ Mixtures of contaminants with $\mathrm{BO}>0.1$, plus the detection of any organic contaminant ${ }^{3}$} \\
\hline Nitrate & Chloroform & & 34.4 & Nutrient, DBP \\
\hline Chloroform & Radon & & 33.5 & DBP, radionuclide \\
\hline Nitrate & Radon & & 32.5 & Nutrient, radionuclide \\
\hline Arsenic & Radon & & 28.5 & Trace element, radionuclide \\
\hline Nitrate & Deethylatrazine & & 27.1 & Nutrient, herbicide degradate \\
\hline Boron & Strontium & & 26.5 & Trace elements \\
\hline Deethylatrazine & Atrazine & & 25.7 & Herbicide degradate, herbicide \\
\hline Nitrate & Atrazine & & 23.9 & Nutrient, herbicide \\
\hline Nitrate & Chloroform & Radon & 23.9 & Nutrient, DBP, radionuclide \\
\hline Nitrate & Deethylatrazine & Atrazine & 23.4 & Nutrient, herbicide degradate, herbicide \\
\hline
\end{tabular}


Twenty-one unique mixtures of contaminants at concentrations greater than individual benchmarks $(\mathrm{BQ}>1)$ were identified, and each of these mixtures was detected in less than 1 percent of the source-water samples from public wells (table 19). These mixtures most commonly were composed of solvents (primarily PCE and TCE), trace elements (such as arsenic and strontium), and nitrate, reflecting a mix of naturally occurring and anthropogenic contaminants (table 18). Of the 21 unique mixtures in the $\mathrm{BQ}>1$ category, 12 mixtures contained a solvent, nine contained a trace element, and eight contained nitrate (table 19).

Sixty-eight unique mixtures of contaminants at concentrations greater than one-tenth of individual benchmarks $(\mathrm{BQ}>0.1)$ each were detected in at least 5 percent of the source-water samples (table 20). All of these unique mixtures were composed of a trace element (arsenic, strontium, or uranium were most common), radon, and (or) nitrate. These contaminants all occur naturally, although nitrate at such concentrations is generally caused by anthropogenic sources. The most common unique mixture of contaminants at concentrations greater than one-tenth of individual benchmarks was nitrate and radon, which was detected in 32.5 percent of samples (table 20). These findings are consistent with DeSimone (2009), in which nitrate, arsenic, radon, and uranium were reported as the most frequently detected individual contaminants with $\mathrm{BQ}>0.1$ in a national study of domestic wells. Anthropogenic organic contaminants, such as PCE and TCE, were not among the most frequently detected mixtures with $\mathrm{BQ}>0.1$ because the overall detection frequencies of such organic contaminants are less than the detection frequencies of many trace elements, nitrate, and radon (Appendixes 10 and 12 and table 10). Additionally, trace elements, nitrate, and radionuclides were more frequently detected at concentrations greater than one-tenth of benchmarks than were organic contaminants (fig. 43).

Table 19. Composition and detection frequency of 21 unique mixtures with concentrations greater than individual human-health benchmarks in 383 public-well samples collected during 1993-2007.

$[\mathrm{BQ}$, Benchmark Quotient (ratio of concentration to human-health benchmark); >, greater than; PCE, perchloroethene; TCE, trichloroethene; DBCP, dibromochloropropane. Data are from 383 public-well samples in which major ions, trace elements, nitrate, radon, and organic contaminants were analyzed. No common assessment level was applied to these data. All unique mixtures of contaminants with $\mathrm{BQ}>1$ are listed.]

\section{Composition of the unique mixtures with $\mathrm{BO}>1^{1}$}

Detection frequency

(percent of samples)

\begin{tabular}{llll}
\hline Boron & Strontium & & 0.8 \\
Arsenic & Manganese & & 0.8 \\
Nitrate & PCE & & 0.5 \\
Arsenic & Molybdenum & & 0.5 \\
Boron & Radon & & 0.4 \\
Nitrate & Strontium & & 0.4 \\
Arsenic & Strontium & & 0.4 \\
PCE & Dieldrin & TCE & 0.3 \\
Nitrate & PCE & TCE & 0.3 \\
Nitrate & PCE & DBCP & 0.3 \\
Nitrate & PCE & & 0.3 \\
Arsenic & Dieldrin & & 0.3 \\
PCE & TCE & DBCP & 0.3 \\
PCE & TCE & DBCP & 0.3 \\
PCE & DBCP & & 0.3 \\
Nitrate & TCE & & 0.3 \\
Nitrate & TCE & DBCP & 0.3 \\
Nitrate & DBCP & & 0.3 \\
Manganese & Uranium & TCE & \\
Uranium & DBCP & & 0.3 \\
TCE & De & & 0.3 \\
\hline
\end{tabular}

\footnotetext{
${ }^{1}$ Radon activities were compared to the proposed Alternative Maximum Contaminant Level of 4,000 picocuries per liter.
} 
Table 20. Composition and detection frequency of 68 unique mixtures with concentrations greater than one-tenth of individual human-health benchmarks in 383 public-well samples collected during 1993-2007.

[BQ, Benchmark Quotient (ratio of concentration to human-health benchmark); >, greater than. Data are from 383 public-well samples in which major ions, trace elements, nitrate, radon, and organic contaminants were analyzed. No common assessment level was applied to these data. All unique mixtures of contaminants with $\mathrm{BQ}>0.1$ that were detected in at least 5 percent of the public-well samples are listed.]

\begin{tabular}{|c|c|c|c|c|c|}
\hline & & & & $\begin{array}{l}\text { Detectio } \\
\text { (percent }\end{array}$ & $\begin{array}{l}\text { equency } \\
\text { samples) }\end{array}$ \\
\hline Comp & sition of the mos & common uni & ixtures with $B 0>0.1$ & $\begin{array}{c}\text { Mixtures of } \\
\text { contaminants } \\
\text { with } B Q>1^{1}\end{array}$ & $\begin{array}{c}\text { Mixtures of } \\
\text { contaminants } \\
\text { with } \mathrm{BQ}>0.1^{2}\end{array}$ \\
\hline Nitrate & Radon & & & 0 & 32.5 \\
\hline Arsenic & Radon & & & 0 & 28.5 \\
\hline Boron & Strontium & & & 0.8 & 26.5 \\
\hline Strontium & Radon & & & 0 & 22.0 \\
\hline Uranium & Radon & & & 0 & 19.8 \\
\hline Nitrate & Strontium & & & 0.4 & 19.5 \\
\hline Nitrate & Arsenic & & & 0 & 19.4 \\
\hline Nitrate & Uranium & & & 0 & 17.8 \\
\hline Nitrate & Arsenic & Radon & & 0 & 16.3 \\
\hline Arsenic & Uranium & & & 0 & 16.0 \\
\hline Arsenic & Strontium & & & 0.4 & 15.8 \\
\hline Nitrate & Uranium & Radon & & 0 & 15.2 \\
\hline Boron & Radon & & & 0.4 & 13.7 \\
\hline Molybdenum & Radon & & & 0 & 13.6 \\
\hline Arsenic & Uranium & Radon & & 0 & 13.6 \\
\hline Nitrate & Strontium & Radon & & 0 & 13.6 \\
\hline Arsenic & Strontium & Radon & & 0 & 12.8 \\
\hline Arsenic & Molybdenum & & & 0.5 & 12.1 \\
\hline Nitrate & Arsenic & Uranium & & 0 & 11.8 \\
\hline Strontium & Uranium & & & 0 & 11.7 \\
\hline Nitrate & Molybdenum & & & 0 & 11.6 \\
\hline Manganese & Radon & & & 0 & 10.5 \\
\hline Nitrate & Arsenic & Uranium & Radon & 0 & 10.2 \\
\hline Arsenic & Boron & & & 0 & 10.0 \\
\hline Strontium & Uranium & Radon & & 0 & 9.5 \\
\hline Boron & Strontium & Radon & & 0 & 9.4 \\
\hline Lead & Radon & & & 0 & 9.3 \\
\hline Arsenic & Molybdenum & Radon & & 0 & 9.2 \\
\hline Nitrate & Arsenic & Strontium & & 0 & 9.2 \\
\hline Molybdenum & Uranium & & & 0 & 8.9 \\
\hline Nitrate & Boron & & & 0 & 8.9 \\
\hline Arsenic & Boron & Radon & & 0 & 8.9 \\
\hline Nitrate & Molybdenum & Radon & & 0 & 8.7 \\
\hline Nitrate & Lead & & & 0 & 8.5 \\
\hline Nitrate & Strontium & Uranium & & 0 & 8.5 \\
\hline Molybdenum & Strontium & & & 0 & 8.1 \\
\hline Nitrate & Arsenic & Strontium & Radon & 0 & 8.1 \\
\hline Arsenic & Strontium & Uranium & & 0 & 8.1 \\
\hline Arsenic & Manganese & & & 0.8 & 7.9 \\
\hline Molybdenum & Uranium & Radon & & 0 & 7.6 \\
\hline Nitrate & Strontium & Uranium & Radon & 0 & 7.4 \\
\hline Arsenic & Strontium & Uranium & Radon & 0 & 7.3 \\
\hline
\end{tabular}


Table 20. Composition and detection frequency of 68 unique mixtures with concentrations greater than onetenth of individual human-health benchmarks in 383 public-well samples collected during 1993-2007.-Continued

[BQ, Benchmark Quotient (ratio of concentration to human-health benchmark); >, greater than. Data are from 383 public-well samples in which major ions, trace elements, nitrate, radon, and organic contaminants were analyzed. No common assessment level was applied to these data. All unique mixtures of contaminants with $\mathrm{BQ}>0.1$ that were detected in at least 5 percent of the public-well samples are listed.]

\begin{tabular}{|c|c|c|c|c|c|c|}
\hline & & & & & $\begin{array}{l}\text { Detectior } \\
\text { (percent }\end{array}$ & $\begin{array}{l}\text { equency } \\
\text { samples) }\end{array}$ \\
\hline Comp & sition of the mos & common unique & lixtures wi & $>0.1$ & & Mixtures of \\
\hline Lead & Strontium & & & & 0 & 7.1 \\
\hline Nitrate & Boron & Radon & & & 0 & 7.1 \\
\hline Boron & Uranium & & & & 0 & 7.0 \\
\hline Boron & Uranium & Radon & & & 0 & 7.0 \\
\hline Arsenic & Boron & Strontium & & & 0 & 6.5 \\
\hline Arsenic & Boron & Strontium & Radon & & 0 & 6.1 \\
\hline Nitrate & Arsenic & Molybdenum & & & 0 & 6.1 \\
\hline Nitrate & Molybdenum & Uranium & & & 0 & 6.1 \\
\hline Boron & Molybdenum & & & & 0 & 6.0 \\
\hline Arsenic & Molybdenum & Strontium & & & 0 & 5.9 \\
\hline Manganese & Strontium & & & & 0 & 5.9 \\
\hline Nitrate & Arsenic & Strontium & Uranium & & 0 & 5.9 \\
\hline Nitrate & Lead & Radon & & & 0 & 5.6 \\
\hline Molybdenum & Strontium & Radon & & & 0 & 5.5 \\
\hline Arsenic & Molybdenum & Uranium & & & 0 & 5.5 \\
\hline Nitrate & Arsenic & Strontium & Uranium & Radon & 0 & 5.5 \\
\hline Boron & Strontium & Uranium & & & 0 & 5.3 \\
\hline Boron & Strontium & Uranium & Radon & & 0 & 5.3 \\
\hline Nitrate & Molybdenum & Uranium & Radon & & 0 & 5.3 \\
\hline Arsenic & Boron & Molybdenum & & & 0 & 5.2 \\
\hline Nitrate & Arsenic & Boron & & & 0 & 5.2 \\
\hline Boron & Molybdenum & Radon & & & 0 & 5.2 \\
\hline Nitrate & Arsenic & Boron & Radon & & 0 & 5.2 \\
\hline Arsenic & Boron & Uranium & & & 0 & 5.2 \\
\hline Arsenic & Boron & Uranium & Radon & & 0 & 5.2 \\
\hline Nitrate & Arsenic & Molybdenum & Radon & & 0 & 5.0 \\
\hline
\end{tabular}

${ }^{1}$ Radon activities were compared to the proposed Alternative Maximum Contaminant Level of 4,000 picocuries per liter (pCi/L).

${ }^{2}$ Radon activities were compared to the proposed Maximum Contaminant Level of $300 \mathrm{pCi} / \mathrm{L}$, which is about one-tenth of the proposed Alternative Maximum Contaminant Level. 
When the unique mixtures of contaminants at concentrations greater than one-tenth of individual benchmarks were expanded to include all detections of pesticide compounds or VOCs, regardless of their concentrations relative to benchmarks or the availability of benchmarks $(\mathrm{BQ}>0.1$ plus any organic contaminant detection category), 125 unique mixtures each were detected in at least 10 percent of source-water samples (table 21). Nitrate and radon were still among the common inorganic contaminants in these unique mixtures, but consideration of all pesticide or VOC detections added herbicides and herbicide degradates, such as atrazine and deethylatrazine; DBPs, such as chloroform; and solvents, such as PCE, to the most common contaminants in the mixtures. The most common unique mixture in this category consisted of nitrate and chloroform, which was detected in 34.4 percent of samples (tables 18 and 21).

Table 21. Composition and detection frequency of 125 unique mixtures with concentrations greater than one-tenth of individual human-health benchmarks plus any organic contaminant detection in 383 public-well samples collected during 1993-2007.

[BQ, Benchmark Quotient (ratio of concentration to human-health benchmark); >, greater than; PCE, perchloroethene; BDCM, bromodichloromethane; MTBE, methyl-tert-butyl ether; -, unique mixture includes an organic contaminant without a benchmark (so was not included in the BQ $>1$ or BQ $>0.1$ categories). Data are from 383 public-well samples in which major ions, trace elements, nitrate, radon, and organic contaminants were analyzed. No common assessment level was applied to these data. All unique mixtures of contaminants with $\mathrm{BQ}>0.1$ plus any organic contaminant detection that were detected in at least 10 percent of the public-well samples are listed.]

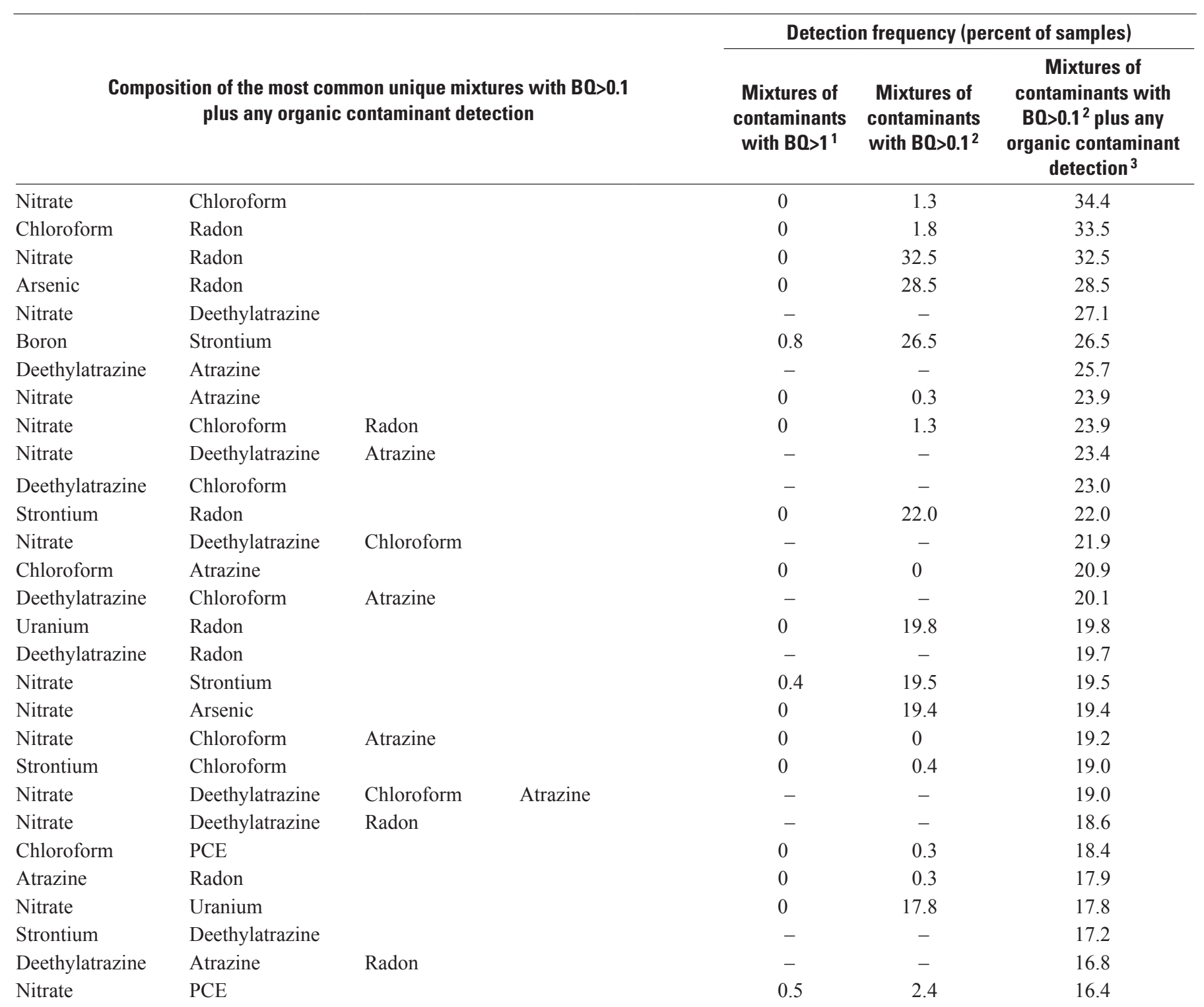


Table 21. Composition and detection frequency of 125 unique mixtures with concentrations greater than one-tenth of individual human-health benchmarks plus any organic contaminant detection in 383 public-well samples collected during 1993-2007.Continued

[BQ, Benchmark Quotient (ratio of concentration to human-health benchmark); >, greater than; PCE, perchloroethene; BDCM, bromodichloromethane; MTBE, methyl-tert-butyl ether; -, unique mixture includes an organic contaminant without a benchmark (so was not included in the $\mathrm{BQ}>1$ or $\mathrm{BQ}>0.1$ categories). Data are from 383 public-well samples in which major ions, trace elements, nitrate, radon, and organic contaminants were analyzed. No common assessment level was applied to these data. All unique mixtures of contaminants with $\mathrm{BQ}>0.1$ plus any organic contaminant detection that were detected in at least 10 percent of the public-well samples are listed.]

\begin{tabular}{|c|c|c|c|c|c|c|}
\hline & & & & Detectio & $n$ frequency (pe & cent of samples) \\
\hline Comp & $\begin{array}{l}\text { tion of the most co } \\
\text { plus any organi }\end{array}$ & $\begin{array}{l}\text { non unique mixtur } \\
\text { ontaminant detec }\end{array}$ & $\begin{array}{l}\text { s with B0>0.1 } \\
\text { ion }\end{array}$ & $\begin{array}{l}\text { Mixtures of } \\
\text { contaminants }\end{array}$ & $\begin{array}{l}\text { Mixtures of } \\
\text { contaminants }\end{array}$ & $\begin{array}{c}\text { Mixtures of } \\
\text { contaminants with } \\
\text { B0 }>0.1^{2} \text { plus any }\end{array}$ \\
\hline Nitrate & Arsenic & Radon & & 0 & 16.3 & 16.3 \\
\hline Arsenic & Uranium & & & 0 & 16.0 & 16.0 \\
\hline Nitrate & Strontium & Chloroform & & 0 & 0.4 & 15.8 \\
\hline Arsenic & Strontium & & & 0.4 & 15.8 & 15.8 \\
\hline Nitrate & Deethylatrazine & Atrazine & Radon & - & - & 15.7 \\
\hline Nitrate & Strontium & Deethylatrazine & & - & - & 15.6 \\
\hline BDCM & Chloroform & & & 0 & 0.3 & 14.9 \\
\hline Deethylatrazine & Chloroform & Radon & & - & - & 14.7 \\
\hline Strontium & Deethylatrazine & Chloroform & & - & - & 14.7 \\
\hline Strontium & Atrazine & & & 0 & 0 & 14.3 \\
\hline Nitrate & Deethylatrazine & Chloroform & Radon & - & - & 14.2 \\
\hline Arsenic & Chloroform & Radon & & 0 & 1.3 & 14.2 \\
\hline Boron & Radon & & & 0.4 & 13.7 & 13.7 \\
\hline Molybdenum & Radon & & & 0 & 13.6 & 13.6 \\
\hline Arsenic & Uranium & Radon & & 0 & 13.6 & 13.6 \\
\hline Nitrate & Strontium & Radon & & 0 & 13.6 & 13.6 \\
\hline Strontium & Chloroform & Radon & & 0 & 0.4 & 12.8 \\
\hline Arsenic & Strontium & Radon & & 0 & 12.8 & 12.8 \\
\hline PCE & Atrazine & & & 0 & 0 & 12.8 \\
\hline Deethylatrazine & Chloroform & Atrazine & Radon & - & - & 12.7 \\
\hline Nitrate & Deethylatrazine & Uranium & & - & - & 12.7 \\
\hline Deethylatrazine & PCE & & & - & - & 12.5 \\
\hline Nitrate & Chloroform & Atrazine & Radon & 0 & 0 & 12.4 \\
\hline Arsenic & Deethylatrazine & & & - & - & 12.4 \\
\hline Uranium & Atrazine & & & 0 & 0.3 & 12.4 \\
\hline Nitrate & BDCM & & & 0 & 0.3 & 12.3 \\
\hline
\end{tabular}


Table 21. Composition and detection frequency of 125 unique mixtures with concentrations greater than one-tenth of individual human-health benchmarks plus any organic contaminant detection in 383 public-well samples collected during 1993-2007.Continued

[BQ, Benchmark Quotient (ratio of concentration to human-health benchmark); >, greater than; PCE, perchloroethene; BDCM, bromodichloromethane; MTBE, methyl-tert-butyl ether; -, unique mixture includes an organic contaminant without a benchmark (so was not included in the $\mathrm{BQ}>1$ or $\mathrm{BQ}>0.1$ categories). Data are from 383 public-well samples in which major ions, trace elements, nitrate, radon, and organic contaminants were analyzed. No common assessment level was applied to these data. All unique mixtures of contaminants with $\mathrm{BQ}>0.1$ plus any organic contaminant detection that were detected in at least 10 percent of the public-well samples are listed.]

\begin{tabular}{|c|c|c|c|c|c|c|c|}
\hline & & & & & Detectio & $n$ frequency (pe & cent of samples) \\
\hline Comp & $\begin{array}{l}\text { tion of the most cc } \\
\text { plus any organ }\end{array}$ & $\begin{array}{l}\text { non unique mixtur } \\
\text { ontaminant detect }\end{array}$ & $\begin{array}{l}\text { es with BO } \\
\text { ion }\end{array}$ & & $\begin{array}{l}\text { Mixtures of } \\
\text { contaminants }\end{array}$ & $\begin{array}{l}\text { Mixtures of } \\
\text { contaminants }\end{array}$ & $\begin{array}{c}\text { Mixtures of } \\
\text { contaminants with } \\
\text { B0 }>0.1^{2} \text { plus any }\end{array}$ \\
\hline Nitrate & BDCM & Chloroform & & & 0 & 0.3 & 12.3 \\
\hline Nitrate & Deethylatrazine & Chloroform & Atrazine & Radon & - & - & 12.2 \\
\hline Nitrate & PCE & Radon & & & 0 & 2.4 & 12.1 \\
\hline Strontium & Chloroform & Atrazine & & & 0 & 0 & 12.1 \\
\hline Strontium & Deethylatrazine & Chloroform & Atrazine & & - & - & 12.1 \\
\hline Arsenic & Molybdenum & & & & 0.5 & 12.1 & 12.1 \\
\hline Nitrate & Arsenic & Deethylatrazine & & & - & - & 11.8 \\
\hline Nitrate & Uranium & Chloroform & & & 0 & 0.8 & 11.8 \\
\hline Nitrate & Arsenic & Uranium & & & 0 & 11.8 & 11.8 \\
\hline Arsenic & Atrazine & & & & 0 & 0.3 & 11.8 \\
\hline Deethylatrazine & Uranium & Atrazine & & & - & - & 11.8 \\
\hline Nitrate & Strontium & Atrazine & & & 0 & 0 & 11.7 \\
\hline Nitrate & Strontium & Deethylatrazine & Atrazine & & - & - & 11.7 \\
\hline Strontium & Uranium & & & & 0 & 11.7 & 11.7 \\
\hline Nitrate & PCE & Atrazine & & & 0 & 0 & 11.6 \\
\hline Nitrate & Deethylatrazine & Chloroform & PCE & & - & - & 11.6 \\
\hline Nitrate & Strontium & Deethylatrazine & Radon & & - & - & 11.3 \\
\hline Nitrate & Uranium & Atrazine & & & 0 & 0.3 & 11.2 \\
\hline Nitrate & Deethylatrazine & Chloroform & PCE & Atrazine & - & - & 11.0 \\
\hline Nitrate & Chloroform & PCE & Atrazine & & 0 & 0 & 11.0 \\
\hline Uranium & Chloroform & Radon & & & 0 & 0.8 & 11.0 \\
\hline Arsenic & Deethylatrazine & Atrazine & & & - & - & 10.9 \\
\hline Simazine & Deethylatrazine & Atrazine & & & - & - & 10.9 \\
\hline Nitrate & Deethylatrazine & Uranium & Atrazine & & - & - & 10.9 \\
\hline Simazine & Deethylatrazine & & & & - & - & 10.9 \\
\hline Simazine & Atrazine & & & & 0 & 0 & 10.9 \\
\hline
\end{tabular}


Table 21. Composition and detection frequency of 125 unique mixtures with concentrations greater than one-tenth of individual human-health benchmarks plus any organic contaminant detection in 383 public-well samples collected during 1993-2007.Continued

[BQ, Benchmark Quotient (ratio of concentration to human-health benchmark); >, greater than; PCE, perchloroethene; BDCM, bromodichloromethane; MTBE, methyl-tert-butyl ether; -, unique mixture includes an organic contaminant without a benchmark (so was not included in the BQ $>1$ or $\mathrm{BQ}>0.1$ categories). Data are from 383 public-well samples in which major ions, trace elements, nitrate, radon, and organic contaminants were analyzed. No common assessment level was applied to these data. All unique mixtures of contaminants with $\mathrm{BQ}>0.1$ plus any organic contaminant detection that were detected in at least 10 percent of the public-well samples are listed.]

\begin{tabular}{|c|c|c|c|c|c|c|c|}
\hline & & & & & Detectio & n frequency (pe & cent of samples) \\
\hline Comp & $\begin{array}{l}\text { tion of the most co } \\
\text { plus any organi }\end{array}$ & $\begin{array}{l}\text { non unique mixtur } \\
\text { ontaminant detect }\end{array}$ & $\begin{array}{l}\text { s with } B 0>0.1 \\
\text { on }\end{array}$ & & $\begin{array}{l}\text { Mixtures of } \\
\text { contaminants }\end{array}$ & $\begin{array}{l}\text { Mixtures of } \\
\text { contaminants }\end{array}$ & $\begin{array}{c}\text { Mixtures of } \\
\text { contaminants with } \\
\text { B0 }>0.1^{2} \text { plus any }\end{array}$ \\
\hline Deethylatrazine & Uranium & Radon & & & - & - & 10.9 \\
\hline Nitrate & Arsenic & Atrazine & & & 0 & 0.3 & 10.7 \\
\hline Nitrate & Deethylatrazine & Uranium & Radon & & - & - & 10.6 \\
\hline Simazine & Chloroform & & & & 0 & 0 & 10.6 \\
\hline Nitrate & Simazine & & & & 0 & 0 & 10.6 \\
\hline Manganese & Radon & & & & 0 & 10.5 & 10.5 \\
\hline Nitrate & Arsenic & Uranium & Radon & & 0 & 10.2 & 10.2 \\
\hline Chloroform & MTBE & & & & - & - & 10.2 \\
\hline Nitrate & Simazine & Deethylatrazine & Atrazine & & - & - & 10.1 \\
\hline Nitrate & Simazine & Deethylatrazine & & & - & - & 10.1 \\
\hline Nitrate & Simazine & Atrazine & & & 0 & 0 & 10.1 \\
\hline Arsenic & Boron & & & & 0 & 10.0 & 10.0 \\
\hline Arsenic & Deethylatrazine & Radon & & & - & - & 10.0 \\
\hline Deethylatrazine & BDCM & & & & - & - & 10.0 \\
\hline Deethylatrazine & BDCM & Chloroform & & & - & - & 10.0 \\
\hline
\end{tabular}

${ }^{1}$ Radon activities were compared to the proposed Alternative Maximum Contaminant Level of 4,000 picocuries per liter (pCi/L).

${ }^{2}$ Radon activities were compared to the proposed Maximum Contaminant Level of $300 \mathrm{pCi} / \mathrm{L}$, which is about one-tenth of the proposed Alternative Maximum Contaminant Level.

${ }^{3}$ Organic contaminants were assessed regardless of the availability of human-health benchmarks or the concentrations relative to individual benchmarks.

In the $\mathrm{BQ}>0.1$ plus any organic contaminant detection category, DeSimone (2009) also reported mixtures containing chloroform, atrazine, or deethylatrazine in domestic wells, although in a smaller proportion of samples. For example, the mixture of radon and chloroform was detected in about 15 percent of domestic-well samples and in 33.5 percent of public-well samples (table 21). In the $\mathrm{BQ}>0.1$ plus any organic contaminant detection category, solvents, such as PCE, were not detected in the most frequently occurring unique mixtures in domestic-well samples (DeSimone, 2009), whereas PCE was a component of 15 percent of the unique mixtures in this category for public-well samples. There were only eight unique mixtures in domestic wells that were detected in
10 percent or more of the samples with $\mathrm{BQ}>0.1$ plus any organic contaminant detection (DeSimone, 2009), which was substantially less than the 125 unique mixtures in public wells in the same category (table 21).

In a separate analysis, using a different subset of the 932 public-well samples in this study, the co-occurrence of any organic contaminant was assessed in 814 public wells in which pesticide compounds analyzed using GCMS and VOCs were analyzed. Mixtures of pesticide compounds and VOCs were assessed without regard to the availability of benchmarks or the concentrations relative to individual benchmarks. The number of public wells for the organics mixtures analysis (814) was greater than the number of wells for the other 
mixtures analyses (383) because other contaminant groups did not need to be analyzed in the samples to be included in the assessment. Anthropogenic organic contaminants were evaluated separately from other contaminant groups because they generally do not have natural sources and there are many possible mixtures of organic contaminants whose occurrence and toxicity are not well understood.

Twenty-three unique mixtures of organic contaminants each were detected in at least 10 percent of the source-water samples (table 22). About three-quarters of the organic mixtures contained an herbicide (atrazine or simazine) or an herbicide degradate (deethylatrazine). About two-thirds of the organic mixtures contained chloroform (a DBP), and about 43 percent contained a solvent (PCE or TCE). The most common mixtures of VOCs in national assessments of public wells and CWSs also included DBPs and solvents (Grady, 2002; Zogorski and others, 2006). The percentage of publicwell samples in which the unique organic mixtures occurred generally was similar to the percentage of samples in which the same unique organic mixtures occurred in the BQ $>0.1$ plus the detection of any organic contaminant category. For example, the mixture of atrazine and deethylatrazine was the most frequently detected organic mixture when only organic contaminants were considered (25.5 percent of samples, table 22) and when organic contaminants were considered with contaminants with $\mathrm{BQ}>0.1$ (25.7 percent of samples, table 21).

Table 22. Composition and detection frequency of 23 unique mixtures of organic contaminants in 814 public-well samples collected during 1993-2007.

[PCE, perchloroethene; MTBE, methyl-tert-butyl ether; TCE, trichloroethene; BDCM, bromodichloromethane. Data are from 814 public-well samples in which pesticide compounds analyzed using gas chromatography/mass spectrometry and volatile organic compounds were analyzed. No common assessment level was applied to these data. All unique mixtures of organic contaminants that were detected in at least 10 percent of the public-well samples are listed]

\begin{tabular}{|c|c|c|c|c|}
\hline \multicolumn{4}{|c|}{ Composition of the most common unique mixtures of organic contaminants ${ }^{1}$} & \multirow{2}{*}{$\begin{array}{c}\begin{array}{c}\text { Detection } \\
\text { frequency } \\
\text { (percent of } \\
\text { samples) }\end{array} \\
25.5\end{array}$} \\
\hline Deethylatrazine & Atrazine & & & \\
\hline Deethylatrazine & Chloroform & & & 24.3 \\
\hline Chloroform & Atrazine & & & 21.4 \\
\hline Deethylatrazine & Chloroform & Atrazine & & 20.3 \\
\hline Chloroform & PCE & & & 19.9 \\
\hline Deethylatrazine & PCE & & & 13.7 \\
\hline Simazine & Chloroform & & & 13.4 \\
\hline Simazine & Deethylatrazine & & & 13.2 \\
\hline Deethylatrazine & Chloroform & PCE & & 13.1 \\
\hline PCE & Atrazine & & & 12.8 \\
\hline Simazine & Atrazine & & & 12.8 \\
\hline Simazine & Deethylatrazine & Atrazine & & 12.5 \\
\hline Chloroform & MTBE & & & 12.5 \\
\hline Deethylatrazine & PCE & Atrazine & & 12.2 \\
\hline Chloroform & PCE & Atrazine & & 12.2 \\
\hline Chloroform & TCE & & & 11.8 \\
\hline Deethylatrazine & Chloroform & PCE & Atrazine & 11.7 \\
\hline Simazine & Deethylatrazine & Chloroform & & 11.6 \\
\hline Simazine & Chloroform & Atrazine & & 11.2 \\
\hline Chloroform & 1,1,1-Trichloroe & & & 11.1 \\
\hline Simazine & Deethylatrazine & Chloroform & Atrazine & 11.0 \\
\hline BDCM & Chloroform & & & 10.9 \\
\hline PCE & TCE & & & 10.6 \\
\hline
\end{tabular}

\footnotetext{
${ }^{1}$ Organic contaminants were assessed regardless of the availability of human-health benchmarks or the concentrations relative to individual benchmarks.
} 
Co-occurrence can reflect the degradation of a parent compound to their by-products (Grady, 2002). For example, deethylatrazine commonly co-occurred with atrazine (fig. 39) because it is one of the degradation products of atrazine, and the common co-occurrence of these contaminants was observed in previous regional- and national-scale studies (Ayers and others, 2000; Squillace and others, 2002; Gilliom and others, 2006; DeSimone, 2009). Co-occurrence also can take place when several contaminants have a common source (Grady and Casey, 2001; Grady, 2002). For example, about 11 percent of the samples contained chloroform and bromodichloromethane, both of which are DBPs (table 22). Several recent studies have begun to evaluate DBP mixtures in drinking water because of widespread exposures to these complex mixtures and because epidemiologic and toxicologic studies of DBPs have raised concerns for human health (Teuschler and Simmons, 2003; U.S. Environmental Protection Agency, 2003b; Simmons and others, 2004; Teuschler and others, 2004).

\section{Assessing the Potential Significance of Mixtures to Human Health}

As mentioned previously, little is known about the potential health effects associated with exposure to multiple contaminants (Yang, 1994; Carpenter and others, 2002). Since 1986, the USEPA and the ATSDR have published several guidance documents on the risk assessment of chemical mixtures (U.S. Environmental Protection Agency, 1986, 2000c, 2003c; Agency for Toxic Substances and Disease Registry, 2004a). The topic of chemical mixtures continues to be an area of active research. The National Academy of Sciences recently recommended that the USEPA increase its research on cumulative risk assessments including interactions among chemical and nonchemical stressors (National Research Council, 2008), and the USEPA has published a resource document to assist with conducting multi-chemical, population-focused cumulative risk assessments (U.S. Environmental Protection Agency, 2007a).

Approaches used in health risk assessment of chemical mixtures include the use of data on (1) the specific mixture of concern, (2) a similar mixture, or (3) each component of the mixture (U.S. Environmental Protection Agency, 2000c). The individual component-based approach is the most often used because it allows the individual risks from each component to be combined to calculate an overall risk for the mixture (Mumtaz, 1995). Dose addition is used for toxicologically similar components with common modes of action, and response addition is used for toxicologically independent components with dissimilar modes of action (Bolt and Mumtaz, 1996; U.S. Environmental Protection Agency, 2000c). Several other methods also are used, and no single approach is suitable for assessing the health risk associated with all exposure scenarios associated with the various types of mixtures (Mumtaz, 1995). Additivity approaches can overestimate the risk from exposure to contaminant mixtures and can, therefore, be used for standard setting because, from a public-health perspective, such results over-protect the public (Bolt and Mumtaz, 1996).

With the exceptions of TTHMs, xylenes, TCT, and gross alpha- and gross beta-particle radioactivities, human-health benchmarks are not available for contaminant mixtures. The occurrence of these contaminant mixtures in publicwell samples was previously discussed in section, "Results and Discussion-Individual Properties and Contaminants" beginning on page 29. Concentrations were less than benchmarks for TTHMs, xylenes, and TCT in all sourcewater samples from public wells, and concentrations of these mixtures were greater than one-tenth of benchmarks in about 0 to 1 percent of the samples (tables 12 and 13). Gross alphaand gross beta-particle radioactivities were greater than onetenth of human-health benchmarks in about one-half of the samples (table 10), but these contaminants were only analyzed in about 9 percent of the samples included in this study, so their occurrence could not be evaluated more broadly.

ATSDR has published a series of documents called Interaction Profiles developed for certain priority mixtures that are of special concern to ATSDR. Interaction Profiles are used to evaluate data on the toxicology of the whole priority mixture (if available) and on the joint toxic action of the contaminants in the mixture in order to recommend approaches for assessing the potential hazard to public health (Agency for Toxic Substances and Disease Registry, 2009). The Interaction Profiles that are most relevant to the commonly occurring mixtures in the public-well samples included in this study were for (1) atrazine, deethylatrazine, diazinon, nitrate, and simazine (Agency for Toxic Substances and Disease Registry, 2006); (2) 1,1,1-trichloroethane, 1,1-dichloroethane, TCE, and PCE (Agency for Toxic Substances and Disease Registry, 2004b); (3) chloroform, 1,1-dichloroethene, TCE, and vinyl chloride (Agency for Toxic Substances and Disease Registry, 2007); and (4) cyanide, fluoride, nitrate, and uranium (Agency for Toxic Substances and Disease Registry, 2004c). For each of these mixtures, no pertinent health effects data or toxicologic models were available for the complete mixtures, so ATSDR evaluated the health effects and mechanistic data for the individual components and the joint toxic action and mechanistic data for various combinations of the components.

ATSDR examined the mixture of atrazine, deethylatrazine, diazinon, nitrate, and simazine because these contaminants frequently co-occur in rural well water. Health effects of concern for this mixture include reproductive effects (atrazine, deethylatrazine, and simazine), neurological effects (diazinon), and hematological effects (nitrate). None of the components in the mixture has been classified as a carcinogen, but atrazine and simazine can react with nitrite (a nitrate metabolite) in the environment and in the body to form potentially carcinogenic nitrosamines (Agency 
for Toxic Substances and Disease Registry, 2006). This five-component mixture was not detected in public-well samples in this study (data not shown), but other combinations of these contaminants were frequently detected. The combination of atrazine and nitrate was detected in about 24 percent of public-well samples. The two-component combinations of simazine and nitrate, the three-component mixture of simazine, atrazine, and deethylatrazine, and the four-component mixture of nitrate, simazine, atrazine, and deethylatrazine each were detected in about 10 to 11 percent of 383 public-well samples (table 21).

The solvents 1,1,1-trichloroethane, 1,1-dichloroethane, TCE, and PCE frequently co-occur in water samples near hazardous waste sites and other sites assessed by ATSDR (Agency for Toxic Substances and Disease Registry, 2004b). Exposure to each of these four individual contaminants can produce neurological impairment and can cause noncarcinogenic and carcinogenic responses in the liver and kidney of animals. The ATSDR determined that additive joint action of binary or trinary mixtures of these contaminants is plausible on the nervous system and on the liver and kidney, with the exception that PCE may inhibit the toxic action of TCE on the liver and kidney (Agency for Toxic Substances and Disease Registry, 2004b). 1,1-Dichloroethane was not a component of the most frequently detected mixtures in this study (tables 21 and 22), but the four-component mixture of 1,1,1-trichloroethane, 1,1-dichloroethane, TCE, and PCE was detected in 3.2 percent of the public-well samples (data not shown). 1,1,1-Trichloroethane co-occurred with PCE in about 9 percent of samples and with TCE in about 7 percent of samples (data not shown). TCE and PCE co-occurred in 10.6 percent of the organic contaminant mixtures in publicwell samples (table 22) and co-occurred at concentrations greater than the MCLs in 0.3 percent of samples (table 19).

Chloroform, 1,1-dichloroethene, TCE, and vinyl chloride frequently are detected in water around hazardous waste sites (Agency for Toxic Substances and Disease Registry, 2007). The health effects of concern for this mixture are hepatic (liver), renal (kidney), and developmental (all four contaminants); immunological and cancer (chloroform, TCE, vinyl chloride); and neurological (chloroform, TCE). The most likely mode of joint action for the individual component pairs was competition for the active sites of enzymes associated with metabolism of xenobiotics in the body, but only at high exposure levels where metabolic saturation may occur. Such high exposures from water near hazardous waste sites are not likely relevant, which means that the additivity assumption may be suitable for protecting human health (Agency for Toxic Substances and Disease Registry, 2007). Chloroform and TCE co-occurred in 11.8 percent of the public-well samples (table 22). Other combinations of these VOCs - chloroform and 1,1-dichloroethene; TCE and 1,1-dichloroethene; and chloroform, TCE, and 1,1-dichloroethene-co-occurred in 5.4 to 6.8 percent of samples (data not shown).
The inorganic contaminants uranium and fluoride have been, and continue to be, used in conjunction with nitrate when separating isotopes of uranium at several U.S. Department of Energy facilities assessed by ATSDR; cyanide also frequently is detected at hazardous waste sites (Agency for Toxic Substances and Disease Registry, 2004c). Cyanide was not analyzed in public-well samples in this study and fluoride was not a component of frequently detected mixtures. The combination of nitrate and uranium, however, was detected in 17.8 percent of public-well samples (table 20). The mechanisms of action of uranium and nitrate do not currently suggest any potential joint actions among these two contaminants (Agency for Toxic Substances and Disease Registry, 2004c).

ATSDR also has published Interaction Profiles for other mixtures of inorganic contaminants analyzed individually in this study, specifically for (1) arsenic, cadmium, chromium, and lead and (2) lead, manganese, zinc, and copper (Agency for Toxic Substances and Disease Registry, 2009). In this study, however, these inorganic contaminants infrequently co-occurred in the public-well samples at concentrations greater than one-tenth of human-health benchmarks; detection frequencies ranged from 0 to 4.3 percent (data not shown).

\section{Comparisons with Previous National- Scale Public-Well Studies}

There have been numerous statewide, regional, and national studies of water quality from public wells or public water systems. For the purposes of this section of the report, only previous national-scale studies conducted by the USGS or USEPA that included groundwater samples from public wells or public water systems are discussed (Appendix 1). This study complements and expands upon findings reported in previous national-scale studies of public wells in several ways, as described in the Introduction, but findings from this study generally confirm and reinforce previous conclusions about many contaminants.

Detailed and comprehensive comparisons among the national-scale studies listed in Appendix 1 were not possible because of differences in study designs. For example, untreated source water from individual public wells was sampled from the wellhead in most USGS studies, whereas treated finished water from public water systems (made up of multiple wells) was sampled at the entry points to distribution systems in many USEPA studies. Additionally, not all studies used the same analytical methods or reporting levels. For each national-scale study included in this section of the report, however, general comparisons were made among detection frequencies and percentages of wells and systems with concentrations greater than benchmarks for individual regulated contaminants (Appendixes 16 and 17) and unregulated contaminants (Appendixes 18 and 19). 


\section{Selected National-Scale Studies}

Previous national-scale USGS water-quality assessments that included findings from (mostly) untreated source water from public wells have focused on specific contaminant groups, such as anthropogenic organic contaminants (Hopple and others, 2009), pesticide compounds (Gilliom and others, 2006), VOCs (Grady, 2002; Zogorski and others, 2006), and radionuclides (Focazio and others, 2001). By contrast, this study examined the occurrence of a broad suite of organic and inorganic contaminant groups (Appendix 4). Most previous USGS studies examined here assessed the occurrence of both regulated and unregulated contaminants in hundreds of public-well samples using nationally consistent sampling and analysis protocols (Appendix 1).

Some national-scale USEPA water-quality assessments also have focused on the occurrence specific contaminant groups in finished water from hundreds to thousands of public wells or systems, including pesticide compounds (U.S. Environmental Protection Agency, 1990, 1992a), VOCs (Westrick and others, 1984; Westrick, 1990), and radionuclides (Horton, 1983; Longtin, 1988). Other USEPA studies have examined the occurrence of multiple contaminant groups in tens of thousands of groundwater samples from public water systems, but focused on either contaminants regulated in drinking water under the SDWA or on unregulated contaminants (Appendix 1). This study included fewer public-well samples than many USEPA studies, but examined a larger number of contaminants.

\section{USEPA Studies of Regulated Contaminants}

For regulated contaminants, the 1996 Amendments to the SDWA require USEPA to review each National Primary Drinking Water Regulation at least once every 6 years, and to revise them, if appropriate. Any revision must maintain or increase public-health protection. As of February 2010, USEPA had reviewed contaminant occurrence in public water systems in 1999 (U.S. Environmental Protection Agency, 1999b) and completed their first Six-Year Review in 2003 (U.S. Environmental Protection Agency, 2003f). In March 2010, USEPA completed their second Six-Year Review (U.S. Environmental Protection Agency, 2010b), but results from that study were not available in time for inclusion in this report. In the March 2010 review of existing drinking water standards, USEPA determined that scientific advances allow for stricter regulations for four carcinogenic contaminants, including PCE and TCE.

In USEPA's 2003 review of contaminant occurrence in public water systems, the occurrence of 61 regulated chemical contaminants for a national cross section of 16 states was evaluated. In that same study, USEPA also examined the occurrence of regulated contaminants in public water systems relative to MCLs for a national cross section of eight states (U.S. Environmental Protection Agency, 2003f). The datasets for these eight states were voluntarily provided by the states, and were previously used for a detailed national analysis of contaminant occurrence in public water systems (U.S. Environmental Protection Agency, 1999b). USEPA used the compliance monitoring contaminant-occurrence data from these eight states because, collectively, they provided a balanced cross section, based on relative rankings for pollution potential (indicating a range of high, medium, and low contaminant occurrence) and geographic coverage (indicating a range of climatic and hydrologic conditions across the United States). The eight states represented more than 25 percent of the U.S. population using public water systems, and more than 20 percent of the public water systems nationally (U.S. Environmental Protection Agency, 2003f).

Data from the 1999 USEPA review of regulated contaminants in public water systems (U.S. Environmental Protection Agency, 1999b) are not presented separately in this report because the dataset from the 1999 USEPA review was included in the dataset for the 2003 USEPA review (U.S. Environmental Protection Agency, 2003f). The 1999 USEPA review examined the occurrence of a larger number of contaminants, however, than the 2003 review. In total, USEPA analyzed data for about 280 contaminants in their 1999 review of contaminant occurrence in public water systems, including the regulated contaminants examined in the 2003 review, a few additional regulated contaminants, such as nitrate and lead, and unregulated contaminants that were required or discretionary for monitoring under the Unregulated Contaminant Monitoring (UCM) program, or were contained in state databases.

\section{USEPA Studies of Unregulated Contaminants}

The USEPA uses the UCM program to collect occurrence data for contaminants suspected to be present in drinking water, but that do not have drinking-water standards (MCLs) set under the SDWA (U.S. Environmental Protection Agency, 2010f). These occurrence data, in part, are used to determine whether a contaminant is detected at a frequency and at concentrations that warrant further analysis and research on potential health effects. Such data could result in the contaminant being added to the CCL (Richardson, 2003).

To date (2009), USEPA has evaluated 19 chemical contaminants on the first and second CCLs for possible regulation in drinking water, including 15 analyzed in this study (table 23). After evaluating available occurrence, exposure, and health-effects information, USEPA determined that no regulatory action was appropriate for these contaminants because they infrequently occur at health levels of concern in public water systems, and regulating these contaminants in drinking water would not "present 
Table 23. Chemical contaminants evaluated by the U.S. Environmental Protection Agency for possible regulation in drinking water.

[CCL, Contaminant Candidate List; Bold indicates contaminants that were analyzed in this study.]

\begin{tabular}{|c|c|}
\hline $\begin{array}{l}\text { Chemical contaminants on the first drinking water } \\
\text { CCL for which regulatory determinations were made } \\
\text { (U.S. Environmental Protection Agency, 2003a) }\end{array}$ & $\begin{array}{l}\text { Chemical contaminants on the second drinking water } \\
\text { CCL for which regulatory determinations were made } \\
\text { (U.S. Environmental Protection Agency, 2008b) }\end{array}$ \\
\hline Aldrin & Boron \\
\hline Dieldrin & Dacthal (DCPA) mono-acid degradate \\
\hline Hexachlorobutadiene & Dacthal (DCPA) di-acid degradate \\
\hline Manganese & DDE (1,1-dichloro-2,2-bis( $p$-chlorophenyl) ethylene) \\
\hline Metribuzin & 1,3-Dichloropropene ${ }^{1}$ \\
\hline Naphthalene & 2,4-Dinitrotoluene \\
\hline Sodium & 2,6-Dinitrotoluene \\
\hline \multirow[t]{4}{*}{ Sulfate } & EPTC (s-ethyl-dipropylthiocarbamate) \\
\hline & Fonofos \\
\hline & Terbacil \\
\hline & 1,1,2,2-Tetrachloroethane \\
\hline
\end{tabular}

${ }^{1}$ In this study, separate cis- and trans- isomers of 1,3-dichloropropene were analyzed.

a meaningful opportunity for health risk reduction" (U.S. Environmental Protection Agency, 2003a, 2008b). Of the 104 chemical contaminants on the third, and most recent, CCL (U.S. Environmental Protection Agency, 2010a), 32 were or will be analyzed during at least one of the UCM monitoring cycles, and 23 were analyzed in public-well samples in this study, including pesticide compounds, industrial chemicals with various uses, naturally occurring trace elements, and MTBE (Appendix 20).

The UCM program has progressed in three primary stages. The original UCM program (UCM Rounds 1 and 2, 1988-1997) was managed by state drinking-water programs and required public water systems serving more than 500 people to monitor select unregulated contaminants (U.S. Environmental Protection Agency, 2010f). The 1996 SDWA Amendments redesigned the UCM program, established the Unregulated Contaminant Monitoring Rule (UCMR) managed by USEPA, and required USEPA to identify no more than 30 contaminants to be monitored every 5 years (U.S. Environmental Protection Agency, 2010f). For the first direct implementation of UCMR (UCMR1, 2001-2005), UCMR1 established a tiered monitoring approach and required all large public water systems and a nationally representative sample of small public water systems to monitor 25 unregulated chemical contaminants (U.S. Environmental Protection Agency, 2006d). Under the second UCMR monitoring cycle (UCMR2), a new set of 25 unregulated chemical contaminants will be monitored in public water systems using a tiered approach during 2008-2010 (U.S. Environmental Protection Agency, 2010g).

\section{Comparison of Detection Frequencies}

Detection frequencies of organic contaminants analyzed in this study were comparable to detection frequencies reported in previous national-scale USGS studies for regulated and unregulated contaminants (Appendixes 16 and $\underline{18}$ ). This similarity results, in part, because about one-quarter to one-third of the public wells sampled in this study also were included in some of the previous USGS studies and because sampling and analytical methods were the same (or similar) in previous USGS studies (Gilliom and others, 2006; Zogorski and others, 2006; Hopple and others, 2009). Those pesticide compounds and VOCs that were most and least frequently detected in this study also were most and least frequently detected in previous USGS studies. By contrast, radium was detected more frequently in this study (about 92 percent of public-well samples) than in a USGS reconnaissance survey of radionuclides (Focazio and others, 2001), where radium-226 and radium-228 each were detected in about 30 percent of the samples (Appendix 16). This difference may be the result of more public-wells being sampled in this study (191 versus 99), and lower reporting levels used for some of the radium-226 measurements in this study $(0.02$ to $1 \mathrm{pCi} / \mathrm{L}$ versus $1 \mathrm{pCi} / \mathrm{L})$.

Detection frequencies in this study also were compared to detection frequencies reported in USEPA studies of specific contaminant groups. Detection frequencies of regulated and unregulated VOCs generally were similar in untreated water sampled in this study and in finished water sampled in the USEPA groundwater supply survey (Westrick and others, 1984) (Appendixes 16 and 18). Detection frequencies of some VOCs were higher in finished water samples from the USEPA 
groundwater supply survey than in source water samples from this study. VOC detection frequencies were higher in the USEPA survey when (1) non-random samples were collected from systems that were likely to show VOCs in groundwater (this study did not focus on areas with known VOC contamination); and (2) THMs were analyzed (Appendix 16) because THMs can form in finished water as a result of chlorination. In this study, about 41 percent of those pesticides analyzed were detected (table 14), whereas about 13 percent of those pesticide compounds analyzed in the National Pesticides Survey were detected (U.S. Environmental Protection Agency, 1990), likely because reporting levels were higher in the National Pesticides Survey than in this study. Radionuclides tended to be more frequently detected in this study than in all selected previous studies (Appendix 16).

For regulated contaminants, those that were most frequently detected in the 16-state cross section for the first USEPA Six-Year Review and in Rounds 1 and 2 of the USEPA UCM program generally also were most frequently detected in this study (Appendix 16). The detection frequencies reported for all of these studies were calculated as a percentage of individual samples with detections in order to increase the comparability of the results among the studies. Most individual regulated contaminants were more frequently detected in this study than in either the first Six-Year Review or the UCM study (Appendix 16) because reporting levels were about 2-fold to more than 1,000-fold lower in this study for most contaminants (data not shown).

More unregulated contaminants were analyzed in this study than in any of the previous national-scale studies (Appendix 18). Most individual unregulated contaminants were more frequently detected in this study than in either the UCMR1 or the original UCM studies (Appendix 18) because reporting levels were about 2 -fold to more than 600 -fold lower in this study for most contaminants (data not shown). The dacthal mono/di-acid degradates were an exception; they were detected in about 3 percent of the samples (and about 6 percent of the systems) collected from groundwater systems under the UCMR1, but were not detected in this study (the di-acid degradate was not analyzed in this study). The UCMR findings are consistent with the National Pesticide Survey, which estimated that 6.4 percent of the $94,600 \mathrm{CWS}$ wells in the United States contain dacthal acid metabolites (U.S. Environmental Protection Agency, 1990).

In 2009, USEPA published preliminary data for the first 15 months of UCMR2 monitoring. Three contaminants analyzed in this study - acetochlor, alachlor, and metolachlor-were analyzed in 4,300 finished drinking-water samples from 616 public water systems as part of the UCMR2 program, but were not detected (U.S. Environmental Protection Agency, 2009d). These three pesticide compounds were detected in 0.3 to 8.6 percent of the source-water samples from public wells in this study (Appendixes 16 and 18), perhaps because the reporting levels in this study were about 170-fold to 670-fold lower than in the UCMR2 program.

\section{Comparison of Concentrations Greater Than Benchmarks}

Few organic contaminants were detected at concentrations greater than human-health benchmarks in this study. The percentage of wells with concentrations greater than benchmarks, and concentrations approaching benchmarks, was similar for regulated and unregulated organic contaminants among the national-scale USGS studies examined (Appendixes 17 and 19).

For each regulated contaminant examined in the first Six-Year Review, USEPA reported the percentage of groundwater-supplied public water systems in eight states with any concentration greater than the MCL or concentrations greater than one-half of the MCL (U.S. Environmental Protection Agency, 2003f). In the Six-Year Review and in this study, concentrations were greater than one-half or one-tenth of MCLs for many contaminants, but concentrations greater than MCLs were not common (Appendix 17). Concentrations of most contaminants analyzed in this study were less than MCLs.

For those contaminants with concentrations greater than MCLs, except for arsenic, the percentage of groundwatersupplied public water systems with concentrations greater than MCLs was greater in USEPA's Six-Year Review than the percentage of public wells with concentrations greater than MCLs in this study (Appendix 17). The percentage of wells with arsenic concentrations greater than the MCL was likely greater in this study than the percentage of systems with such concentrations in the Six-Year Review because the MCL was lowered from $50 \mu \mathrm{g} / \mathrm{L}$ (used in the Six-Year Review) to $10 \mu \mathrm{g} / \mathrm{L}$ (used in this study) in 2001 (U.S. Environmental Protection Agency, 2001b). The percentage of systems with concentrations greater than MCLs for other contaminants was likely greater in the Six-Year Review than the percentage of wells with such concentrations reported in this study because many more systems than individual public wells were sampled, providing more opportunities for contaminants to be detected at concentrations greater than MCLs. The frequency of concentrations approaching MCLs was similar among the groundwater systems in the Six-Year Review and the individual public wells in this study (Appendix 17).

Percentages of public wells sampled in this study with concentrations greater than benchmarks also were compared to percentages of groundwater-supplied public water systems sampled in the UCM program with concentrations greater than benchmarks. The percentage of wells or systems with concentrations greater than benchmarks for individual contaminants in both studies was similar, typically between 0 and 0.5 percent of systems or samples (Appendixes 17 and 19). TCE and PCE were the VOCs that most frequently were detected at concentrations greater than benchmarks in this study (in about 1 percent of samples); TCE and PCE also were detected at concentrations greater than benchmarks in about 
1 percent of the public water systems in the UCM program (Appendix 17). Dieldrin was more frequently detected at concentrations greater than human-health benchmarks in this study (3 percent of samples) than in the UCM program (0.09 percent of systems) (Appendix 19), likely because the minimum detected dieldrin concentration in the UCM program was 10 -fold greater than the benchmark (data not shown).

\section{USEPA Data on Health-Based Violations}

Public-well samples evaluated in this study represent untreated source water, and any concentrations greater than MCLs do not represent MCL violations because MCLs apply to finished drinking water and none of the source-water samples in this study were collected for regulatory compliance purposes. Those individual contaminants with concentrations greater than MCLs in source-water samples from public wells, however, generally were indicative of which contaminants were reported by USEPA as having MCL violations in finished drinking water. In 2008, about 9,000 out of 140,000 groundwater-supplied public water systems reported 14,000 MCL violations; about 7.7 million people were served by those systems reporting violations (U.S. Environmental Protection Agency, 2008g). About 94 percent of the violations were in very small or small systems, consistent with the findings of previous studies (U.S. General Accounting Office, 1997).

Of the reported MCL violations in 2008, about 15 percent of the violations were for arsenic, about 9 percent were for radionuclides (radium-226 plus radium-228, uranium, and gross alpha- and gross beta-particle radioactivities), and 8 percent were for nitrate (U.S. Environmental Protection Agency, 2008g). Arsenic, radionuclides, and nitrate were among those contaminants analyzed in this study that most frequently were detected at concentrations greater than benchmarks in source water (fig. 42). As described above, only general comparisons can be made among the results of this study and previous USEPA studies; however, these general comparisons suggest that concentrations of contaminants, such as arsenic and nitrate, are being successfully managed in finished drinking water from groundwater supplies. For example, in untreated source water in this study, concentrations of arsenic and nitrate were greater than MCLs in about 10 and 2 percent of samples, respectively (Appendix 17). In finished drinking water in 2008, there were MCL violations for arsenic and nitrate in about 0.7 and 0.4 percent of groundwater-supplied public water systems, respectively (U.S. Environmental Protection Agency, 2008g).

In 2008, most MCL violations (about 59 percent) were for the Total Coliform Rule and about 6 percent of the violations were for TTHMs and total haloacetic acids (U.S. Environmental Protection Agency, 2008g). Other studies have noted similar findings. For example, of the systems with reported MCL violations in 2007, 84 percent of these cases pertained to rules governing treatment to prevent waterborne diseases - the most widespread and acute threat to health from drinking water-or the contaminants created by such treatment (U.S. Environmental Protection Agency, 2008a). In this study, the percentage of source-water samples from public wells with concentrations greater than the MCL for total coliforms and E. coli could not be calculated because the MCL for these organisms is based on monthly sampling, but total coliforms and E. coli were detected in about 10 and 2 percent of the source-water samples, respectively (table 10). TTHM concentrations were less than the MCL in all source-water samples in this study (table 13), likely because the source water was sampled prior to treatment with disinfectants, such as chlorine, that can react with DOC in the water to form THMs (Richardson and others, 2002).

USEPA used SDWA compliance data to establish a water-quality indicator that tracks trends in the total population served by CWSs for which no violations of health-based drinking-water standards were reported by states. Of the population served by groundwater and surface-water CWSs nationally, the percentage served by systems for which no health-based violations were reported for the entire year increased overall from 79 percent in 1993 to 92 percent in 2007, with a peak of 94 percent in 2002 (U.S. Environmental Protection Agency, 2008a).

\section{Comparisons with Previous National- Scale USGS Domestic-Well Study}

The results from this study were compared to results from a recently completed USGS national assessment of the quality of source water from domestic wells (DeSimone, 2009). In this public-well study and in the domestic-well study, essentially the same contaminants were analyzed, and similar methodologies were used to evaluate the water-quality data, although more than twice as many domestic wells were sampled than were public wells. Overall, the quality of source waters that supply domestic and public wells in the United States is similar (Appendix 21). In the domestic and public-well assessments, one or more contaminants with concentrations greater than human-health benchmarks were detected in somewhat more than one in five samples, and nearly the same naturally occurring trace elements and radionuclides were most frequently detected at concentrations greater than benchmarks. Contaminants usually co-occurred with other contaminants as mixtures in domestic- and public-well samples. In the domestic- and public-well assessments, mixtures of two or more individual contaminants with concentrations greater than human-health benchmarks were detected in about 4 percent of samples, and contaminant mixtures with concentrations greater than one-tenth of their individual benchmarks were detected in most (nearly three-quarters or more) samples (Appendix 21). 
The greatest differences in findings among the domestic-and public-well studies were related to the occurrence of organic contaminants and nitrate. Pesticide compounds and VOCs were detected more frequently at concentrations greater than human-health benchmarks in samples from public wells (4.5 percent) than from domestic wells ( 0.8 percent). By contrast, nitrate was detected more frequently at concentrations greater than the MCL in samples from domestic wells (4.4 percent) than from public wells (1.9 percent) (Appendix 21). Although the overall detection frequencies of organic contaminants were similar in both studies, the detection frequencies of some individual organic contaminants at a common assessment level of $0.02 \mu \mathrm{g} / \mathrm{L}$ were 2-fold to 6-fold greater in public-well samples than in domestic-well samples, likely because of the proximity of public wells to developed areas and high pumping rates. Organic contaminants detected more frequently in public-well samples than in domestic-well samples included some DBPs such as chloroform and bromodichloromethane; solvents such as PCE, TCE, and 1,1,1-trichloroethane; the herbicide simazine; and the gasoline oxygenate MTBE. As a result, organic contaminants played a much larger role in contaminant mixtures in public-well samples than in domestic-well samples. For example, in public-well samples, there were 125 unique mixtures detected in at least 10 percent of samples that were composed of contaminants with concentrations greater than one-tenth of human-health benchmarks or any organic contaminant. By contrast, there were only eight unique mixtures that met these criteria in domestic-well samples (Appendix 21). These findings are consistent with a previous VOC study (Zogorski and others, 2006) which found that VOC detection frequencies, concentrations, and occurrence in mixtures were lower in domestic-well samples than in public-well samples.

\section{Summary and Conclusions}

In 2008, about 105 million people in the United Statesabout 34 percent of the Nation's population-obtained their drinking water from public water systems that use groundwater as their source. The quality of the finished (treated) drinking water from public water systems is regulated by the U.S. Environmental Protection Agency (USEPA) under the Safe Drinking Water Act (SDWA). In this study, source (untreated) groundwater-quality conditions were assessed for 932 public-supply wells, hereafter referred to as public wells, sampled across the Nation by the U.S. Geological Survey's (USGS) National Water-Quality Assessment (NAWQA) Program during 1993-2007. The primary objectives of this study were to evaluate (1) contaminant occurrence in source water from public wells and the potential significance of contaminant concentrations to human health, (2) national and regional distributions of groundwater quality and selected contaminants in public wells, and (3) the occurrence and characteristics of contaminant mixtures. Treated finished water was not sampled.

The 932 public wells are widely distributed nationally, and include wells in selected parts of 41 states and within major hydrogeologic settings in parts of 30 regionally extensive aquifers (about one-half of the principal aquifers) used for water supply in the United States. These wells are distributed among 629 unique public water systems - less than 1 percent of all groundwater-supplied public water systems in the United States - but the wells were randomly selected within the sampled hydrogeologic settings to represent typical aquifer conditions. Samples from the 629 systems represent source water used by one-quarter of the U.S. population served by groundwater-supplied public water systems, or about 9 percent of the entire U.S. population in 2008.

Groundwater samples were collected from public wells prior to any treatment or blending, and may not represent the quality of water ingested by the people served by these wells. Each public well was sampled once during 1993-2007; trends within this 15 -year study period were not assessed. Sourcewater samples from public wells were analyzed for as many as six water-quality properties (such as temperature and $\mathrm{pH}$ ) and 215 contaminants. Consistent with the terminology used in the SDWA, all constituents analyzed in water samples in this study are referred to as "contaminants," regardless of their source, concentration, or potential for health effects. Nearly three-quarters of the contaminants analyzed in this study are not regulated by USEPA in drinking water under the SDWA, and USEPA uses USGS data on the occurrence of unregulated contaminants in water resources to fulfill part of the SDWA requirements for determining whether specific contaminants should be regulated in drinking water in the future. More contaminant groups were assessed in this study than in any previous national study of public wells and included major ions, nutrients, radon, trace elements, pesticide compounds, and volatile organic compounds (VOCs). Fecal-indicator microorganisms and additional radionuclides were analyzed in a subset of samples. Contaminant mixtures were assessed in subsets of 383 and 814 samples in which most contaminants were analyzed.

This study was not designed as a single, national-scale assessment of public-well water quality. Rather, this study synthesized data from multiple USGS groundwater studies that were integrated assessments of water resources and represented study areas in typical hydrogeologic settings within regionally extensive principal aquifers. A nationally consistent sampling and analysis design was used following well-documented quality-assurance procedures. By focusing on the water quality of source water and by analyzing many contaminants that are not regulated in drinking water by USEPA, this study (1) provides new information about sources of drinking water to agencies and organizations that manage the protection of drinking water and human health, (2) complements the extensive sampling of public 
water systems that is routinely conducted for the purposes of regulatory compliance monitoring by federal, state, and local drinking-water programs, and (3) provides a foundation for improving our understanding and management of this critical source of drinking water.

\section{Contaminant Occurrence and Comparison of Concentrations to Human-Health Benchmarks}

Overall, 73 percent (157 of 215) of the contaminants analyzed in this study were detected in one or more source-water samples from public wells. Major ions, trace elements, and radionuclides occur naturally and are part of soil and bedrock materials. One or more of these inorganic contaminants were detected in all samples. Detection frequencies of most individual trace elements ranged from about 50 to 100 percent, and individual radionuclides were detected in 73 to 98 percent of samples.

Anthropogenic contaminants also were frequently detected in source-water samples from public wells. Nitrate was detected in about 72 percent of the samples. Nitrate occurs naturally in groundwater, but concentrations often are increased by anthropogenic sources, such as fertilizers, livestock, and wastewater. Collectively, organic contaminants were detected in about 64 percent of the samples; pesticide compounds and VOCs were detected in about 41 and 60 percent of samples, respectively. The most frequently detected organic contaminants were disinfection by-products, such as chloroform and bromodichloromethane; the gasoline oxygenate methyl-tert-butyl ether (MTBE); solvents, such as perchloroethene (PCE), trichloroethene (TCE), and 1,1,1-trichloroethane; and the herbicide atrazine and one of its degradates, deethylatrazine. These organic contaminants were detected in about 8 to 41 percent of public-well samples at concentrations greater than $0.02 \mu \mathrm{g} / \mathrm{L}$. Fecal-indicator microorganisms were detected in about 12 percent of 353 source-water samples.

Contaminant concentrations in source water were compared to regulatory and non-regulatory human-health benchmarks to provide an initial perspective on the potential significance of detected contaminants to human health. Concentrations of contaminants that are regulated in finished drinking water by USEPA under the SDWA were compared to USEPA Maximum Contaminant Levels (MCLs), and concentrations of unregulated contaminants were compared to USGS Health-Based Screening Levels (HBSLs), when available. Contaminant concentrations that are greater than MCLs in source water do not represent MCL violations because MCLs apply to finished water. MCLs or HBSLs were available for about two-thirds of detected contaminants, but were not available for some frequently detected contaminants, such as deethylatrazine and MTBE.
More than one in five (22 percent) source-water samples from public wells contained one or more naturally occurring or man-made contaminants at concentrations greater than human-health benchmarks when radon activities were compared to the proposed Alternative MCL (AMCL) of 4,000 picocuries per liter ( $\mathrm{pCi} / \mathrm{L})$; this percentage increased to about 46 percent of samples when radon activities were compared to the proposed MCL of $300 \mathrm{pCi} / \mathrm{L}$. All together, 80 percent of samples contained one or more contaminants at concentrations greater than one-tenth of benchmarks. Most individual contaminant detections, however, were less than one-tenth of human-health benchmarks, and many detections were several orders of magnitude less than benchmarks. Public wells yielding water with contaminant concentrations greater than benchmarks, as well as those with concentrations greater than one-tenth of benchmarks, were distributed throughout the United States and included wells that withdraw water from all principal aquifer rock types included in this study.

Concentrations of 23 contaminants were greater than MCLs or HBSLs in one or more source-water samples from public wells. Ten of these 23 contaminants were detected at concentrations greater than human-health benchmarks in at least 1 percent of samples and collectively accounted for most concentrations greater than benchmarks. Seven of these 10 contaminants are naturally occurring inorganic contaminants, including three radionuclides (radon, radium, and gross alpha-particle radioactivity) and four trace elements (arsenic, manganese, strontium, and boron); three of the 10 contaminants (dieldrin, nitrate, and PCE) are primarily of anthropogenic origin. These 10 contaminants, except for dieldrin, also were detected in at least 20 percent of sourcewater samples. Five of these 10 contaminants (radium, gross alpha-particle radioactivity, arsenic, nitrate, and PCE) currently are regulated by USEPA under the SDWA and, therefore, managed in finished drinking water; radon has proposed MCLs. Manganese, boron, and dieldrin have undergone USEPA's regulatory determination process under the SDWA, but were not selected for regulation in drinking water, and strontium is listed on USEPA's most recent (third) Contaminant Candidate List. Collectively, contaminants regulated in drinking water accounted for 60 percent of concentrations greater than human-health benchmarks, and unregulated contaminants accounted for 40 percent of concentrations greater than benchmarks.

Contaminants from natural sources accounted for about three-quarters of contaminant concentrations greater than human-health benchmarks in source-water samples. Radon activities were greater than the proposed MCL of $300 \mathrm{pCi} / \mathrm{L}$ in about 55 percent of source-water samples and were greater than the proposed AMCL of $4,000 \mathrm{pCi} / \mathrm{L}$ in 0.6 percent of samples. The remaining six inorganic contaminants each were detected at concentrations greater than human-health benchmarks in 3 to 19 percent of samples. Contaminants 
that originate entirely or primarily from man-made sources accounted for about one-quarter of contaminant concentrations greater than benchmarks in source-water samples. Dieldrin, PCE, and nitrate each were detected at concentrations greater than human-health benchmarks in 1 to 3 percent of samples. Overall, seven of 168 pesticide compounds or VOCs were detected at concentrations greater than MCLs or HBSLs in source-water samples from public wells. Concentrations of one or more pesticide compounds or VOCs were greater than benchmarks in 4.5 percent of samples, and were greater than one-tenth of benchmarks in nearly 10 percent of samples.

One or more properties or contaminants were detected at concentrations outside of USEPA's recommended ranges for the aesthetic quality of water in about one-half (53 percent) of the source-water samples. Values or concentrations of $\mathrm{pH}$, total dissolved solids (TDS), sodium, iron, and manganese were individually outside the ranges defined by USEPA nonhealth guidelines in about 15 to 20 percent of samples. In addition, groundwater was "very hard" in about 50 percent of the samples, mainly in the southeastern and midwestern United States.

\section{Implications}

- Source water from a substantial proportion of public wells - about one of every five sampled — would require treatment or blending with higher-quality water sources to decrease contaminant concentrations to less than humanhealth benchmarks. Water utilities, however, are not required to treat water for unregulated contaminants, which accounted for about 40 percent of the concentrations greater than benchmarks. Contaminant concentrations greater than benchmarks in source water are potential human-health concerns, but do not necessarily indicate that adverse effects will occur because the benchmarks are conservative (protective) and samples were collected prior to any treatment or blending of water.

- Most public wells sampled - four of every five-contained one or more contaminants at concentrations greater than one-tenth of a benchmark. Contaminant concentrations greater than one-tenth of a benchmark provide an early and conservative indication of contaminant concentrations that may at some time approach or exceed benchmarks and identify contaminants that may warrant additional monitoring. Early attention to potential groundwater contamination is vital because groundwater contamination is difficult and costly to reverse once it occurs.

- The widespread occurrence of contaminants at concentrations greater than one-tenth of benchmarks, including the relatively common occurrence of concentrations greater than benchmarks, indicates the ubiquitous nature of natural and man-made contaminant sources and that all principal aquifer rock types included in this study are vulnerable to contamination. The occurrence of contaminants of primary concern, however, differed among regions and aquifers.

- More than 20 years after being banned, dieldrin is still detected at concentrations greater than benchmarks in some source waters because of historical use. Source-water protection strategies that rely on changes in human activities and practices at the land surface to achieve water-quality objectives can take many decades to affect the quality of water in some public wells.

- Based only on comparisons of contaminant concentrations to individual human-health benchmarks, contaminants from man-made sources may have less potential humanhealth significance in public wells than contaminants from natural sources. Human-health benchmarks are not available for many organic contaminants, however, and the full significance of their occurrence to human health cannot yet be assessed.

- The occurrence of contaminants for which human-health benchmarks are not yet available could not be evaluated in the context of potential human-health significance. Continued development of human-health benchmarks is needed to fill this information gap and to help interpret monitoring data, especially for contaminants that frequently occur in water resources.

- Continued monitoring of contaminants for which humanhealth benchmarks are not yet available is essential for identifying those contaminants for which toxicity assessments are most needed, as well as to track emerging issues. As improved data on toxicity and environmental concentrations become available, human-health benchmarks can be developed, and water-quality assessments can be improved and expanded.

\section{National and Regional Distributions of Water Quality}

The occurrence and concentrations of some contaminants and water-quality properties varied regionally and by principal aquifer and, therefore, may be of greater potential concern for human health or aesthetic quality in some regions compared to others. For example, most (87 percent) public-well samples with nitrate concentrations greater than its MCL were collected from unconsolidated sand and gravel aquifers in the western United States, specifically in California, Arizona, and Washington, where irrigation is a necessity. The highest concentrations of some water-quality properties and inorganic contaminants such as TDS, water hardness, boron, strontium, and radium, were detected in samples from the confined sandstone aquifers in the Cambrian-Ordovician aquifer system in Iowa and Illinois, yet some frequently detected organic 
contaminants, such as PCE, TCE, and chloroform, were infrequently detected in samples from this aquifer system. For other contaminants, concentrations greater than benchmarks were geographically distributed across the United States and were detected in samples from every principal aquifer rock type, such as for radon activities greater than the proposed MCL of $300 \mathrm{pCi} / \mathrm{L}$.

More organic contaminants were detected per public-well sample along the East Coast and in California than elsewhere in the United States. Additionally, more than two-thirds of samples with concentrations of organic contaminants greater than benchmarks were collected from public wells in states bordering the East Coast, mainly in semi-consolidated sand and gravel aquifers that underlie the Coastal Plains. MTBE detections were largely concentrated in areas of high MTBE use, such as the northeastern United States, the mid-Atlantic regions, and California. By contrast, atrazine and deethylatrazine were detected in source-water samples from public wells throughout the United States, but were not most frequently detected in regions of highest atrazine use, such as Illinois and Iowa.

Trace elements and radionuclides were detected at concentrations greater than human-health benchmarks in samples from both confined and unconfined aquifers, consistent with the fact that these contaminants originate primarily from aquifer materials. By contrast, man-made contaminants were detected at concentrations greater than benchmarks mainly in samples from unconfined aquifers, consistent with the fact that these contaminants originate from man-made sources at the land surface. Contaminants with concentrations greater than benchmarks were detected in samples from all sizes of public water systems and from all principal aquifer rock types, with no obvious patterns observed by contaminant group.

Some contaminant concentrations were related to geochemical conditions, such as redox conditions and $\mathrm{pH}$. For example, nitrate concentrations were positively correlated with dissolved oxygen in samples from most principal aquifer rock types, consistent with the fact that nitrate most commonly occurs under the oxidizing conditions commonly observed in unconfined aquifers. Concentrations of trace elements greater than benchmarks generally were positively correlated with TDS because trace elements in groundwater tend to originate from natural sources, such as leaching from geologic materials. Water hardness also was strongly positively correlated with alkalinity and TDS in samples from most principal aquifer rock types. The ionic composition of most groundwater samples was variable, consistent with the fact that the principal aquifer rock types represent a broad range of lithologies and geochemical processes.

\section{Implications}

- Naturally occurring trace elements and radionuclides may be present in groundwater at concentrations of potential human-health concern even in undeveloped areas or confined aquifers where contamination usually is not expected.

- Traditional wellhead protection approaches designed to reduce man-made sources of contaminants to groundwater generally are not designed to protect against natural sources of contaminants and, therefore, most occurrences of naturally occurring contaminants at concentrations greater than benchmarks are unlikely to be affected by these approaches.

- The frequent detections of man-made contaminants in samples from aquifers used for public water supply, particularly in samples from unconfined aquifers, indicate the vulnerability of many water-supply aquifers to contamination from human activities at the land surface. This finding underscores the importance of wellhead protection programs designed to reduce groundwater contamination from man-made sources. Reduction of contaminant sources potentially reduces needs for water treatment and blending, and may avoid the loss of some public wells as sources of drinking water.

- The occurrence of man-made contaminants in some samples from confined aquifers indicates that the large pumping rates typical for public wells, combined with the proximity of the wells to developed areas and the possible presence of short-circuiting flow paths to such wells, make even some deep wells that withdraw water from confined aquifers vulnerable to contamination from man-made sources.

\section{Contaminant Mixtures}

Contaminants detected in source-water samples from public wells usually co-occurred with other contaminants as mixtures. Although few human-health benchmarks have been established for mixtures of contaminants, concentrations of the contaminants in mixtures were compared to individual benchmarks. About 4 percent of source-water samples contained mixtures of two or more contaminants at concentrations greater than individual human-health benchmarks, whereas most samples ( 84 percent) contained mixtures of two or more contaminants at concentrations greater than one-tenth of individual benchmarks. Mixtures that also included detections of any pesticide compound or VOC (regardless of concentration) were detected in 92 percent of samples. 
The most common contaminants in the unique mixtures were those that were most frequently detected individually. Unique mixtures of contaminants with concentrations greater than individual benchmarks each were detected in less than 1 percent of samples. These mixtures were composed of solvents (primarily PCE and TCE), trace elements (such as arsenic and strontium), and nitrate, reflecting a mix of naturally occurring and anthropogenic contaminants. All of the most common mixtures (those detected in 5 to 33 percent of source-water samples) in which contaminant concentrations were greater than one-tenth of individual benchmarks were composed of one or more trace elements (arsenic, strontium, or uranium were most common), nitrate, and (or) radon (activities greater than $300 \mathrm{pCi} / \mathrm{L}$ ). The most common unique mixture of contaminants with concentrations greater than one-tenth of benchmarks was nitrate and radon, which was detected in about 33 percent of samples.

When mixtures of organic contaminants were assessed only on the basis of detections and without regard to the availability of human-health benchmarks, three-quarters of the most common organic-contaminant mixtures (those detected in at least 10 percent of source-water samples) contained an herbicide (atrazine or simazine) or an herbicide degradate (deethylatrazine). Two-thirds of these mixtures contained chloroform, and 43 percent contained the solvents PCE or TCE. The most common unique mixture of organic contaminants was atrazine and deethylatrazine, which was detected in about 26 percent of samples.

Mixtures with the largest number of contaminants (5 to 10) detected at concentrations greater than one-tenth of individual human-health benchmarks were distributed among a number of sampled areas throughout the United States, but were most common in public wells sampled in parts of the western United States. About three-quarters of the public wells with five or more contaminants detected at concentrations greater than one-tenth of individual benchmarks withdraw water from unconsolidated sand and gravel aquifers in the western United States, mostly in California, Utah, Nevada, and Arizona. In general, the complexity of the mixtures increased with TDS concentrations, indicating that the unique mixtures were composed, in large part, of inorganic contaminants that contribute to TDS concentrations.

Mixtures with the greatest number of contaminants were detected more frequently in source-water samples from public wells that withdraw water from shallower unconfined aquifers than in samples from deeper confined aquifers. For example, about two-thirds of the mixtures containing three contaminants, and nearly all mixtures containing 10 contaminants, were detected in samples from unconfined aquifers. This finding was observed for mixtures that were assessed relative to individual human-health benchmarks and for mixtures of organic contaminants that were assessed without regard to the availability of benchmarks. Generally, as the number of contaminants in mixtures increased, the proportion of samples containing organic contaminants also increased, reflecting the greater vulnerability of unconfined aquifers to contaminants from man-made sources.

\section{Implications}

- The widespread and frequent detections of contaminant mixtures in source water is a matter of increasing concern and attention because the total combined toxicity of contaminants in water may be greater than that of any individual contaminant. Little is known about the potential health effects associated with exposure to multiple contaminants at concentrations detected in the environment, and more investigation is needed to evaluate the potential toxicity of contaminant mixtures to humans.

- This study identifies which contaminant mixtures may be of most concern in groundwater used for public water supply on the basis of frequency of occurrence and comparisons of contaminant concentrations to individual human-health benchmarks. This information can help human-health researchers to target and prioritize toxicity assessments of contaminant mixtures.

- The frequent occurrence of complex contaminant mixtures, particularly in source-water samples from unconfined aquifers, reinforces the implication derived from the occurrence of individual contaminants, that multiple contaminant sources and transport pathways may affect the quality of water from public wells.

- Measures to protect groundwater used for public-water supply often need to take into consideration multiple sources of man-made contaminants and their co-occurrence with contaminants from natural sources.

\section{Acknowledgments}

The authors thank the many individuals from the U.S. Geological Survey (USGS) for their contributions. Leslie DeSimone, Robert Gilliom, Wayne Lapham, Gregory Delzer, Michael Focazio, and John Zogorski provided valuable advice and reviews. Curtis Price and Richard Bell assisted with assembling and retrieving the water-quality datasets from USGS databases. Individuals from many USGS Study Units provided additional ancillary public-well data. Naomi Nakagaki identified public wells located within 1 kilometer of each other. Terri Arnold provided guidance on the identification of principal aquifer rock types. Stewart Rounds checked the methods used to compute alkalinity for this report. Marilee Horn provided data on system type, system size, and population served for each public well from the U.S. Environmental Protection Agency Safe Drinking Water Information System. Jonathon Scott performed the analyses that resulted in the mixtures datasets. David Lorenz assisted with statistical methods and analyses. Linda Rogers and Eavon Mobley were the technical editors. Yvonne Roque did the graphic design and Sharon Wahlstrom did the layout. 


\section{References Cited}

Agency for Toxic Substances and Disease Registry, 1997, ToxFAQs for tetrachloroethylene (PCE): U.S. Department of Health and Human Services, Agency for Toxic Substances and Disease Registry, updated February 18, 2010, accessed April 2, 2010, at http://www.atsdr.cdc.gov/

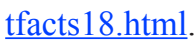

Agency for Toxic Substances and Disease Registry, 2002a, ToxFAQs for aldrin/dieldrin: U.S. Department of Health and Human Services, Agency for Toxic Substances and Disease Registry, updated February 18, 2010, accessed February 24, 2010, at http://www.atsdr.cdc.gov/tfacts1.html.

Agency for Toxic Substances and Disease Registry, 2002b, Toxicological profile for aldrin/dieldrin: U.S. Department of Health and Human Services, Agency for Toxic Substances and Disease Registry, September 2002, 354 p. Available at http://www.atsdr.cdc.gov/toxprofiles/tp1.html.

Agency for Toxic Substances and Disease Registry, 2003, ToxFAQs for trichloroethylene (TCE): U.S. Department of Health and Human Services, Agency for Toxic Substances and Disease Registry, updated February 18, 2010, accessed April 2, 2010, at http://www.atsdr.cdc.gov/tfacts19.html.

Agency for Toxic Substances and Disease Registry, 2004a, Guidance manual for the assessment of joint toxic action of chemical mixtures: U.S. Department of Health and Human Services, Agency for Toxic Substances and Disease Registry, May 2004, 107 p. Available at http://www.atsdr. cdc.gov/interactionprofiles/IP-ga/ipga.pdf.

Agency for Toxic Substances and Disease Registry, 2004b, Interaction profile for: 1,1,1-trichloroethane, 1,1-dichloroethane, trichloroethylene, and tetrachloroethylene: U.S. Department of Health and Human Services, Agency for Toxic Substances and Disease Registry, May 2004, 87 p. Available at http://www.atsdr.cdc. gov/interactionprofiles/ip02.html.

Agency for Toxic Substances and Disease Registry, 2004c, Interaction profile for: cyanide, fluoride, nitrate, and uranium: U.S. Department of Health and Human Services, Agency for Toxic Substances and Disease Registry, May 2004, 82 p. Available at http://www.atsdr.cdc.gov/ interactionprofiles/IP-09/ip09.pdf.

Agency for Toxic Substances and Disease Registry, 2004d, Toxicological profile for strontium: U.S. Department of Health and Human Services, Agency for Toxic Substances and Disease Registry, April 2004, 445 p. Available at http:// www.atsdr.cdc.gov/toxprofiles/tp159.html.
Agency for Toxic Substances and Disease Registry, 2006, Interaction profile for: atrazine, deethylatrazine, diazinon, nitrate, and simazine: U.S. Department of Health and Human Services, Agency for Toxic Substances and Disease Registry, August 2006, 68 p. Available at http://www.atsdr. cdc.gov/interactionprofiles/IP-10/ip10.pdf.

Agency for Toxic Substances and Disease Registry, 2007, Draft interaction profile for: chloroform, 1,1-dichloroethylene, trichloroethylene, and vinyl chloride: U.S. Department of Health and Human Services, Agency for Toxic Substances and Disease Registry, August 2007, 114 p. Available at http://www.atsdr.cdc.gov/interactionprofiles/ ip13.html.

Agency for Toxic Substances and Disease Registry, 2008, Draft toxicological profile for manganese: U.S. Department of Health and Human Services, Agency for Toxic Substances and Disease Registry, September 2008, 539 p. Available at http://www.atsdr.cdc.gov/toxprofiles/tp151. $\underline{\mathrm{html}}$.

Agency for Toxic Substances and Disease Registry, 2009, Interaction profiles for toxic substances: U.S. Department of Health and Human Services, Agency for Toxic Substances and Disease Registry, updated September 1, 2009, accessed April 2, 2010, at http://www.atsdr.cdc.gov/ interactionprofiles/.

American Water Works Association Disinfection Systems Committee, 2008, Committee report: disinfection survey, part 1 -recent changes, current practices, and water quality: Journal American Water Works Association, v. 100, no. 10, p. $76-90$.

American Water Works Association Inorganics Committee, and Inorganic Contaminants Research Committee, 2009, Committee report: a survey of the "other" inorganics: Journal American Water Works Association, v. 101, no. 8, p. 79-86.

Andrews, W.J., Stark, J.R., Fong, A.L., and Fallon, J.D., 2005, Water-quality assessment of part of the Upper Mississippi River Basin, Minnesota and Wisconsin-ground-water quality along a flow system in the Twin Cities metropolitan area, Minnesota, 1997-98: U.S. Geological Survey Scientific Investigations Report 2005-5120, 44 p. Available at http://pubs.usgs.gov/sir/2005/5120/.

Ayers, M.A., Kennen, J.G., and Stackelberg, P.E., 2000, Water quality in the Long Island-New Jersey coastal drainages, New York and New Jersey, 1996-98: U.S. Geological Survey Circular 1201, 40 p. Available at http://water.usgs. gov/pubs/circ/circ1201/. 
Ayotte, J.D., Flanagan, S.M., and Morrow, W.S., 2007, Occurrence of uranium and ${ }^{222}$ radon in glacial and bedrock aquifers in the northern United States, 1993-2003: U.S. Geological Survey Scientific Investigations Report 20075037, 84 p. Available at http://pubs.usgs.gov/sir/2007/5037/.

Ayotte, J.D., Montgomery, D.L., Flanagan, S.M., and Robinson, K.W., 2003, Arsenic in groundwater in eastern New England: occurrence, controls, and human health implications: Environmental Science and Technology, v. 37, no. 10 , p. 2075-2083.

Back, W., 1961, Techniques for mapping of hydrochemical facies, U.S. Geological Survey Professional Paper 424-D, p. 380-382.

Back, W., and Hanshaw, B.B., 1965, Chemical geohydrology, in Chow, V.T., ed., Advances in Hydrosciences: New York, Academic Press, p. 49-109.

Barbash, J.E., and Roberts, P.V., 1986, Volatile organic chemical contamination of groundwater resources in the U.S.: Journal Water Pollution Control Federation, v. 58, no. 5 , p. 343-348.

Barlow, P.M., 2003, Ground water in freshwater-saltwater environments of the Atlantic Coast: U.S. Geological Survey Circular 1262, 113 p. Available at http://pubs.usgs.gov/ circ/2003/circ1262/.

Bartos, T.T., Eddy-Miller, C.A., Norris, J.R., Gamper, M.E., and Hallberg, L.L., 2004, Water-quality characteristics of quaternary unconsolidated-deposit aquifers and lower tertiary aquifers of the Bighorn Basin, Wyoming and Montana, 1999-2001: U.S. Geological Survey Scientific Investigations Report 2004-5252, 155 p. Available at http:// pubs.usgs.gov/sir/2004/5252/.

Bates, R.L., and Jackson, J.A., eds., 1984, Dictionary of geological terms (Third ed.): New York, Anchor Books, Doubleday, $571 \mathrm{p}$.

Bitton, G., 1994, Wastewater microbiology: New York, Wiley-Liss, 478 p.

Blatt, H., and Tracy, R.J., 2001, Petrology: igneous, sedimentary, and metamorphic (Second ed.): New York, W.H. Freeman and Company, 529 p.

Bolt, H.M., and Mumtaz, M.M., 1996, Risk assessment of mixtures and standard setting: working towards practical compromises: Food and Chemical Toxicology, v. 34, no. $11-12$, p. 1179-1181.

Bonn, B.A., 2008, Using the U.S. Geological Survey National Water Quality Laboratory LT-MDL to evaluate and analyze data: U.S. Geological Survey Open-File Report 2008-1277, 73 p. Available at http://pubs.usgs.gov/of/2008/1227/.
Bossert, I., and Bartha, R., 1984, The fate of petroleum in soil ecosystems, in Atlas, R.M., ed., Petroleum microbiology: New York, Macmillan Publishing Company, p. 435-473.

Brion, G.M., Meschke, J.S., and Sobsey, M.D., 2002, F-specific RNA coliphages: occurrence, types, and survival in natural waters: Water Research, v. 36, no. 9, p. 2419-2425.

Burkart, M., Kolpin, D.W., Jaquis, R., and Cole, K., 2001, Soil characteristics and agrichemicals in groundwater of the midwestern United States: Water Science and Technology, v. 43 , no. 5 , p. $251-260$.

Buszka, P.M., Fitzpatrick, J., Watson, L.R., and Kay, R.T., 2007, Evaluation of ground-water and boron sources by use of boron stable-isotope ratios, tritium, and selected waterchemistry constituents near Beverly Shores, northwestern Indiana, 2004: U.S. Geological Survey Scientific Investigations Report 2007-5166, 46 p. Available at http:// pubs.usgs.gov/sir/2007/5166/.

Carpenter, D.O., Arcaro, K., and Spink, D.C., 2002, Understanding the human health effects of chemical mixtures: Environmental Health Perspectives, v. 110, Supplement 1, p. 25-42.

Carter, J.M., Delzer, G.C., Kingsbury, J.A., and Hopple, J.A., 2007, Concentration data for anthropogenic organic compounds in ground water, surface water, and finished water of selected community water systems in the United States, 2002-05: U.S. Geological Survey Data Series 268, 30 p. Available at http://pubs.usgs.gov/ds/2007/268/.

Carter, J.M., Grady, S.J., Delzer, G.C., Koch, B., and Zogorski, J.S., 2006, Occurrence of MTBE and other gasoline oxygenates in CWS source waters: Journal American Water Works Association, v. 98, no. 4, p. 91-104.

Carter, J.M., Lapham, W.W., and Zogorski, J.S., 2008, Occurrence of volatile organic compounds in aquifers of the United States: Journal of the American Water Resources Association (JAWRA), v. 44, no. 2, p. 399-416.

Childress, C.J.O., Foreman, W.T., Connor, B.F., and Maloney, T.J., 1999, New reporting procedures based on long-term method detection levels and some considerations for interpretations of water-quality data provided by the U.S. Geological Survey National Water Quality Laboratory: U.S. Geological Survey Open-File Report 99-193, 19 p. Available at http://water.usgs.gov/owq/OFR 99-193/ ofr99 193.pdf.

Commonwealth of Massachusetts, 2009, Standards and guidelines for contaminants in Massachusetts drinking waters: Executive Office of Energy and Environmental Affairs, Department of Environmental Protection; Office of Research and Standards, Spring 2009, 14 p. Available at http://www.mass.gov/dep/water/dwstand.pdf. 
Connecticut Department of Public Health, 2005, Radon in your water: Division of Environmental Health, Radon Program Fact Sheet, March 2005, 2 p. Available at http:// humanservices.townofmanchester.org/health/documents/ RadonProgram-waterfactsheet.pdf.

Connor, B.F., Rose, D.L., Noriega, M.C., Murtagh, L.K., and Abney, S.R., 1998, Methods of analysis by the U.S. Geological Survey National Water Quality Laboratorydetermination of 86 volatile organic compounds in water by gas chromatography/mass spectrometry, including detections less than reporting limits: U.S. Geological Survey Open-File Report 97-829, 78 p. Available at http:// nwql.usgs.gov/Public/pubs/OFR97-829.pdf.

Delzer, G.C., and Hamilton, P.A., 2007, National WaterQuality Assessment Program-Source Water-Quality Assessments: U.S. Geological Survey Fact Sheet 20073069, 2 p. Available at http://pubs.usgs.gov/fs/2007/3069/ pdf/fs2007-3069web.pdf.

DeSimone, L.A., 2009, Quality of water from domestic wells in principal aquifers of the United States, 1991-2004: U.S. Geological Survey Scientific Investigations Report 2008-5227, 139 p. Available at http://pubs.usgs.gov/ sir/2008/5227/.

Domenico, P.A., and Schwartz, F.W., 1990, Physical and chemical hydrogeology: New York, John Wiley \& Sons, Inc., 824 p.

Durfor, C.N., and Becker, E., 1964, Public water supplies of the 100 largest cities in the United States, 1962: U.S. Geological Survey Water-Supply Paper 1812, 364 p. Available at http://pubs.er.usgs.gov/usgspubs/wsp/wsp1812.

Eaton, D.L., and Klaassen, C.D., 2001, Principles of toxicology, in Klaassen, C.D., ed., Casarett and Doull's toxicology: the basic science of poisons (Sixth ed.): New York, McGraw-Hill, p. 1236.

Eberts, S.M., Erwin, M.L., and Hamilton, P.A., 2005, Assessing the vulnerability of public-supply wells to contamination from urban, agricultural, and natural sources: U.S. Geological Survey Fact Sheet 2005-3022, 4 p. Available at http://pubs.usgs.gov/fs/2005/3022/pdf/fs20053022.pdf.

Embrey, S.S., and Runkle, D.L., 2006, Microbial quality of the Nation's ground-water resources, 1993-2004: U.S. Geological Survey Scientific Investigations Report 20065290, 34 p. Available at http://pubs.usgs.gov/sir/2006/5290/.

Focazio, M.J., Reilly, T.E., Rupert, M.G., and Helsel, D.R., 2002, Assessing ground-water vulnerability to contamination: providing scientifically defensible information for decision makers: U.S. Geological Survey Circular 1224, 33 p. Available at http://pubs.usgs.gov/ circ/2002/circ1224/.
Focazio, M.J., Szabo, Z., Kraemer, T.F., Mullin, A.H., Barringer, T.H., and dePaul, V.T., 2001, Occurrence of selected radionuclides in ground water used for drinking water in the United States; a reconnaissance survey, 1998: U.S. Geological Survey Water-Resources Investigations Report 00-4273, 39 p. Available at http://pubs.usgs.gov/wri/ wri004273/.

Focazio, M.J., Welch, A.H., Watkins, S.A., Helsel, D.R., and Horn, M.A., 2000, A retrospective analysis on the occurrence of arsenic in ground-water resources of the United States and limitations in drinking-water-supply characterization: U.S. Geological Survey Water-Resources Investigations Report 99-4279, 21 p. Available at http:// pubs.usgs.gov/wri/wri994279/.

Foreman, B., and Gilliom, R.J., 1998, Changes in reporting levels and data qualifiers for selected pesticides and degradation products in schedules 2050 and 2051: U.S. Geological Survey, National Water Quality Laboratory Technical Memorandum 98.03A, updated August 28, 1998, accessed April 2, 2010, at http://nwql.usgs.gov/Public/ tech memos/nwq1.98-03A.html.

Fortescue, J.A.C., 1980, Environmental geochemistry a holistic approach: Ecological Studies 35: New York, Springer-Verlag, 347 p.

Francy, D.S., Bushon, R.N., Stopar, J., Luzano, E.J., and Fout, G.S., 2004, Environmental factors and chemical and microbiological water-quality constituents related to the presence of enteric viruses in ground water from small public water supplies in southeastern Michigan: U.S. Geological Survey Scientific Investigations Report 2004-5219, 54 p. Available at http://pubs.usgs.gov/ $\underline{\operatorname{sir} / 2004 / 5219 / .}$.

Francy, D.S., Myers, D.N., and Helsel, D.R., 2000, Microbiological monitoring for the U.S. Geological Survey National Water-Quality Assessment program: U.S. Geological Survey Water-Resources Investigations Report 00-4018, 31 p. Available at http://oh.water.usgs.gov/ reports/wrir/wrir.00-4018.pdf.

Franke, O.L., Reilly, T.E., Pollock, D.W., and LaBaugh, J.W., 1998, Estimating areas contributing recharge to wellslessons from previous studies: U.S. Geological Survey Circular 1174, 14 p. Available at http://water.usgs.gov/ogw/ pubs/Circ1174/.

Freeze, R.A., and Cherry, J.A., 1979, Groundwater: Englewood Cliffs, N.J., Prentice Hall, Inc., 604 p.

Frey, M.M., and Edwards, M.A., 1997, Surveying arsenic occurrence: Journal American Water Works Association, v. 89 , no. 3 , p. $105-117$. 
Furlong, E.T., Blomquist, J., and Gilliom, R.J., 2003, Datareporting conventions and implications for interpreting results from custom method 9060 for samples collected from March 1, 1999, to December 31, 1999: U.S. Geological Survey, National Water Quality Laboratory Technical Memorandum 03.01, February 28, 2003 Available at http://nwql.usgs.gov/Public/tech_memos/nwql.2003-01. html.

Gallard, H., and von Gunten, U., 2002, Chlorination of natural organic matter: kinetics of chlorination and of THM formation: Water Research, v. 36, no. 1, p. 65-74.

Gilkeson, R.H., and Cowart, J.B., 1987, Radium, radon, and uranium isotopes in groundwater from CambrianOrdovician sandstone aquifers in Illinois, in Graves, B., ed., Radon, radium, and other radioactivity in ground water: Somerset, NJ, Lewis Publishers, p. 403-422.

Gilliom, R.J., Alley, W.M., and Gurtz, M.E., 1995, Design of the National Water-Quality Assessment Program: occurrence and distribution of water-quality conditions: U.S. Geological Survey Circular 1112, 33 p. Available at http://pubs.usgs.gov/circ/circ1112/.

Gilliom, R.J., Barbash, J.E., Crawford, C.G., Hamilton, P.A., Martin, J.D., Nakagaki, N., Nowell, L.H., Scott, J.C., Stackelberg, P.E., Thelin, G.P., and Wolock, D.M., 2006, The quality of our Nation's waters - pesticides in the Nation's streams and ground water, 1992-2001: U.S. Geological Survey Circular 1291, 172 p. Available at http:// pubs.usgs.gov/circ/2005/1291/.

Gilliom, R.J., Hamilton, P.A., and Miller, T.L., 2001, The National Water-Quality Assessment Program — entering a new decade of investigations: U.S. Geological Survey Fact sheet 071-01, 6 p. Available at http://water.usgs.gov/pubs/ FS/fs-071-01/.

Grady, S.J., 2002, A national survey of methyl tert-butyl ether and other volatile organic compounds in drinking-water sources: results of the random survey: U.S. Geological Survey Water-Resources Investigations Report 02-4079, 85 p. Available at http://sd.water.usgs.gov/nawqa/pubs/wrir/ wrir02 4079.html.

Grady, S.J., and Casey, G.D., 2001, Occurrence and distribution of methyl tert-butyl ether and other volatile organic compounds in drinking water in the northeast and mid-Atlantic regions of the United States, 1993-98: U.S. Geological Survey Water-Resources Investigations Report 00-4228, 123 p. Available at http://sd.water.usgs. gov/nawqa/pubs/wrir/wrir00.4228.pdf.

Güler, C., Thyne, G.D., McCray, J.E., and Turner, A.K., 2002, Evaluation of graphical and multivariate statistical methods for classification of water chemistry data: Hydrogeology Journal, v. 10, p. 455-474.
Hallberg, G.R., 1989, Pesticide pollution of groundwater in the humid United States: Agriculture, Ecosystems and Environment, v. 26, no. 3-4, p. 299-367.

Hasegawa, R., Takayama, S., and Ito, N., 1994, Effects of low level exposure to multiple carcinogens in combination, in Yang, R.S.H., ed., Toxicology of chemical mixtures: San Diego, CA, Academic Press, p. 361-382.

Havelaar, A.H., van Olphen, M., and Drost, Y.C., 1993, F-specific RNA bacteriophages are adequate model organisms for enteric viruses in fresh water: Applied and Environmental Microbiology, v. 59, no. 9, p. 2956-2962.

Heath, R.C., 1983, Basic ground-water hydrology: U.S. Geological Survey Water-Supply Paper 2220, 84 p. Available at http://pubs.er.usgs.gov/djvu/WSP/wsp 2220. pdf.

Helsel, D.R., 2005a, Insider censoring: distortion of data with nondetects: Human and Ecological Risk Assessment, v. 11, no. 6 , p. $1127-1137$.

Helsel, D.R., 2005b, Nondetects and data analysis: Hoboken, N.J., Wiley-Interscience, $250 \mathrm{p}$.

Helsel, D.R., and Hirsch, R.M., 2002, Statistical methods in water resources: U.S. Geological Survey Techniques of Water-Resources Investigations, Book 4, Hydrologic analysis and interpretation, Chapter A3, $510 \mathrm{p}$. Available at http://pubs.usgs.gov/twri/twri4a3/pdf/twri4a3-new.pdf.

Hem, J.D., 1985, Study and interpretation of the chemical characteristics of natural water: U.S. Geological Survey Water-Supply Paper 2254, 272 p. Available at http://pubs. usgs.gov/wsp/wsp2254/pdf/wsp2254a.pdf.

Hemond, H.F., and Fechner, E.J., 1994, Chemical fate and transport in the environment: San Diego, CA, Academic Press, Inc., 338 p.

Hering, J.G., and Kraemer, S., 1998, Environmental chemistry of trace metals, in Macalady, D.L., ed., Perspectives in environmental chemistry: New York, Oxford University Press, p. 57-74.

Hertzberg, R.C., and MacDonell, M.M., 2002, Synergy and other ineffective mixture risk definitions: Science of the Total Environment, v. 288, no. 1-2, p. 31-42.

Hess, C.T., Michael, J., Horton, T.R., Prichard, H.M., and Coniglio, W.A., 1985, The occurrence of radioactivity in public water supplies in the United States: Health Physics, v. 48 , no. 5 , p. $553-586$. 
Homer, C., Huang, C., Yang, L., Wylie, B., and Coan, M., 2004, Development of a 2001 national land-cover database for the United States: Photogrammetric Engineering and Remote Sensing, v. 70, no. 7, p. 829-840.

Hopple, J.A., Delzer, G.C., and Kingsbury, J.A., 2009, Anthropogenic organic compounds in source water of selected community water systems that use groundwater, 2002-05: U.S. Geological Survey Scientific Investigations Report 2009-5200, 74 p. Available at http://pubs.usgs.gov/ $\underline{\text { sir/2009/5200/. }}$.

Horton, T.R., 1983, Methods and results of EPA's study of radon in drinking water: U.S. Environmental Protection Agency, Office of Radiation Programs EPA 520/5-83-027, December 1983, 29 p.

Ivahnenko, T., and Barbash, J.E., 2004, Chloroform in the hydrologic system - sources, transport, fate, occurrence, and effects on human health and aquatic organisms: U.S. Geological Survey Scientific Investigations Report 20045137, 34 p. Available at http://pubs.usgs.gov/sir/2004/5137/.

Ivahnenko, T., and Zogorski, J.S., 2006, Sources and occurrence of chloroform and other trihalomethanes in drinking-water supply wells in the United States, 19862001: U.S. Geological Survey Scientific Investigations Report 2006-5015, 13 p. Available at http://pubs.usgs.gov/ sir/2006/5015/.

Johnson, R., Pankow, J., Bender, D., Price, C., and Zogorski, J., 2000, MTBE: to what extent will past releases contaminate community water supply wells?: Environmental Science and Technology, v. 34, no. 9, p. 210A-217A.

Johnson, T.D., and Belitz, K., 2009, Assigning land use to supply wells for the statistical characterization of regional groundwater quality: correlating urban land use and VOC occurrence: Journal of Hydrology, v. 370, no. 1-4, p. 100-108.

Kauffman, L.J., Baehr, A.L., Ayers, M.A., and Stackelberg, P.E., 2001, Effects of land use and travel time on the distribution of nitrate in the Kirkwood-Cohansey aquifer system in southern New Jersey: U.S. Geological Survey Water-Resources Investigations Report 01-4117, 49 p. Available at http://nj.usgs.gov/nawqa/linj/pdf/wrir 01-4117. pdf.

Kelly, W.R., Holm, T.R., Wilson, S.D., and Roadcap, G.S., 2005, Arsenic in glacial aquifers: sources and geochemical controls: Ground Water, v. 43, no. 4, p. 500-510.

Kendall, C., Caldwell, E., and Snyder, D., 2004, Resources on isotopes - periodic table-boron: U.S. Geological Survey Isotope Tracers Project, updated January 2004, accessed April 2, 2010, at http://wwwrcamnl.wr.usgs.gov/isoig/ period/b iig.html.
Kenny, J.F., Barber, N.L., Hutson, S.S., Linsey, K.S., Lovelace, J.K., and Maupin, M.A., 2009, Estimated use of water in the United States in 2005: U.S. Geological Survey Circular 1344, 52 p. Available at http://pubs.usgs.gov/ circ/1344/.

Keppel, G., 1991, Design and analysis: a researcher's handbook: Upper Saddle River, NJ, Prentice-Hall, 594 p.

Kleiss, B.A., Coupe, R.H., Gonthier, G.J., and Justus, B.G., 2000, Water quality in the Mississippi Embayment, Mississippi, Louisiana, Arkansas, Missouri, Tennessee, and Kentucky, 1995-98: U.S. Geological Survey Circular 1208, 37 p. Available at http://pubs.usgs.gov/circ/circ1208/.

Kolpin, D.W., Barbash, J.E., and Gilliom, R.J., 2000, Pesticides in ground water of the United States, 1992-1996: Ground Water, v. 38, no. 6, p. 858-863.

Kolpin, D.W., Burkart, M.R., and Thurman, E.M., 1994, Herbicides and nitrate in near-surface aquifers in the midcontinental United States, 1991: U.S. Geological Survey Water-Supply Paper 2413, 34 p. Available at http://pubs. er.usgs.gov/usgspubs/wsp/wsp2413.

Koterba, M.T., 1998, Ground-water data-collection protocols and procedures for the National Water-Quality Assessment program: collection, documentation, and compilation of required site, well, subsurface, and landscape data for wells: U.S. Geological Survey Water-Resources Investigations Report 98-4107, 91 p.

Koterba, M.T., Franceska, W.D., and Lapham, W.W., 1995, Ground-water data-collection protocols and procedures for the National Water-Quality Assessment program: collection and documentation of water-quality samples and related data: U.S. Geological Survey Open-File Report 95-399, 113 p. Available at http://pubs.usgs.gov/of/1995/ofr-95-399/.

Landon, M.K., Eberts, S.M., Jurgens, B.C., Katz, B.G., Burow, K.R., Crandall, C.A., Brown, C.J., and Starn, J.J., 2006, Knowledge of where and how contamination-susceptible water enters public-supply wells can be used to improve monitoring strategies and protection plans: Ground Water Protection Council Annual Forum, Miami Beach, FL, September 30-October 4, 2006, 15 p. Available at http:// oh.water.usgs.gov/tanc/pubs/Landon_Eberts CA-3521 gwpe paper final ss.pdf.

Landon, M.K., Jurgens, B.C., Katz, B.G., Eberts, S.M., Burow, K.R., and Crandall, C.A., 2009, Depth-dependent sampling to identify short-circuit pathways to public-supply wells in multiple aquifer settings in the United States: Hydrogeology Journal, Online October 20, 2009, 17 p. Available at http:// www.springerlink.com/content/0m70737w621mkv65/ fulltext.pdf. 
Lapham, W.W., Hamilton, P.A., and Myers, D.N., 2005, National Water-Quality Assessment Program-Cycle II, regional assessments of aquifers: U.S. Geological Survey Fact Sheet 2005-3013, 4 p. Available at http://pubs.usgs. gov/fs/2005/3013/.

Lapham, W.W., Wilde, F.D., and Koterba, M.T., 1995, Ground-water data-collection protocols and procedures for the National Water-Quality Assessment Program: selection, installation, and documentation of wells, and collection of related data: U.S. Geological Survey Open-File Report 95-398, 71 p. Available at http://pubs.usgs.gov/of/1995/ofr95-398/.

Lapham, W.W., Wilde, F.D., and Koterba, M.T., 1997, Guidelines and standard procedures for studies of groundwater quality; selection and installation of wells, and supporting documentation: U.S. Geological Survey WaterResources Investigations Report 96-4233, 110 p. Available at http:/water.usgs.gov/owq/pubs/wri/wri964233/.

Lindsey, B.D., Berndt, M.P., Katz, B.G., Ardis, A.F., and Skach, K.A., 2009, Factors affecting water quality in selected carbonate aquifers in the United States, 19932005: U.S. Geological Survey Scientific Investigations Report 2008-5240, 117 p. Available at http://pubs.usgs.gov/ sir/2008/5240/.

Longtin, J.P., 1988, Occurrence of radon, radium, and uranium in groundwater: Journal American Water Works Association, v. 80, no. 7, p. 84-93.

Macalady, D.L., and Ranville, J.F., 1998, The chemistry and geochemistry of natural organic matter (NOM), in Macalady, D.L., ed., Perspectives in environmental chemistry: New York, Oxford University Press, p. 94-137.

Madigan, M.T., Martinko, J.M., and Parker, J., 1997, Brock Biology of microorganisms (Eighth ed.): Upper Saddle River, NJ, Prentice Hall, 986 p.

Maine Center for Disease Control and Prevention, 2006, Frequently asked questions about the $4,000 \mathrm{pCi} / \mathrm{L}$ MEG for radon in well water: Department of Health and Human Services, Division of Environmental Health, updated 2006, accessed April 2, 2010, at http://www.maine.gov/dhhs/eohp/ RealEstate/RadonMEGFAQ.htm.

Maupin, M.A., and Barber, N.L., 2005, Estimated withdrawals from principal aquifers in the United States, 2000: U.S. Geological Survey Circular 1279, 46 p. Available at http:// pubs.usgs.gov/circ/2005/1279/pdf/circ1279.pdf.

McMahon, P.B., Burow, K.R., Kauffman, L.J., Eberts, S.M., Böhlke, J.K., and Gurdak, J.J., 2008, Simulated response of water quality in public supply wells to land use change: Water Resources Research, v. 44, W00A06, doi:10.1029/2007WR006731.
Miller, J.A., 2000, Ground water atlas of the United States: U.S. Geological Survey, Chapters archived online 19901999, accessed April 2, 2010, at http://capp.water.usgs.gov/ gwa/gwa.html.

Moran, M.J., 2006, Occurrence and implications of selected chlorinated solvents in ground water and source water in the United States and in drinking water in 12 northeast and mid-Atlantic states, 1993-2002: U.S. Geological Survey Scientific Investigations Report 2005-5268, 70 p. Available at http://pubs.usgs.gov/sir/2005/5268/.

Moran, M.J., Zogorski, J.S., and Rowe, B.L., 2006, Approach to an assessment of volatile organic compounds in the Nation's ground water and drinking-water supply wells: U.S. Geological Survey Open-File Report 2005-1452, 36 p. Available at http://pubs.usgs.gov/of/2005/1452/pdf/ofr20051452.pdf.

Moran, M.J., Zogorski, J.S., and Squillace, P.J., 2005, MTBE and gasoline hydrocarbons in ground water of the United States: Ground Water, v. 43, no. 4, p. 615-627.

Moran, M.J., Zogorski, J.S., and Squillace, P.J., 2007, Chlorinated solvents in groundwater of the United States: Environmental Science and Technology, v. 41, no. 1, p. $74-81$.

Mueller, D.K., Hamilton, P.A., Helsel, D.R., Hitt, K.J., and Ruddy, B.C., 1995, Nutrients in ground water and surface water of the United States; an analysis of data through 1992: U.S. Geological Survey Water-Resources Investigations Report 95-4031, 74 p. Available at http://pubs.er.usgs.gov/ usgspubs/wri/wri954031.

Mumtaz, M.M., 1995, Risk assessment of chemical mixtures from a public health perspective: Toxicology Letters, v. $82-83$, p. $527-532$.

Myers, D.N., Stoeckel, D.M., Bushon, R.N., Francy, D.S., and Brady, A.M.G., 2007, Fecal indicator bacteria: U.S. Geological Survey techniques of water-resources investigations, book 9, chap. A7, section 7.1 (version 2.0): U.S. Geological Survey, February 2007, accessed October 8, 2009, at http://water.usgs.gov/owq/FieldManual/ Chapter7/7.1.html.

Nakagaki, N., and Wolock, D.M., 2005, Estimation of agricultural pesticide use in drainage basins using land cover maps and county pesticide data: U.S. Geological Survey Open-File Report 2005-1188, 46 p. Available at http://pubs.usgs.gov/of/2005/1188/.

National Atmospheric Deposition Program, 2007, Hydrogen ion concentration as $\mathrm{pH}$ from measurements made at the Central Analytical Laboratory, 2007: Illinois State Water Survey, University of Illinois at Urbana-Champaign, accessed April 2, 2010, at http://nadp.sws.uiuc.edu/NTN/ maps.aspx. 
National Research Council, 1999a, Identifying future drinking water contaminants: Commission on Geosciences, Environment and Resources (CGER), 260 p. Available at http://www.nap.edu/books/0309064325/html/1.html.

National Research Council, 1999b, Risk assessment of radon in drinking water: Washington, DC, National Academy Press, 296 p.

National Research Council, 2001, Arsenic in drinking water: 2001 update: Washington, DC, National Academy Press, $244 \mathrm{p}$.

National Research Council, 2006a, Fluoride in drinking water: a scientific review of EPA's standards: The National Academies Report in Brief, March 2006, 4 p. Available at http://www.nap.edu/catalog.php?record_id=11571.

National Research Council, 2006b, Fluoride in drinking water: a scientific review of EPA's standards: Washington, DC, National Academy Press, $530 \mathrm{p}$.

National Research Council, 2008, Science and decisions, advancing risk assessment, committee on improving risk analysis approaches used by the U.S. EPA: Washington D.C., National Academy Press, 424 p.

National Water Quality Laboratory, 2009, NWQL current and historical reporting level information: U.S. Geological Survey, updated October 1, 2009, accessed April 2, 2010, at http://nwql.usgs.gov/.

Nebraska Department of Agriculture, 1997, Nebraska pesticides and groundwater generic state management plan: Pesticide Program, March 18, 1997, variously paged. Available at http://www.agr.state.ne.us/division/bpi/pes/ gsmp.pdf.

New Hampshire Department of Environmental Services, 2008, Radon program frequently asked questions: Air Resources Division, Radon Program, updated 2008, accessed February 24, 2010, at http://des.nh.gov/organization/divisions/air/ pehb/ehs/radon/categories/faq.htm.

New Jersey Department of Environmental Protection, 2003, Susceptibility of source water to community water-supply wells in New Jersey to contamination by volatile organic compounds: New Jersey Department of Environmental Protection, 21 p. Available at http://www.state.nj.us/dep/ swap/reports/gw voc.pdf.

New Jersey Department of Environmental Protection, 2004, New Jersey source water assessment program statewide summary: New Jersey Department of Environmental Protection, December 2004, 30 p. Available at http://www. state.nj.us/dep/swap/reports/swap sum200412.pdf.
Nolan, B.T., and Hitt, K.J., 2003, Nutrients in shallow ground waters beneath relatively undeveloped areas in the conterminous United States: U.S. Geological Survey WaterResources Investigations Report 2002-4289, 17 p. Available at http://pubs.usgs.gov/wri/wri024289/.

Nolan, B.T., and Hitt, K.J., 2006, Vulnerability of shallow groundwater and drinking-water wells to nitrate in the United States: Environmental Science and Technology, v. 40 , no. 24 , p. $7834-7840$.

Nolan, B.T., Ruddy, B.C., Hitt, K.J., and Helsel, D.R., 1997, Risk of nitrate in groundwaters of the United States - a national perspective: Environmental Science and Technology, v. 31, no. 8, p. 2229-2236.

Nordstrom, D.K., 2002, Worldwide occurrences of arsenic in ground water: Science, v. 296, no. 5576, p. 2143-2145.

Nowell, L.H., Capel, P.D., and Dileanis, P.D., 1999, Pesticides in stream sediment and aquatic biota - distribution, trends, and governing factors: Pesticides in the Hydrologic System: Boca Raton, FL, CRC Press, v. 4, 1040 p.

Nurmi, J.T., and Tratnyek, P.G., 2002, Electrochemical properties of natural organic matter (NOM), fractions of NOM, and model biogeochemical electron shuttles: Environmental Science and Technology, v. 36, no. 4, p. 617-624.

Olcott, P.G., 1992, Ground water atlas of the United States; Iowa, Michigan, Minnesota, Wisconsin HA 730-J: U.S. Geological Survey, accessed April 2, 2010, at http://pubs. usgs.gov/ha/ha730/ch j/index.html.

Pankow, J.F., 1991, Aquatic chemistry concepts: Chelsea, MI, Lewis Publishers, Inc., 673 p.

Perry, J.J., 1979, Microbial cooxidations involving hydrocarbons: Microbiological Reviews, v. 43, no. 1, p. 59-72.

Piper, A.M., 1944, A graphic procedure in the geochemical interpretation of water analyses: Transactions American Geophysical Union, v. 25, p. 914-923.

Richardson, S.D., 2003, Water analysis: emerging contaminants and current issues: Analytical Chemistry, v. 75 , no. 12 , p. $2831-2857$.

Richardson, S.D., Simmons, J.E., and Rice, G., 2002, Disinfection byproducts: the next generation: Environmental Science and Technology, v. 36, no. 9, p. 198A-205A. 
Rose, D.L., and Schroeder, M.P., 1995, Methods of analysis by the U.S. Geological Survey National Water Quality Laboratory; determination of volatile organic compounds in water by purge and trap capillary gas chromatography/ mass spectrometry: U.S. Geological Survey Open-File Report 94-708-W, 26 p. Available at http://pubs.er.usgs.gov/ usgspubs/ofr/ofr $94708 \mathrm{~W}$.

Rowe, B.L., Toccalino, P.L., Moran, M.J., Zogorski, J.S., and Price, C.V., 2007, Occurrence and potential human-health relevance of volatile organic compounds in drinking water from domestic wells in the United States: Environmental Health Perspectives, v. 115, no. 11, p. 1539-1546.

Ryker, S.J., 2001, Mapping arsenic in groundwater: a real need, but a hard problem: Geotimes, November, p. 34-36, accessed February 24, 2010 at http://www.agiweb.org/ geotimes/nov01/feature Asmap.html.

Ryker, S.J., 2003, Arsenic in ground water used for drinking water in the United States, in Welch, A.H., and Stollenwerk, K.G., eds., Arsenic in ground water geochemistry and occurrence: Boston, MA, Kluwer Academic Publishers, p. $165-178$.

Ryker, S.J., and Small, M.J., 2008, Combining occurrence and toxicity information to identify priorities for drinking-water mixture research: Risk Analysis, v. 28, no. 3, p. 653-666.

Schaap, B.D., and Zogorski, J.S., 2006, Occurrence of trihalomethanes in the Nation's ground water and drinkingwater supply wells, 1985-2002: U.S. Geological Survey Scientific Investigations Report 2006-2058, 64 p. Available at http://pubs.usgs.gov/sir/2006/5068/.

Shapiro, S.D., Busenberg, E., Focazio, M.J., and Plummer, L.N., 2004, Historical trends in occurrence and atmospheric inputs of halogenated volatile organic compounds in untreated ground water used as a source of drinking water: Science of the Total Environment, v. 321, no. 1-3, p. 201217.

Simmons, J.E., Teuschler, L.K., Gennings, C., Speth, T.F., Richardson, S.D., Miltner, R.J., Nartosky, M.G., Schneck, K.D., Hunter III, E.S., Hertzberg, R.C., and Rice, G., 2004, Component-based and whole-mixture techniques for addressing the toxicity of drinking-water disinfection by-product mixtures: Journal of Toxicology \& Environmental Health: Part A, v. 67, no. 8-10, p. 741-754.

Solley, W.B., Pierce, R.R., and Perlman, H.A., 1998, Estimated use of water in the United States in 1995: U.S. Geological Survey Circular 1200, 71 p. Available at http:// water.usgs.gov/watuse/pdf1995/html/, data accessed from http://water.usgs.gov/watuse/.

Spalding, R.F., and Exner, M.E., 1993, Occurrence of nitrate in groundwater - a review: Journal of Environmental Quality, v. 22, no. 3, p. 392-402.
Squillace, P.J., Moran, M.J., Lapham, W.W., Price, C.V., Clawges, R.M., and Zogorski, J.S., 1999, Volatile organic compounds in untreated ambient groundwater of the United States, 1985-1995: Environmental Science and Technology, v. 33 , no. 23 , p. $4176-4187$.

Squillace, P.J., Pankow, J.F., Korte, N.E., and Zogorski, J.S., 1997, Review of the environmental behavior and fate of methyl tert-butyl ether: Environmental Toxicology and Chemistry, v. 16, no. 9, p. 1836-1844.

Squillace, P.J., Scott, J.C., Moran, M.J., Nolan, B.T., and Kolpin, D.W., 2002, VOCs, pesticides, nitrate, and their mixtures in groundwater used for drinking water in the United States: Environmental Science and Technology, v. 36, no. 9, p. 1923-1930.

State of Maine, 1998, The presence of MTBE and other gasoline compounds in Maine's drinking water - a preliminary report: Bureau of Health, Department of Human Services, October 13, 1998, 24 p. Available at http://www. maine.gov/dhhs/eohp/wells/documents/MTBE.PDF.

Szabo, Z., and DePaul, V.T., 1998, Radium-226 and radium-228 in shallow ground water, southern New Jersey: U.S. Geological Survey Fact Sheet 062-98, 6 p. Available at http://nj.usgs.gov/publications/FS/fs-062-98.pdf.

Szabo, Z., dePaul, V.T., Kraemer, T.F., and Parsa, B., 2005, Occurrence of radium-224, radium-226, and radium-228 in water of the unconfined Kirkwood-Cohansey aquifer system, southern New Jersey: U.S. Geological Survey Scientific Investigations Report 2004-5224, 101 p. Available at http://pubs.usgs.gov/sir/2004/5224/.

Teuschler, L.K., Rice, G.E., Wilkes, C.R., Lipscomb, J.C., and Power, F.W., 2004, A feasibility study of cumulative risk assessment methods for drinking water disinfection by-product mixtures: Journal of Toxicology \& Environmental Health: Part A, v. 67, no. 8-10, p. 755-777.

Teuschler, L.K., and Simmons, J.E., 2003, Approaching DBP toxicity as a mixtures problem: Journal American Water Works Association, v. 95, no. 6, p. 131-138.

The National Academies, 2008, Drinking water: understanding the science and policy behind a critical resource: The National Academies, Water Science and Technology Board, 28 p. Available at http://water.nationalacademies.org/basics. shtml.

Thelin, G.P., and Stone, W.W., 2010, Method for estimating annual atrazine use for counties in the conterminous United States, 1992-2007: U.S. Geological Survey Scientific Investigations Report 2010-5034, 129 p. Available at http:// pubs.usgs.gov/sir/2010/5034/. 
Thomas, M.A., 2007, The association of arsenic with redox conditions, depth, and ground-water age in the glacial aquifer system of the northern United States: U.S. Geological Survey Scientific Investigations Report 20075036, 26 p. Available at http://pubs.usgs.gov/sir/2007/5036/.

Timme, P.J., 1995, National water quality laboratory 1995 services catalog: U.S. Geological Survey Open-File Report 95-352, 120 p. Available at http://pubs.er.usgs.gov/ usgspubs/ofr/ofr95352.

Toccalino, P.L., 2007, Development and application of healthbased screening levels for use in water-quality assessments: U.S. Geological Survey Scientific Investigations Report 2007-5106, 12 p. Available at http://pubs.usgs.gov/ sir/2007/5106/.

Toccalino, P.L., Norman, J.E., Booth, N.L., and Zogorski, J.S., 2008, Health-based screening levels: a tool for evaluating what water-quality data may mean to human health: U.S. Geological Survey, National Water-Quality Assessment Program, updated April 10, 2008, accessed February 24, 2010, at http://water.usgs.gov/nawqa/HBSL.

Toccalino, P.L., Norman, J.E., Phillips, R.H., Kauffman, L.J., Stackelberg, P.E., Nowell, L.H., Krietzman, S.J., and Post, G.B., 2004, Application of health-based screening levels to ground-water quality data in a state-scale pilot effort: U.S. Geological Survey Scientific Investigations Report 20045174, 64 p. Available at http://pubs.usgs.gov/sir/2004/5174/ sir20045174.pdf.

Toccalino, P.L., Nowell, L.H., Wilber, W.G., Zogorski, J.S., Donohue, J.M., Eiden, C.A., Krietzman, S.J., and Post, G.B., 2003, Development of health-based screening levels for use in state- or local-scale water-quality assessments: U.S. Geological Survey Water-Resources Investigations Report 03-4054, 22 p. Available at http://sd.water.usgs.gov/ nawqa/pubs/wrir/wrir03 4054.pdf.

Toccalino, P.L., Rowe, B.L., and Norman, J.E., 2006, Volatile organic compounds in the Nation's drinking-water supply wells - what findings may mean to human health: U.S. Geological Survey Fact Sheet 2006-3043, 4 p. Available at http://pubs.usgs.gov/fs/2006/3043/.

Toccalino, P.L., Zogorski, J.S., and Norman, J.E., 2005, Health-based screening levels and their application to waterquality data: U.S. Geological Survey Fact Sheet 2005-2059, 2 p. Available at http://water.usgs.gov/nawqa/FS 20053059.pdf.

U.S. Census Bureau, 2009, Population estimates: updated March 20, 2009, accessed April 23, 2009, at http://www. census.gov/popest/estimates.html.
U.S. Centers for Disease Control and Prevention, 2001, Recommendations for using fluoride to prevent and control dental caries in the United States: Morbidity and Mortality Weekly Report, v. 50, no. RR14, p. 1-42.

U.S. Code, 1996, Safe Drinking Water Act amendments of 1996: Title 42 The Public Health and Welfare, Chapter 6A Public Health Service, SubChapter XII Safety of Public Water Systems, Public Law 104-182, Enacted August 6, 1996, accessed January 6, 2010, at http://uscode.house.gov/ download/pls/42C6A.txt.

U.S. Environmental Protection Agency, 1980, Ambient water quality criteria for aldrin/dieldrin: U.S. Environmental Protection Agency, Office of Water, Regulations and Standards, Criteria and Standards Division EPA 440/5-80019, variously paged. Available at http://www.epa.gov/ waterscience/criteria/library/ambientwqc/aldrindieldrin.pdf.

U.S. Environmental Protection Agency, 1986, Guidelines for carcinogen risk assessment: U.S. Environmental Protection Agency, Office of Research and Development, National Center for Environmental Assessment Federal Register EPA/630/R-00/004, September 24, 1986, 33992-34003 p. Available at http://www.epa.gov/raf/publications/pdfs/ CA\%20GUIDELINES 1986.PDF.

U.S. Environmental Protection Agency, 1987, Integrated risk information system: dieldrin (CASRN 60-57-1): U.S. Environmental Protection Agency, Office of Research and Development, National Center for Environmental Assessment, verification dates March 5, 1987 and April 16, 1987, accessed February 24, 2010, at http://www.epa.gov/ ncea/iris/subst/0225.htm.

U.S. Environmental Protection Agency, 1989, Risk assessment guidance for superfund - volume 1-human health evaluation manual (part A), interim final: U.S. Environmental Protection Agency, Office of Emergency and Remedial Response EPA/540/1-89/002, December 1989, variously paged. Available at http://www.epa.gov/oswer/ riskassessment/ragsa/pdf/preface.pdf.

U.S. Environmental Protection Agency, 1990, National survey of pesticides in drinking water wells phase 1 report: U.S. Environmental Protection Agency, Office of Water and Office of Pesticides and Toxic Substances EPA 570/9-90015, November 1990, 335 p. Available at http://nepis.epa. gov/EPA/html/Pubs/pubtitleOSWER.htm.

U.S. Environmental Protection Agency, 1992a, Another look: national survey of pesticides in drinking water wells phase 2 report: U.S. Environmental Protection Agency, Office of Water and Office of Pesticides and Toxic Substances EPA 570/9-91-020, January 1992, 196 p. Available at http:// nepis.epa.gov/EPA/html/Pubs/pubtitleOSWER.htm. 
U.S. Environmental Protection Agency, 1992b, Integrated risk information system: strontium (CASRN 7440-24-6): U.S. Environmental Protection Agency, Office of Research and Development, National Center for Environmental Assessment, Verification date June 23, 1992, accessed February 24, 2010, at http://www.epa.gov/ncea/iris/ subst/0550.htm.

U.S. Environmental Protection Agency, 1992c, Secondary drinking water regulations: guidance for nuisance chemicals: U.S. Environmental Protection Agency, Office of Ground Water and Drinking Water EPA 810/K-92-001, July 1992, 4 p. Available at http://www.epa.gov/safewater/ consumer/2ndstandards.html.

U.S. Environmental Protection Agency, 1993, Risk assessment: technical guidance manual, selecting exposure routes and contaminants of concern by riskbased screening: U.S. Environmental Protection Agency, Region 3, Hazardous Waste Management Division EPA/903/R-93-001, January 1993, 5 p. Available at http:// www.epa.gov/reg3hwmd/risk/human/info/guide2.htm.

U.S. Environmental Protection Agency, 1994, Evaluating and identifying contaminants of concern for human health: U.S. Environmental Protection Agency, Region 8, Hazardous Waste Management Division Region 8 Superfund Technical Guidance No. RA-03, September 1994, 10 p. Available at http://www.epa.gov/region8/r8risk/pdf/r8_ra03-cocs.pdf.

U.S. Environmental Protection Agency, 1995, Integrated risk information system: manganese (CASRN 7439-96-5): U.S. Environmental Protection Agency, Office of Research and Development, National Center for Environmental Assessment, Verification date May 12, 1995, accessed February 24, 2010, at http://www.epa.gov/ncea/iris/ subst/0373.htm.

U.S. Environmental Protection Agency, 1998, Code of Federal Regulations, title 40 - protection of environment, chapter 1-Environmental Protection Agency, subchapter Epesticide programs, part 159 - statements of policies and interpretations, subpart D-reporting requirements for risk/ benefit information, 40 CFR 159.184: Washington D.C., National Archives and Records Administration, September 19, 1997; amended June 19, 1998, accessed February 24, 2010, at http://www.gpoaccess.gov/ecfr/index.html.

U.S. Environmental Protection Agency, 1999a, Proposed radon in drinking water rule, technical fact sheet: U.S. Environmental Protection Agency, Office of Water EPA 815-F-99-006, October 1999, 6 p. Available at http://www. epa.gov/safewater/radon/fact.html and http://www.epa.gov/ ogwdw000/radon/fact10.pdf.
U.S. Environmental Protection Agency, 1999b, A review of contaminant occurrence in public water systems: U.S. Environmental Protection Agency, Office of Water EPA 816-R-99-006, November 1999, 78 p. Available at http:// www.epa.gov/safewater/occur/occur.html.

U.S. Environmental Protection Agency, 2000a, National primary drinking water regulations; radionuclides; final rule: U.S. Environmental Protection Agency Federal Register, 40 CFR Parts 9, 141, and 142, v. 65, no. 236, December 7, 2000, 76708-76753 p. Available at http:// www.gpo.gov/fdsys/pkg/FR-2000-12-07/pdf/00-30421.pdf.

U.S. Environmental Protection Agency, 2000b, Radionuclides notice of data availability technical support document: U.S. Environmental Protection Agency, Office of Ground Water and Drinking Water, Standards and Risk Management Division, March 2000, 164 p. Available at http://www.epa. gov/safewater/radionuclides/pdfs/regulation_radionuclides rulemaking_techsupportdoc.pdf.

U.S. Environmental Protection Agency, 2000c, Supplementary guidance for conducting health risk assessment of chemical mixtures: U.S. Environmental Protection Agency, Risk Assessment Forum EPA/630/R-00/002, August 2000, 143 p.

U.S. Environmental Protection Agency, 2001a, Method 1601: male-specific $(\mathrm{F}+)$ and somatic coliphage in water by twostep enrichment procedure: U.S. Environmental Protection Agency, Office of Water EPA 821-R-01-030, 40 p. Available at http://www.epa.gov/nerlcwww/1601ap01.pdf.

U.S. Environmental Protection Agency, 2001b, National primary drinking water regulations; arsenic and clarifications to compliance and new source contaminants monitoring: U.S. Environmental Protection Agency, Federal Register, 40 CFR Parts 9, 141, and 142, v. 66, no. 14, January 22, 2001, 6975-7066 p. Available at http://www. epa.gov/fedrgstr/EPA-WATER/2001/January/Day-22/ w1668.htm.

U.S. Environmental Protection Agency, 2001c, Occurrence of unregulated contaminants in public water systems - an initial assessment: U.S. Environmental Protection Agency, Office of Water EPA 815-P-00-001, May 2001, 508 p. Available at http://www.epa.gov/ogwdw000/ucmr/data/ report ucm1-2_no uc.pdf.

U.S. Environmental Protection Agency, 2001d, Total coliform rule: a quick reference guide: U.S. Environmental Protection Agency, Office of Water EPA 816-F-01-035, November 2001, 2 p. Available at http://www.epa.gov/ OGWDW/disinfection/tcr/pdfs/qrg ter_v10.pdf. 
U.S. Environmental Protection Agency, 2002a, Community water system survey 2000, volume 1: overview: U.S. Environmental Protection Agency, Office of Water EPA 815-R-02-005A, December 2002, 58 p. Available at http://www.epa.gov/safewater/consumer/pdf/cwss 2000 volume i.pdf.

U.S. Environmental Protection Agency, 2002b, Occurrence data, accessing unregulated contaminant monitoring data: UCM rounds 1 and 2 and the six-year review data: U.S. Environmental Protection Agency, Office of Water, updated November 20, 2002, accessed February 24, 2010, at http:// www.epa.gov/safewater/ucmr/data.html\#1.

U.S. Environmental Protection Agency, 2003a, Fact sheet: announcement of regulatory determinations for priority contaminants on the drinking water contaminant candidate list: U.S. Environmental Protection Agency, Office of Water EPA 815-F-03-007, July 2003, 3 p. Available at http:// www.epa.gov/safewater/ccl/pdfs/reg_determine $1 / \mathrm{fs}$ _ccl1 regdetermine july03.pdf.

U.S. Environmental Protection Agency, 2003b, The feasibility of performing cumulative risk assessments for mixtures of disinfection by-products in drinking water: U.S. Environmental Protection Agency, National Center for Environmental Assessment, Office of Research and Development EPA/600/R-03/051, June 2003, 435 p. Available at http://cfpub.epa.gov/ncea/cfm/recordisplay. cfm?deid $=56834$.

U.S. Environmental Protection Agency, 2003c, Framework for cumulative risk assessment: U.S. Environmental Protection Agency, Risk Assessment Forum EPA/630/P-02/001F, May 2003, 109 p. Available at http://cfpub.epa.gov/ncea/ cfm/recordisplay.cfm?deid $=54944$.

U.S. Environmental Protection Agency, 2003d, Health effects support document for aldrin/dieldrin: U.S. Environmental Protection Agency, Office of Water, Health and Ecological Criteria Division EPA 822-R-03-001, February 2003, variously paged. Available at http://www.epa.gov/ OGWDW/ccl/pdfs/reg_determine1/support cc1_aldrindieldrin healtheffects.pdf.

U.S. Environmental Protection Agency, 2003e, Interim reregistration eligibility decision for atrazine, case no. 0062: U.S. Environmental Protection Agency, Office of Pesticide Programs, 304 p. Available at http://www.epa.gov/ pesticides/reregistration/REDs/atrazine ired.pdf.

U.S. Environmental Protection Agency, 2003f, Occurrence estimation methodology and occurrence findings report for the six-year review of existing national primary drinking water regulations: U.S. Environmental Protection Agency, Office of Water EPA-815-R-03-006, June 2003, 874 p. Available at http://www.epa.gov/safewater/standard/review/ pdfs/support 6yr_occurancemethods_final.pdf.
U.S. Environmental Protection Agency, 2003g, Water on tap: what you need to know: U.S. Environmental Protection Agency, Office of Water EPA 816-K-03-007, October 2003, $36 \mathrm{p}$.

U.S. Environmental Protection Agency, 2004a, Integrated risk information system: boron and compounds (CASRN 7440-42-8): U.S. Environmental Protection Agency, Office of Research and Development, National Center for Environmental Assessment, Agency completion date May 26, 2004, accessed February 24, 2010, at http://www.epa. gov/ncea/iris/subst/0410.htm.

U.S. Environmental Protection Agency, 2004b, State actions banning MTBE (statewide): U.S. Environmental Protection Agency EPA 420-B-04-009, June 2004, 3 p. Available at http://www.epa.gov/mtbe/420b04009.pdf.

U.S. Environmental Protection Agency, 2004c, Understanding the safe drinking water act: U.S. Environmental Protection Agency, Office of Water EPA 816-F-04-030, June 2004, 4 p. Available at http://www.epa.gov/safewater/sdwa/pdfs/ fs_30ann_sdwa_web.pdf.

U.S. Environmental Protection Agency, 2006a, 2006 Edition of the drinking water standards and health advisories: U.S. Environmental Protection Agency, Office of Water EPA 822-R-06-013, August 2006, 18 p. Available at http://www. epa.gov/waterscience/criteria/drinking/dwstandards.pdf.

U.S. Environmental Protection Agency, 2006b, Ground water rule (GWR) basic information: U.S. Environmental Protection Agency, Office of Water, updated October 25, 2006, accessed April 2, 2010, at http://www.epa.gov/ safewater/disinfection/gwr/basicinformation.html.

U.S. Environmental Protection Agency, 2006c, Triazine cumulative risk assessment: U.S. Environmental Protection Agency, Office of Pesticide Programs, Health Effects Division, March 28, 2006, 67 p. Available at http://www. epa.gov/oppsrrd1/REDs/triazine cumulative risk.pdf.

U.S. Environmental Protection Agency, 2006d, Unregulated contaminant monitoring rule 1 (UCMR1) fact sheet: U.S. Environmental Protection Agency, Office of Ground Water and Drinking Water, updated February 28, 2006, accessed April 2, 2010, at http://www.epa.gov/safewater/ucmr/ ucmr1/factsheet.html.

U.S. Environmental Protection Agency, 2007a, Concepts, methods and data sources for cumulative health risk assessment of multiple chemicals, exposures and effects: a resource document (final report): U.S. Environmental Protection Agency, Office of Research and Development, National Center for Environmental Assessment EPA/600/R06/013F, August 2007, variously paged. Available at http:// cfpub.epa.gov/ncea/cfm/recordisplay.cfm?deid=190187. 
U.S. Environmental Protection Agency, 2007b, Occurrence data, accessing unregulated contaminant monitoring data: UCMR1 (2001-2005) occurrence data: U.S. Environmental Protection Agency, Office of Water, Pivot table dated October 30, 2007, accessed April 3, 2010, at http://www. epa.gov/safewater/ucmr/data.html.

U.S. Environmental Protection Agency, 2008a, EPA's 2008 report on the environment: U.S. Environmental Protection Agency, National Center for Environmental Assessment EPA/600/R-07/045F, May 2008, 366 p. Available at http:// www.epa.gov/roe/.

U.S. Environmental Protection Agency, 2008b, Fact sheet: final regulatory determinations for the second drinking water contaminant candidate list (CCL 2): U.S. Environmental Protection Agency, Office of Water EPA 815-F-08-005, July 2008, 4 p. Available at http://www.epa. gov/safewater/ccl/pdfs/reg_determine2/fs_ccl2-reg2.pdf.

U.S. Environmental Protection Agency, 2008c, Factoids: drinking water and ground water statistics for 2008: U.S. Environmental Protection Agency, Office of Water EPA 816-K-08-004, November 2008, 16 p. Available at http:// www.epa.gov/safewater/databases/pdfs/data factoids 2008 . pdf.

U.S. Environmental Protection Agency, 2008d, Methyl tertiary butyl ether (MTBE): overview: U.S. Environmental Protection Agency, updated November 24, 2008, accessed April 3, 2010, at http://www.epa.gov/mtbe/faq.htm.

U.S. Environmental Protection Agency, 2008e, Methyl tertiary butyl ether (MTBE): recommendations and actions: U.S. Environmental Protection Agency, updated November 24, 2008, accessed April 3, 2010, at http://www.epa.gov/mtbe/ action.htm.

U.S. Environmental Protection Agency, 2008f, Regulatory determinations support document for selected contaminants from the second drinking water contaminant candidate list (CCL 2), chapter 3 boron: U.S. Environmental Protection Agency, Office of Water EPA 815-R-08-012, June 2008, variously paged. Available at http://www.epa. gov/safewater/ccl/pdfs/reg_determine2/report_ccl2-reg2 supportdocument full.pdf.

U.S. Environmental Protection Agency, 2008g, Safe drinking water information system (SDWIS), how to access local drinking water information: download and manipulate SDWIS/FED data in MS Excel pivot tables: U.S. Environmental Protection Agency, Office of Water, Pivot table dated October 9, 2008, accessed April 3, 2010, at http://www.epa.gov/safewater/databases/sdwis/ howtoaccessdata.html.
U.S. Environmental Protection Agency, 2009a, 2009 Edition of the drinking water standards and health advisories: U.S. Environmental Protection Agency, Office of Water EPA 822-R-09-011, October 2009, 18 p. Available at http://www. epa.gov/waterscience/criteria/drinking/dwstandards2009. pdf.

U.S. Environmental Protection Agency, 2009b, Drinking water contaminants: U.S. Environmental Protection Agency, Office of Water, updated September 11, 2009, accessed February 24, 2010, at http://www.epa.gov/safewater/ contaminants/index.html.

U.S. Environmental Protection Agency, 2009c, FIFRA scientific advisory panel; notice of public meeting: U.S. Environmental Protection Agency, Federal Register, v. 74, no. 193, p. 51593-51596, updated October 7, 2009, accessed January 5, 2010, at http://edocket.access.gpo. gov/2009/pdf/E9-24229.pdf.

U.S. Environmental Protection Agency, 2009d, Occurrence data, accessing unregulated contaminant monitoring data: UCMR2 (2007-2011) occurrence data: U.S. Environmental Protection Agency, Office of Water, Zip file dated April 2009, accessed April 3, 2010, at http://www.epa.gov/ safewater/ucmr/data.html.

U.S. Environmental Protection Agency, 2009e, Proposed radon in drinking water rule: U.S. Environmental Protection Agency, Office of Water, updated September 3, 2009, accessed February 24, 2010, at http://www.epa.gov/ safewater/radon/proposal.html.

U.S. Environmental Protection Agency, 2010a, Drinking water contaminant candidate list and regulatory determinations: U.S. Environmental Protection Agency, Office of Water, updated February 22, 2010, accessed February 24, 2010, at http://www.epa.gov/safewater/ccl/.

U.S. Environmental Protection Agency, 2010b, Fact sheet: announcement of completion of EPA's second review of existing drinking water standards: U.S. Environmental Protection Agency, Office of Water EPA 815-F-09-002, March 2010, 5 p. available at http://www.epa.gov/safewater/ review/pdfs/psfs_2ndSix-Year/fs_federalregisternotice.pdf.

U.S. Environmental Protection Agency, 2010c, Integrated risk information system (IRIS) recent additions: U.S. Environmental Protection Agency, Office of Research and Development, National Center for Environmental Assessment, updated March 31, 2010, accessed April 3, 2010, at http://www.epa.gov/ncea/iris/recent.htm.

U.S. Environmental Protection Agency, 2010d, Public drinking water systems: facts and figures: U.S. Environmental Protection Agency, Office of Water, updated February 24, 2010, accessed February 24, 2010, at http:// www.epa.gov/safewater/pws/factoids.html. 
U.S. Environmental Protection Agency, 2010e, Regulating public water systems and contaminants under the safe drinking water act: U.S. Environmental Protection Agency, Office of Water, Office of Ground Water and Drinking Water, updated March 22, 2010, accessed April 2, 2010, at http://www.epa.gov/safewater/standard/setting.html.

U.S. Environmental Protection Agency, 2010f, Unregulated contaminant monitoring program: U.S. Environmental Protection Agency, Office of Ground Water and Drinking Water, updated February 23, 2010, accessed February 24, 2010, at http://www.epa.gov/safewater/ucmr/index.html.

U.S. Environmental Protection Agency, 2010g, Unregulated contaminant monitoring rule 2 (UCMR 2) basic information: U.S. Environmental Protection Agency, Office of Water, updated January 27, 2010, accessed April 3, 2010, at http://www.epa.gov/ogwdw000/ucmr/ucmr2/ basicinformation.html.

U.S. General Accounting Office, 1997, Drinking waterinformation on the quality of water found at community water systems and private wells: U.S. General Accounting Office, Resources, Community, and Economic Development Division GAO/RCED-97-123, June 12, 1997, 51 p. Available at http://www.gao.gov/archive/1997/rc97123.pdf.

U.S. Geological Survey, 1999, The quality of our Nation's waters-nutrients and pesticides: U.S. Geological Survey Circular 1225, 82 p. Available at http://water.usgs.gov/pubs/ circ/circ1225/.

U.S. Geological Survey, 2003, Principal aquifers of the 48 conterminous United States, Hawaii, Puerto Rico, and the U.S. Virgin Islands: U.S. Geological Survey, accessed February 24, 2010, at http://www.nationalatlas.gov/mld/ aquifrp.html.

U.S. Geological Survey, 2004, User's manual for the national water information system of the U.S. Geological Survey: ground-water site-inventory system (ver. 4.3): U.S. Geological Survey Open-File Report 2004-1238, 275 p. Available at http://pubs.usgs.gov/of/2004/1238/.

U.S. Geological Survey, 2006, Collection of water samples (ver. 2.0): U.S. Geological Survey techniques of waterresources investigations, book 9, chap. A4, updated September 2006, accessed February 24, 2010, at http:// water.usgs.gov/owq/FieldManual/chapter $4 / \mathrm{html} / \mathrm{Ch} 4$ contents.html.

U.S. Geological Survey, 2009, Aquifer basics: U.S. Geological Survey, Office of Ground Water, updated April 29, 2009, accessed February 24, 2010, at http://capp.water.usgs.gov/ aquiferBasics/index.html.
U.S. Geological Survey, 2010a, National Water-Quality Assessment (NAWQA) Program: National Water-Quality Assessment Program, updated February 12, 2010, accessed February 24, 2010, at http://water.usgs.gov/nawqa/.

U.S. Geological Survey, 2010b, NAWQA data warehouse home: U.S. Geological Survey, National Water Quality Assessment Program, updated March 31, 2010, accessed March 31, 2010, at http://water.usgs.gov/nawqa/data.

U.S. Geological Survey, 2010c, Water-quality assessments of principal aquifers: updated March 31, 2010, accessed March 31, 2010, at http://water.usgs.gov/nawqa/studies/ praq/.

U.S. Geological Survey, variously dated, National field manual for the collection of water-quality data: U.S. Geological Survey techniques of water-resources investigations, book 9, chaps. A1-A9: U.S. Geological Survey, updated January 22, 2010, accessed April 3, 2010, at http://water. usgs.gov/owq/FieldManual/.

Vogelmann, J.E., Howard, S.M., Yang, L., Larson, C.R., Wylie, B.K., and Van Driel, N., 2001, Completion of the 1990's national land cover dataset for the conterminous United States from landsat thematic mapper data and ancillary data sources: Photogrammetric Engineering and Remote Sensing, v. 67, p. 650-662.

Warner, K.L., and Arnold, T.L., 2006, Framework for regional synthesis of water-quality data for the glacial aquifer system in the United States: U.S. Geological Survey Scientific Investigations Report 2005-5223, 6 p. Available at http:// pubs.usgs.gov/sir/2005/5223/.

Weaver, T.R., and Bahr, J.M., 1991, Geochemical evolution in the Cambrian-Ordovician sandstone aquifer, eastern Wisconsin-1. Major ion and radionuclide distribution: Ground Water, v. 29, no. 3, p. 350-356.

Welch, A.H., Westjohn, D.B., Helsel, D.R., and Wanty, R.B., 2000, Arsenic in ground water of the United States: occurrence and geochemistry: Ground Water, v. 38, no. 4, p. 589-604.

Werner, S.L., Burkhardt, M.R., and DeRusseau, S.N., 1996, Methods of analysis by the U.S. Geological Survey National Water Quality Laboratory-determination of pesticides in water by carbopak-B solid-phase extraction and highperformance liquid chromatography: U.S. Geological Survey Open-File Report 96-216, 42 p. Available at http:// nwql.usgs.gov/Public/pubs/OFR96-216/OFR96-216.html.

Westrick, J.J., 1990, National surveys of volatile organic compounds in ground and surface waters, in Ram, N.M., Christman, R.F., and Cantor, K.P., eds., Significance and treatment of volatile organic compounds in water supplies: Chelsea, MI, Lewis Publishers, p. 103-125. 
Westrick, J.J., Mello, J.W., and Thomas, R.F., 1984, The groundwater supply survey: Journal American Water Works Association, v. 76, no. 5, p. 52-59.

Woo, Y.-T., Lai, D., McLain, J.L., Manibusan, M.K., and Dellarco, V., 2002, Use of mechanism-based structureactivity relationships analysis in carcinogenic potential ranking for drinking water disinfection by-products: Environmental Health Perspectives, v. 110, Supplement 1, p. $75-87$.

World Health Organization, 2004, Guidelines for drinking water quality (Third ed.): Geneva, World Health Organization v. 1 recommendations, 515 p. Available at http://www.who.int/water_sanitation_health/dwq/ GDWQ2004web.pdf.

Yang, R.S.H., 1994, Introduction to the toxicology of chemical mixtures, in Yang, R.S.H., ed., Toxicology of chemical mixtures: San Diego, CA, Academic Press, p. 1-10.

Younger, P.L., 2007, Groundwater in the environment: an introduction: Malden, MA and Oxford, UK, Blackwell Publishing, 318 p.
Zapecza, O.S., and Szabo, Z., 1986, Natural radioactivity in ground water - a review, in U.S. Geological Survey, and Moody, D.W., Carr, J., Chase, E.B., and Paulson, R.W., eds., National water summary 1986; hydrologic events and ground-water quality, U.S. Geological Survey Water-Supply Paper 2325, p. 50-57.

Zaugg, S.D., Sandstrom, M.W., Smith, S.G., and Fehlberg, K.M., 1995, Methods of analysis by the U.S. Geological Survey National Water Quality Laboratory-determination of pesticides in water by $\mathrm{C}-18$ solid-phase extraction and capillary-column gas chromatography/mass spectrometry with selected-ion monitoring: U.S. Geological Survey Open-File Report 95-181, 49 p. Available at http://nwql. usgs.gov/Public/pubs/OFR95-181/OFR95-181.html.

Zogorski, J.S., Carter, J.M., Ivahnenko, T., Lapham, W.W., Moran, M.J., Rowe, B.L., Squillace, P.J., and Toccalino, P.L., 2006, The quality of our Nation's waters - volatile organic compounds in the Nation's ground water and drinking-water supply wells: U.S. Geological Survey Circular 1292, 101 p. Available at http://pubs.usgs.gov/circ/ circ1292/. 


\section{Appendixes}

The appendixes can be accessed and downloaded at URL http://pubs.usgs.gov/sir/2010/5024/.

Appendix 1. Summary of selected national-scale studies on contaminant occurrence in public wells in the United States.

Appendix 2. Description of the sampling networks (groundwater assessment studies) associated with 932 public wells sampled during 1993-2007.

Appendix 3. Descriptions of principal aquifer rock types.

Appendix 4. List of six water-quality properties and 215 contaminants analyzed in public-well samples collected during 1993-2007, including reporting levels for non-detections and human-health benchmarks for drinking water.

Appendix 5. Primary use groups associated with pesticide compounds and volatile organic compounds analyzed in public-well samples collected during 1993-2007.

Appendix 6. Alkalinity calculations.

Appendix 7. Water hardness calculations.

Appendix 8. Concentration statistics for water-quality properties, major ions, nutrients, radionuclides, and fecal-indicator microorganisms analyzed in public-well samples collected during 1993-2007.

Appendix 9. Concentration statistics for trace elements analyzed in public-well samples collected during 1993-2007.

Appendix 10. Detection frequencies for trace elements at various common assessment levels in public-well samples collected during 1993-2007.

Appendix 11. Detection frequencies for pesticide compounds at various common assessment levels in public-well samples collected during 1993-2007.

Appendix 12. Detection frequencies for volatile organic compounds at various common assessment levels in public-well samples collected during 1993-2007.

Appendix 13. Concentration statistics for pesticide compounds and volatile organic compounds detected in at least 1 percent of public-well samples collected during 1993-2007.

Appendix 14. Organic contaminants not detected in any public-well sample collected during 1993-2007.

Appendix 15. Contaminants that were detected, but do not have human-health benchmarks, in public-well samples collected during 1993-2007.

Appendix 16. Comparison among detection frequencies for regulated contaminants analyzed in selected national-scale public-well studies.

Appendix 17. Comparison among percentages of public wells or public water systems with concentrations greater than human-health benchmarks for regulated contaminants analyzed in selected national-scale public-well studies.

Appendix 18. Comparison among detection frequencies for unregulated contaminants analyzed in selected national-scale public-well studies.

Appendix 19. Comparison among percentages of public wells or public water systems with concentrations greater than human-health benchmarks for unregulated contaminants analyzed in selected national-scale public-well studies.

Appendix 20. Comparison among contaminants on the third Contaminant Candidate List, those analyzed in public-well samples collected by the NAWQA Program, 1993-2007, and those analyzed for the Unregulated Contaminant Monitoring Program.

Appendix 21. Comparison of findings from this national-scale public-well study to findings from a national-scale domestic-well study. 
This page intentionally left blank. 
Publishing support provided by the U.S. Geological Survey

Publishing Network, Sacramento and Tacoma Publishing Service Centers

For more information concerning the research in this report, contact:

Chief, National Water-Quality Assessment Program

U.S. Geological Survey

413 National Center

12201 Sunrise Valley Drive

Reston, VA 20192

or visit our Web site at:

http://water.usgs.gov/nawqa/studies/public_wells/ 
